\title{
Examining the folate status of Canadians: An analysis of the Canadian Health Measures Survey to assess and guide folate policies
}

\author{
Cynthia K. Colapinto
}

Thesis submitted to the

Faculty of Graduate and Postdoctoral Studies in partial fulfillment of the requirements for

the PhD degree in Population Health

PhD program in Population Health

University of Ottawa

(C) Cynthia Katherine Colapinto, Ottawa, Canada 2013 


\section{Table of Contents}

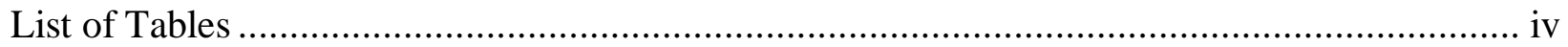

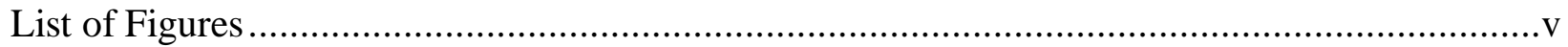

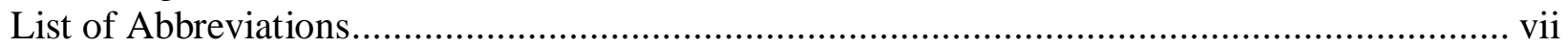

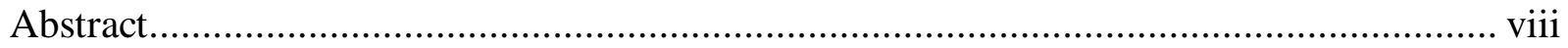

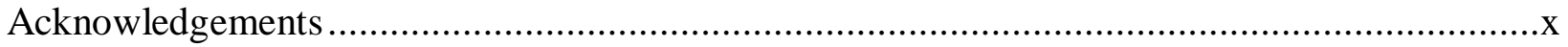

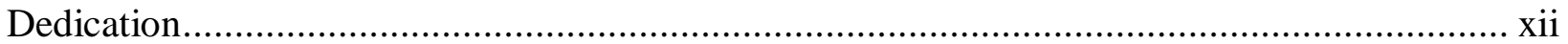

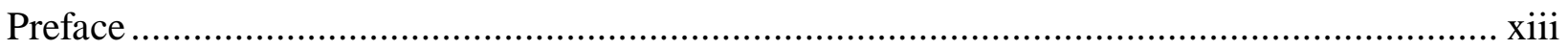

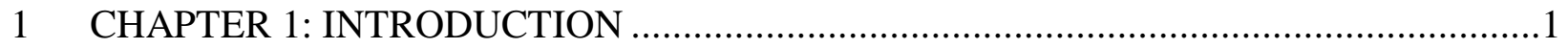

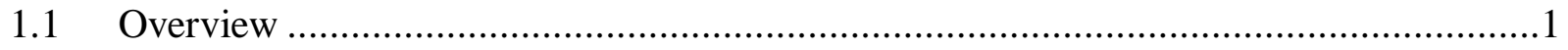

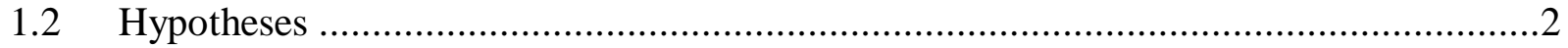

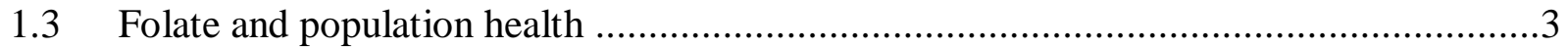

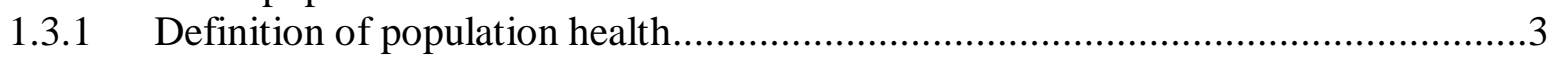

1.3.2 The importance of studying population folate status ..............................................

1.3.3 A population health framework for early child development ................................11

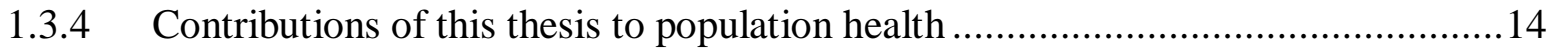

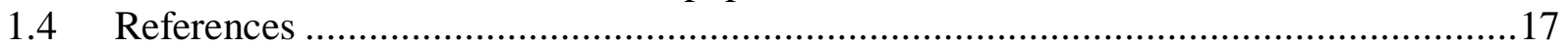

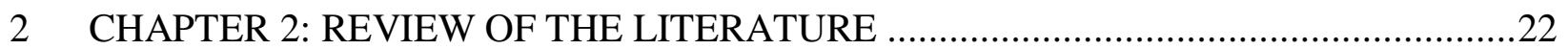

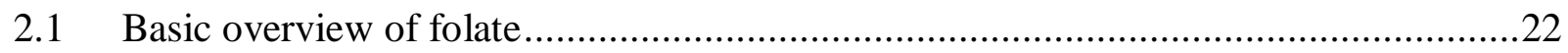

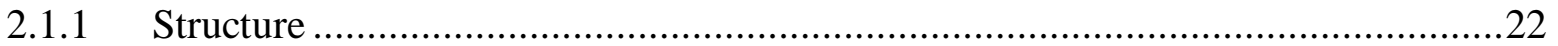

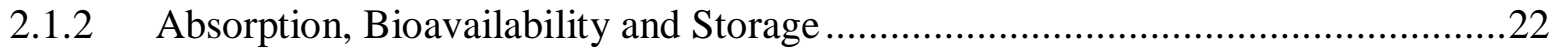

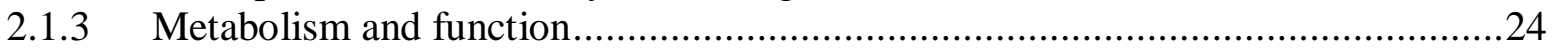

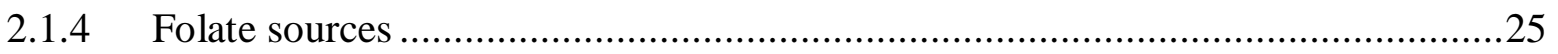

2.1.5 Red blood cell folate analytical methods ...........................................................26

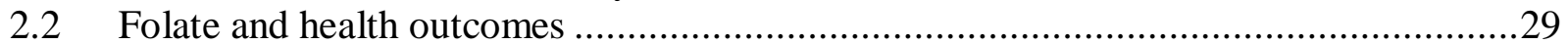

2.3 Folate status of the Canadian population (1970-2010) ..............................................4

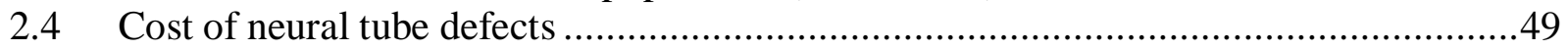

2.5 Populations at risk of folate deficiency ..................................................................49

2.6 The regulatory context in Canada: Canadian folic acid fortification and supplementation

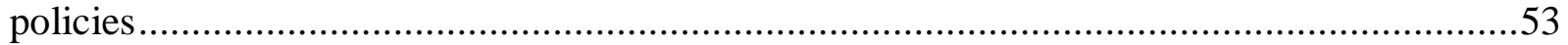

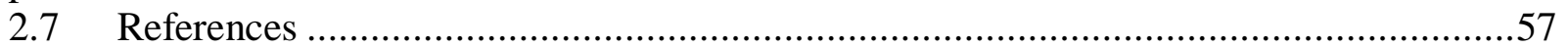

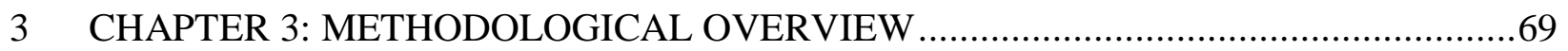

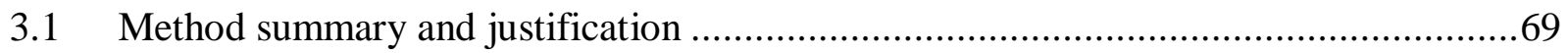

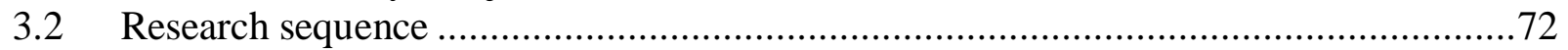

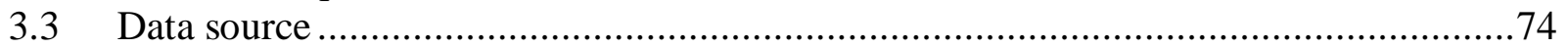

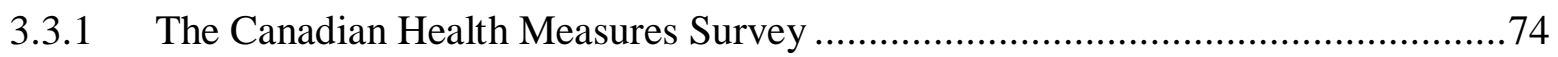

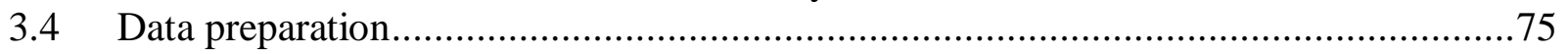

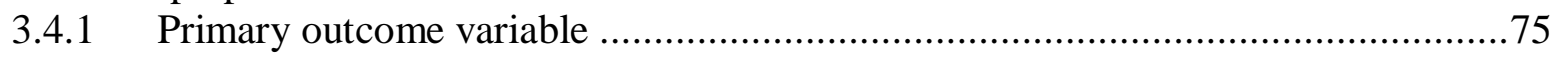

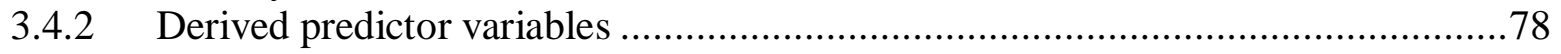

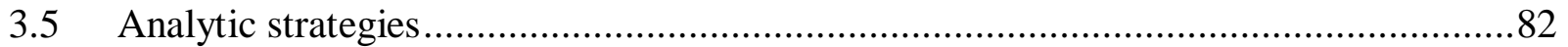

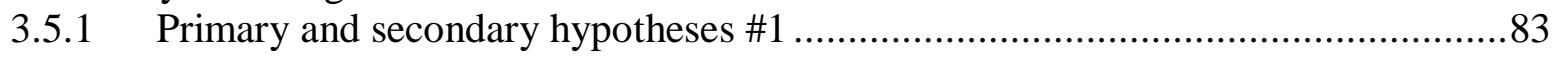

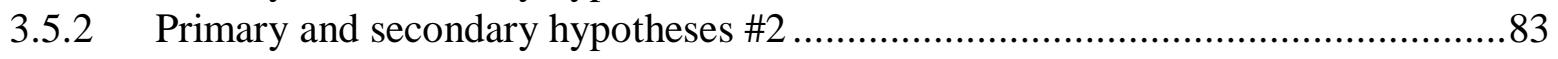

3.5.3 Primary and secondary hypotheses \#3 ............................................................. 84

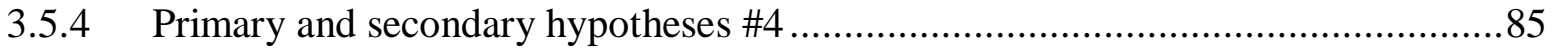




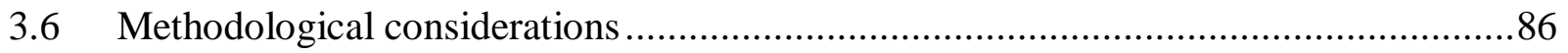

3.6.1 Limited degrees of freedom for regression analyses: ..........................................8

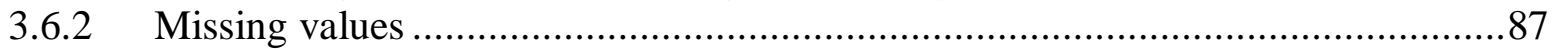

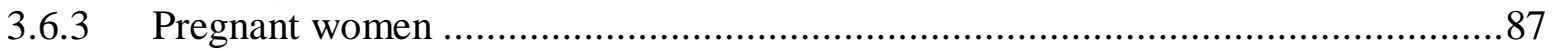

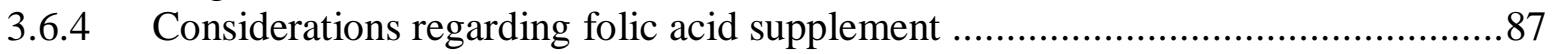

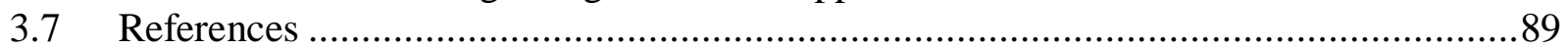

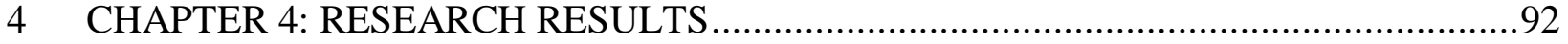

4.1 Folate status of the population in the Canadian Health Measures Survey .....................92

4.2 Prevalence and correlates of folic acid supplement use in Canada ............................104

4.3 Folic acid supplement use is the most significant predictor of folate concentrations in

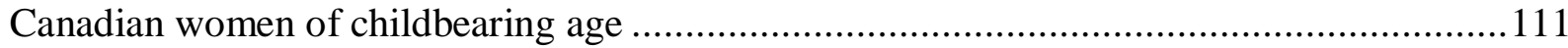

4.4 Prevalence of high RBC folate concentration using three proposed cut-offs ...............121

4.5 Comparison of Canadian and American red blood cell folate concentrations ..............141

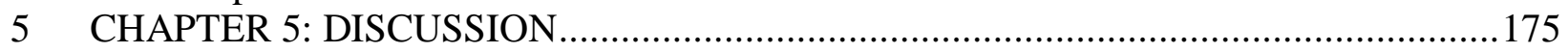

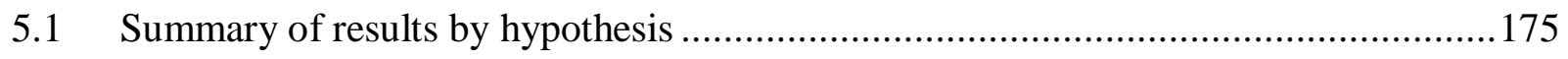

5.2 Interpretation within a socioecological framework ..................................................178

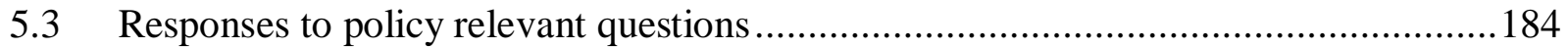

5.3.1 Do doses of folic acid in the food supply or supplements need to be increased?.184

5.3.2 Are folate concentrations of particular concern for any population subgroups?...186

5.3.3 Is Vitamin $B_{12}$ masking a concern for the Canadian population? .........................187

5.3.4 Should Canada continue to monitor RBC folate concentrations? ........................187

5.3.5 Is a cut-off needed to define "high" folate status? .............................................. 188

5.4 Summary of limitations and strengths of the research .............................................18

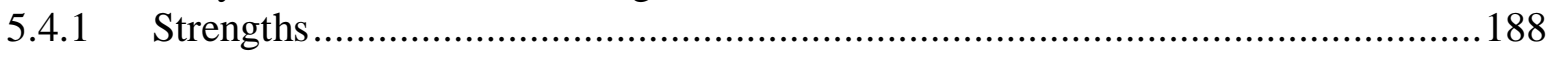

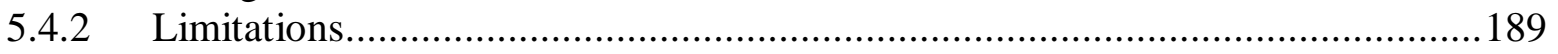

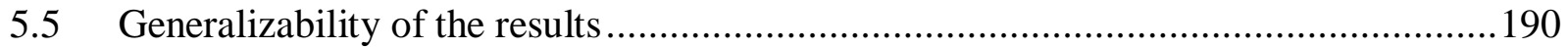

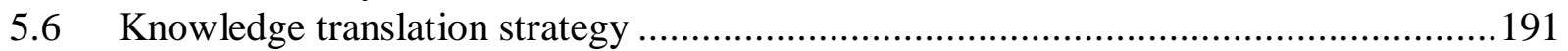

5.7 Core evidence-based policy and research recommendations .....................................192

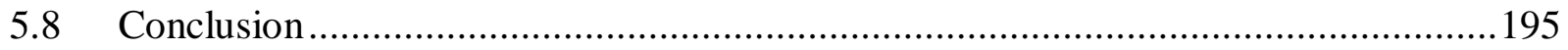

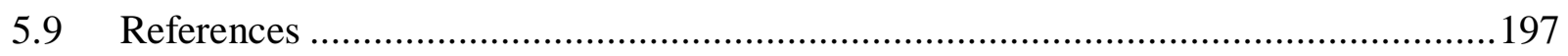

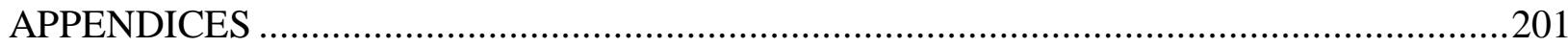

Appendix A: Two Canadian agency definitions of population health ..................................201

Appendix B: Dietary reference intake table for folate .......................................................202

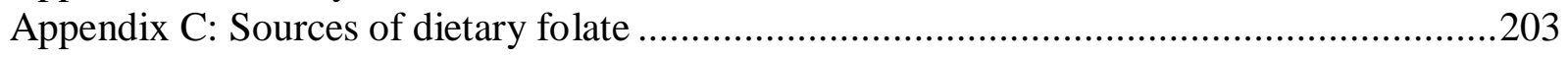

Appendix D: Research Ethics Board approval documents..................................................20

Appendix E: Media coverage following release of first manuscript....................................2212

Appendix F: Supplementary detail regarding the methods comparison study …...................213

Appendix G: Conversion equation study documents..........................................................2218

Appendix H: Generation of the conversion equation step-by-step .......................................237 


\section{List of Tables}

\section{Chapter 2}

\section{Section 2.2}

Table 1

Summary of cited studies that examine negative health outcomes in relation to folate intake and concentrations

Table 2 Summary of selected meta-analyses focused on cancer and folic acid supplement intake

\section{Section 2.3}

Table 3

Folate status of the Canadian population (1970-2010)

\section{Section 2.5}

Table 4

Risk factors for sub-optimal folate status

\section{Chapter 4}

Section 4.1

Table 1

Demographic characteristics of participants

Table 2 Selected population percentile values for red blood cell folate concentrations (nmol/L) by sex and age group

\section{Section 4.2}

Table 1

Prevalence and adjusted odds of folic acid-containing supplement use, by selected characteristics, household population aged 6 to 79, Canada, 2007 to 2009

\section{Section 4.3}

Table 1

Associations between red blood cell folate $\geq 906 \mathrm{nmol} / \mathrm{L}$ and sociodemographic, behavioural, and clinical factors in Canadian women of childbearing age

Table 2 Folic acid supplement use in Canadian women of childbearing age

\section{Section 4.4}

Table 1

Summary description of population demographics and folic acid supplement use, by country

Table $2 \quad$ Selected percentiles for RBC folate concentrations by country

Table 3 Median RBC folate for country by age, race/ethnicity and folic acid supplement use for the general population

Supplemental

Table $1 \quad$ Selected percentiles for whole blood folate by country

\section{Section 4.5}

Table 1

Proposed high RBC folate cut-offs from literature scan

Table 2

Proportions above proposed high red blood cell folate cut-offs by sociodemographic, behavioural and clinical factors in the Canadian population 


\section{List of Figures \\ Chapter 1}

Figure 1 The Total Environment Assessment Model for Early Child Development (TEAM-ECD)

\section{Chapter 2}

Figure 1

Structures of folates

Figure 2

Overview of how high folic acid intakes correct DNA synthesis but not homocysteine remethylation during vitamin $\mathrm{B}_{12}$ deficiency

\section{Chapter 3}

Figure 1

Analytical framework of risk factors for deficient folate status

\section{Chapter 4}

Section 4.1

Figure 1

Cumulative percentile distributions of red blood cell folate concentrations by age group among female (A) and male (B) participants in the Canadian Health Measures Survey, 2007-2009

Figure 1a Median red blood cell (RBC) folate concentrations by age group and income quartile among the entire population from the Canadian Health Measures Survey, 2007-2009

Figure 1b Median red blood cell (RBC) folate concentrations by age group and highest level of education (household) among the entire population from the Canadian Health Measures Survey, 2007-2009

Section 4.2

Figure 1

Reported dose of folic acid-containing supplement, by sex, household population aged 6 to 79, Canada, 2007 to 2009

Figure 2 Reported dose of folic acid-containing supplement, by age group, household population aged 6 to 79, Canada, 2007 to 2009

\section{Section 4.3}

Figure 1

Cumulative percentile distributions of red blood cell folate concentrations by folic-acid supplement use from the 2007-2009 Canadian Health Measures Survey

\section{Section 4.4}

Figure 1a

Cumulative percentile distributions of red blood cell (RBC) folate concentrations by country from the Canadian Health Measures Survey, 2007-2009 (adjusted for microbiologic assay comparison and unadjusted) and the National Health and Nutrition Examination Survey 2007-2008

Figure 1b Cumulative percentile distributions of red blood cell (RBC) folate concentrations by country among women of childbearing age (15-45 years old) from the Canadian Health Measures Survey, 2007-2009 (adjusted for microbiologic assay comparison and unadjusted) and the National Health and Nutrition Examination Survey, 2007-2008 
Supplemental

Figure 1a Altman Bland difference plot

Supplemental

Figure 1b Scatterplot of microbiologic assay results by Immulite 2000 immunoassay result with weighted Deming regression fit

Supplemental

Figure 2a Boundary assessment examining the bottom and top 95\% CI for the conversion equation for the general population and B) women of childbearing age

Supplemental

Figure $2 \mathrm{~b}$ Boundary assessment examining the bottom and top 95\% CI for the conversion equation for women of childbearing age

\section{Section 4.5}

Figure 1

Forest plot of univariate logistic regression of proposed cut-offs for high RBC folate concentrations and folic acid supplement use in the general population 


\section{List of Abbreviations}

\begin{tabular}{|c|c|}
\hline BMI & Body Mass Index \\
\hline CCHS & Canadian Community Health Survey \\
\hline $\mathrm{CDC}$ & Centers for Disease Control and Prevention \\
\hline CHEO & Children's Hospital of Eastern Ontario \\
\hline CHMS & Canadian Health Measures Survey \\
\hline $\mathrm{CI}$ & Confidence interval \\
\hline CIHR & Canadian Institutes of Health Research \\
\hline DDF & Denominator degrees of freedom \\
\hline DFE & Dietary Folate Equivalent \\
\hline DNA & Deoxyribonucleic acid \\
\hline DRI & Dietary Reference Intake \\
\hline Hcy & Homocysteine \\
\hline $\mathrm{LC} / \mathrm{MS} / \mathrm{MS}$ & Liquid chromatography-tandem mass spectrometry \\
\hline MAPE & Mean Absolute Percentage Error \\
\hline Methyl-THF & Methyltetrahydrofolate \\
\hline MTHFR & Methylenetetrahydrofolate reductase \\
\hline NCHS & National Center for Health Statistics \\
\hline NCNS & Nutrition Canada National Survey \\
\hline NHANES & National Health and Nutrition Examination Survey \\
\hline NIBSC & National Institute for Biological Standards and Control \\
\hline $\mathrm{ng} / \mathrm{L} *$ & Nanagram per mililiters \\
\hline $\mathrm{nmol} / \mathrm{L}$ & Nanamoles per litres \\
\hline NTD & Neural tube defect \\
\hline OR & Odds ratio \\
\hline PSU & Primary Sampling Unit \\
\hline $\mathrm{RBC}$ & Red blood cell \\
\hline $\mathrm{RCT}$ & Randomized Controlled Trail \\
\hline RDA & Recommended Dietary Allowance \\
\hline RR & Relative risk \\
\hline SACN & Scientific Advisory Committee on Nutrition \\
\hline SOGC & Society of Obstetricians and Gynecologists of Canada \\
\hline TEAM-ECD & Total Environmental Assessment Model for Early Child Development \\
\hline UL & Tolerable Upper Intake Level \\
\hline USD & United States Dollar \\
\hline WCBA & Women of childbearing age \\
\hline WHO & World Health Organization \\
\hline
\end{tabular}

*To convert conventional units (ng/mL) to SI units (nmol/L) multiply by 2.265 


\section{Abstract}

Canada fortifies certain products with folic acid and has periconceptional supplementation guidelines - policies designed to improve folate status and reduce the incidence of poor birth outcomes. Though optimal folate concentrations have been linked to health benefits, concerns have been raised regarding potential associations with adverse health outcomes. Direct biochemical assessment of the folate status of Canadians based on a nationally representative sample has not been done in more than 40 years. The overall purpose of this research was to investigate the folate status of the Canadian population.

All analyses used the nationally representative 2007-2009 Canadian Health Measures Survey (CHMS). Red blood cell (RBC) folate was measured by Immulite 2000 immunoassay. Key findings indicate that folate deficiency $(<305 \mathrm{nmol} / \mathrm{L}$ ) was virtually non-existent in the Canadian population (6-79 years old). Still, one-fifth of women of childbearing age (WCBA; 15-45 years old) had sub-optimal concentrations for the prevention of neural tube defects $(<906 \mathrm{nmol} / \mathrm{L})$. Folic acid supplement intake was a primary determinant of WCBA achieving a RBC folate concentration $\geq 906 \mathrm{nmol} / \mathrm{L}$. A distinct shift towards elevated RBC folate concentrations emerged. Three hypothetical cut-offs ( $1450 \mathrm{nmol} / \mathrm{L}, 1800 \mathrm{nmol} / \mathrm{L}$ and $2150 \mathrm{nmol} / \mathrm{L}$ ) were examined to create dialogue since a universal definition of high $\mathrm{RBC}$ folate concentration does not exist. Females, participants aged 60-79 years, and those who were overweight or obese had the greatest prevalence of having high $\mathrm{RBC}$ folate at each cut-off. We conducted the first national-level comparison of RBC folate concentrations between the United States and Canada. Two different folate assay methods - microbiologic assay (NHANES) and Immulite 2000 immunoassay (CHMS) - necessitated the application of a conversion equation. Median Canadian $\mathrm{RBC}$ folate concentrations (adjusted to microbiologic assay) were lower than those of Americans 
but unadjusted Canadian median RBC folate values were higher. Canadian WCBA were less likely than American WCBA to have RBC folate $\geq 906 \mathrm{nmol} / \mathrm{L}$, though Canadian WCBA with unadjusted RBC folate values were more likely to achieve this cut-off.

These results indicate a need for strategies targeting WCBA to improve compliance with folic acid supplement recommendations. The strength and necessity of supplements for the general population should be re-assessed. Further, harmonization of folate measurement procedures in future surveillance efforts would support comparisons and inform policy directions. 


\section{Acknowledgements}

My dissertation experience has exceeded my expectations. Every day of this process has been exciting and educational. I have many people to thank for making this work possible.

I was fortunate to have worked with Mark Tremblay, Deborah O'Connor and Lise Dubois, an experienced and dedicated committee that unwaveringly provided their time and support, despite their incredibly busy schedules.

Mark, I'm grateful to have had you as my supervisor and that you welcomed me to HALO. Thank you for being a consistently responsive, available, knowledgeable and dedicated mentor. I've appreciated this opportunity to work with you.

I am thankful, Debbie, that you brought your contagious enthusiasm for research to my committee. Thank you for sharing your world-class knowledge of folate and for teaching me how to succeed throughout this process and in the future. Your attention to detail is unmatched, and always valued.

Lise, thank you for your guidance throughout this process and for always being available to provide advice on my dissertation as well as my career.

I spent much of my time during this dissertation with different health research and policy teams. I enjoyed working with the HALO team, and thank the students and scientists for being a constant source of lively debate and interesting ideas. I thank the Health Analysis Division at Statistics Canada - in particular Tracey Bushnik, Julie Bernier, Kelly Langlois, Deirdre Hennesey, Claudia San Martin and Michelle Rottermann - for orienting me to the CHMS database, for being supportive of my project over the years and for always being enthusiastic about helping me overcome any obstacles I encountered. I would like to thank the Health Canada Office of Nutrition Policy and Promotion - in particular Hélène Lowell and Janet Pronks - for providing me with front-line insight into government policy and research. I thank Penny Jee, Lois Fernandez and Steve Brooks at the Health Canada Nutrition Research Division for their support during the methods comparison study. I also thank Susanne Aufreiter and everyone at the Hospital for Sick Children who assisted with the crossover equation sub-study data collection and microbiologic assay.

I am grateful to the Canadian Institutes for Health Research for supporting this research. The Health Professionals Fellowship allowed me to immerse myself in a full-time doctorate and I was able to benefit from a variety of experiences. I am an example of how this funding has achieved its goal of training clinicians, in a way that is supportive of career advancement for women, to produce successful Canadian researchers. 
I have many phenomenal people in my life that made this experience enjoyable. Elspeth and Alison (and their wonderful babies), thank you for your friendship and for providing many excellent opportunities to escape from the pressures that come along with this dissertation. Misty, thank you for always being available for a good brainstorming session.

I'd like to thank my wonderful East Coast in-laws. You have provided incredible advice throughout this dissertation, whether it's debating policy issues or hearing "Have a good day", your support and visits have meant a lot.

To my parents, Nicholas and Margaret Colapinto, thank you for your consistent love and support. Dad, when you encouraged me to pursue my Masters degree, I don't think either of us predicted that research would become such an important part of my life. Thank you for the best advice you could have possibly given me. It truly altered the course of my career and led to all the wonderful opportunities and people I have in my life today. To my siblings and their families, thank you for inspiring me every day. 


\section{Dedication}

This thesis is dedicated to my family. To my husband, Trevor Stewart, you supported this endeavour wholeheartedly and are an unfailing source of support. And to my gorgeous sons, you make every day of my life joyful. It was impossible not to stay positive in the final years of this experience. I love you both very much. I hope, someday, that you are inspired by the time, effort and incredible satisfaction that came along with this work, and that this will contribute to the great things you will both achieve. 


\section{Preface}

The impetus for this dissertation research stemmed from my work as a dietitian in public health in Sudbury, Ontario, where I specialized in maternal and infant nutrition. I chaired a provincial family health nutrition advisory group, which provided unique insights into health and policy issues that could benefit from research. This included the need to understand the current folate status of women of childbearing age, which became apparent with the 2007 release of the Society of Obstetricians and Gynecologists Canada guidelines "Pre-conceptional Vitamin/Folic Acid Supplementation 2007: The Use of Folic Acid in Combination With a Multivitamin Supplement for the Prevention of Neural Tube Defects and Other Congenital Anomalies”. Key recommendations in these guidelines suggest that most women of childbearing age need $5 \mathrm{mg} / \mathrm{d}$ of supplemental folic acid and that the Federal government should consider evaluating the need to double the level of folic acid in currently fortified food products. When I hosted an education session for the Healthy Babies, Healthy Children nurses on these guidelines, I realized that without current national-level data on the folate status of women of childbearing age, I was unable to justify why the vulnerable women they worked with everyday - who were low socioeconomic status and unable to access a family doctor to get the prescription needed for higher doses of folic acid - required $5 \mathrm{mg} / \mathrm{d}$ of folic acid. Further to the questions of accessibility for women of childbearing age, the safety and necessity of higher doses, through fortification and supplementation, for the general population was not clear. These issue became a frequent discussion topic among my colleagues.

In the summer of 2007, I participated in a meeting of public health nutritionists in Toronto. I attended Dr. Mark Tremblay’s presentation on the Canadian Health Measures Survey and immediately knew that this survey was my opportunity to examine and disseminate directly 
measured biomarkers of folate concentrations and folic acid supplement intake. These data would provide critical directions for clinicians and policy makers. I approached Dr. Tremblay with this plan and he agreed to supervise my research. Following a successful application to the CIHR Health Professionals Fellowship award competition, I entered the PhD program in Population Health at the University of Ottawa in September 2008. This dissertation has grown to provide an extensive evidence base, including an international comparison, which policy makers, researchers and clinicians can use to inform decisions regarding folic acid policy and guidelines. 


\section{CHAPTER 1: INTRODUCTION}

\subsection{Overview}

This thesis examines the current folate status of Canadians. This research uses new, nationally representative data from the 2007-2009 Canadian Health Measures Survey (CHMS) to examine the socioeconomic, behavioural and clinical determinants of folate concentrations. This chapter describes the context and rationale for investigating the folate status of Canadians, including the topic's relationship with population health. Chapter 2 is a review of the existing literature. Chapter 3 provides an overview of the methodology used to address the specific research questions. Chapter 4 presents the results of the analyses in the form of five manuscripts that examine:

1) The folate status of the Canadian population;

2) Prevalence and correlates of folic acid supplement use in Canada;

3) Predictors of folate concentrations in Canadian women of childbearing age;

4) The prevalence of high red blood cell $(\mathrm{RBC})$ folate concentration at three proposed cut-offs; and

5) Canadian versus American RBC folate concentrations.

Chapter 5 summarizes the results, answers critical questions arising from this research, and offers evidence-based recommendations. It also discusses the limitations and strengths of the study and suggests future policy and research directions.

I would like to highlight a fundamental distinction to ease the interpretation of this work. Low folate concentrations are defined differently in the two primary populations studied throughout this dissertation - the general population and a subgroup of women of 
childbearing age (15 to 45 years old). In the general population - which includes women of childbearing age - folate deficiency is defined as a RBC folate concentration $<305 \mathrm{nmol} / \mathrm{L}$. Women of childbearing age are assessed at a different folate concentration, RBC folate $\geq 906$ nmol/L, a level considered optimal for maximum neural tube defect (NTD) risk reduction. Therefore, a woman can have a sufficient RBC folate concentration ( $\geq 305 \mathrm{nmol} / \mathrm{L})$ without achieving a concentration considered optimal for NTD risk reduction ( $\geq 906 \mathrm{nmol} / \mathrm{L})$.

\subsection{Hypotheses}

The proposed research focused on the following four primary hypotheses and accompanying secondary hypotheses:

1. Less than $5 \%$ of Canadians demonstrate folate deficiency ( $\mathrm{RBC}$ folate $<305 \mathrm{nmol} / \mathrm{L}$ ) and less than $5 \%$ demonstrate high folate ( $\mathrm{RBC}$ folate $>1360 \mathrm{nmol} / \mathrm{L})$, but proportions vary by age, sex, and socioeconomic status. Adolescents (versus adults), females (versus males) and Canadians of low socioeconomic status (versus higher socioeconomic status) are more likely to be folate deficient.

2. At least $40 \%$ of Canadian women of childbearing age demonstrate inadequate folate status for maximal protection against NTDs (RBC folate $<906 \mathrm{nmol} / \mathrm{L}$ ). Canadian women of childbearing age of low socioeconomic status are more likely to have inadequate folate status for maximal protection against NTDs (RBC folate $<906 \mathrm{nmol} / \mathrm{L}$ ) than those of higher socioeconomic status.

3. At least $50 \%$ of Canadian women of childbearing age do not consume folic acid supplements.

- Canadians of low socioeconomic status in general, and Canadian women of 
childbearing age of low socioeconomic status specifically, will be less likely to consume folic acid supplements than those of higher socioeconomic status.

- Canadian women of childbearing age who do not consume folic acid supplements are less likely to have $\mathrm{RBC}$ folate concentrations that are maximally protective against NTD (RBC folate $\geq 906 \mathrm{nmol} / \mathrm{L})$.

- Canadian women of childbearing age with clinical risk factors for NTD (e.g. obesity, diabetes mellitus, regular use of folic acid antagonist medications) who do not comply with high dose folic acid supplement recommendations $(5 \mathrm{mg} / \mathrm{d})$ will be more likely to have inadequate folate status for maximal protection against NTDs (RBC folate $<906 \mathrm{nmol} / \mathrm{L}$ ) than those who comply.

4. Canadians in general are less likely to be folate deficient ( $\mathrm{RBC}$ folate $<305 \mathrm{nmol} / \mathrm{L}$ ) than Americans. Canadian women of childbearing age are less likely to have inadequate folate for maximal protection against NTDs (RBC folate $<906 \mathrm{nmol} / \mathrm{L}$ ) than American women of childbearing age.

\subsection{Folate and population health}

\subsubsection{Definition of population health}

A consensus definition for population health has yet to be formulated, though many scholars and agencies have worked to capture its essence. Kindig and Stoddard defined population health as "the health outcomes of a group of individuals, including the distribution of such outcomes within the group."1 This terminology has evolved to encompass a broader perspective that extends beyond the literal definition. Three key, interrelated factors form the basis of the population health approach: 1) the determinants 
affecting health (e.g. social and economic environment; physical environment; and individual characteristics and behaviours); 2) health inequities; and 3) the manner in which these factors can be addressed through interventions, such as research and public health policies. $^{2}$ Since these factors are not mutually exclusive, and have the potential to influence each other, it is important to consider all of these aspects when planning any population health intervention. The Canadian Institutes of Health Research (CIHR) Institute of Population and Public Health and The Public Health Agency of Canada have adopted definitions of population health that strongly identify these concepts (Appendix A). ${ }^{3,4}$

\subsubsection{The importance of studying population folate status}

\section{Informing relevant policies}

Main components of a population health approach include health interventions and the measurement of these interventions while considering the determinants of health. Two primary policies have the potential to influence the folate status of the Canadian population: 1) fortification of certain grain products with folic acid and 2) nutrition recommendations for women of childbearing age (i.e. daily multivitamin supplement as well as the amount of folate found in a healthy diet). Government policies act as population health interventions as they have the potential to shift the distribution of health risk - positively or negatively - by addressing the underlying social, economic and environmental conditions that affect communities, families and individuals. ${ }^{2}$ Thus, a population health approach can use both upstream (e.g. policies supporting fortification, strategies to promote folic acid supplements for women of childbearing age and research) and downstream (e.g. patient education, clinician information, family health) strategies to achieve desired health outcomes.

In 1998, Canada introduced mandatory fortification of certain grains, following a similar 
decision by the United States in 1996. ${ }^{5,6}$ The decision to implement a folic acid fortification policy for certain Canadian grain products occurred in response to evidence associating folate status with the occurrence of NTDs. ${ }^{7,8}$ See Section 2.2 for more detail on folic acid and health outcomes. Canada fortifies white wheat flour and cornmeal with folic acid at a level of $0.15 \mathrm{mg} / 100 \mathrm{~g}$, and pasta labelled enriched at a level of $0.20 \mathrm{mg} / 100 \mathrm{~g}$. Discretionary fortification of ready-to-eat breakfast cereals allows up to $0.06 \mathrm{mg} / \mathrm{serving}$ in Canada. Further information on fortification policies and the regulatory context in Canada can be found in Section 2.6. Fortification has been associated with a $46 \%$ decrease in the rate of NTD births in Canada. ${ }^{9}$ Fortification with folic acid is a low-cost population health intervention, with a small per-person cost that was estimated in 2008 to be approximately USD \$1.50 per metric tonne of wheat flour. ${ }^{10-12}$ More than 50 countries have reported a requirement to add folic acid to flour, though regulations may not yet be implemented in all of those countries. ${ }^{13,14}$ A range of low-, middle- and high-income countries across the globe have these regulations, including those in Central and Eastern Europe; the Middle East; North and Sub-Saharan Africa; East and Southeast Asia; the Caribbean; Latin America; North America; and Oceania. ${ }^{13}$

In addition to intake of folate-rich foods, Health Canada recommends all women who are capable of becoming pregnant consume $0.4 \mathrm{mg}$ of folic acid daily as part of a multivitamin (Appendix B). ${ }^{15,16}$ This diverges from the Dietary Reference Intakes (DRIs), which recommend this dose be achieved through intake of folic acid supplements and fortified foods with additional food folate from a varied diet. It is further suggested that pregnant women consume $0.6 \mathrm{mg} / \mathrm{d}$ of dietary folate equivalents (DFEs). ${ }^{16}$ DFEs were created to account for differences in bioavailability between synthetic and food sources of folate, with 
$1 \mu \mathrm{g}$ DFE equalling $1 \mu \mathrm{g}$ of food folate, $0.6 \mu \mathrm{g}$ of folic acid consumed with food or $0.5 \mu \mathrm{g}$ folic acid consumed in a fasted state. The Society of Obstetricians and Gynecologists of Canada (SOGC) recommends that if a woman exhibits any of the clinical risk factors for NTDs (e.g. maternal obesity, epilepsy, folic acid antagonist medication use) a daily supplement of $4-5 \mathrm{mg}$ is recommended. ${ }^{17}$

Though these policies are designed to reduce NTD risk in women of childbearing age, they may have a population-level impact on folate status. In monitoring folate status, our understanding of two current population-level issues will be improved: 1) Folic acid supplementation guidelines may lead to a widening of the socioeconomic status gap in health if certain women of childbearing age are unable to access folic acid supplements; and 2) folate levels in Canadians may be elevated, which may be a concern as there are speculated health risks associated with high folic acid intake.

Speculated health risks associated with high folic acid intake

Folic acid intake is associated with many positive health outcomes, which are outlined in more detail in Section 2.2. However, there is a lack of consensus regarding whether or not high folic acid intake is associated with adverse health outcomes. ${ }^{18-23}$ Many countries, including the United Kingdom and New Zealand, have debated mandatory folic acid fortification. After considerable review of the literature, the United Kingdom Scientific Advisory Committee on Nutrition (SACN) recommended in 2006 the adoption of mandatory fortification, with controls on intake of folic acid from voluntarily fortified foods. ${ }^{24}$ This recommendation was upheld following a 2009 SACN review that concluded that insufficient data existed to support concerns of a link between folic acid fortification and cancer progression. ${ }^{25}$ New Zealand suspended 2009 plans for mandatory folic acid fortification of 
its food supply, instead opting for voluntary fortification policy, which came into force in September $2012 .^{26}$ This decision was made, in part, due to emerging evidence suggesting that high folic acid intake may have negative consequences beyond masking of vitamin $\mathrm{B}_{12}$ deficiency, including cancer progression and reduced natural killer cell cytotoxicity. ${ }^{16,27-29}$ For example, a randomized, double-blind, placebo-controlled trial - the Aspirin/Folate Polyp Prevention Trial - aimed to determine the potential for colorectal adenoma prevention, in those with a history of adenomas, through the use of oral aspirin, folic acid supplementation, or both. ${ }^{27}$ Participants who had a recent history of colorectal adenoma were randomly assigned to consume either $1 \mathrm{mg} / \mathrm{d}$ of folic acid or a placebo, concurrent with a separate randomization to receive Aspirin. The study demonstrated unforeseen, non-significant increases in the incidence of advanced colorectal adenomas and prostate cancer. An observational study, also released in 2007, presented an examination of age-adjusted incidence of colorectal cancer in Canada and the United States from 1986 to $2002 .{ }^{28} \mathrm{~A}$ steady decline in colorectal cancer incidence was illustrated for both countries from 1986 to 1996, which was interrupted by a sharp increase from 1996 to 1998 in the United States and from 1997 to 2000 in Canada, followed by a slow return towards the previous baseline.

These studies stimulated several systematic reviews and meta-analyses, many of which did not demonstrate a relationship between folic acid supplement intake and most cancers. For example, a 2013 meta-analysis included individual participant datasets from 13 trials $(\mathrm{N}=49,969)$ that compared folic acid supplementation (in amounts ranging from $0.5 \mathrm{mg} / \mathrm{d}$ to $40 \mathrm{mg} / \mathrm{d}$ ) to placebo, had a duration of at least one year, included at least 500 participants and recorded data on cancer incidence. ${ }^{23}$ Though plasma folate concentrations increased in the folic acid supplemented participants, no short-term effects on overall or site-specific cancer 
incidence were demonstrated.

In addition to speculated concerns regarding cancer, a combination of high folate concentrations and low vitamin $\mathrm{B}_{12}$ status has been associated with increased cognitive impairment in seniors. ${ }^{30}$ Further, the potential for folic acid consumed during pregnancy to alter gene expression during early development has been studied in relation to the promotion of an allergenic phenotype; in particular, researchers have raised concerns regarding increased risk of lower respiratory tract infections, wheeze and childhood asthma. ${ }^{31,32}$ However, a 2012 cohort study did not support an association between folic acid supplementation in early pregnancy and the development of asthma in offspring at six years of age. ${ }^{33}$ Another study found an association between high folate concentrations and low vitamin $\mathrm{B}_{12}$ status in pregnant women and increased insulin resistance and higher central adiposity in their children. ${ }^{34,35}$ These speculated health risks highlight the importance of monitoring population folate status in currently fortifying countries. Through this dissertation, the national-level folate status of the Canadian population will be reported for the first time since fortification of certain grain products with folic acid so that the potential for deficiency and elevated concentrations can be assessed.

The socioeconomic status gap in health and folate status

Policies affecting maternal and infant health, and subsequently, early child development, may lead to a widening of the well-documented socioeconomic status gap in health. ${ }^{36}$ Simply, the socioeconomic status gap in health occurs when lower socioeconomic status populations have poorer health than those of higher socioeconomic status. Examining the complex socioeconomic status gradient in health to understand the folate status of Canadians, in particular women of childbearing age, was an important lens for the current research. 
Policies - such as folic acid supplement guidelines - may have a differential impact on certain subgroups depending on sociodemographic or behavioural characteristics. ${ }^{37,38}$ When this inequality in health is judged to be unfair in the context of societal norms then health inequity may also be present. ${ }^{39}$ Further, a socioeconomic status gradient may be identified in a population if an increasing or decreasing pattern in a health outcome variable occurs in association with a similar fluctuation in a measure of socioeconomic status. ${ }^{40}$ For example, women without adequate education or prenatal care may also be less aware of clinical risk factors for NTD birth, such as diabetes, maternal obesity and use of folic acid antagonist medications. ${ }^{41}$ Compounding this issue, some lower socioeconomic status women are at higher obesity risk, and obese women are at increased risk of type 2 diabetes. Most women of childbearing age need supplements to achieve adequate folate status to prevent NTDs as this is difficult through diet alone. ${ }^{42}$ The neural tube is formed in the first four weeks postconception and approximately 50\% of pregnancies are unplanned, thus the opportunity to reduce NTD risk may be limited for women who do not consume folic acid preconceptually. ${ }^{43-45}$ Other studies have demonstrated that some women are aware of the impact of folic acid supplementation on NTD risk but still do not take supplements. ${ }^{43-45}$ Women cite barriers to adherence such as wanting to prevent folate deficiency through diet alone; considering supplements unnecessary since no pregnancy is planned; forgetting to take supplements; and lacking the money to access supplements. ${ }^{43-45}$

Poor maternal diet and compliance with supplementation are addressed in a set of guidelines released in 2007 by the SOGC and Motherisk. ${ }^{\mathrm{i}, 46}$ These guidelines include

\footnotetext{
${ }^{\mathrm{i}}$ Motherisk is a program at the Hospital for Sick Children (Toronto) that provides information for health professionals and the community on clinical issues during pregnancy and lactation that can affect fetal and infant health, including: nutrition; nausea and vomiting in pregnancy; and alcohol, nicotine and substance.
} 
recommendations that women take a daily multivitamin supplement containing $5 \mathrm{mg}$ of folic acid - an amount that is more than 10 times the current Canadian recommendations - if there is a clinical risk factor for NTD birth or if they have a history of poor adherence with medications and lifestyle issues, such as variable diet, inconsistent birth control, and possible teratogenic substance use. ${ }^{46}$ This thesis aims to inform these guidelines, by assessing blood folate concentrations. ${ }^{15}$

The SOGC/Motherisk guidelines present a number of population health concerns, in addition to the unknown health risks of taking large doses of folic acid. The guidelines inadvertently target lower socioeconomic status women and demonstrate a lack of consideration for a woman's ability to afford and access this dosage level. The need for a prescription to purchase doses above $1 \mathrm{mg}$ of folic acid in Canada complicates access to high-dose supplements. It is also possible that a woman does not have access to a health care provider who can write a prescription and offer information on appropriate prevention strategies. Further, most health benefit plans do not cover the cost of vitamin supplements. It should also be noted that the SOGC/Motherisk guidelines are not consistent with the national guidelines from Health Canada. As such, different recommendations from well-respected organizations could cause confusion, for both women of childbearing age and the health professionals charged with offering guidance to patients.

Monitoring folate status is critical in assessing the population health impact of folic acid fortification and supplementation policy. The current research was formulated to develop a better understanding of the health behaviours and socio-demographic factors related to folate status. These findings can be used by health professionals to provide evidence-based care, researchers to conceive follow-up studies, and policy makers to refine interventions if 
needed. These outcomes will contribute to the population achieving the maximal benefit of folic acid with minimal harm.

\subsubsection{A population health framework for early child development}

Two theoretical assumptions informed this research: 1) A socioeconomic status gradient in folate status exists, with those of lower socioeconomic status having diminished folate status; and 2) Policies intended to improve the folate status of the population may lead to high folate status in certain subgroups or may not be accessible to all Canadians. These assumptions are best explored through socioecological theory, which forms the basis of this research as it considers the multiple influences on health behaviours that exist at different societal levels. ${ }^{47}$ Interrelated systems are presented in socioecological theory at the macro-, exo-, meso- and micro-levels. ${ }^{47}$ Policy decisions occur at the macro-level, which strongly influence the community (exo-level), family (meso-level) and individual (micro-level).

\section{The Total Environmental Assessment Model for Early Child Development (TEAM-} ECD) from the World Health Organization Commission on the Social Determinants of Health Early Child Development working group illustrates socioecological theory and is an appropriate model for this examination of the folate status of the Canadian population (Figure 1). ${ }^{38,48-50}$

The TEAM-ECD represents a synthesis of multiple frameworks including developmental psychology, social epidemiology and social capital. ${ }^{38}$ The model is a comprehensive representation of the contextual factors influencing each level of the socioecological framework, which allows levers for action to be readily identified. Three aspects of the TEAM-ECD model - the lifecourse approach, the social determinants of health and the multiple spheres of influence - are particularly relevant to this research. 


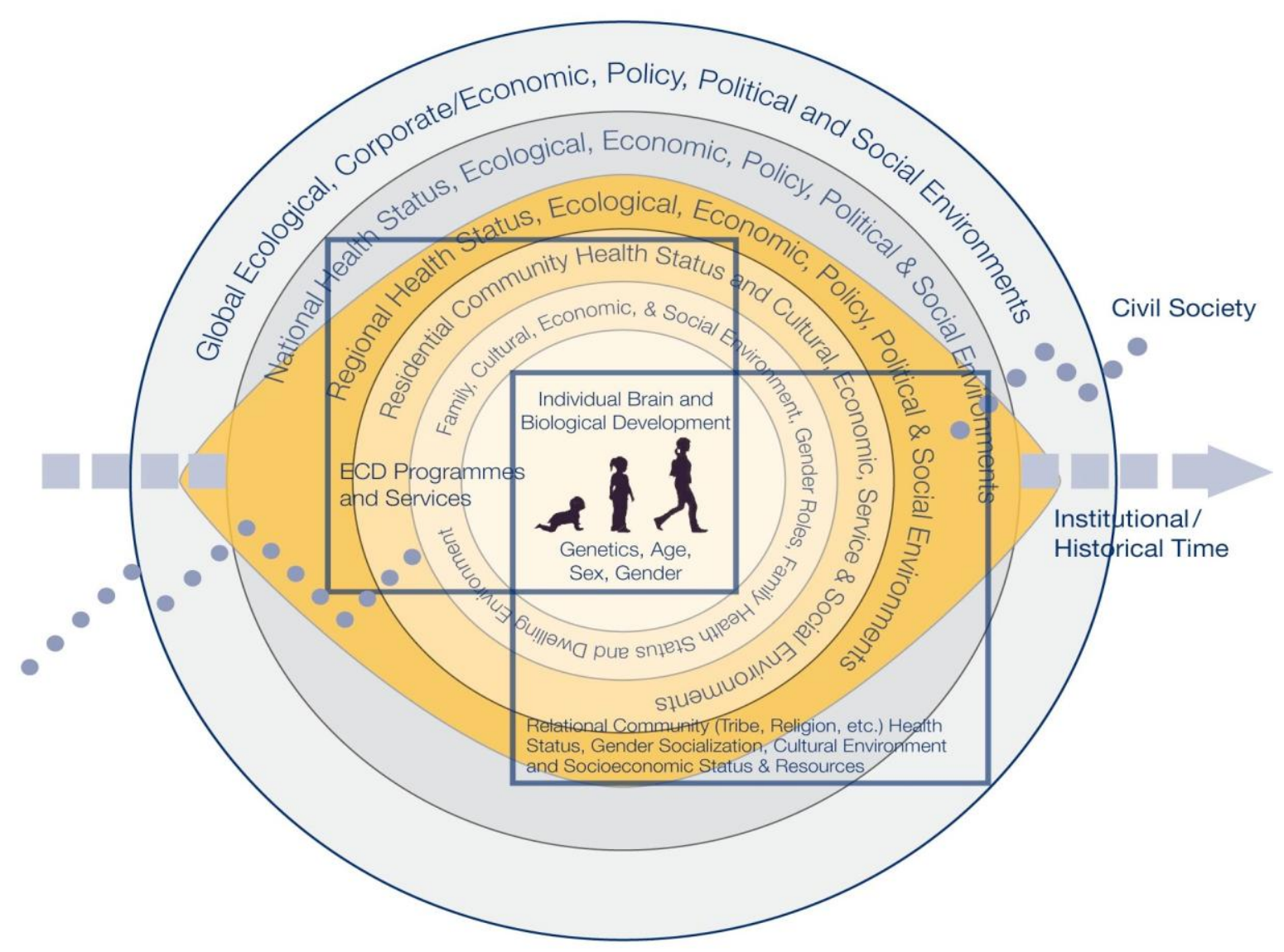

Figure 1: The Total Environment Assessment Model for Early Child Development (TEAM-ECD). Evidence report for the Commission on the Social Determinants of Health (p.15). by A. Siddiqi, L.G. Irwin, and C. Hertzman, 2007, Geneva, Switzerland: World Health Organization, Commission on the Social Determinants of Health [Reprinted with permission of the World Health Organization]

\section{The lifecourse approach}

The lifecourse approach is at the centre of the model. This characterizes an individual's journey from infancy to older adulthood. Paramount to the discussion of folate status, the lifecourse approach includes factors such as periconceptional and prenatal nutrition that determine health at the beginning of life. Healthy child development is a critical social determinant of health that affects both the child and the family. A child's experience early in life impacts their future ability to grow and prosper in society. The compounding impact of NTD through diminished physical health status and various environmental pressures 
throughout childhood, adolescence and adulthood may lead to poor morbidity and mortality outcomes. Women who have had a pregnancy terminated early as a result of a NTD, or who have delivered a baby with a NTD, may experience the emotional strain of self-blame associated with poor birth outcomes. ${ }^{51}$ Further, if the infant survives, both parent and child carry the burden of social and emotional pressures related to the child living with a mental and physical disability. ${ }^{52-55}$

\section{The social determinants of health}

The model identifies the social determinants of health, which distinguish target population subgroups that may at higher risk of low folate status and assists in identifying predictor variables. As outlined in Section 2.5, many factors can influence folate concentrations, including sociodemographic characteristics, so these were considered throughout the research process. This research investigates the socioeconomic status gradient in folate status, thus explores the existence of a potential underlying and pervasive root of health inequity that may contribute to adverse health outcomes.

\section{Multiple spheres of influence}

The multiple spheres of influence, which capture the interrelated social determinants of health, illustrate the complexity of the child's environment and the various agents that exert influence on periconceptional and prenatal health. The importance of the policy environment, including policies for food fortification with folic acid and guidelines on folic acid supplementation, are captured in the outermost spheres with their impact resonating at the innermost levels. The framework also highlights the need to consider how healthy child development is impacted by the introduction, refinement and elimination of influential policies and programs over long periods of time. 


\subsubsection{Contributions of this thesis to population health}

This thesis makes three key contributions to population health in Canada. The research: 1) has strong policy implications; 2) informs folate measurement methodology; and 3) explores a definition for high folate status. We present new information on the folate status of Canadians that policy makers, researchers and health professionals can use to make policy and clinical decisions.

\section{Has strong policy implications}

This research examines the behavioural, clinical and sociodemographic determinants of folate concentrations in the Canadian population. Prior to this thesis' publications, the national level RBC folate status of Canadians had not been studied in close to 40 years. The Nutrition Canada National Survey (NCNS) - conducted in 1971 - provided some insight into Canadians' folate status; however, the study explored serum folate, a measure of recent folate intake, and was conducted prior to fortification of certain grain products with folic acid. This dissertation's data source is the 2007-2009 CHMS, which directly measured RBC folate status - a reflection of long-term folate stores - and offered a post-fortification picture of national folate status. The results of this research illustrate the folate concentrations of Canadians, and identify key determinants of folate status in the general population and women of childbearing age. Correlates of folic acid supplement intake were also explored given the potential for synthetic folic acid to influence folate concentrations. Gaining an understanding of correlates will provide policy direction that can be used to narrow the gap if a socioeconomic gradient exists in folate concentrations and supplement use. Identifying the social determinants of these folate concentrations will help determine the need for targeted efforts in certain segments of the population. For example, low socioeconomic status women 
of childbearing age may need assistance accessing folic acid supplements to achieve folate concentrations considered optimal for maximal NTD risk reduction. Examining the RBC folate concentrations of Canadians and identifying key determinants may positively influence policies that could improve maternal, fetal and infant health and development in Canada and internationally.

\section{Informs folate measurement methodology}

The methodology used for national-level folate surveillance and monitoring was assessed through a comparison of folate concentrations between the United States and Canada. The United States National Health and Nutrition Examination Survey (NHANES) and the CHMS use different methods to measure RBC folate concentrations: microbiologic assay and Immulite 2000 immunoassay, respectively. Previous research has shown large discrepancies between folate measurement methods, which precludes direct comparison of folate concentrations between studies as this could lead to erroneous conclusions. ${ }^{56,57}$ To facilitate a between-country comparison, a conversion equation was generated through a separate substudy, detailed in Appendix F, to adjust the CHMS Immulite 2000 immunoassay to correspond to microbiologic assay. The results of this study, detailed in Section 4.5, underscore the importance of harmonizing folate laboratory measures prior to betweencountry comparisons. Further, this raises awareness in researchers who are new to the field regarding appropriate methods for accurate interlaboratory and interassay comparison of $\mathrm{RBC}$ folate. This novel comparison will inform population health monitoring of folate status on national and international levels.

\section{Explores a definition for high folate status}

Several folate concentration cut-offs are investigated and discussed in this thesis. The 
cut-offs for deficiency in the general population is $305 \mathrm{nmol} / \mathrm{L}$ and the cut-off for optimal concentrations for maximal NTD risk reduction in women of childbearing age is

$906 \mathrm{nmol} / \mathrm{L} .^{16,58}$ The folate concentration considered optimal for NTD risk reduction among women of childbearing age ( $\geq 906 \mathrm{nmol} / \mathrm{L}$ ) has been widely adopted by experts in the field. This cut-off was derived from a large Irish case-control study of antenatal women from 1986 to 1990 that demonstrated a continuous, inverse dose-response relationship between RBC folate concentration (up to $1292 \mathrm{nmol} / \mathrm{L}$ ) and NTD risk. ${ }^{16,58}$ The concentration of 906 $\mathrm{nmol} / \mathrm{L}$ represents the lower boundary of the uppermost $\mathrm{RBC}$ folate concentration group in this study population, as well as the category with the lowest risk of a NTD birth.

Researchers and policy makers have yet to arrive at a consensus definition for high folate concentrations. In this thesis, several possible high folate concentration cut-offs are explored with the aim of stimulating discussion and exploration in this area. Consensus on a high folate concentration cut-off has the potential to change current clinical practice as RBC folate has not generally been measured in clinical settings since fortification with folic acid was implemented. Defining high folate status will also contribute to the knowledge base used by organizations, such as SOGC, and policy makers when relevant policies and guidelines are refined so the appropriate segment of the population can be targeted while limiting potential harm to the general population. 


\subsection{References}

1. Kindig D, Stoddart G. What is population health? Am J Public Health 2003;93(3):380-3.

2. Hawe P, Potvin L. What is population health intervention research? Can J Public Health 2009;100(1):Suppl I8-14.

3. Canadian Institute of Health Research Institute of Population and Public Health. Strategic plan (2009-2014): Health equity matters. Ottawa (ON): Her Majesty the Queen in Right of Canada; 2009.

4. What is the population health approach? Ottawa (ON): Public Health Agency of Canada. Available: http://www.phac-aspc.gc.ca/ph-sp/approach-approche/ (Accessed 2013 May 11).

5. Food and Drug Administration. Food standards: amendment of standards of identity for enriched grain products to require addition of folic acid. Final Rule. 21 CFR Parts 136, 137, and 139. Federal Register. 1996;61:8781-8789.

6. Canada Gazette Part II. Regulatory impact analysis statement. In: Bureau of Food Regulatory IaIA, Health Canada, ed. 1998:3029-33. (SOR/98-550.)

7. MRC Vitamin Study Research Group. Prevention of neural tube defects: Results of the Medical Research Council vitamin study. Lancet 1991;338(8760):131-7.

8. Czeizel AE, Dudas I. Prevention of the first occurrence of neural-tube defects by periconceptional vitamin supplementation. N Engl J Med 1992;327(26):1832-5.

9. De Wals P, Tairou F, Van Allen MI, et al. Reduction in neural-tube defects after folic acid fortification in Canada. N Engl J Med 2007;357(2):135-42.

10. Bentley TG, Weinstein MC, Willett WC, et al. A cost-effectiveness analysis of folic acid fortification policy in the United States. Public Health Nutr 2009;12(4):455-67.

11. Llanos A, Hertrampf E, Cortes F, et al. Cost-effectiveness of a folic acid fortification program in Chile. Health Policy 2007;83(2-3):295-303.

12. Centers for Disease Control and Prevention (CDC). Trends in wheat-flour fortification with folic acid and iron--worldwide, 2004 and 2007. MMWR Morb Mortal Wkly Rep 2008;57(1):8-10.

13. Global progress mandatory wheat flour fortification legislation - August 2012. Ottawa (ON): Flour Fortification Initiative; 2012. Available:

http://www.ffinetwork.org/global_progress/index.php (Accessed December 11, 2012). 
14. Crider KS, Bailey LB, Berry RJ. Folic acid food fortification-its history, effect, concerns, and future directions. Nutrients 2011;3(3):370-84.

15. Nutrition for a healthy pregnancy - National guidelines for the childbearing years. Ottawa (ON): Health Canada, 2009. Available: http://www.hc-sc.gc.ca.proxy.bib.uottawa.ca/fnan/pubs/nutrition/folate-eng.php (Accessed October 10, 2009).

16. Institute of Medicine. DRI dietary reference intakes for thiamin, riboflavin, niacin, vitamin B6, folate, vitamin B12, pantothenic acid, biotin, and choline. Washington, (DC): National Academy Press; 1998.

17. Wilson RD, Davies G, Desilets V, et al. The use of folic acid for the prevention of neural tube defects and other congenital anomalies. J Obstet Gynaecol Can 2003;25(11):95973.

18. Mason JB. Unraveling the complex relationship between folate and cancer risk. Biofactors 2011;37(4):253-60.

19. Morris MS, Jacques PF, Rosenberg IH, et al. Circulating unmetabolized folic acid and 5methyltetrahydrofolate in relation to anemia, macrocytosis, and cognitive test performance in American seniors. Am J Clin Nutr 2010;91(6):1733-44.

20. Fife J, Raniga S, Hider PN, Frizelle FA. Folic acid supplementation and colorectal cancer risk: A meta-analysis. Colorectal Dis 2011;13(2):132-7.

21. Baggott JE, Oster RA, Tamura T. Meta-analysis of cancer risk in folic acid supplementation trials. Cancer Epidemiol 2012;36(1):78-81.

22. Wien TN, Pike E, Wisloff T, et al. Cancer risk with folic acid supplements: A systematic review and meta-analysis. BMJ Open 2012;2(1):e000653.

23. Vollset SE, Clarke R, Lewington S, et al. Effects of folic acid supplementation on overall and site-specific cancer incidence during the randomised trials: Meta-analyses of data on 50000 individuals. Lancet 2013;381(9871):1029-36.

24. Scientific Advisory Committee on Nutrition. Folate and disease prevention. Norwich, (UK): The Stationary Office; 2006.

25. Scientific Advisory Committee on Nutrition. Folic acid and colorectal cancer risk: Review of recommendation for mandatory folic acid fortification. Norwich (UK): The Stationary Office; 2009.

26. Ministry for Primary Industries. Food standard: New Zealand (permitted fortification of bread with folic acid) food standard 2012. Wellington, (NZ): Ministry for Primary Industries; 2012. 
27. Cole BF, Baron JA, Sandler RS, et al. Folic acid for the prevention of colorectal adenomas: A randomized clinical trial. JAMA 2007;297(21):2351-9.

28. Mason JB, Dickstein A, Jacques PF, et al. A temporal association between folic acid fortification and an increase in colorectal cancer rates may be illuminating important biological principles: A hypothesis. Cancer Epidemiol Biomarkers Prev 2007;16(7):1325-9.

29. Troen AM, Mitchell B, Sorensen B, et al. Unmetabolized folic acid in plasma is associated with reduced natural killer cell cytotoxicity among postmenopausal women. $\mathrm{J}$ Nutr 2006;136(1):189-94.

30. Selhub J, Morris MS, Jacques PF, et al. Folate-vitamin B-12 interaction in relation to cognitive impairment, anemia, and biochemical indicators of vitamin B12 deficiency. Am J Clin Nutr 2009;89(2):702S-6S.

31. Haberg SE, London SJ, Stigum H, et al. Folic acid supplements in pregnancy and early childhood respiratory health. Arch Dis Child 2009;94(3):180-4.

32. Whitrow M, Moore VM, Rumbold A, et al. Effect of supplemental folic acid in pregnancy on childhood asthma: A prospective birth cohort study. Am J Epidemiol 2009;170(12):1486-93.

33. Martinussen MP, Risnes KR, Jacobsen GW, et al. Folic acid supplementation in early pregnancy and asthma in children aged 6 years. Am J Obstet Gynecol 2012;206(1):72.e1,72.e7.

34. Morris MS, Jacques PF, Rosenberg IH, et al. Folate and vitamin B12 status in relation to anemia, macrocytosis, and cognitive impairment in older Americans in the age of folic acid fortification. Am J Clin Nutr 2007;85(1):193-200.

35. Yajnik CS, Deshpande SS, Jackson AA, et al. Vitamin B12 and folate concentrations during pregnancy and insulin resistance in the offspring: The Pune maternal nutrition study. Diabetologia 2008;51(1):29-38.

36. Commission on the Social Determinants of Health. Closing the gap in a generation: Health equity through action on the social determinants of health: final report of the Commission on the Social Determinants of Health. Geneva $(\mathrm{CH})$ : World Health Organization; 2008.

37. Mustard J. Early child development and experienced-based brain development: The scientific underpinnings of the importance of early child development in a globalized world. Toronto (ON): Canadian Institute for Advanced Research; 2006. 
38. Irwin, L., Siddiqi, A. Hertzman, C. Early child development: A powerful equalizer (final report for the WHO commission on the social determinants of health). Vancouver (BC): Human Early Learning Partnership (HELP); 2007.

39. Whitehead M. The concepts and principles of equity in health. Int J Health Serv 1992;22(3):429-45.

40. Keating, DP., Hertzman, C. Developmental health and the wealth of nations: Social, biological and educational determinants. New York (NY): Guildford Press; 2000.

41. van der Pal-de Bruin KM, de Walle HE, de Rover CM, et al. Influence of educational level on determinants of folic acid use. Paediatr Perinat Epidemiol 2003;17(3):256-63.

42. Sherwood KL, Houghton LA, Tarasuk V, et al. One-third of pregnant and lactating women may not be meeting their folate requirements from diet alone based on mandated levels of folic acid fortification. J Nutr 2006;136(11):2820-6.

43. Koren G, Goh I. Increasing folate supplementation for selected groups of Canadian women. J Obstet Gynaecol Can 2007;29(12):992-6.

44. Kallen B. Congenital malformations in infants whose mothers reported the use of folic acid in early pregnancy in Sweden. A prospective population study. Congenit Anom (Kyoto) 2007;47(4):119-24.

45. Bar-Oz B, Koren G, Nguyen P, et al. Folate fortification and supplementation--are we there yet? Reprod Toxicol 2008;25(4):408-12.

46. Wilson RD, Johnson JA, Wyatt P, et al. Pre-conceptional vitamin/folic acid supplementation 2007: The use of folic acid in combination with a multivitamin supplement for the prevention of neural tube defects and other congenital anomalies. J Obstet Gynaecol Can 2007;29(12):1003-26.

47. Institute of Medicine Committee on assuring the health of the public in the 21st century. The future of the public's health in the 21st century. Washington (DC): The National Academies Press; 2003.

48. EtchesV, Frank J, DiRuggerio E, Manuel D. Measuring population health: A review of indicators. Annu Rev Public Health 2006;27:29-55.

49. Hertzman C, Frank J, Evans RG. Heterogeneities in health status and the determinants of population health. In: Evans, RG, Barer, ML, Marmor, TL, eds. Why are some people healthy and others are not? Hathorne (NY): Walter de Gruyter, Inc.; 1994.

50. Dahlgren, G., Whitehead, M. Policies and strategies to promote social equity and health. Copenhagen (DK): World Health Organization; 1992. 
51. Hobdell E. Chronic sorrow and depression in parents of children with neural tube defects. J Neurosci Nurs 2004;36(2):82-94.

52. Blum RW, Resnick MD, Nelson R, et al. Family and peer issues among adolescents with spina bifida and cerebral palsy. Pediatrics 1991;88(2):280-5.

53. Kirpalani HM, Parkin PC, Willan AR, et al. Quality of life in spina bifida: Importance of parental hope. Arch Dis Child 2000;83(4):293-7.

54. Roux G, Sawin KJ, Bellin MH, et al. The experience of adolescent women living with spina bifida. part II: Peer relationships. Rehabil Nurs 2007;32(3):112-9.

55. Pitkin RM. Folate and neural tube defects. Am J Clin Nutr 2007;85(1):285S-8S.

56. Gunter EW, Bowman BA, Caudill SP, et al. Results of an international round robin for serum and whole-blood folate. Clin Chem 1996;42(10):1689-94.

57. Owen WE, Roberts WL. Comparison of five automated serum and whole blood folate assays. Am J Clin Pathol 2003;120(1):121-6.

58. Daly LE, Kirke PN, Molloy A, et al. Folate levels and neural tube defects: Implications for prevention. JAMA 1995;274(21):1698-702. 


\section{CHAPTER 2: REVIEW OF THE LITERATURE}

\subsection{Basic overview of folate}

Folate is a water-soluble B-complex vitamin. A basic overview of folate is outlined below to provide context for this population based investigation of Canadian RBC folate concentrations.

\subsubsection{Structure}

Folate is the generic term for both naturally occurring folates in food and folic acid. Most food folates are pteroylpolyglutamates, which contain one to six additional glutamate molecules joined in a peptide linkage to the $\gamma$-carboxyl of glutamate. Folic acid rarely occurs naturally in food, and is the most oxidized, monoglutamate form that is used in dietary supplements and fortified foods (Figure 1). ${ }^{1,2}$

\subsubsection{Absorption, Bioavailability and Storage}

Most folates found naturally in foods are hydrolysed to a monoglutamate form in the gut prior to being absorbed by an active transport process across the intestinal mucosa and into the portal circulation. ${ }^{3}$ Synthetic folic acid can also be absorbed by non-saturable passive diffusion. Folate is taken up from the portal circulation by the liver, where it is metabolized and retained or released into the blood or bile. When released from tissues into circulation, folate polyglutamates are reconverted to the monoglutamate form. Some folate is excreted in the urine, bile and feces.

The hydrolysis of food folate by brush border and intracellular mucosal folyl conjugases prior to absorption can be inefficient and, thus, impact the bioavailability of food folate. ${ }^{3}$ When taken with food, synthetic folic acid is approximately $85 \%$ bioavailable, and up to $100 \%$ bioavailable when supplemental folic acid is taken in a fasted state. ${ }^{2}$ Naturally 
occurring folates are estimated to be about $50 \%$ bioavailable, though this has been shown to vary from $30 \%$ to $98 \%{ }^{3}$ Dietary Folate Equivalents (DFE) were created to account for these differences in bioavailability, with $1 \mu \mathrm{g}$ DFE being equivalent to $1 \mu \mathrm{g}$ of food folate, $0.6 \mu \mathrm{g}$ of folic acid consumed with food or $0.5 \mu \mathrm{g}$ folic acid consumed in a fasted state. ${ }^{2}$

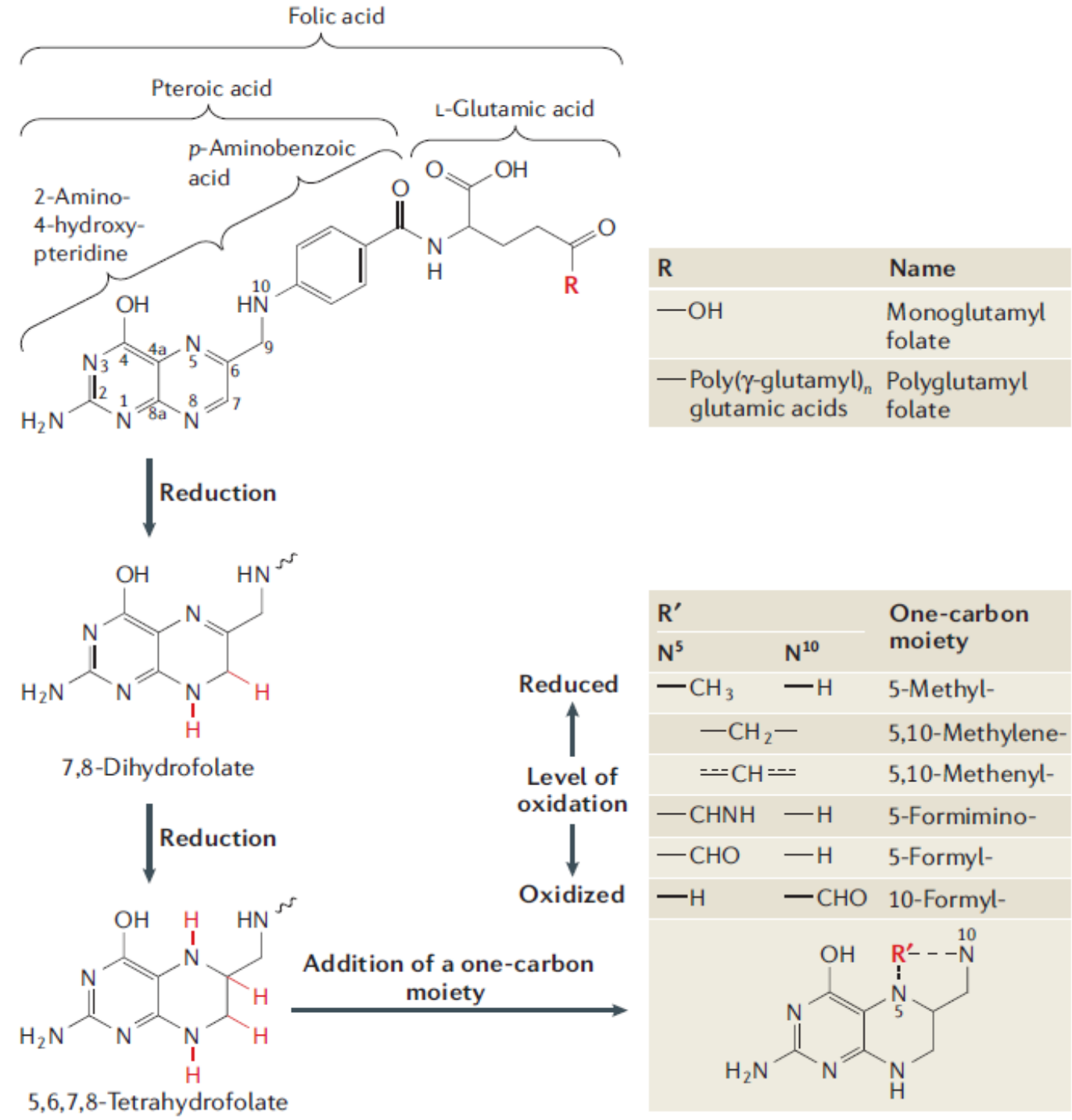

Figure 1: The structure of folic acid: Synthetic folic acid must be reduced to tetrahydrofolate (THF), the naturally bioactive form. A one-carbon unit is added to THF followed by reduction steps to produce 5-methyltetrahydrofolate (5-MeTHF). This is the main form of folate found in the blood stream. [Reprinted with permission from Nature Reviews Neuroscience 7(9):724-731 @2006] 


\subsubsection{Metabolism and function}

Folate metabolism is essential in cellular functioning, particularly in periods of rapid growth. Folate is a coenzyme in an interrelated set of biochemical reactions that involve one-carbon metabolism, or the transfer of one-carbon groups from one compound to another. ${ }^{4}$ Folate coenzymes play an important and complex role in the remethylation and transulphuration pathways in the body by acting as acceptors and donors of one-carbon moieties in reactions involving amino acid and nucleotide metabolism. Thus, folate plays a key role in multiple metabolic processes, including DNA synthesis and metabolism, regulation of gene expression, and synthesis of proteins and lipids.

Folate is not synthesized by the body, thus serum folate is depleted when folate is not consumed. This is paralleled by a depletion of stored folate in the RBC. ${ }^{5}$ Mature RBCs have limited ability to transport and accumulate folate. RBCs build folate stores during erythropoeisis, in the bone marrow, that are retained through the 120-day life span of the $\mathrm{RBC}$; thus, $\mathrm{RBC}$ concentrations are a common measure of long-term folate status. ${ }^{5}$ Consumption of supraphysiologic doses of folic acid - estimated to be above $266 \mu \mathrm{g}$ at one meal - results in unmetabolized folic acid in the circulating serum. ${ }^{6}$ This has been observed within several subgroups (e.g. pregnant women, infant (cord blood) and older adults) but is unlikely to be achieved in the absence of synthetic folic acid intake. Implications of free folic acid in the blood remain unknown..$^{6-9}$

Vitamin $\mathrm{B}_{12}$ and homocysteine (Hcy) are also implicated in these pathways (Figure 2). Hcy is formed from methionine, and is either converted to cysteine (transulphuration pathway) or remethylated to methionine. ${ }^{10,11}$ The formation of methionine from Hcy involves methionine synthase, an enzyme that utilizes vitamin $\mathrm{B}_{12}$ as a cofactor and 
methyltetrahydrofolate as a substrate. A rise in Hcy concentration is observed when poor folate intake leads to lower serum and RBC folate concentration.

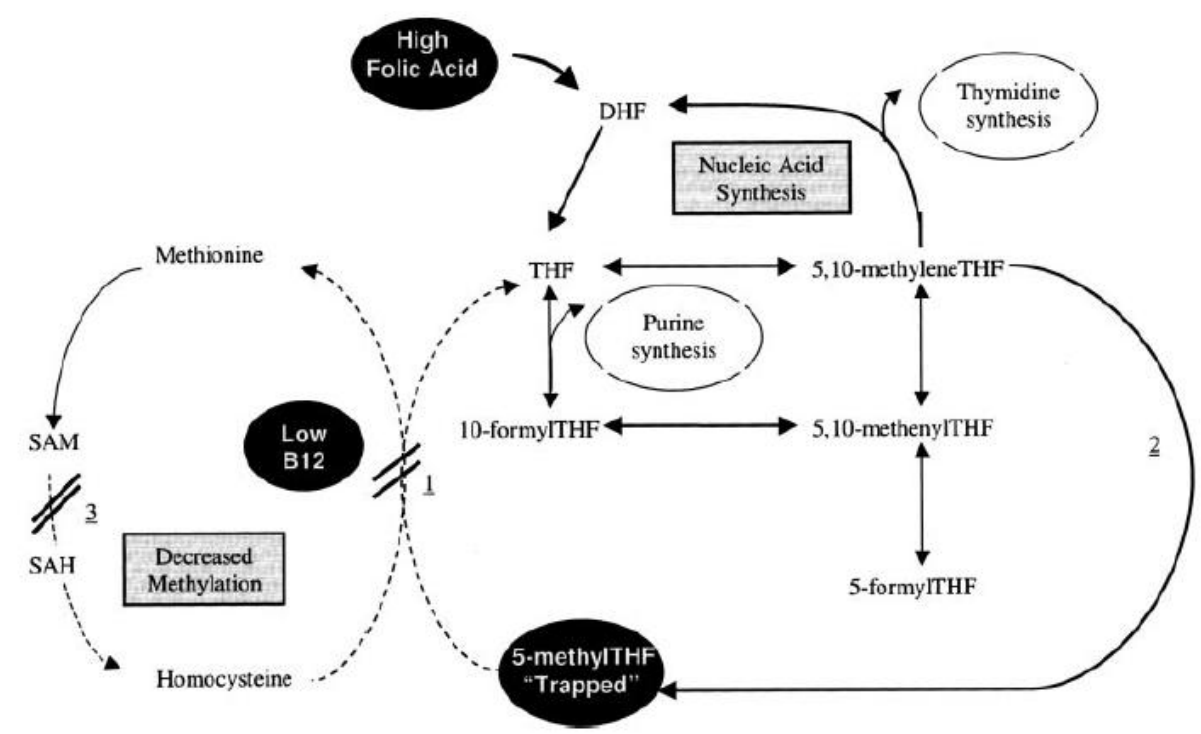

Figure 2: Overview of how high folic acid intakes correct DNA synthesis but not homocysteine remethylation during vitamin $\mathrm{B}_{12}$ deficiency. ${ }^{10}$ DHF, dihydrofolate; THF, tetrahydrofolate; 5-methyTHF, 5-

methyltetrahydrofolate; SAM, $S$-adenosylmethionine; SAH, $S$-adenosylhomocysteine; 1, methionine synthase; 2 , methylenetetrahydrofolate reductase; 3 , glycine- $N$-methyltransferase; $\mathrm{B}_{12}$, vitamin $\mathrm{B}_{12}$. [Reprinted with permission from The American Journal of Clinical Nutrition 83(4):2820-2826@2006]

\subsubsection{Folate sources}

Several foods contain naturally occurring folates, for example cooked beans, orange juice, dark leafy greens and melon. A more comprehensive list can be found in Appendix C.

Depending on a country's fortification policies, enriched white wheat flour, cornmeal, pasta, cereal and white rice may contain synthetic folic acid if fortified with the vitamin. Canada fortifies white wheat flour and cornmeal with folic acid at a level of $0.15 \mathrm{mg} / 100 \mathrm{~g}$, and pasta labelled enriched at a level of $0.20 \mathrm{mg} / 100 \mathrm{~g} .{ }^{12}$ Discretionary fortification of ready-to-eat breakfast cereals allows up to $0.06 \mathrm{mg} / \mathrm{serving}$. 


\subsubsection{Red blood cell folate analytical methods}

Multiple methods are used to measure RBC folate concentrations. This section will provide a brief overview of analytical methods for $\mathrm{RBC}$ folate that are pertinent to this thesis.

Protein-binding assays: There are many types of protein-binding assays, but in general these use a folate binding protein to specifically bind folate from a sample. The Bio-Rad Quantaphase II radioassay, is the type of protein-binding assay that was used to measure RBC folate in the NHANES from 1991 to $2007 .{ }^{13}$ Most radioassays are competitive binding assays, which involve the competition between an unlabelled whole blood hemolysate sample and a radiolabeled tracer folate (e.g. ${ }^{125}$ I-tyramide of pteroylglutamic acid $\left[{ }^{125} \mathrm{I}-\right.$ PGA]) for available binding sites on a limited amount of folate binding protein. ${ }^{14,15}$ To quantify the amount of folate in the sample, differences are observed in the degree of saturation of the folate binding protein by the unlabeled whole blood hemolysate or the extent of competition with the radiolabeled tracer folate for binding sites. This procedure is considered to be easy to use and has high sensitivity and specificity. ${ }^{5,16}$ Common limitations are intermittent imprecision caused by inaccurate micropipettors, multiple freeze-thaw cycles and exposure of the samples to light, which may cause folate degradation.

The Canadian Health Measures Survey (CHMS), Cycle 1 used another type of proteinbinding assay (automated, nonradioassay) to measure RBC folate, specifically a competitive immunoassay procedure using the Immulite 2000 analyser. ${ }^{17}$ This method, a competitive immunoassay, is based on the immune-reaction between an antibody and an antigen (the whole blood hemolysate), and chemiluminescence is used for detection. ${ }^{14}$ With chemiluminescence, there is a proportional relationship between the amount of folate 
conjugate bound to folate binding protein and the resulting light signal, and an inversely proportional association between the folate concentration in the sample and the resulting light signal. Key strengths of this methodology are that it is simple, precise and inexpensive. Some examples of the limitations of immunoassay are the need to know the participant's hematocrit to calculate $\mathrm{RBC}$ folate results from whole blood and the potential for folate degradation on exposure to light or multiple freeze-thaw cycles.

Microbiologic assays: Microbiologic assay is currently considered the gold standard for measuring RBC folate. ${ }^{18}$ In general, this method involves adding a diluted whole blood hemolysate to an assay medium containing a bacteria - Lactobacillus rhamnosus (National Collection of Industrial Bacteria [NCIB] 10463) - and all of the nutrients necessary for bacterial growth except for folate. Since the bacterial growth is proportional to the amount of total folate present in whole blood samples, the total folate level can be assessed by measuring the turbidity of the inoculated medium. A key strength of microbiologic assay is the measurement of all biologically active forms of folate equally but does not measure degradation products that lack biological activity. In addition, microbiologic assays are considered less costly than chromotographic assays, relatively easy to perform and reliable. Multiple limitations have been cited including the inability to provide values for different forms of folate, the inhibition of the microorganism growth if antibiotics are in the samples and the concern that non-folate compounds may stimulate the growth of the microorganism. The most common causes of imprecision are pipetting errors, the requirement for fresh assay medium and sodium ascorbate daily as well as the degredation of folates resulting from multiple freeze-thaw cycles and exposure to strong sunlight. 


\section{Interassay differences and impact of methylenetetrahydrofolate reductase genotype}

Researchers have observed significant interassay differences, which can impair the ability to compare $\mathrm{RBC}$ folate measurement methods. These differences exist due to multiple complications that exist in folate measurement, for example reduced folates are unstable at extreme $\mathrm{pH}$ values and when exposed to elevated temperatures, oxygen or light. Owen et al. compared whole blood results from the Bio-Rad Quantaphase II radioassay to five automated, nonisotopic methods that used folate-binding protein. ${ }^{19}$ It was demonstrated that the Immulite 2000 immunoassay results were almost three times higher than the Bio-Rad. Limitations in the hemolysate preparation conditions and calibration differences were thought to account for the poor agreement. Fazili et al. conducted a methods comparison study analysing whole blood hemolysates, from an American and a European blood bank, to examine differences in total folate concentrations measured by liquid chromatographytandem mass spectrometry (LC/MS/MS), microbiologic assay (using L. Rhamnosus) and Bio-Rad. ${ }^{20}$ The microbiologic assay was comparable to the LC/MS/MS within $\pm 10 \%$, but the values were $45 \%$ lower for Bio-Rad assay in whole blood samples.

Though the CHMS does not currently measure methylenetetrahydrofolate reductase (MTHFR), it is valuable to note the potential impact of this enzyme, which is imperative in folate metabolism, on laboratory measures of RBC folate (Figure 2) ${ }^{21}$ The MTHFR C677T polymorphism is a genetic alteration that can impair folate metabolism by reducing the activity of MTHFR, which leads to lower folate concentrations in the blood. Since methyltetrahydofolate (methyl-THF) is the major transport form of folate, reduced MTHFR activity is expected to decrease the amount of circulating folate, estimated to be $10 \%$ to $25 \%$ in association with the homozygous TT variant. ${ }^{21}$ The methods comparison study by Fazili et 
al. determined that Bio-Rad results were found to be MTHFR C677T genotype dependent; those with the TT differed from microbiologic assay by $31 \%$ and those with CC or CT genotypes differed by $48 \% .{ }^{20}$ Genotype did not affect the correlation between LC/MS/MS and microbiologic assay. It was postulated that the different recovery of folate forms may explain these differences.

\subsection{Folate and health outcomes}

The folate literature is laden with studies examining associated health benefits and harms. Consuming synthetic folic acid - from supplements and fortified food - is more effective in elevating blood concentrations and tissue folate stores than intake of folate from natural sources. Thus, the health impact of folic acid supplement intake is a primary area of research.

Folate intake has been implicated in the promotion or hindrance of health status, and key issues are the dose, timing and duration of intake. ${ }^{22}$ Two population-level distinctions are noteworthy. First, the health of the general population is assessed for folate deficiency (RBC folate concentration $<305 \mathrm{nmol} / \mathrm{L}$ ), and potentially high folate concentrations, which have yet to be defined. ${ }^{2,23}$ Second, women of childbearing age are assessed at a different folate concentration specific to optimal concentrations for maximum NTD risk reduction ( $\geq 906$ $\mathrm{nmol} / \mathrm{L}) .{ }^{24}$ Thus, women of childbearing age can have sufficient folate concentrations, but still not achieve optimal concentrations for NTD risk reduction.

\section{Folate deficiency}

Deficient folate status can lead to megaloblastic anemia, which is characterized by enlarged erythrocytes caused by interrupted DNA synthesis with continued RNA synthesis. ${ }^{25}$ 
Multiple risk factors for folate deficiency exist, including the use of folic acid antagonist medications, alcohol abuse, overall poor diet quality and malabsorptive disorders. Symptoms of this anemia are fatigue, grey hair, mouth ulcers, poor growth and a swollen tongue.

\section{Neural tube defect risk reduction}

Since folic acid consumed periconceptionally and NTD prevention in offspring were linked, poor folate intake has gained global attention. ${ }^{26}$ Though the exact mechanism is unknown, the role of folate in nucleic acid formation, as well as cell development and proliferation, has been proposed. ${ }^{27}$ Therefore, the formation of the neural tube may be compromised if the process of neurulation lacks required nutrients. ${ }^{28}$ Two major studies are most often cited as characterizing this association, the Medical Research Council (MRC) vitamin study and the Czeizel et al. Hungarian randomized controlled trial (RCT). ${ }^{29,30}$ The MRC vitamin study (1983-1991), was a randomised double-blind prevention trial involving 33 centres in the United Kingdom, Canada, Israel, Hungary, Australia, the Former Soviet Union and France. ${ }^{29}$ The trial involved 1800 non-supplementing women who were planning a pregnancy following a previous pregnancy affected by an NTD. The participants were randomly assigned to consume varying doses of folic acid periconceptionally with and without other vitamins, as follows: 1) $4 \mathrm{mg}$ folic acid with other vitamins; 2) $4 \mathrm{mg}$ folic acid without other vitamins; 3) no folic acid but other vitamins; and 4) no vitamin supplement. Vitamin capsules contained a control substance of dried ferrous sulphate $(120 \mathrm{mg})$ and dicalcium phosphate $(240 \mathrm{mg})$. Data from the 1200 women with a completed pregnancy were analysed revealing that $72 \%$ of NTDs were prevented in the folic acid group compared to the control group (relative risk of 0.28 ). 
A Hungarian RCT, conducted from 1984 to 1991, also provided evidence that folic acid reduced the incidence of a first NTD occurrence. ${ }^{30}$ A total of 7540 women were enrolled and randomized into two periconceptional multivitamin supplementation groups: 1) a multivitamin including $0.8 \mathrm{mg}$ of folic acid or 2) a trace element supplement. Of the 4753 confirmed pregnancies, 2104 were in the vitamin supplemented group, and the other 2052 were in the trace-element supplement group. Researchers observed 28 congenital anomalies and no NTD in the vitamin supplemented group. Those in the trace-element group exhibited a total of 47 congenital anomalies and six NTDs.

The evidence from these RCTs, demonstrating that 50-75\% of all NTD cases could be prevented through maternal intake of folic acid, was a key driver for many countries to fortify certain grain products with folic acid. ${ }^{29,30}$ Subsequently, the prevalence of NTDaffected pregnancies - post-fortification of grain products with folic acid - has been reduced to an estimated 0.86 per 1000 births in Canada, and 1 per 1000 births in the United States. ${ }^{31}$

The folate concentration considered optimal for NTD risk reduction among women of childbearing age ( $\geq 906 \mathrm{nmol} / \mathrm{L})$ was derived from a large Irish case-control study of antenatal women, conducted from 1986 to 1990, that demonstrated a continuous, inverse dose-response relationship between RBC folate concentration (up to $1292 \mathrm{nmol} / \mathrm{L}$ ) and NTD risk. $^{24}$ The cut-off of $906 \mathrm{nmol} / \mathrm{L}$ represents the lower boundary of the uppermost RBC folate concentration group in this study population, as well as the category with the lowest risk of a NTD birth. This cut-off has been widely adopted by experts in the field, though the use of this cut-off is not without limitations. ${ }^{2,24}$ The cut-off is based on a single study, and the small sample size at RBC folate concentrations above $1292 \mathrm{nmol} / \mathrm{L}$ (the mean level of all controls in the $\geq 906 \mathrm{nmol} / \mathrm{L}$ group) limited the ability to examine whether NTD risk would 
continue to decrease at higher concentrations, thus the cut-off of $906 \mathrm{nmol} / \mathrm{L}$ is considered a conservative estimate. Further, RBC folate was measured using microbiologic assay (using L. Casei); thus there is potential for interassay and interlaboratory variation. ${ }^{32}$

\section{Further evidence on health outcomes}

In addition to reducing NTD risk, folic acid intake has been studied in association with a decreased risk of other congenital anomalies, including cardiovascular defects, oral cleft, urinary tract abnormalities, congenital hydrocephalus and limb defects. ${ }^{33-36}$ Safe doses of folic acid, as defined by the dietary reference intakes, have also been implicated in lower risk of colorectal cancer - and other cancers such as breast, lung and prostate - in the general population. ${ }^{2,37,38}$ Folic acid also lowers homocysteine levels, which was once implicated in lowering heart disease risk. A meta-analyses involving $28 \mathrm{RCTs}(\mathrm{N}=58,804)$ did not support an association between folic acid supplementation and decreased risk of cardiovascular disease, but a potential link was made to a decreasing trend in stroke risk. ${ }^{2,11}$

Multiple reviews have disputed the health benefits of folic acid intake, with the exception of NTD prevention, instead speculating a neutral or potentially detrimental impact. A 2010 Cochrane review that included five RCTs, concluded that folic acid supplementation was not significantly associated with prevention of birth defects, other than NTD. ${ }^{39}$ Further, it has been postulated that multivitamin use, not necessarily single source folic acid, is protective against cleft lip with or without cleft palate, though it is unknown whether this association is due to lifestyle factors associated with multivitamin use or the multivitamin itself. ${ }^{40}$

A summary of studies related to folate and negative health outcomes, cited in this section, can be found in Table 1. Folic acid influences DNA methylation, thus has been implicated in epigenetic changes that could alter the way genes are expressed - without changing the DNA 
sequence - potentially leading to adverse birth outcomes. ${ }^{41}$ The potential for folic acid consumed during pregnancy to alter gene expression during early development has been studied in relation to the promotion of an allergenic phenotype, in particular concerns have been raised regarding increased risk of lower respiratory tract infections, wheeze and childhood asthma. ${ }^{42,43}$ However, a more recent cohort study did not support an association between folic acid supplementation in early pregnancy and the development of asthma in offspring at six years of age. ${ }^{44}$ In another study, high folate concentrations in pregnant women were associated with increased insulin resistance and higher central adiposity in their children. ${ }^{45}$ Further, low vitamin $\mathrm{B}_{12}$ status in pregnancy predicted higher insulin resistance, though this was most pronounced in mothers who also had high folate concentrations.

The safety of higher doses of folic acid has also been questioned for the general population. Folic acid may mask vitamin $\mathrm{B}_{12}$ deficiency when consumed at unsafe levels ( $\geq 5 \mathrm{mg} / \mathrm{d}$ ) so that neurological symptoms of vitamin $\mathrm{B}_{12}$ deficiency go undetected and untreated leading to neurological damage. ${ }^{11}$ This is of particular concern in the elderly population; however, it has been suggested that current recommended intakes of folic acid pose a minimal threat of masking or exacerbating neuropathies. ${ }^{41,46}$

Emerging evidence has demonstrated a possible association between folic acid intake and increased risk of cancer in individuals with pre-existing neo-plasms, has stimulated research in this area. ${ }^{22,47}$ Animal studies and clinical observations have illustrated a U-shaped curve in relation to cancer, where folate can be cancer promoting or suppressing. ${ }^{48}$ For example, a double-blind, placebo controlled RCT - the Aspirin/Folate Polyp Prevention Trial - aimed to determine the potential to prevent colorectal adenomas in those with a history of adenomas with oral aspirin and folic acid supplementation. ${ }^{49}$ Participants who had a recent history of 
colorectal adenoma were randomly assigned to consume either $1 \mathrm{mg} / \mathrm{d}$ of folic acid or a placebo, concurrent with a separate randomization to receive Aspirin. The study demonstrated unforeseen, non-significant increases in the incidence of advanced colorectal adenomas and prostate cancer. An observational study, also released in 2007, presented an examination of age-adjusted incidence of colorectal cancer in Canada and the United States from 1986 to $2002 .{ }^{38}$ The study illustrated a steady decline in colorectal cancer incidence for both countries from 1986 to 1996, which was interrupted by a sharp increase from 1996 to 1998 in the United States) and from 1997 to 2000 in Canada, followed by a slow return towards the previous baseline. In Chile, a significant increase (162\%) in the hospital discharge rate due to colon cancer between the pre-fortification period (1992-1994) and the post-fortification period (2001-2004) was observed in participants 45-64 years. ${ }^{47}$

Recent meta-analyses examining available RCTs of folic acid supplementation have provided some evidence of a cancer-promoting effect (Table 2). Most trials include folic acid supplement treatment in the range of $0.5 \mathrm{mg} / \mathrm{d}$ to $2.5 \mathrm{mg} / \mathrm{d}$. Fife et al. examined three RCTs, finding a colorectal cancer-promoting effect associated with a three-year folic acid supplementation treatment, with 1.35 (95\% CI 1.06, 1.70) times the odds of adenomatous lesions and 1.50 (95\% CI: $1.06,2.10)$ times the odds of occurrence of advanced lesions. ${ }^{50}$ Baggott et al. found that cancer incidence was higher in folic acid supplemented groups, over those not taking supplements (RR $1.21,95 \%$ CI: $1.05,1.31) .{ }^{51}$ Frequency of overall cancer was shown to be slightly increased following folic acid treatment by Wien et al., with prostate cancer being the only type to significantly increase following folic acid supplementation. ${ }^{52}$ Supplemental folate in those with a pre-existing neoplasm may promote 
colorectal cancer; however, the timing and dose of the intervention appear to be critical in preventing cancer in a safe and effective way. ${ }^{48}$

Unmetabolized folic acid in the serum has been found in multiple segments of the population, including women of childbearing age, infant (cord blood) and older adults. ${ }^{7-9}$ In the latter, free folic acid in the serum has been linked to cognitive impairment. This finding was potentially limited by pernicious anemia - which is caused by a lack of intrinsic factor needed for the absorption of vitamin $\mathrm{B}_{12}$ - thus increasing the risk for megaloblastic anemia and associated neurological disorder. ${ }^{9}$ This area needs continued surveillance and monitoring to investigate potential associations with other health problems. Technology to analyse free folic acid in the blood is relatively new; thus, the literature will likely expand over the next few years. ${ }^{53}$ This is an emerging and uncharted area of study and the implications remain controversial.

Speculations of the adverse health outcomes of folate intake have subsequently been challenged. For example, Martinussen et al. did not demonstrate an association between reported folic acid supplement consumption in the first trimester of pregnancy and the development of asthma in their offspring at six years of age. ${ }^{44}$ Recent systematic reviews and meta-analyses on folate intake have indicated that there is no overall harm, but actually a beneficial or neutral effect for cancer prevention. ${ }^{54,55}$ For example, a 2013 meta-analysis included individual participant datasets from 13 trials $(\mathrm{N}=49,969)$ that compared folic acid supplements (in amounts ranging from $0.5 \mathrm{mg} / \mathrm{d}$ to $40 \mathrm{mg} / \mathrm{d}$ ) versus placebo, had a duration of at least one year, included at least 500 participants and recorded data on cancer incidence. ${ }^{54}$ Though plasma folate concentrations increased in the folic acid supplemented participants, short-term effects on overall or site-specific cancer incidence were not 
demonstrated.

Though many reviews have been dedicated to investigating the potential link between high folate and adverse effects, little consensus has been reached. Issues regarding heterogeneity between studies, for example timing and dose of folic acid supplement, as well as inconsistencies in blood concentration measurement can hinder comparisons. Understanding the health outcomes related to folic acid intake remains a controversial area. Each study - with the exception of the well-established link between folic acid intake and NTD prevention - appears to be offset by an opposite or neutral finding. Regardless, the lack of agreement in the field is evidence that the association between folic acid and various health outcomes is a vital area of investigation. Exploring the folate status of the population is an important first step in building this knowledge base. 
Table 1: Summary of cited studies that examine negative health outcomes in relation to folate intake and concentrations

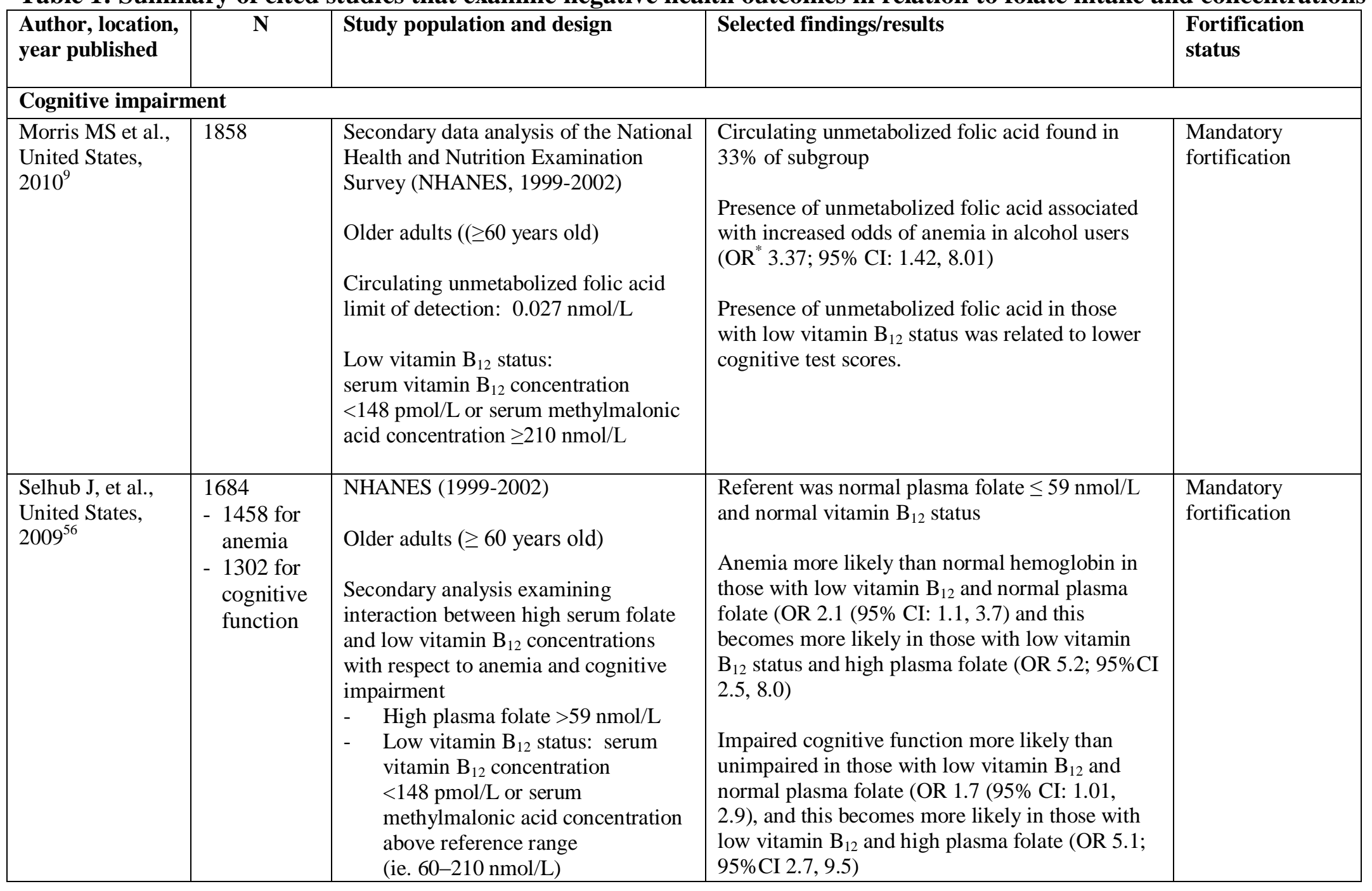




\begin{tabular}{|c|c|c|c|c|}
\hline $\begin{array}{l}\text { Morris MS, } \\
\text { United States, } \\
2007^{57}\end{array}$ & 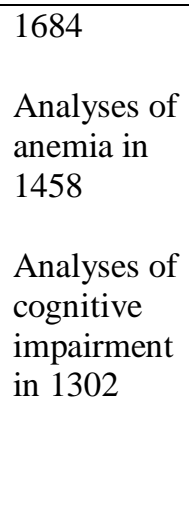 & $\begin{array}{l}\text { NHANES }(1999-2000) \\
\text { Secondary data analysis } \\
\text { Older adults } \geq 60 \text { years of age } \\
\text { High plasma folate }>59 \mathrm{nmol} / \mathrm{L} \\
\text { Low vitamin } \mathrm{B}_{12} \text { status: serum vitamin } \\
\mathrm{B}_{12} \text { concentration }<148 \mathrm{pmol} / \mathrm{L} \text { or } \\
\text { serum methylmalonic acid } \\
\text { concentration } \geq 210 \mathrm{nmol} / \mathrm{L}\end{array}$ & $\begin{array}{l}\text { Low vitamin } \mathrm{B}_{12} / \text { high folate status, as opposed to } \\
\text { low vitamin } \mathrm{B}_{12} / \text { normal folate status, was } \\
\text { associated with increased likelihood of } \\
\text { anemia (OR: } 3.1 ; 95 \% \text { CI: } 1.5,6.6 \text { ) and } \\
\text { cognitive impairment (OR: } 2.6 ; 95 \% \text { CI: } 1.1,6.1 \text { ) }\end{array}$ & $\begin{array}{l}\text { Mandatory } \\
\text { fortification }\end{array}$ \\
\hline \multicolumn{5}{|l|}{ Cancer } \\
\hline $\begin{array}{l}\text { Cole BF, et al., } \\
\text { United States and } \\
\text { Canada, 20074,57 }\end{array}$ & 1021 & $\begin{array}{l}\text { Double-blind, placebo controlled } \\
\text { randomized controlled trial (RCT) (The } \\
\text { Aspirin/Folate Polyp Prevention Trial) } \\
\text { Included adults with a histologically } \\
\text { confirmed colorectal adenoma removed } \\
\text { either } 3 \text { months before recruitment, or } \\
16 \text { months before recruitment with a } \\
\text { history of at least } 2 \text { adenomas or if the } \\
\text { adenoma was > } 1 \mathrm{~cm} \\
\text { Randomly assigned to consume either } \\
1 \text { mg/d of folic acid or a placebo, } \\
\text { concurrent with a separate } \\
\text { randomization to receive Aspirin }\end{array}$ & $\begin{array}{l}\text { Non-significant increases in the incidence of } \\
\text { advanced colorectal adenomas and prostate cancer } \\
\text { Non-colorectal cancer rate: Placebo }(6.3 \%) \text {, folic } \\
\text { acid }(10.5 \%), p=0.02 \\
\\
\text { Colorectal cancer: Placebo }(0.8 \%) \text {, folic acid } \\
(0.6 \%), p=0.72 \\
3 \text { or more adenomas occurred in } 11 \text { participants } \\
(4.3 \%) \text { in the placebo group and } 27 \text { participants } \\
(10.9 \%) \text { in the folic acid group (RR, } 2.52 ; 95 \% \\
\text { CI: } 1.28,4.98 ; p=.008) . \\
\text { Prostate cancer: Placebo }(2.8 \%) \text {, folic acid } \\
(7.3 \%), p=0.01\end{array}$ & $\begin{array}{l}\text { Mandatory } \\
\text { fortification in } \\
\text { Canada and the } \\
\text { US was } \\
\text { introduced during } \\
\text { the trial }\end{array}$ \\
\hline
\end{tabular}




\begin{tabular}{|c|c|c|c|c|}
\hline $\begin{array}{l}\text { Mason JB, et al. } \\
\text { United States and } \\
\text { Canada, 2007 }\end{array}$ & Not known & $\begin{array}{l}\text { Observational study of age-adjusted } \\
\text { incidence of colorectal cancer in } \\
\text { Canada and the United States (1986- } \\
\text { 2002) } \\
\text { Used the } 2006 \text { Canadian Cancer } \\
\text { Statistics and the U.S. } \\
\text { Surveillance, Epidemiology and End } \\
\text { Result registry }\end{array}$ & $\begin{array}{l}\text { Steady decline in colorectal cancer incidence for } \\
\text { both countries from } 1986 \text { to } 1996 \\
\text { A sharp increase occurred from } 1996 \text { to } 1998 \\
\text { (United States) and } 1997 \text { to } 2000 \text { (Canada). } \\
\text { After } 2000 \text { there was a slow return towards the } \\
\text { previous baseline. } \\
\text { As of } 2007 \text {, the incidence continued to exceed the } \\
\text { pre-1996/1997 trends by } 4 \text { to } 6 \text { additional cases } \\
\text { per } 100,000 \text { individuals }\end{array}$ & $\begin{array}{l}\text { Pre- to post- } \\
\text { fortification in } \\
\text { Canada and the } \\
\text { United States }\end{array}$ \\
\hline $\begin{array}{l}\text { Hirsch S, et al., } \\
\text { Chile, } 2009^{47}\end{array}$ & Not known & $\begin{array}{l}\text { Descriptive, population-based study } \\
\text { Health data from the Chilean Ministry } \\
\text { of Health and the National Institute for } \\
\text { Statistics to examine trends in cancer } \\
\text { and cardiovascular discharges from } \\
\text { pre-fortification (1992-1994) and post- } \\
\text { fortification (2001-2004) }\end{array}$ & $\begin{array}{l}\text { Highest rate ratios between pre- and post- } \\
\text { fortification for participants } 45 \text { to } 64 \text { years of age } \\
(2.6,99 \% \text { CI: } 2.93,2.58) \text { and for participants } 65 \text { to } \\
79 \text { years of age }(2.9,99 \% \text { CI: } 3.25,2.86) \text {. }\end{array}$ & $\begin{array}{l}\text { Pre- to post- } \\
\text { fortification in } \\
\text { Chile }\end{array}$ \\
\hline \multicolumn{5}{|c|}{ Health of offspring } \\
\hline $\begin{array}{l}\text { Martinussen MP, } \\
\text { et al., United } \\
\text { States, } 2012^{44}\end{array}$ & 1499 & $\begin{array}{l}\text { Prospective cohort } \\
\text { Pregnant women who consumed folic } \\
\text { acid supplements and their offspring }\end{array}$ & $\begin{array}{l}51 \% \text { of the women reported using folic acid in the } \\
\text { month before conception and } 88 \% \text { in the third } \\
\text { month of pregnancy. } \\
\text { No evidence of associations between daily folate } \\
\text { intake and childhood asthma } \\
\text { No evidence of any dose response relationship for } \\
\text { any time period }\end{array}$ & $\begin{array}{l}\text { Mandatory } \\
\text { fortification }\end{array}$ \\
\hline
\end{tabular}




\begin{tabular}{|c|c|c|c|c|}
\hline $\begin{array}{l}\text { Whitrow M, et } \\
\text { al., Australia, } \\
2009^{42}\end{array}$ & $\begin{array}{l}557 \text { enrolled } \\
-490 \text { at } 3.5 \\
\text { years } \\
-423 \text { at } 5.5 \\
\text { years }\end{array}$ & $\begin{array}{l}\text { Prospective birth cohort Australia } \\
\text { (1998 to 2005) }\end{array}$ & $\begin{array}{l}\text { Supplemental folic acid taken in late pregnancy } \\
\text { was associated with an increased risk of } \\
\text { childhood asthma at } 3.5 \text { years }\left(\mathrm{RR}^{*}=1.26,95 \%\right. \\
\text { CI: } 1.08,1.43) \text { and with persistent asthma (RR }= \\
1.32,95 \% \text { CI: } 1.03,1.69) \text {. } \\
\text { Similar association, not statistically significant at } \\
5.5 \text { years }\end{array}$ & $\begin{array}{l}\text { Mothers were } \\
\text { recruited prior to } \\
\text { the introduction } \\
\text { of voluntary folic } \\
\text { acid fortification } \\
\text { of food in } \\
\text { Australia }\end{array}$ \\
\hline $\begin{array}{l}\text { Håberg SE, et al., } \\
\text { Norway, } 2009^{43}\end{array}$ & $\begin{array}{l}32,077 \\
\text { children } \\
\text { born } \\
\text { between } \\
2000 \text { and } \\
2005\end{array}$ & $\begin{array}{l}\text { Secondary data analysis of the } \\
\text { Norwegian Mother and Child Cohort } \\
\text { Study to assess the effects of folate } \\
\text { supplement intake during pregnancy on } \\
\text { respiratory outcomes up to } 18 \text { months } \\
\text { of age, accounting for other } \\
\text { supplements in pregnancy and } \\
\text { supplementation in infancy. }\end{array}$ & $\begin{array}{l}\text { Adjusting for exposure later in pregnancy and in } \\
\text { infancy, children exposed to folic acid } \\
\text { supplements in the first trimester } \\
\text { Increased risk for: } \\
\text { wheeze (RR: } 1.06 \text { ( } 95 \% \text { CI: } 1.03,1.10) \text {; } \\
\text { lower respiratory tract infections (RR: } 1.09(95 \% \\
\text { CI: } 1.02,1.15) \text {; } \\
\text { hospitalizations for lower respiratory tract } \\
\text { infections (RR: } 1.24(95 \% \text { CI: } 1.09,1.41)\end{array}$ & $\begin{array}{l}\text { No fortification in } \\
\text { Norway }\end{array}$ \\
\hline $\begin{array}{l}\text { Yajnik CS, et al., } \\
\text { India, } 2008\end{array}$ & 700 & $\begin{array}{l}\text { Pune Maternal Nutrition Study of } \\
\text { pregnant women in six villages } \\
\text { Measures at } 18 \text { and } 28 \text { weeks gestation: } \\
\text { Nutritional intake } \\
\text { Low } \mathrm{RBC} \text { folate }<283 \mathrm{nmol} / \mathrm{L} \\
\text { Low vitamin } \mathrm{B}_{12}<150 \mathrm{pmol} / \mathrm{L} \\
\text { Elevated homocysteine }>10 \mu \mathrm{mol} / \mathrm{L} \\
\text { Elevated methylmalonic acid } \\
>260 \mathrm{nmol} / \mathrm{L} \\
\text { Offspring at } 6 \text { years: anthropometry, } \\
\text { body composition (dual-energy X-ray } \\
\text { absorptiometry scan) and insulin } \\
\text { resistance (homeostatic model } \\
\text { assessment of insulin resistance } \\
\text { [HOMA-R]) }\end{array}$ & $\begin{array}{l}\text { Higher maternal RBC folate concentrations at } \\
28 \text { weeks predicted significantly higher offspring } \\
\text { adiposity and higher HOMA-R. } \\
\text { Low maternal vitamin } \mathrm{B}_{12} \text { at } 18 \text { weeks predicted } \\
\text { significantly higher HOMA-R in the children. } \\
\text { The offspring of mothers with a combination of } \\
\text { high folate and low vitamin } \mathrm{B}_{12} \text { concentrations } \\
\text { were the most insulin resistant. }\end{array}$ & $\begin{array}{l}\text { No mandatory } \\
\text { wheat flour } \\
\text { fortification in } \\
\text { India }\end{array}$ \\
\hline
\end{tabular}

*OR=Odds Ration; RR=Relative Risk; CI=Confidence interval 
Table 2: Summary of selected meta-analyses focused on cancer and folic acid supplement intake

\begin{tabular}{|c|c|c|c|c|c|c|}
\hline $\begin{array}{l}\text { Author(s), } \\
\text { year }\end{array}$ & N; Design & Trial eligibility & Trials included* & $\begin{array}{l}\text { Dosage of folic acid } \\
\text { supplement }\end{array}$ & Findings/Results & $\begin{array}{l}\text { Pre- and/or } \\
\text { post- } \\
\text { fortification } \\
\text { studies } \\
\text { included }\end{array}$ \\
\hline $\begin{array}{l}\text { Vollset SE, et } \\
\text { al., } 20133^{54}\end{array}$ & $\begin{array}{l}49,969 ; \\
\text { Meta- } \\
\text { analysis of } \\
\text { folic acid } \\
\text { supplementa } \\
\text { tion on total } \\
\text { and site } \\
\text { specific } \\
\text { cancer } \\
\text { incidence }\end{array}$ & $\begin{array}{l}\text { Trials were eligible } \\
\text { for inclusion if: at } \\
\text { least one } \\
\text { randomised } \\
\text { comparison was } \\
\text { folic acid versus } \\
\text { placebo with } \\
\text { scheduled treatment } \\
\text { duration of at least } \\
1 \text { year; the trial } \\
\text { included at least } \\
500 \text { participants; } \\
\text { data on cancer } \\
\text { incidence had been } \\
\text { recorded }\end{array}$ & $\begin{array}{l}\text { Colorectal } \\
\text { adenoma trials } \\
\text { UK CAP } \\
\text { Harvard } \\
\text { (NHS/HPFS) } \\
\text { AFPPS }^{59} \\
\text { Vascular disease } \\
\text { trials } \\
\text { VITRO } \\
\text { HOST }^{61} \\
\text { WENBIT }^{62} \\
\text { NORVIT }^{63} \\
\text { SU.FOL.OM }^{\text {OM. }} \\
3^{64} \\
\text { VISP }^{65} \\
\text { VITATOPS }^{66} \\
\text { WAFACS }^{67} \\
\text { HOPE-2 }^{68} \\
\text { SEARCH }^{69}\end{array}$ & $\begin{array}{l}\text { Generally ranged } \\
\text { from } 0.5 \mathrm{mg} / \mathrm{d} \text { to } \\
2.5 \mathrm{mg} / \mathrm{d} \text {, though } \\
\text { there was a } 5 \mathrm{mg} / \mathrm{d} \\
\text { and a } 40 \mathrm{mg} / \mathrm{d} \\
\text { Weighted average } \\
\text { treatment duration } \\
\text { of } 5.2 \text { years }\end{array}$ & $\begin{array}{l}\text { Allocation to folic acid } \\
\text { quadrupled plasma } \\
\text { concentrations of folic acid } \\
\text { ( } 57.3 \mathrm{nmol} / \mathrm{L} \text { for the folic acid } \\
\text { groups vs. } 13.5 \mathrm{nmol} / \mathrm{L} \text { for the } \\
\text { placebo groups) } \\
\text { No significant effect on overall } \\
\text { cancer incidence and no trend } \\
\text { towards greater effect with longer } \\
\text { treatment. No significant effect } \\
\text { on site specific cancer incidence. } \\
\text { No significant heterogeneity } \\
\text { between the results of the } 13 \\
\text { individual trials (p=0.23), or } \\
\text { between the two overall results in } \\
\text { the cardiovascular prevention } \\
\text { trials and the adenoma trials } \\
\text { (p=0.13). }\end{array}$ & $\begin{array}{l}\text { Both pre- and } \\
\text { post- } \\
\text { fortification } \\
\text { studies } \\
\text { included }\end{array}$ \\
\hline $\begin{array}{l}\text { Qin X, et al., } \\
2013^{70}\end{array}$ & $\begin{array}{l}49,406 ; \\
\text { Meta- } \\
\text { analysis of } \\
\text { association } \\
\text { between } \\
\text { folic acid } \\
\text { supplementa } \\
\text { tion and } \\
\text { cancer }\end{array}$ & $\begin{array}{l}\text { RCT }^{* *} \text { eligible if } \\
\text { there was reporting } \\
\text { of the number of } \\
\text { events of cancer } \\
\text { incidence and/or } \\
\text { mortality; } \\
\text { intervention } \\
\text { consisted of folic } \\
\text { acid } \\
\text { supplementation } \\
\text { (with or without }\end{array}$ & $\begin{array}{l}\text { Author classified } \\
\text { studies according } \\
\text { to country } \\
\text { fortification } \\
\text { status. } \\
\text { Fortified: } \\
\quad \text { WAFACS } \\
\quad \text { Harvard } \\
\quad \text { (NHS/HPFS) }^{59} \\
\quad \text { VISP }^{65} \\
\text { BVAIT }^{71}\end{array}$ & $\begin{array}{l}\text { Generally ranged } \\
\text { from } 0.5 \mathrm{mg} / \mathrm{d} \text { to } \\
2.5 \mathrm{mg} / \mathrm{d} \text {, though } \\
\text { there was a } 5 \mathrm{mg} / \mathrm{d} \\
\text { and a } 40 \mathrm{mg} / \mathrm{d}\end{array}$ & $\begin{array}{l}\text { Overall, folic acid } \\
\text { supplementation had no } \\
\text { significant effect on total cancer } \\
\text { incidence. No significant effect } \\
\text { was found in subgroup analysis, } \\
\text { for example by cancer type, } \\
\text { fortification status of country, } \\
\text { folic acid dose, intervention } \\
\text { duration. } \\
\text { Heterogeneity testing for all } \\
\text { analyses were not significant }\end{array}$ & $\begin{array}{l}\text { Both pre- and } \\
\text { post- } \\
\text { fortification } \\
\text { studies } \\
\text { included }\end{array}$ \\
\hline
\end{tabular}




\begin{tabular}{|c|c|c|c|c|c|c|}
\hline $\begin{array}{l}\text { Author(s), } \\
\text { year }\end{array}$ & N; Design & Trial eligibility & Trials included* & $\begin{array}{l}\text { Dosage of folic acid } \\
\text { supplement }\end{array}$ & Findings/Results & $\begin{array}{l}\text { Pre- and/or } \\
\text { post- } \\
\text { fortification } \\
\text { studies } \\
\text { included }\end{array}$ \\
\hline & & $\begin{array}{l}\text { additional B } \\
\text { vitamins); and the } \\
\text { at least } 6 \text { months in } \\
\text { duration. }\end{array}$ & $\begin{array}{c}\text { HOST }^{61} \\
\text { AFPPS }^{49} \\
\text { Partly fortified: } \\
\text { HOPE-2 }^{68} \\
\text { Not fortified: } \\
\text { SU.FOL.OM } \\
3^{64} \\
\text { SEARCH }^{69} \\
\text { VITATOPS }^{66} \\
\text { NORVIT }^{63} \\
\text { WENBIT }^{62} \\
\text { UK CAP }^{58}\end{array}$ & & $\begin{array}{l}(\mathrm{p}>0.10) \text { (besides the result for } \\
\text { prostate cancer, } \mathrm{p}=0.07)\end{array}$ & \\
\hline $\begin{array}{l}\text { Baggott, et } \\
\text { al., } 2012\end{array}$ & $\begin{array}{l}\text { Meta- } \\
\text { analysis of } \\
\text { folic acid } \\
\text { supplementa } \\
\text { tion on } \\
\text { cancer } \\
\text { incidence }\end{array}$ & $\begin{array}{l}\text { Randomized } \\
\text { placebo controlled } \\
\text { trials including folic } \\
\text { acid } \\
\text { supplementation, } \\
\text { published in } \\
\text { English, minimum } \\
\text { follow-up of } 1 \text { year }\end{array}$ & $\begin{array}{l}\text { HOPE- } 2^{68} \\
\text { NORVIT }^{63} \\
\text { AFPPS }^{49} \\
\text { WENBIT }^{62} \\
\text { UK CAP }^{58} \\
\text { SEARCH }^{69}\end{array}$ & $\begin{array}{l}\text { Ranged from } 0.5 \\
\mathrm{mg} / \mathrm{d} \text { to } 2.5 \mathrm{mg} / \mathrm{d}\end{array}$ & $\begin{array}{l}\text { Total cancer (cases }=2416) \text { higher } \\
\text { in folic acid supplemented } \\
\text { groups, compared to those not } \\
\text { taking supplements }\left(\mathrm{RR}^{* *} 1.21 \text {, }\right. \\
\left.95 \% \mathrm{CI}^{* *}: 1.05,1.39\right) \\
\text { Heterogeneity not reported }\end{array}$ & $\begin{array}{l}\text { Both pre- and } \\
\text { post- } \\
\text { fortification } \\
\text { studies } \\
\text { included }\end{array}$ \\
\hline $\begin{array}{l}\text { Wien TN, et } \\
\text { al., } 2012\end{array}$ & $\begin{array}{l}\text { Meta- } \\
\text { analysis of } \\
\text { folic acid } \\
\text { supplementa } \\
\text { tion on total } \\
\text { and site } \\
\text { specific } \\
\text { cancer } \\
\text { incidence }\end{array}$ & $\begin{array}{l}\text { Included systematic } \\
\text { reviews, RCTs, } \\
\text { controlled } \\
\text { observational } \\
\text { studies of cancer } \\
\text { incidence/mortality } \\
\text { in any population } \\
\text { taking } \\
\text { supplements }\end{array}$ & $\begin{array}{l}\text { UK CAP }^{58} \\
\text { AFPPS }^{49} \\
\text { Harvard } \\
\text { (NHS/HPFS) }^{59} \\
\text { HOST }^{61} \\
\text { VISP }^{65} \\
\text { WAFACS } \\
\text { WENBIT }^{62} \\
\text { SEARCH }^{69}\end{array}$ & $\begin{array}{l}\text { Ranged from } 0.5 \text { to } \\
2.5 \mathrm{mg} / \text { day }\end{array}$ & $\begin{array}{l}\text { Total cancer slightly increased } \\
\text { following folic acid treatment } \\
\text { (cases }=3515) \\
\text { RR } 1.07(95 \% \text { CI: } 1.00,1.14) \\
\text { Heterogeneity not significant } \\
(p=0.45) \\
\text { Significant increase in prostate } \\
\text { cancer (cases }=632)\end{array}$ & $\begin{array}{l}\text { Both pre- and } \\
\text { post- } \\
\text { fortification } \\
\text { studies } \\
\text { included }\end{array}$ \\
\hline
\end{tabular}




\begin{tabular}{|c|c|c|c|c|c|c|}
\hline $\begin{array}{l}\text { Author(s), } \\
\text { year }\end{array}$ & N; Design & Trial eligibility & Trials included* & $\begin{array}{l}\text { Dosage of folic acid } \\
\text { supplement }\end{array}$ & Findings/Results & $\begin{array}{l}\text { Pre- and/or } \\
\text { post- } \\
\text { fortification } \\
\text { studies } \\
\text { included }\end{array}$ \\
\hline & & $0.4 \mathrm{mg} /$ day & $\begin{array}{l}\text { Charles }^{72} \\
\text { Zhu }^{73}\end{array}$ & & 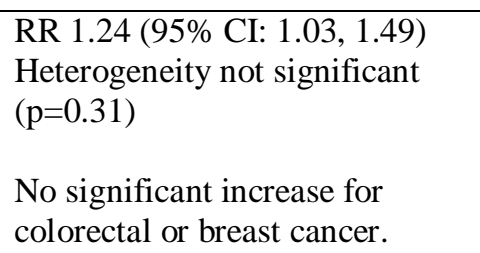 & \\
\hline $\begin{array}{l}\text { Fife J, et al., } \\
2011^{50}\end{array}$ & $\begin{array}{l}\text { Meta- } \\
\text { analysis to } \\
\text { examine } \\
\text { association } \\
\text { between } \\
\text { folic acid } \\
\text { supplementa } \\
\text { tion and } \\
\text { recurrence } \\
\text { of colorectal } \\
\text { adenomas }\end{array}$ & RCT's & $\begin{array}{l}\text { AFPPS }^{49} \\
\text { UK CAP }^{58} \\
\text { HOPE-2 }^{68}\end{array}$ & $\begin{array}{l}\text { Ranged from } 0.5 \text { to } \\
2.5 \mathrm{mg} / \text { day }\end{array}$ & $\begin{array}{l}\text { Colorectal cancer-promoting } \\
\text { effect associated with three-year } \\
\text { folic acid supplementation } \\
\text { treatment: adenomatous lesions } \\
\left(\mathrm{OR}^{* *} 1.35 \text { ( } 95 \% \text { CI } 1.06,1.70\right) \text {; } \\
\text { advanced lesions at follow-up of } \\
\geq 4 \text { years } 1.50 \text { (95\% CI } 1.06 \text {, } \\
2.10) \text {. } \\
\text { Heterogeneity not significant } \\
(\mathrm{p}=0.48) \text {. }\end{array}$ & $\begin{array}{l}\text { Both pre- and } \\
\text { post- } \\
\text { fortification } \\
\text { studies } \\
\text { included }\end{array}$ \\
\hline
\end{tabular}

*Abbreviations for studies in table are as follows: UK CAP - United Kingdom Colorectal Adenoma Prevention (UK and Denmark); AFPPS - Aspiring Folic Acid Polyp Prevention Study (US, Canada); NHS/HPFS - Nurses Health Study and Health Professional Follow-up Study (US); VITRO - the Vitamins and Thrombosis Study (Netherlands, Italy, Austria); HOST - Homocysteinemia in Kidney and End Stage Renal Disease (US); WENBIT - Western Norway B Vitamin Intervention Trial (Norway); NORVIT - Norwegian Vitamin Trial (Norway); SU.FOL.OM3 - Supplémentation en Folates et Omega-3 (France); VISP Vitamin Intervention for Stroke Prevention (US, Canada, Scotland); VITATOPS - VITAmins TO Prevent Stroke (Australia, India, UK); WAFACS - Women's Antioxidant and Folic Acid Cardiovascular Study (US); HOPE-2 - Heart Outcomes Prevention Evaluation 2 (Canada, US, Brazil, Western EU, Slovakia); SEARCH - Study of the Effectiveness of Additional Reductions in Cholesterol and Homocysteine (UK); BVAIT - B-Vitamin Atherosclerosis Intervention Trial (US).

**RCT=Randomized Controlled Trial; RR=Relative Risk; CI=Confidence Interval; OR=Odds Ratio 


\subsection{Folate status of the Canadian population (1970-2010)}

Evidence of Canadian population-level folate concentrations is limited. A summary of pertinent studies can be found in Table 3. The 1970-1972 Nutrition Canada National Survey (NCNS) was the only national-level measure of Canadian folate status available prior to the implementation of fortification of certain grain products with folic acid. Folate status was measured by examining serum folate. Serum folate concentrations considered high risk $(<5.7$ $\mathrm{nmol} / \mathrm{L}$ ) were seen in $10-20 \%$ of teenagers and adults, and $50 \%$ of the population was classified as moderate risk $(<11.3 \mathrm{nmol} / \mathrm{L}){ }^{74,75}$ For women $20-39$ years of age and pregnant women, $21 \%$ and $17 \%$ had serum folate concentrations considered high risk, relatively. Males and females had similar serum folate values, and no consistent difference existed between age groups, though children tended to have a higher serum folate than adults. ${ }^{74,75} \mathrm{~A}$ higher prevalence of pregnant women demonstrated serum folate $>35.1 \mathrm{nmol} / \mathrm{L}(16 \mathrm{ng} / \mathrm{mL})$ than the general population ( $34 \%$ versus $<5 \%$ in all other age groups).

Since the NCNS, small sub-studies examined the folate status of Canadians, which mostly focused on women of childbearing age due to the association between folate intake and NTDs. In a small sample of pregnant adolescents in Ontario $(\mathrm{N}=58)$, which took place prior to fortification, it was demonstrated that $31 \%$ of those who inconsistently consumed folic acid supplements had suboptimal RBC folate ( $<362 \mathrm{nmol} / \mathrm{L}$, measured by Bio-Rad), and $24 \%$ of the total population had hypersegmented neutrophils, a characteristic of megaloblastic anemia. ${ }^{76}$ Other studies examining Canadian folate status drew on retrospective laboratory data to compare $\mathrm{RBC}$ folate concentrations pre- and postfortification. One such study, based in Ontario, examined folate concentrations retrospectively from samples that had been analysed at a Toronto laboratory by competitive 
protein binding assay (Bio-Rad). Pre- and post-fortification samples were compared for women of childbearing age. ${ }^{77}$ The geometric mean for RBC folate increased from 527 $\mathrm{nmol} / \mathrm{L}$ to $741 \mathrm{nmol} / \mathrm{L}$. In a similar Ontario study, blood samples from six laboratories were examined for women of childbearing age; it was found that in 1995 and 1997 the mean RBC folate was $514 \mathrm{nmol} / \mathrm{L}$ (upper $95^{\text {th }}$ percentile $855 \mathrm{nmol} / \mathrm{L}$ ) and $424 \mathrm{nmol} / \mathrm{L}$ (upper $95^{\text {th }}$ percentile $815 \mathrm{nmol} / \mathrm{L})$, respectively. ${ }^{78}$ Following fortification, from 1998 to 2006, the mean RBC folate ranged from $814 \mathrm{nmol} / \mathrm{L}$ to $1235 \mathrm{nmol} / \mathrm{L}$, with upper $95^{\text {th }}$ percentiles from $1487 \mathrm{nmol} / \mathrm{L}$ to $1887 \mathrm{nmol} / \mathrm{L}$. RBC folate data from a large clinical laboratory in Toronto were examined in 1998 focusing on women of reproductive age, and demonstrated that $49 \%$ had concentrations below levels considered optimal for NTD prevention $(<906 \mathrm{nmol} / \mathrm{L}){ }^{79}$ Another examination involved a retrospective study of Ontario and British Columbia laboratory databases of women aged 65 years and older who had both serum folate and vitamin $B_{12}$ tested. Researchers examined the data at two time points, pre- and postfortification, revealing the geometric mean for serum folate increased, from $14.8 \mathrm{nmol} / \mathrm{L}$ to $24.2 \mathrm{nmol} / \mathrm{L}$, and folate deficiency was almost eliminated, with serum folate $<6.0 \mathrm{nmol} / \mathrm{L}$ decreasing from $6.3 \%$ to $0.88 \% .^{80}$

In a sample of Newfoundlanders aged 65 years or older, low RBC folate concentrations $(<373 \mathrm{nmol} / \mathrm{L})$ in the post-fortification era was less than $1.6 \%$, with a pre- to postfortification increase in RBC folate concentrations of $745 \mathrm{nmol} / \mathrm{L}$ to $916 \mathrm{nmol} / \mathrm{L}{ }^{81}$ In the same study, RBC folate increased in a sample of women of childbearing age from $625 \mathrm{nmol} / \mathrm{L}$ to $818 \mathrm{nmol} / \mathrm{L}$, pre- to post-fortification. Further, researchers used Bio-Rad competitive protein binding assay to measure $\mathrm{RBC}$ folate in a sample of 95 female University of Manitoba students, who were of childbearing age, and found a median of 650 
$\mathrm{nmol} / \mathrm{L}$, with a $10^{\text {th }}$ to $90^{\text {th }}$ percentile range of $409 \mathrm{nmol} / \mathrm{L}$ to $1049 \mathrm{nmol} / \mathrm{L}{ }^{82}$ It is evident from these sub-studies that folate status has increased since the implementation of folic acid fortification of certain grain products in Canada. However, data were not yet available to give a comprehensive, nationally-representative assessment. 
Table 3: Folate status of the Canadian population (1970-2010)

\begin{tabular}{|c|c|c|c|c|c|}
\hline $\begin{array}{l}\text { Author, } \\
\text { location, } \\
\text { year } \\
\text { published }\end{array}$ & $\mathbf{N}$ & Study population & $\begin{array}{l}\text { Measure of folate } \\
\text { concentration }\end{array}$ & Findings & $\begin{array}{l}\text { Fortification } \\
\text { status }\end{array}$ \\
\hline $\begin{array}{l}\text { Nutrition } \\
\text { Canada } \\
\text { National } \\
\text { Survey, } \\
1975^{74,75}\end{array}$ & 8594 & $\begin{array}{l}\text { Nationally } \\
\text { representative } \\
\text { sample of } \\
\text { Canadians }\end{array}$ & $\begin{array}{l}\text { Serum folate (Microbiologic } \\
\text { assay }[\text { L.Casei }]) \\
\text { - } \quad \text { High risk: } \\
\quad<5.7 \mathrm{nmol} / \mathrm{L} \\
\text { - } \quad \text { Moderate risk: } \\
\quad<11.3 \mathrm{nmol} / \mathrm{L}\end{array}$ & $\begin{array}{l}\text { Teenagers and adults } \\
-\quad 10 \% \text { to } 20 \% \text { high risk } \\
-\quad 50 \% \text { moderate risk } \\
\text { Women age } 20 \text { to } 39 \text { years } \\
-\quad 21 \% \text { high risk } \\
\text { Pregnant women } \\
-\quad 17 \% \text { high risk }\end{array}$ & Pre-fortification \\
\hline $\begin{array}{l}\text { Gadowsky } \\
\text { et al., } \\
\text { Ontario, } \\
1995^{76}\end{array}$ & 58 & $\begin{array}{l}\text { Pregnant } \\
\text { adolescents }\end{array}$ & $\begin{array}{l}\text { RBC folate (Bio-Rad } \\
\text { radioassay) } \\
\text { - } \quad \text { Sub-optimal folate } \\
\text { concentration: }<362 \\
\text { nmol/L }\end{array}$ & $\begin{array}{l}\text { Sub-optimal RBC folate in } 31 \% \text { of those with } \\
\text { inconsistent folic acid supplement use } \\
\text { Hypersegmented neutrophils (indicator of folate } \\
\text { deficiency) in } 24 \% \text { of total population }\end{array}$ & Pre-fortification \\
\hline $\begin{array}{l}\text { Ray et al., } \\
\text { Ontario, } \\
2002^{77}\end{array}$ & $\begin{array}{l}8408 \\
\text { pre-fortification } \\
30,061 \\
\text { post-fortification }\end{array}$ & $\begin{array}{l}\text { Retrospective } \\
\text { examination of } \\
\text { laboratory blood } \\
\text { samples for } \\
\text { women of } \\
\text { childbearing age }\end{array}$ & $\begin{array}{l}\mathrm{RBC} \text { folate (Bio-Rad } \\
\text { radioassay) }\end{array}$ & $\begin{array}{l}\text { Geometric mean RBC folate increased from } 527 \\
\mathrm{nmol} / \mathrm{L} \text { (pre-fortification) to } 741 \mathrm{nmol} / \mathrm{L} \text { (post- } \\
\text { fortification) }\end{array}$ & $\begin{array}{l}\text { Compared pre- to } \\
\text { post-fortification } \\
\text { (Jan. 1996-Dec. } \\
1997 \text { to Jan. } 1998 \\
\text {-Dec. 2000) }\end{array}$ \\
\hline $\begin{array}{l}\text { Bar-Oz, et } \\
\text { al. } \\
\text { Ontario, } \\
2008^{78}\end{array}$ & $\begin{array}{l}316 \\
\text { pre-fortification } \\
7681 \\
\text { post-fortification }\end{array}$ & $\begin{array}{l}\text { Retrospective } \\
\text { examination of } \\
\text { blood samples } \\
\text { from six } \\
\text { laboratories for } \\
\text { women of } \\
\text { childbearing age }\end{array}$ & $\begin{array}{l}\text { RBC folate (unclear } \\
\text { measurement method) }\end{array}$ & $\begin{array}{l}\text { Pre-fortification mean RBC folate } \\
\text { - } 514 \mathrm{nmol} / \mathrm{L} \text { (upper } 95^{\text {th }} \text { percentile } \\
855 \mathrm{nmol} / \mathrm{L} \text { ) in } 1995 \text { and } 424 \mathrm{nmol} / \mathrm{L} \\
\quad \text { (upper } 95^{\text {th }} \text { percentile } 815 \mathrm{nmol} / \mathrm{L} \text { ) in } 1997 \\
\text { Post-fortification mean RBC folate } \\
\text { - } \quad \text { Ranged from } 814 \mathrm{nmol} / \mathrm{L} \text { to } 1235 \mathrm{nmol} / \mathrm{L} \text {, } \\
\text { with upper } 95^{\text {th }} \text { percentiles of } 1487 \text { to } 1887 \\
\text { nmol/L }\end{array}$ & $\begin{array}{l}\text { Compared Pre- } \\
\text { fortification (1995 } \\
\text { and 1997) to post- } \\
\text { fortification } \\
(1998-2006)\end{array}$ \\
\hline
\end{tabular}




\begin{tabular}{|c|c|c|c|c|c|}
\hline & & & & $\begin{array}{l}\text { Women of childbearing age with RBC folate } \\
<906 \mathrm{nmol} / \mathrm{L} \text { in } 96 \% \text { of population in } 1995 \text { and } \\
41 \% \text { of the population in } 2006 .\end{array}$ & \\
\hline $\begin{array}{l}\text { Kapur et } \\
\text { al, } \\
\text { Ontario, } \\
2002^{79}\end{array}$ & 23,109 & $\begin{array}{l}\text { Retrospective } \\
\text { examination of } \\
\text { laboratory blood } \\
\text { samples for } \\
\text { women of } \\
\text { childbearing age }\end{array}$ & $\begin{array}{l}\text { RBC folate (measurement } \\
\text { method unknown) } \\
\text { - } \quad \text { Concentrations } \\
\quad \text { considered optimal for } \\
\text { NTD prevention } \\
\quad(<906 \mathrm{nmol} / \mathrm{L})\end{array}$ & $\begin{array}{l}\mathrm{RBC} \text { folate concentration }<906 \mathrm{nmol} / \mathrm{L} \text { in } 49 \% \text { of } \\
\text { the population }\end{array}$ & Post-fortification \\
\hline $\begin{array}{l}\text { Ray et al, } \\
\text { Ontario } \\
\text { and British } \\
\text { Columbia, } \\
2003^{80}\end{array}$ & $\begin{array}{l}\text { Pre-fortification: } \\
733 \text { (Ontario) } \\
3839 \text { (British } \\
\text { Columbia) } \\
\\
\text { Post-fortification: } \\
4415 \text { (Ontario) } \\
6677 \text { (British } \\
\text { Columbia) }\end{array}$ & $\begin{array}{l}\text { Retrospective } \\
\text { examination of } \\
\text { laboratory } \\
\text { databases for } \\
\text { women }>65 \text { years } \\
\text { of age }\end{array}$ & $\begin{array}{l}\text { Serum folate } \\
-\quad \text { Deficiency }<6.0 \mathrm{nmol} / \mathrm{L}\end{array}$ & $\begin{array}{l}\text { Geometric mean serum } \\
-\quad 14.8 \mathrm{nmol} / \mathrm{L} \text { to } 24.2 \mathrm{nmol} / \mathrm{L} \text {, pre- to post- } \\
\text { fortification respectively } \\
\text { Serum folate }<6.0 \mathrm{nmol} / \mathrm{L} \\
-\quad 6.3 \% \text { to } 0.88 \%, \text { pre- to post-fortification } \\
\quad \text { respectively }\end{array}$ & $\begin{array}{l}\text { Compares pre- } \\
\text { fortification (Jan. } \\
\text { 1996-Dec. 1997) } \\
\text { to post- } \\
\text { fortification (Jan. } \\
\text { 1998-Dec. 2000) }\end{array}$ \\
\hline $\begin{array}{l}\text { Liu et al., } \\
\text { Newfound } \\
\text {-land, } \\
2004^{81}\end{array}$ & $\begin{array}{l}\text { Women of } \\
\text { childbearing age: } \\
\text { Pre-fortification: } \\
233 \\
\text { Post-fortification: } \\
204 \\
\\
\text { Older adults: } \\
\text { pre-fortification: } \\
202 \\
\text { post-fortification: } \\
186\end{array}$ & $\begin{array}{l}\text { Women of } \\
\text { childbearing age } \\
\text { Older adults }>65 \\
\text { years }\end{array}$ & $\begin{array}{l}\text { RBC folate (method not } \\
\text { specified) } \\
-\quad \text { Low folate concentrations } \\
\quad<373 \mathrm{nmol} / \mathrm{L}\end{array}$ & $\begin{array}{l}\text { For women of childbearing age, RBC folate } \\
\text { concentrations increased } \\
-\quad 625 \mathrm{nmol} / \mathrm{L} \text { to } 818 \mathrm{nmol} / \mathrm{L} \text {, pre- to post- } \\
\text { fortification } \\
\text { For older adults, } \mathrm{RBC} \text { folate concentrations } \\
\text { increased } \\
745 \mathrm{nmol} / \mathrm{L} \text { to } 916 \mathrm{nmol} / \mathrm{L} \text {, pre- to post- } \\
\text { fortification }\end{array}$ & $\begin{array}{l}\text { Compares pre- } \\
\text { fortification } \\
\text { (1996/1997) to } \\
\text { post-fortification } \\
(2000 / 2001)\end{array}$ \\
\hline $\begin{array}{l}\text { Shuaibi et } \\
\text { al., } \\
\text { Manitoba, } \\
2008^{82}\end{array}$ & 95 & $\begin{array}{l}\text { Women of } \\
\text { childbearing age }\end{array}$ & $\begin{array}{l}\text { RBC folate (measured by Bio- } \\
\text { Rad) }\end{array}$ & $\begin{array}{l}\text { Median } \mathrm{RBC} \text { folate concentration of } 650 \mathrm{nmol} / \mathrm{L} \\
\left(10^{\text {th }} \text { to } 90^{\text {th }} \text { percentile range of } 409 \mathrm{nmol} / \mathrm{L} \text { to }\right. \\
1049 \mathrm{nmol} / \mathrm{L})\end{array}$ & Post-fortification \\
\hline
\end{tabular}




\subsection{Cost of neural tube defects}

Considerable direct and indirect costs have been associated with NTDs. A recent systematic review estimated the economic and social burden of NTDs and determined that the benefit of preventing these defects with folic acid appear to outweigh the costs of these initiatives, though the literature is limited. ${ }^{83}$ In the United States, the lifetime direct and indirect costs of spina bifida were estimated to be $\$ 636,000$ per infant in $2002 .{ }^{84}$ Recent Canadian estimates are currently unavailable; however, in 1987 the total costs of hospital and rehabilitation during the first ten years of a spina bifida affected child's life were estimated at $\$ 42,507$, which amounts to $\$ 77,394$ in 2013 dollars (calculated at an average annual rate of inflation of $2.33 \%) .{ }^{85,86}$ Since fortification with folic acid began in the United States, a net cost savings between USD $\$ 88$ to $\$ 145$ million per year has been postulated. ${ }^{87}$ These costs do not account for the emotional burden on NTD-affected children and their families. For women who have had a NTD-affected birth, the emotional burden of self-blame associated with poor birth outcomes can be significant. ${ }^{88}$ Further, if the child survives, they will cope with the burden related to social and emotional pressures associated with a mental or physical disability. ${ }^{89-91}$

\subsection{Populations at risk of folate deficiency}

Researchers have identified a number of risk factors for NTD birth including inadequate folate intake, certain health conditions, and select medication use. While the relationship between folate intake and NTDs is well established, the risk factors for dietary folate intake and supplemental folic acid adherence at a population level - post-fortification of certain grain products with folic acid - are not. Similarly, while certain health conditions are known 
to be associated with NTDs, and birth defects in general, it remains to be determined at a population level, post-fortification, whether individuals with these health conditions are at greater risk of sub-optimal folate concentrations than the rest of the population. Table 4 provides an overview of risk factors for low folate intake.

Socioeconomic and demographic factors: Variations in the prevalence of folate deficiency and NTDs have been identified for several factors, including age, sex, race, ethnicity, socioeconomic status and geographical region. ${ }^{92-94}$ While comparable national-level, postfortification Canadian data were unavailable prior to the CHMS, NHANES data from the American population show that, post-fortification of the food supply, folate status varies by age and sex, with adolescents under 18 years of age and females 60 years and older having the lowest RBC folate. ${ }^{95}$ A higher prevalence of spina bifida exists among Hispanic Americans, in comparison to Non-Hispanic White and Non-Hispanic Black Americans, which may be due to maize flour (masa) not being fortified with folic acid in the U.S. ${ }^{93,96-98}$ In Canada, folate intake was assessed, post-fortification, by 24-hour recall in a cohort of women of Cree descent living in the Eastern James Bay region $(\mathrm{N}=219)$ - a remote population known to have a high rate of spina bifida - reporting an average dietary folate intake of $98 \mu \mathrm{g} / \mathrm{d} .^{99}$ The risk factors for NTDs in Ontario were investigated retrospectively among women who underwent antenatal maternal screening between 1994 and $2000 .^{92}$ First $^{2}$ Nations women were found to be more likely than white women to have a NTD-affected pregnancy (OR 5.2, 95\% CI: 2.1-12.9), though the wide confidence interval indicates a need for further research. Some of the increased risk may be attributed to genetic predisposition or impaired glucose metabolism associated with race/ethnicity or higher body mass index; however, the influence of socioeconomic status and demographic setting may also explain 
the manifestation of NTDs in these subgroups. Low socioeconomic status has been identified as a risk factor for NTD birth and low folate intake. ${ }^{100,101}$ This may be attributable to an inability to afford folate-rich foods and supplements, or women of a lower education level may not have access to, or an understanding of, health information. ${ }^{94,102}$ There is some evidence of geographic variations as possible determinants of NTDs, as researchers noted higher prevalence in Northern China, rural India, the Northwest United Kingdom, the Eastern U.S., and Eastern Canada. ${ }^{31,94,103-107}$

Alcohol use and cigarette smoking: Studies have identified low folate status among chronic alcoholics and smokers. ${ }^{108}$ Animal studies have shown that ethanol intake may impair folate absorption and metabolism and cause an increase in renal folate excretion. ${ }^{2}$ Poor intake of folate-rich foods is also a likely contributor to the low folate status found in smokers and alcoholics. ${ }^{109}$

Clinical risk factors for sub-optimal folate status: Clinical risk factors for NTD births include maternal obesity, diabetes mellitus and regular use of folic acid antagonist medications; often these risk factors are interrelated. ${ }^{110}$ Altered folate metabolism in relation to maternal obesity and diabetes mellitus may play a role in the etiology of birth defects; however, this has not been confirmed. ${ }^{111}$ Though the mechanisms remain unclear, pregestational diabetes, both type 1 and type 2 , is a known risk factor for birth defects. ${ }^{112}$ One study found infants of mothers with diabetes were twice as likely to be diagnosed with central nervous system defects, including spina bifida, and three times more likely to have anencephaly than controls. ${ }^{113}$ Hyperglycemia appears to play a central role as women with adequate glucose control were less likely to have an infant with a birth defect than those with poor glucose control. Maternal obesity has been associated with an increased risk of 
congenital anomalies, including NTDs. ${ }^{114,115}$ A 2009 systematic review and meta-analysis demonstrated that women who were obese at the start of their pregnancy were at a significantly increased risk of a NTD-affected pregnancy (OR 2.24, 95\% CI 1.86-2.69) than normal-weight women. ${ }^{116}$ Folic acid antagonists cause an increase in the required intake of folate and exist in two broad groups: 1) those that inhibit dihydrofolate reductase, which include aminopterin, methotrexate and trimethoprim; and 2) those that may impair folate metabolism and absorption, which are primarily antiepileptic drugs, such as Carbamazepine and Phenobarbital. ${ }^{117}$ Further, large, therapeutic doses (3900 mg/day) of nonsteroidal antiinflammatory drugs may have possible anti-folate activity. ${ }^{2}$

Table 4: Risk factors for sub-optimal folate status

\begin{tabular}{|c|c|}
\hline Factor & Notes \\
\hline $\begin{array}{l}\text { Lifestyle and } \\
\text { demographic } \\
\text { factors }\end{array}$ & $\begin{array}{l}\text { Poor supplement compliance } \\
\text { Energy restricted diets }^{112}, 119^{*} \\
\text { Food insecurity }^{101} \\
\text { Low socioeconomic status }{ }^{100,101} \\
\text { Age: Women }>60 \text { years of age have higher folate concentrations than men } \\
>60 \text { years of age. }{ }^{95} \text { Adolescents have lower folate status and intake than } \\
\text { adults. } \\
\text { Ethnicity: Median RBC folate lower in non-Hispanic black women (as opposed } \\
\text { to non-Hispanic white and Mexican-American women). }{ }^{95} \text { Folate deficiency } \\
\text { higher among Canadian Aboriginal. } \\
\text { Nations }{ }^{92 * *} \text { NTD rate higher among First } \\
\text { Smoking }^{108,123-126} \\
\text { Alcohol }^{25}\end{array}$ \\
\hline Maternal obesity & $\begin{array}{l}\text { Prepregnancy body mass index is inversely associated with folate intake. }{ }^{127} \\
\text { Obesity itself may also be a risk factor for NTDs. }\end{array}$ \\
\hline $\begin{array}{l}\text { Pregestational } \\
\text { diabetes }\end{array}$ & $\begin{array}{l}\text { Poorly controlled diabetes mellitus (type } 1 \text { or type } 2 \text { ) are risk factors for } \\
\text { NTDs }{ }^{128^{*}}\end{array}$ \\
\hline $\begin{array}{l}\text { Use of folic acid } \\
\text { antagonists }\end{array}$ & $\begin{array}{l}\text { NTD risk increased in women taking antiseizure medications }{ }^{129^{*}, 130^{*}} \\
\text { Blood folate levels are lower in pregnant and nonpregnant women taking } \\
\text { antiseizure medications }{ }^{97,131^{*}} \text { (Carbamazepine }{ }^{117^{*}} \text {, Trimethoprim }+/- \\
\text { sulfonamide, }^{11 *}, 132^{*} \text { Aminopterin } \\
\end{array}$ \\
\hline
\end{tabular}

Adapted with permission, Therapeutic Drug Monitoring 31(3):319-26 @2009. ${ }^{133}$

*Study occurred in the pre-fortification period.

**Study duration included pre- to post-fortification period. 


\subsection{The regulatory context in Canada: Canadian folic acid fortification and supplementation policies}

Population health interventions are defined by Hawe and Potvin as "policies or programs that shift the distribution of health risk by addressing the underlying social, economic and environmental conditions." ${ }^{\prime 34}$ Food fortification is a policy-based strategy to alleviate micronutrient deficiency and related health issues in the population. ${ }^{135}$ Common global micronutrient deficiencies are iron, vitamin A, iodine, zinc, folate and other B vitamins, vitamin $\mathrm{C}$, vitamin $\mathrm{D}$, calcium, selenium and fluoride. ${ }^{135}$ In addition to folic acid fortified grain products, many commonly eaten foods are fortified with micronutrients, including iodized salt and iron fortified breakfast cereal.

Fortification policies are legally mediated through a framework consisting of legislation and regulations, administrative procedures and mechanisms for enforcement. ${ }^{136,137}$ Internationally, countries planning to formulate laws and regulations for the addition of vitamins and minerals to foods are guided by general principles created by the Codex Alimentarius Commission of the joint Food and Agriculture Organization (FAO)/World Health Organization (WHO) food standard programme. ${ }^{138}$ Fortification in Canada falls under the Canada Food and Drugs Act and associated regulations, which prohibit the manufacture and sale of unsafe food products. ${ }^{139,140}$ Administration of the Act and regulations is the responsibility of Health Canada, and duty of enforcement lies with the Canadian Food Inspection Agency. ${ }^{137}$ Within Health Canada, the Nutrition Regulations and Standards Division of the Bureau of Nutritional Sciences works within the Food Directorate (housed by the Health Products and Food Branch) and is responsible for food fortification, nutrition labelling and food health claim petitions, policies and standards. ${ }^{137}$ Canadian regulations 
apply to all food sold in Canada, regardless of origin. ${ }^{141}$

The driver of folic acid fortification policy was to decrease the incidence of NTD births. ${ }^{142,143}$ Since government decisions are made in a dynamic scientific and political context, fortification policies are made cautiously. Numerous sources, including research and key stakeholder input, are used to inform the associated laws and regulations. Current, national-level prevalence data for folate deficiency was not available to Canadian policy makers pre-fortification; thus, fortification policy was, in part, estimated based on American NHANES data.

Canadian food fortification policy discussions can be traced back to the 1930 s, closely following the discovery of vitamins in the $1920 \mathrm{~s}^{2}$ Consumer protection became a public health priority with the potential for unsafe addition of synthetic vitamins to foods and inaccurate health claims. Enrichment - or the replacement of nutrients lost during processing - gained favour following nutrition surveys and reports that revealed widespread malnutrition. ${ }^{141}$ Health Canada permits food fortification to replace nutrients lost in the manufacturing process and to act as a public health intervention. ${ }^{141}$

Though prevention of disease was a key impetus for folic acid fortification policies, global trade agreements were another important consideration. Canada's first encounter with harmonizing trade standards occurred when Newfoundland joined Confederation in $1949 .{ }^{144}$ Enrichment policies were amended to achieve inter-provincial harmonization. Since that time, harmonizing international trade has become a driver of enrichment and fortification policies across borders. The Technical Barriers to Trade Agreement is a global trade agreement administered by the World Trade Organization - responsible for global trade rules that cover $90 \%$ of the world's trade - with the objective of eliminating unnecessary obstacles 
to international trade. ${ }^{135}$ This includes rules related to mandatory and discretionary food fortification. The agreement also allows countries to take measures to protect human health at levels considered appropriate, but not in a way that constitutes protectionism. ${ }^{135}$

The U.S. Food and Drug Administration permitted the voluntary addition of folic acid to enriched flour and other enriched cereal grain products in March 1996 and this addition became mandatory in January $1998 .{ }^{145}$ Canada followed a similar path, allowing voluntary fortification of white flour, enriched pasta and cornmeal in December 1996, with this becoming mandatory in November $1998 .{ }^{12}$ It is estimated that with voluntary fortification an average Canadian consumes approximately $200 \mu \mathrm{g} / \mathrm{d}$ of synthetic folic acid, though there has been evidence of folic acid overages in folic acid fortified grain products. ${ }^{146}$ The fortification level, when combined with folate from all other food and recommended supplement sources, was estimated to be below the safe upper limit of $1000 \mu \mathrm{g} /$ day for women of childbearing age and the general population. ${ }^{141}$

Discretionary fortification in Canada is still a topic of debate. Health Canada defines limits for discretionary fortification, and the manufacturer determines implementation based on consumer demand. ${ }^{143}$ Proposed amendments to Canadian fortification policy may allow manufacturers to add vitamins and minerals to less healthy foods, such as potato chips and chocolate bars, at their discretion. ${ }^{143,147}$ Nutrients are assigned to one of three risk categories - A, B or $\mathrm{C}$ - with $\mathrm{C}$ representing the highest-risk nutrients. ${ }^{143}$ Folic acid falls into risk category B, "nutrients with serious adverse effects, but with low risk of excessive intake at the proposed level of addition for discretionary fortification.” Health Canada and relevant stakeholders have debated these policies since $1998 .{ }^{143}$ The final policy amendments were to be released in June 2009, but discussions are still ongoing. Food manufacturers view 
discretionary fortification as an opportunity to be technologically competitive. ${ }^{148}$ In general, stakeholders agreed that mandatory fortification is necessary; however, they were divided over whether or not nutritionally relevant justification should be required; the criteria for fortifiable foods; and the type and amount of nutrients that would be allowed. ${ }^{143}$

The goal of folic acid policies is to find folate concentrations that maximize health benefits, while minimizing harm, in a given population. It is evident that folate status has increased in the post-fortification era. The next step towards achieving this goal, and the aim of this thesis, is to examine folate concentrations in the population - general population and women of childbearing age - on a national level. The CHMS provides the first nationally representative Canadian data on $\mathrm{RBC}$ folate that can be used to inform folic acid fortification and supplementation policies, and subsequently aid in optimizing the health of Canadians. 


\subsection{References}

1. Goh YI, Koren G. Folic acid in pregnancy and fetal outcomes. J Obstet Gynaecol Can 2008;28(1):3-13.

2. Institute of Medicine. DRI dietary reference intakes for thiamin, riboflavin, niacin, vitamin B6, folate, vitamin B12, pantothenic acid, biotin, and choline. Washington (DC): National Academy Press; 1998.

3. McNulty, H, Pentieva, K. Folate bioavailability. In: Bailey L.B., ed. Folate in health and disease. $2^{\text {nd }}$ ed. Boca Raton (FL): Taylor \& Francis Group, L.L.C.; 2010 .

4. Blom HJ, Shaw GM, den Heijer M, et al. Neural tube defects and folate: Case far from closed. Nat Rev Neurosci 2006;7(9):724-31.

5. Shane B. Folate status assessment history: Implications for measurement of biomarkers in NHANES. Am J Clin Nutr 2011;94(1):337S-42S.

6. Kelly P, McPartlin J, Goggins M, et al. Unmetabolized folic acid in serum: Acute studies in subjects consuming fortified food and supplements. Am J Clin Nutr 1997;65(6):17905.

7. Sweeney MR, McPartlin J, Weir DG, et al. Evidence of unmetabolised folic acid in cord blood of newborn and serum of 4-day-old infants. Br J Nutr 2005;94(5):727-30.

8. Bailey RL, Mills JL, Yetley EA, et al. Unmetabolized serum folic acid and its relation to folic acid intake from diet and supplements in a nationally representative sample of adults aged > or $=60 \mathrm{y}$ in the united states. Am J Clin Nutr 2010;92(2):383-9.

9. Morris MS, Jacques PF, Rosenberg IH, et al. Circulating unmetabolized folic acid and 5methyltetrahydrofolate in relation to anemia, macrocytosis, and cognitive test performance in american seniors. Am J Clin Nutr 2010;91(6):1733-44.

10. Houghton LA, Sherwood KL, Pawlosky R, et al. 6S]-5-methyltetrahydrofolate is at least as effective as folic acid in preventing a decline in blood folate concentrations during lactation. Am J Clin Nutr 2006;83(4):842-50.

11. Refsum H. Folate, vitamin B12 and homocysteine in relation to birth defects and pregnancy outcome. Br J Nutr 2001;85 Suppl 2:S109-13.

12. Canada Gazette Part II. Regulatory impact analysis statement. In: Bureau of Food Regulatory IaIA, Health Canada, ed. 1998:3029-33. (SOR/98-550.)

13. Yetley EA, Johnson CL. Folate and vitamin B-12 biomarkers in NHANES: History of their measurement and use. Am J Clin Nutr 2011 Jul;94(1):322S-31S. 
14. Pfeiffer CM, Fazili Z, Zhang M. Folate analytical methodology. In: LB Bailey, ed. Folate in health in disease. $2^{\text {nd }}$ ed. Boca Raton (FL): CRC Press, Taylor \& Francis Group; 2010.

15. Laboratory procedure manual: Folate. Centres for Disease Control and Prevention. Washington (DC). Available: http://www.cdc.gov/nchs/data/nhanes/nhanes_07_08/FOLATE_E_met.pdf. (Accessed December 9, 2012).

16. Yetley EA, Pfeiffer CM, Phinney KW, et al. Biomarkers of folate status in NHANES: A roundtable summary. Am J Clin Nutr 2011;94(1):303S-12S.

17. Immulite 2000 folic acid insert. Mississauga (ON): Siemans Canada, Ltd.; 2009.

18. Yetley EA, Coates PM, Johnson CL. Overview of a roundtable on NHANES monitoring of biomarkers of folate and vitamin B12 status: Measurement procedure issues. Am J Clin Nutr 2011;94(1):297S-302S.

19. Owen WE, Roberts WL. Comparison of five automated serum and whole blood folate assays. Am J Clin Pathol 2003 Jul;120(1):121-6.

20. Fazili Z, Pfeiffer CM, Zhang M, et al. Influence of 5,10-methylenetetrahydrofolate reductase polymorphism on whole-blood folate concentrations measured by LCMS/MS, microbiologic assay, and Bio-Rad radioassay. Clin Chem 2008;54(1):197-201.

21. Christensen, KE, Rozen, R. Genetic variation: Effect on folate metabolism and health. In: Bailey LB, ed. Folate in health and disease. $2^{\text {nd }}$ ed. Boca Raton, FL: Taylor \& Francis Group, L.L.C.; 2010.

22. Kim YI. Folic acid fortification and supplementation-good for some but not so good for others. Nutr Rev 2007;65(11):504-11.

23. Colapinto CK, O'Connor DL, Tremblay MS. Folate status of the population in the Canadian Health Measures Survey. CMAJ 2011;183(2):E100-6.

24. Daly LE, Kirke PN, Molloy A, et al. Folate levels and neural tube defects. Implications for prevention. JAMA 1995;274(21):1698-702.

25. Stabler S. Clinical folate deficiency. In: Bailey LB, ed. Folate in health and disease. $2^{\text {nd }}$ ed. Boca Raton, FL: Taylor \& Francis Group, LLC; 2010.

26. Pitkin RM. Folate and neural tube defects. Am J Clin Nutr 2007;85(1):285S-8S.

27. Cabrera RM, Hill DS, Etheredge AJ, et al. Investigations into the etiology of neural tube defects. Birth Defects Res C Embryo Today 2004;72(4):330-44. 
28. Padmanabhan R. Etiology, pathogenesis and prevention of neural tube defects. Congenit Anom (Kyoto) 2006;46(2):55-67.

29. MRC Vitamin Study Research Group. Prevention of neural tube defects: Results of the Medical Research Council vitamin study. Lancet 1991;338(8760):131-7.

30. Czeizel AE, Dudas I. Prevention of the first occurrence of neural-tube defects by periconceptional vitamin supplementation. N Engl J Med 1992;327(26):1832-5.

31. De Wals P, Tairou F, Van Allen MI, et al. Reduction in neural-tube defects after folic acid fortification in Canada. N Engl J Med 2007;357(2):135-42.

32. O'Broin S, Kelleher B. Microbiological assay on microtitre plates of folate in serum and red cells. J Clin Pathol 1992;45(4):344-7.

33. Gardiner HM, Fouron JC. Folic acid fortification and congenital heart disease. BMJ 2009;338:b1144.

34. Czeizel AE. Periconceptional folic acid and multivitamin supplementation for the prevention of neural tube defects and other congenital abnormalities. Birth Defects Res A Clin Mol Teratol 2009;85(4):260-8.

35. Godwin KA, Sibbald B, Bedard T, et al. Changes in frequencies of select congenital anomalies since the onset of folic acid fortification in a Canadian birth defect registry. Can J Public Health 2008;99(4):271-5.

36. Goh YI, Bollano E, Einarson TR, et al. Prenatal multivitamin supplementation and rates of congenital anomalies: A meta-analysis. J Obstet Gynaecol Can 2006;28(8):680-9.

37. Mason JB. Folate, cancer risk, and the Greek god, proteus: A tale of two chameleons. Nutr Rev 2009;67(4):206-12..

38. Mason JB, Dickstein A, Jacques PF, et al. A temporal association between folic acid fortification and an increase in colorectal cancer rates may be illuminating important biological principles: A hypothesis. Cancer Epidemiol Biomarkers Prev 2007;16(7):1325-9.

39. De-Regil LM, Fernandez-Gaxiola AC, Dowswell T, et al. Effects and safety of periconceptional folate supplementation for preventing birth defects (Review). In: The Cochrane Library, Issue 10, 2010. Chichester: Wiley.

40. Johnson CY, Little J. Folate intake, markers of folate status and oral clefts: Is the evidence converging? Int J Epidemiol 2008;37(5):1041-58. 
41. Crider KS, Bailey LB, Berry RJ. Folic acid food fortification-its history, effect, concerns, and future directions. Nutrients 2011;3(3):370-84.

42. Whitrow M, Moore VM, Rumbold A, et al. Effect of supplemental folic acid in pregnancy on childhood asthma: A prospective birth cohort study. Am J Epidemiol 2009;170(12):1486-1493.

43. Haberg SE, London SJ, Stigum H, et al. Folic acid supplements in pregnancy and early childhood respiratory health. Arch Dis Child 2009;94(3):180-4.

44. Martinussen MP, Risnes KR, Jacobsen GW, et al. Folic acid supplementation in early pregnancy and asthma in children aged 6 years. Am J Obstet Gynecol 2012;206(1):72.e1,72.e7.

45. Yajnik CS, Deshpande SS, Jackson AA, et al. Vitamin B12 and folate concentrations during pregnancy and insulin resistance in the offspring: The Pune maternal nutrition study. Diabetologia 2008;51(1):29-38.

46. Cuskelly GJ, Mooney KM, Young IS. Folate and vitamin B12: Friendly or enemy nutrients for the elderly. Proc Nutr Soc 2007;66(4):548-58.

47. Hirsch S, Sanchez H, Albala C, et al. Colon cancer in Chile before and after the start of the flour fortification program with folic acid. Eur J Gastroenterol Hepatol 2009;21(4):436-9.

48. Kim YI. Folate, colorectal carcinogenesis, and DNA methylation: Lessons from animal studies. Environ Mol Mutagen 2004;44(1):10-25.

49. Cole BF, Baron JA, Sandler RS, et al. Folic acid for the prevention of colorectal adenomas: A randomized clinical trial. JAMA 2007;297(21):2351-9.

50. Fife J, Raniga S, Hider PN, et al. Folic acid supplementation and colorectal cancer risk: A meta-analysis. Colorectal Dis 2011;13(2):132-7.

51. Baggott JE, Oster RA, Tamura T. Meta-analysis of cancer risk in folic acid supplementation trials. Cancer Epidemiol 2012;36(1):78-81.

52. Wien TN, Pike E, Wisloff T, Staff A, et al. Cancer risk with folic acid supplements: A systematic review and meta-analysis. BMJ Open 2012;2(1):e000653.

53. Mason JB. Unraveling the complex relationship between folate and cancer risk. Biofactors 2011;37(4):253-60. 
54. Vollset SE, Clarke R, Lewington S, et al. Effects of folic acid supplementation on overall and site-specific cancer incidence during the randomised trials: Meta-analyses of data on 50000 individuals. Lancet 2013;381(9871):1029-36.

55. Science and Risk Directorate of the Ministry for Primary Industries. Voluntary folic acid fortification: Monitoring and evaluation report. Wellington, (NZ): New Zealand Government; 2012.

56. Selhub J, Morris MS, Jacques PF, et al. Folate-vitamin B12 interaction in relation to cognitive impairment, anemia, and biochemical indicators of vitamin B12 deficiency. Am J Clin Nutr 2009;89(2):702S-6S.

57. Morris MS, Jacques PF, Rosenberg IH, et al. Folate and vitamin B12 status in relation to anemia, macrocytosis, and cognitive impairment in older Americans in the age of folic acid fortification. Am J Clin Nutr 2007;85(1):193-200.

58. Logan RF, Grainge MJ, Shepherd VC, et al. Aspirin and folic acid for the prevention of recurrent colorectal adenomas. Gastroenterology 2008;134(1):29-38.

59. Wu K, Platz EA, Willett WC, et al. A randomized trial on folic acid supplementation and risk of recurrent colorectal adenoma. Am J Clin Nutr 2009;90(6):1623-31.

60. den Heijer M, Willems HP, Blom HJ, et al. Homocysteine lowering by B vitamins and the secondary prevention of deep vein thrombosis and pulmonary embolism: A randomized, placebo-controlled, double-blind trial. Blood 2007;109(1):139-44.

61. Jamison RL, Hartigan P, Kaufman JS, et al. Effect of homocysteine lowering on mortality and vascular disease in advanced chronic kidney disease and end-stage renal disease: A randomized controlled trial. JAMA 2007;298(10):1163-70.

62. Ebbing M, Bonaa KH, Nygard O, et al. Cancer incidence and mortality after treatment with folic acid and vitamin B12. JAMA 2009;302(19):2119-26.

63. Bonaa KH, Njolstad I, Ueland PM, et al. Homocysteine lowering and cardiovascular events after acute myocardial infarction. N Engl J Med 2006;354(15):1578-88.

64. Galan P, Kesse-Guyot E, Czernichow S, et al. Effects of B vitamins and omega 3 fatty acids on cardiovascular diseases: A randomised placebo controlled trial. BMJ 2010;341:c6273.

65. Toole JF, Malinow MR, Chambless LE, et al. Lowering homocysteine in patients with ischemic stroke to prevent recurrent stroke, myocardial infarction, and death: The vitamin intervention for stroke prevention (VISP) randomized controlled trial. JAMA 2004;291(5):565-75. 
66. VITATOPS Trial Study Group. B vitamins in patients with recent transient ischaemic attack or stroke in the VITAmins TO Prevent Stroke (VITATOPS) trial: A randomised, double-blind, parallel, placebo-controlled trial. Lancet Neurol 2010;9(9):855-65.

67. Zhang SM, Cook NR, Albert CM, et al. Effect of combined folic acid, vitamin B6, and vitamin B12 on cancer risk in women: A randomized trial. JAMA 2008;300(17):201221.

68. Lonn E, Yusuf S, Arnold MJ, et al. Homocysteine lowering with folic acid and B vitamins in vascular disease. N Engl J Med 2006;354(15):1567-77.

69. Study of the Effectiveness of Additional Reductions in Cholesterol and Homocysteine (SEARCH) Collaborative Group, Armitage JM, Bowman L, et al. Effects of homocysteine-lowering with folic acid plus vitamin B12 vs placebo on mortality and major morbidity in myocardial infarction survivors: A randomized trial. JAMA 2010;303(24):2486-94.

70. Qin X, Cui Y, Shen L, et al. Folic acid supplementation and cancer risk: A meta-analysis of randomized controlled trials. Int J Cancer 2013. Published on-line Feb. 15, 2013.

71. Hodis HN, Mack WJ, Dustin L, et al. High-dose B vitamin supplementation and progression of subclinical atherosclerosis: A randomized controlled trial. Stroke 2009;40(3):730-6.

72. Charles D, Ness AR, Campbell D, et al. Taking folate in pregnancy and risk of maternal breast cancer. BMJ 2004;329(7479):1375-6.

73. Zhu S, Mason J, Shi Y, et al. The effect of folic acid on the development of stomach and other gastrointestinal cancers. Chin Med J (Engl) 2003;116(1):15-9.

74. Nutrition Canada National Survey: 1970-1972 [Internet]: University of Toronto Data Library Service; c2005 [cited 2009 09/01]. Available from: http://prod.library.utoronto.ca:8090/datalib/codebooks/nac/g0000577/nutrition70.htm\#p artD.

75. Nutrition Canada. Nutrition Canada: The Ontario survey report. Ottawa (ON): The Bureau of Nutritional Sciences, Department of National Health and Welfare; 1975.

76. Gadowsky SL, Gale K, Wolfe SA, et al. Biochemical folate, B12, and iron status of a group of pregnant adolescents accessed through the public health system in southern Ontario. J Adolesc Health 1995;16(6):465-74.

77. Ray JG, Vermeulen MJ, Boss SC, et al. Increased red cell folate concentrations in women of reproductive age after Canadian folic acid food fortification. Epidemiology 2002;13(2):238-40. 
78. Bar-Oz B, Koren G, Nguyen P, et al. Folate fortification and supplementation-are we there yet? Reprod Toxicol 2008;25(4):408-12.

79. Kapur B, Soldin OP, Koren G. Potential prevention of neural tube defects by assessment of women of childbearing age through monitoring of folate. Ther Drug Monit 2002;24(5):628-30.

80. Ray JG, Vermeulen MJ, Langman LJ, et al. Persistence of vitamin B12 insufficiency among elderly women after folic acid food fortification. Clin Biochem 2003;36(5):38791.

81. Liu S, West R, Randell E, et al. A comprehensive evaluation of food fortification with folic acid for the primary prevention of neural tube defects. BMC Pregnancy Childbirth 2004;4(1):20.

82. Shuaibi AM, House JD, Sevenhuysen GP. Folate status of young Canadian women after folic acid fortification of grain products. J Am Diet Assoc 2008;108(12):2090-4.

83. Yi Y, Lindemann M, Colligs A, et al. Economic burden of neural tube defects and impact of prevention with folic acid: A literature review. Eur J Pediatr 2011;170(11):1391-400.

84. Grosse SD, Waitzman NJ, Romano PS, et al. Reevaluating the benefits of folic acid fortification in the United States: Economic analysis, regulation, and public health. Am J Public Health 2005;95(11):1917-22..

85. Tosi LL, Detsky AS, Roye DP, et al. When does mass screening for open neural tube defects in low-risk pregnancies result in cost savings? CMAJ 1987;136(3):255-65.

86. Inflation Calculator: Bank of Canada, Ottawa (ON). Available: http://www.bankofcanada.ca/rates/related/inflation-calculator/ (Accessed January 13, 2013).

87. Berry RJ, Mulinare J, Hamner H. Folic acid fortification. In: Bailey, LB. ed. Folate in health and disease. $2^{\text {nd }}$ ed. Boca Raton, FL: CRC Press, Taylor \& Francis Group; 2010.

88. Hobdell E. Chronic sorrow and depression in parents of children with neural tube defects. J Neurosci Nurs 2004;36(2):82-94.

89. Blum RW, Resnick MD, Nelson R, et al. Family and peer issues among adolescents with spina bifida and cerebral palsy. Pediatrics 1991;88(2):280-5.

90. Roux G, Sawin KJ, Bellin MH, et al. The experience of adolescent women living with spina bifida. part II: Peer relationships. Rehabil Nurs 2007;32(3):112-9. 
91. Kirpalani HM, Parkin PC, Willan AR, et al. Quality of life in spina bifida: Importance of parental hope. Arch Dis Child 2000;83(4):293-7.

92. Ray JG, Vermeulen MJ, Meier C, et al. Maternal ethnicity and risk of neural tube defects: A population-based study. CMAJ 2004;171(4):343-5.

93. Williams LJ, Rasmussen SA, Flores A, et al. Decline in the prevalence of spina bifida and anencephaly by race/ethnicity: 1995-2002. Pediatrics 2005;116(3):580-6.

94. Campbell LR, Dayton DH, Sohal GS. Neural tube defects: A review of human and animal studies on the etiology of neural tube defects. Teratology 1986;34(2):171-87.

95. McDowell MA, Lacher DA, Pfeiffer CM, et al. Blood folate levels: The latest NHANES results. NCHS Data Brief 2008;(6)(6):1-8.

96. Boulet SL, Yang Q, Mai C, et al. Trends in the postfortification prevalence of spina bifida and anencephaly in the United States. Birth Defects Res A Clin Mol Teratol 2008;82(7):527-32.

97. Centers for Disease Control and Prevention (CDC). CDC grand rounds: Additional opportunities to prevent neural tube defects with folic acid fortification. MMWR Morb Mortal Wkly Rep 2010;59(31):980-4.

98. Hamner HC, Mulinare J, Cogswell ME, et al. Predicted contribution of folic acid fortification of corn masa flour to the usual folic acid intake for the US population: National Health and Nutrition Examination Survey 2001-2004. Am J Clin Nutr 2009;89(1):305-15.

99. Arbour L, Christensen B, Delormier T, et al. Spina bifida, folate metabolism, and dietary folate intake in a Northern Canadian Aboriginal population. Int J Circumpolar Health 2002;61(4):341-51.

100. Power EM. Determinants of healthy eating among low-income Canadians. Can J Public Health 2005;96 Suppl 3:S37,42, S42-8.

101. Kirkpatrick SI, Tarasuk V. Food insecurity is associated with nutrient inadequacies among Canadian adults and adolescents. J Nutr 2008;138(3):604-12.

102. Chen CP. Syndromes, disorders and maternal risk factors associated with neural tube defects (VI). Taiwan J Obstet Gynecol 2008;47(3):267-75.

103. Blanco Munoz J, Lacasana M, Borja Aburto VH, et al. Socioeconomic factors and the risk of anencephaly in a Mexican population: A case-control study. Public Health Rep 2005;120(1):39-45. 
104. Li Z, Ren A, Zhang L, et al. A population-based case-control study of risk factors for neural tube defects in four high-prevalence areas of Shanxi province, China. Paediatr Perinat Epidemiol 2006;20(1):43-53.

105. Salvi VS, Damania KR. Neural tube defects in India--time for action. Lancet 2005;366(9489):871-2.

106. Frey L, Hauser WA. Epidemiology of neural tube defects. Epilepsia 2003;44 Suppl 3:413.

107. Roebothan BV, Carmichael J, Barter V, et al. Mandatory folic acid fortification in Newfoundland and Labrador. Can J Diet Pract Res 2007;68(3):143-5.

108. Grewal J, Carmichael SL, Ma C, et al. Maternal periconceptional smoking and alcohol consumption and risk for select congenital anomalies. Birth Defects Res A Clin Mol Teratol 2008;82(7):519-26.

109. Subar AF, Harlan LC, Mattson ME. Food and nutrient intake differences between smokers and non-smokers in the US. Am J Public Health 1990;80(11):1323-9.

110. Wilson RD, Johnson JA, Wyatt P, et al. Pre-conceptional vitamin/folic acid supplementation 2007: The use of folic acid in combination with a multivitamin supplement for the prevention of neural tube defects and other congenital anomalies. $\mathbf{J}$ Obstet Gynaecol Can 2007;29(12):1003-26.

111. High dose folic acid supplementation - questions and answers for health professionals. Health Canada, Ottawa (ON). Available: http://www.hc-sc.gc.ca/fnan/nutrition/prenatal/fol-qa-qr-eng.php\#a2 (Accessed May 3, 2013).

112. Correa A, Gilboa SM, Besser LM, et al. Diabetes mellitus and birth defects. Am J Obstet Gynecol 2008;199(3):237.e1,237.e9.

113. Mills JL, Baker L, Goldman AS. Malformations in infants of diabetic mothers occur before the seventh gestational week. Implications for treatment. Diabetes 1979;28(4):292-3.

114. Chen CP. Syndromes, disorders and maternal risk factors associated with neural tube defects (I). Taiwan J Obstet Gynecol 2008;47(1):1-9.

115. Ray JG, Wyatt PR, Vermeulen MJ, et al. Greater maternal weight and the ongoing risk of neural tube defects after folic acid flour fortification. Obstet Gynecol 2005; 105(2):261-5. 
116. Stothard KJ, Tennant PW, Bell R, et al. Maternal overweight and obesity and the risk of congenital anomalies: A systematic review and meta-analysis. JAMA 2009 Feb;301(6):636-50.

117. Hernandez-Diaz S, Werler MM, Walker AM, et al. Folic acid antagonists during pregnancy and the risk of birth defects. N Engl J Med 2000;343(22):1608-14.

118. Ray JG, Singh G, Burrows RF. Evidence for suboptimal use of periconceptional folic acid supplements globally. BJOG 2004;111(5):399-408.

119. Brown JE, Jacobs DR, Hartman TJ, et al. Predictors of red cell folate level in women attempting pregnancy. JAMA 1997;277(7):548-52.

120. Larson NI, Neumark-Sztainer D, Story M. Weight control behaviors and dietary intake among adolescents and young adults: Longitudinal findings from project EAT. J Am Diet Assoc 2009;109(11):1869-77.

121. Ren A, Zhang L, Li Z, et al. Awareness and use of folic acid, and blood folate concentrations among pregnant women in northern China-an area with a high prevalence of neural tube defects. Reprod Toxicol 2006;22(3):431-6.

122. Baird PA. Neural tube defects in the Sikhs. Am J Med Genet 1983;16(1):49-56.

123. Kallen K. Maternal smoking and congenital malformations. Fetal Matern Med Rev 2002;13(1):63-86.

124. McDonald SD, Perkins SL, Jodouin CA, et al. Folate levels in pregnant women who smoke: An important gene/environment interaction. Am J Obstet Gynecol 2002;187(3):620-5.

125. Suarez L, Felkner M, Brender JD, et al. Maternal exposures to cigarette smoke, alcohol, and street drugs and neural tube defect occurrence in offspring. Matern Child Health J 2008;12(3):394-401.

126. Stark KD, Pawlosky RJ, Sokol RJ, et al. Maternal smoking is associated with decreased 5-methyltetrahydrofolate in cord plasma. Am J Clin Nutr 2007;85(3):796-802.

127. Laraia BA, Bodnar LM, Siega-Riz AM. Pregravid body mass index is negatively associated with diet quality during pregnancy. Public Health Nutr 2007;10(9):920-6.

128. Becerra JE, Khoury MJ, Cordero JF, et al. Diabetes mellitus during pregnancy and the risks for specific birth defects: A population-based case-control study. Pediatrics 1990;85(1):1-9. 
129. Rosa FW. Spina bifida in infants of women treated with Carbamazepine during pregnancy. N Engl J Med 1991;324(10):674-7.

130. Lindhout D, Schmidt D. In-utero exposure to Valproate and neural tube defects. Lancet 1986;1(8494):1392-3.

131. Dansky LV, Andermann E, Rosenblatt D, et al. Anticonvulsants, folate levels, and pregnancy outcome: A prospective study. Ann Neurol 1987;21(2):176-82.

132. Sivojelezova A, Einarson A, Shuhaiber S, et al. Trimethoprim-sulfonamide combination therapy in early pregnancy. Can Fam Physician 2003;49:1085-6.

133. Tam C, McKenna K, Goh YI, et al. Periconceptional folic acid supplementation: A new indication for therapeutic drug monitoring. Ther Drug Monit 2009;31(3):319-26.

134. Hawe P, Potvin L. What is population health intervention research? Can J Public Health 2009;100(1):Suppl I8-14.

135. World Health Organization. Guidelines on food fortification with micronutrients. Geneva $(\mathrm{CH})$ : World Health Organization; 2006.

136. Health Canada. Canadian consumer perspectives on food fortification. Ottawa (ON): Government of Canada; 2005.

137. Canada's Food and Drug Act and Regulations. Health Canada, Ottawa (ON): Available: http://www.hc-sc.gc.ca/fn-an/legislation/acts-lois/act-loi reg-eng.php (Accessed May 3, 2013).

138. FAO/WHO Food Standards Codex Alimentarius. Available: http://www.codexalimentarius.net/web/index_en.jsp (Accessed May 3, 2013).

139. Food and Drugs Regulations. Minister of Justice, Ottawa (ON): Available: http://laws.justice.gc.ca.proxy.bib.uottawa.ca/en/ShowFullDoc/cr/C.R.C.c.870//20090612/en (Accessed May 3, 2013).

140. Food and Drugs Regulations [Internet]Ottawa: Minister of Justice; c2009 [cited 2009 06/12]. Available from: http://laws.justice.gc.ca.proxy.bib.uottawa.ca/en/ShowFullDoc/cr/C.R.C.c.870//20090612/en.

141. Institute of Medicine Committee on use of dietary reference intakes in nutrition labeling. Dietary reference intakes guiding principles for nutrition labeling and fortification. Washington (DC): The National Academies Press; 2001. 
142. Orriss GL. Food fortification: Safety and legislation. Food Nutr Bull 1998;19(2):109116.

143. Health Canada. Addition of vitamins and minerals to foods: Health Canada's proposed policy and implementation plans. Ottawa (ON): Health Canada; 2005.

144. Nathoo T, Holmes CP, Ostry A. An analysis of the development of Canadian food fortification policies: The case of vitamin B. Health Promot Int 2005;20(4):375-82.

145. Food and Drug Administration. Food standards: amendment of standards of identity for enriched grain products to require addition of folic acid. Final Rule. 21 CFR Parts 136, 137, and 139. Federal Register. 1996;61:8781-8789.

146. Shakur YA, Rogenstein C, Hartman-Craven B, et al. How much folate is in Canadian fortified products 10 years after mandated fortification? Can J Public Health 2009;100(4):281-4.

147. Beauchesne E, Kondro W. Health Canada contemplates providing food industry with "discretionary" authority to fortify junk foods. CMAJ 2009;180(12):1196-7.

148. The George Morris Centre for Food \& Consumers Products of Canada. Food regulatory systems: Canada's performance in the global marketplace. Guelph: Food \& Consumer Products of Canada; 2008. 


\section{CHAPTER 3: METHODOLOGICAL OVERVIEW}

\subsection{Method summary and justification}

This thesis presents the results of five studies. All five examined the 2007-2009 Canadian Health Measures Survey (CHMS) data, while Study 5 also used data from the 2007-2008 National Health and Nutrition Examination Survey (NHANES) from the United States. The first study, entitled Folate status of the population in the Canadian Health Measures Survey, was designed to provide a descriptive overview of the current folate status of Canadians, examining the general population and women of childbearing age separately. Medians, percentiles and cumulative percentile distributions were presented for red blood cell (RBC) folate concentrations, and these results were examined by age group, sex and income quartile. We used t-tests to compare median RBC folate between groups as these are potential risk factors for differing folate status. We determined deficiency was virtually nonexistent in the Canadian population, and exposed a shift towards high folate concentrations. Further, a significant proportion (22\%) of women of childbearing age were still not achieving a folate status considered optimally protective against neural tube defect (NTD) risk.

These results led to our second investigation, which focused on Prevalence and correlates of folic acid supplement use in Canada to develop a deeper understanding of the relationship between synthetic folic acid supplement intake and RBC folate in the general population. The exploration employed descriptive analysis (frequencies and percentiles) to examine folic acid supplement use. We used t-tests to examine differences in folic acid supplement use for each potential correlate. Logistic regression was used to identify potential correlates of low supplement use (e.g. age, sex, income), as well as RBC folate concentration. The third study 
focused on women of childbearing age to determine correlates of folate status considered optimal for maximal reduction of neural tube defect (NTD) risk ( $\geq 906 \mathrm{nmol} / \mathrm{L})$. As evidenced by the title of the study, we found that Folic acid supplement use is the most significant predictor of folate concentrations in Canadian women of childbearing age. Separate logistic regression models, controlling for age and income, examined a number of predictors. We similarly explored predictors of folic acid supplement use in women of childbearing age. These studies provided insight into Canadians' RBC folate concentrations and relevant correlates. Our next step compared Canadian RBC folate to those of Americans, as an important indicator of progress with respect to public health goals.

Elevated RBC folate status was persistent throughout the studies in this dissertation. We conceptualized the fourth paper based on two key findings: 1) Canadian folate data should be adjusted to microbiologic assay prior to examining the high cut-offs, and 2) Agreement is needed on a definition of high folate status. In the paper, titled Prevalence of high red blood cell folate concentration in the Canadian population using three proposed cut-offs, we proposed cut-offs using descriptive statistics. Where the sample size was adequate, we used t-tests to examine differences between relevant sociodemographic, behavioural and clinical factors. We employed regression models to examine folic acid supplement intake as a predictor of high RBC folate concentrations. The primary purpose of this paper was to create dialogue among experts in the field to ultimately produce a consensus driven cut-off.

The CHMS was modeled after the NHANES, a population based health survey in the U.S. from the National Center for Health Statistics (NCHS). The NHANES has collected direct measures of folate status since 1974. Similar to Canada, the U.S. has been fortifying certain grain products with folic acid since the late 1990s, and folic acid supplementation 
recommendations are similar in both countries. Therefore, a comparison of the folate status of these two populations is of particular interest and is addressed in the fifth study, titled Comparison of Canadian and American red blood cell folate concentrations. Recognizing that a discrepancy between the methods used to analyse folate status may exist, we conducted a methods comparison study to adjust the Canadian RBC folate data, measured by Immulite 2000 immunoassay, to microbiologic assay, which was conducted in Deborah O'Connor's laboratory at the Hospital for Sick Children using a similar method to the 20072008 NHANES. ${ }^{1}$ The methods and results for this methods comparison study are detailed in Appendix F. Frequencies and percentiles of RBC folate concentrations were reported for relevant sociodemographic and behavioural factors. Country was the main predictor of RBC folate in a logistic regression model, controlling for important determinants, for example age, sex, income, race/ethnicity and folic acid supplement use.

The methodology planned for this thesis was appropriate for the CHMS design, SAS and SAS-callable SUDAAN were used for all analyses. We encountered two primary methodological difficulties:

1) The availability of only one cycle of the survey, thus the degrees of freedom (DDF=11) allowed for a maximum of 10 parameters to be included in regression models. Further, the sample size of the population $(\mathrm{N}=5248)$ limited the analyses that could be performed on subgroups.

2) We could not conduct a direct comparison of Canadian and American RBC folate data due to differences in RBC folate assay methods. This was overcome by conducting a substudy and subsequently generating a conversion equation to adjust the CHMS RBC folate 
data. A successful collaboration was forged with the U.S. Centers for Disease Control and Prevention (CDC) to explore this issue.

The articles presented in Chapter 4 provide substantial detail on the methods. The remainder of the current chapter will focus on outlining the research sequence and add supplementary information regarding outcome and predictor variables, the creation of derived variables and methodological considerations.

\subsection{Research sequence}

I was able to access preliminary CHMS data prior to the public release as a 2009 Tom Symon's Fellow (Statistics Canada). I familiarized myself with the dataset, created SAS code and began to understand preliminary results. When the CHMS nutrition biochemical dataset was released in March 2010, I was well positioned to analyze the RBC folate data. Ethics approval for the secondary data analysis of the CHMS was given by CHEO on December 17, 2009 (Appendix D). Data preparation, analysis, writing and submission of the first manuscript occurred from September 2009 to April 2010. This manuscript was accepted for publication by the Canadian Medical Association Journal (CMAJ) on August 20, 2010 and garnered substantial international media attention, including from CBC's The National, The

Globe and Mail and The Times of India (Appendix E). I successfully defended my thesis proposal on February 16, 2010. Data preparation, analysis and manuscript preparation for the second and third manuscripts occurred from April 2010 to November 2011. During this period, I completed the requirements for the Diploma in Health Services and Policy Research. This consisted of a 200-hour practicum with the Office of Nutrition Policy and Promotion at Health Canada, a mixed methods research course and a week-long summer 
institute. Manuscripts \#2 and \#3 were submitted in November 2011, and accepted for publication December 19, 2011 and December 13, 2011, respectively.

In March 2010, our research group applied for a two-year CIHR Operating Grant for the methods comparison study to generate the conversion equation (Appendix F). This grant was successfully awarded in June 2010, with Mark Tremblay and Deborah O’Connor as Principal Investigators, and myself and Lise Dubois as Co-Investigators. Ethics approval for the methods comparison study was granted by CHEO (November 9, 2010), the University of Ottawa (administrative review following CHEO approval), Health Canada (November 23, 2010) and the Hospital for Sick Children (February 3, 2011) (Appendix D). The conversion equation sub-study participant recruitment was conducted from March 2011 to December 2011 through Dr. O’Connor's laboratory at the Hospital for Sick Children (SickKids). Blood was analysed at SickKids and Health Canada Laboratories and final results were available in March, 2012. We generated the conversion equation from July to August 2012. This was followed by the CHMS-NHANES comparison data preparation and analysis, from September to October 2012. The results of this comparison were written up from October 2012 to April 2013, and will undergo internal review by Statistics Canada and the U.S. CDC prior to submission to the Journal of Nutrition. For the paper Prevalence of high red blood cell folate concentration in the Canadian population using three proposed cut-offs, the team conceptualized the study on an on-going basis. The study evolved from September 2009 to November 2012. We undertook the final analysis and write-up for this study between October 2012 to April 2013, and was submitted to the European Journal of Clinical Nutrition. 


\subsection{Data source}

\subsubsection{The Canadian Health Measures Survey}

The analyses used data from the 2007-2009 CHMS, Cycle 1. The survey methodology is described briefly here and in greater detail elsewhere. ${ }^{15,16}$ The CHMS used a complex, multistage, cluster sampling protocol to achieve a nationally representative cross-sectional sample. The sampling frame was used to create 257 collection sites, which were stratified based on five regions. It was determined that a sample of 15 primary sampling units (PSUs) was needed and these were stratified into five strata represented the following regions (number of sites): Atlantic (1), Quebec (4), Ontario (6), Prairies (2) and British Columbia (2). The final sample included 5604 Canadians aged 6-79 years, balanced by sex in each of the following age groups: 6-11, 12-19, 20-39, 40-59, and 60-79 years, and is representative of approximately $96 \%$ of the Canadian population. People living in institutions, on Indian reserves or Crown lands, full-time members of the Canadian Forces, and residents of certain remote regions were excluded. Data collection occurred between March 2007 and February 2009. A Statistics Canada interviewer administered a detailed in-home health questionnaire, which included medication and natural health product use as well as sociodemographic characteristics. One day to six weeks later, blood samples were taken by a certified phlebotomist in a mobile examination centre to measure a variety of analytes. ${ }^{16}$ Of the 8,772 dwellings selected, $70 \%$ agreed to participate; $88 \%$ participated in the household survey and of those $85 \%$ attended the mobile clinic. The overall response rate was $52 \%$. Implied consent occurred in the household and a comprehensive consent process was employed in the clinic. ${ }^{17}$ The Health Canada Research Ethics Board approved the CHMS protocol and the Children's Hospital of Eastern Ontario and University of Ottawa Research Ethics Boards 
approved the secondary data analyses.

We used the 2007-2008 NHANES public data file to compare Canada to the United States. The 2007-2008 NHANES is a two-year cycle release from the continuous NHANES survey. A complex, multi-stage design was employed to represent the American population on the basis of age, sex and race/ethnicity. In 2007-2008, African-Americans, Hispanics, persons with low income, and $\geq 60$ y old were oversampled to obtain reliable estimates for these population subgroups. ${ }^{2}$ Our study included a final sample of 6-79 year olds $(n=7996)$, from a total sample of 10149 participants, to match the age range in the CHMS. Similar to the CHMS, an interviewer-administered survey, which included information on sociodemographic characteristics and dietary supplement use, was completed in participant's homes followed by a physical examination and blood collection in a Mobile Examination Center one to two weeks later. All respondents provided informed consent, and the NHANES protocol was reviewed and approved by the NCHS Research Ethics Review Board.

\subsection{Data preparation}

\subsubsection{Primary outcome variable}

RBC folate allows for an estimate of tissue folate stores. ${ }^{3}$ In the CHMS Immunoassay, samples were thawed, diluted (1/26) with a $5 \mathrm{~g} / \mathrm{L}$ ascorbic acid solution, allowed to incubate for 180 minutes at room temperature, and then analyzed for folate using the Immulite 2000 immunoassay. ${ }^{4}$ RBC folate concentration was calculated from the measured whole-blood folate concentration adjusting for RBC volume, without correction for serum folate concentration. Accuracy and reproducibility of these procedures was assessed using the 
manufacturer's serum controls (Con6: Tri-level multi-constituent control) and whole blood controls (Bio-Rad Lyphochek Tri-level; Bio-Rad Laboratories, Hercules, CA). Serum controls had an inter-assay coefficient of variation of $6-8.5 \%$ and $8 \%$ for whole blood. All analyzed controls (serum, whole blood) were within $10 \%$ of target values. NHANES microbiologic assay (data used in Study 5, Section 4.5): Thawed samples were prepared by diluting serum 1/100 and whole-blood lysate 1/140 with $5 \mathrm{~g} / \mathrm{L}$ sodium ascorbate. ${ }^{1,5}$ These dilution factors are appropriate for a population consuming folic acid fortified foods. Diluted samples were added to a 96 -well plate together with assay medium containing chloramphenicol-resistant Lactobacillus Rhamnosus (ATCC number 27773; National Collection of Industrial Bacteria [NCIB] 10463) and all of the nutrients necessary for the growth of L. Rhamnosus, with the exception of folate, then incubated for $45 \mathrm{~h}$ at $37^{\circ} \mathrm{C}$. The total folate concentration was assessed by measuring the turbidity of the inoculated medium at $590 \mathrm{~nm}$ in a PowerWave microplate reader (Bio-Tek Instrument). The calibration curve for this assay was generated with 5-methyltetrahydrofolate (5-methylTHF) from Merck Cie (Schaffhausen, Switzerland). ${ }^{1,5}$ Long-term CVs from three whole blood lysate quality control pools analyzed in every run were $8.0 \%-14 \%$ at $402-1570 \mathrm{nmol} / \mathrm{L}$. The National Institute for Biological Standards and Control (NIBSC) World Health Organization (WHO) reference material (lyophilized) for whole blood folate (95/528, established 1996) was analyzed several times a year to verify comparability of results over time. The mean (standard deviation) obtained was 11.5 (1.15) ng/ampoule, 12\% lower than the assigned content of $13 \mathrm{ng} / \mathrm{ampoule}$. This is an expected result as it has been previously demonstrated that calibration with 5-methylTHF versus folic acid produces lower results and the assigned content was obtained by calibration with folic acid. ${ }^{1}$ 


\subsubsection{Cut-offs for RBC folate concentration}

Deficiency: Folate deficiency was defined as RBC folate $<305 \mathrm{nmol} / \mathrm{L}(<135 \mathrm{ng} / \mathrm{mL})$. This cut-off is used by the Institute of Medicine based on several studies reporting the appearance of hypersegmented neutrophils - a characteristic of megaloblastic anemia - at RBC folate concentrations below this level. ${ }^{6}$

Optimal concentrations for reducing NTD risk in the offspring of women of childbearing age: We defined the folate concentration considered optimal for NTD risk reduction among women of childbearing age as RBC folate $\geq 906 \mathrm{nmol} / \mathrm{L}(\geq 400 \mathrm{ng} / \mathrm{mL})$, which was derived from a large Irish case-control study of antenatal women from 1986 to 1990 that demonstrated a continuous, inverse dose-response relationship between RBC folate concentration (up to $1292 \mathrm{nmol} / \mathrm{L}$ ) and NTD risk. ${ }^{7}$ The cut-off of $906 \mathrm{nmol} / \mathrm{L}$ represents the lower boundary of the uppermost RBC folate concentration group in this study population, as well as the category with the lowest risk of a NTD birth. This cut-off has been widely accepted by experts in the field..$^{8,9}$

High RBC folate status: The concentration of RBC folate at which adverse effects occur in association with high intakes of folic acid is unknown, and no universally accepted cut-off is available. Leading researchers in the area have used distribution cut-offs from the NHANES data in the United States to establish a high serum folate cut-off, but this has not been done for RBC folate. ${ }^{10-12}$ When we were planning our first manuscript, recent national Canadian data were unavailable, thus a similar but more conservative approach was taken to establish a cut-off for high RBC folate concentration from the most recent post-fortification national American data. In our first study, a RBC folate concentration $>1360 \mathrm{nmol} / \mathrm{L}(>600 \mathrm{ng} / \mathrm{mL})$, which reflects the 97th percentile from the NHANES (1999-2004) measured by Bio-Rad 
assay, was chosen as a cut-off for high RBC folate. ${ }^{10}$ As our interpretation of these data evolved, it became clear that basing this cut-off on an RBC folate measured by Bio-Rad could overestimate the prevalence of high folate status in the population. Further, a universally accepted definition of high folate concentrations, using data adjusted to microbiologic assay, would be useful to scientists studying in this area. Thus, in the fourth study, high RBC folate cut-offs of $1450 \mathrm{nmol} / \mathrm{L}, 1800 \mathrm{nmol} / \mathrm{L}$ and $2150 \mathrm{nmol} / \mathrm{L}$ were proposed to capture a range of postulated high folate values from the literature (see Section 4.4). The aim of this research is to create dialogue by examining three hypothetical cut-offs for high RBC folate concentrations.

\subsubsection{Derived predictor variables}

Risk factors for low folate status included in the analyses were outlined in an analytical framework (Figure 1).

Sociodemographic factors:

The CHMS sample age groups were used for most analyses. Dietary reference intake age groups were used in the second study to examine supplement intake (Appendix B). ${ }^{6} \mathrm{~A}$ variable for women of childbearing age (aged 15-45 years) was created. We assessed a potential socioeconomic status gradient for RBC folate levels by examining household income (quartiles). These were created using the low income measure, which adjusts household income for family size and composition using an equivalence scale. ${ }^{13}$ Total household income was self-reported as a specific amount or within a range (e.g. between $\$ 20,000$ and $\$ 30,000$ annually). Where income was reported as a range, the midpoint of the interval was used to calculate per person household equivalents. Highest level of household education was categorized as less than secondary, secondary graduation, some post- 
secondary and post-secondary graduation. Participants were also categorized dichotomously as born or not born in Canada. Race/ethnicity was defined as non-Hispanic white or all other responses for race/ethnicity.

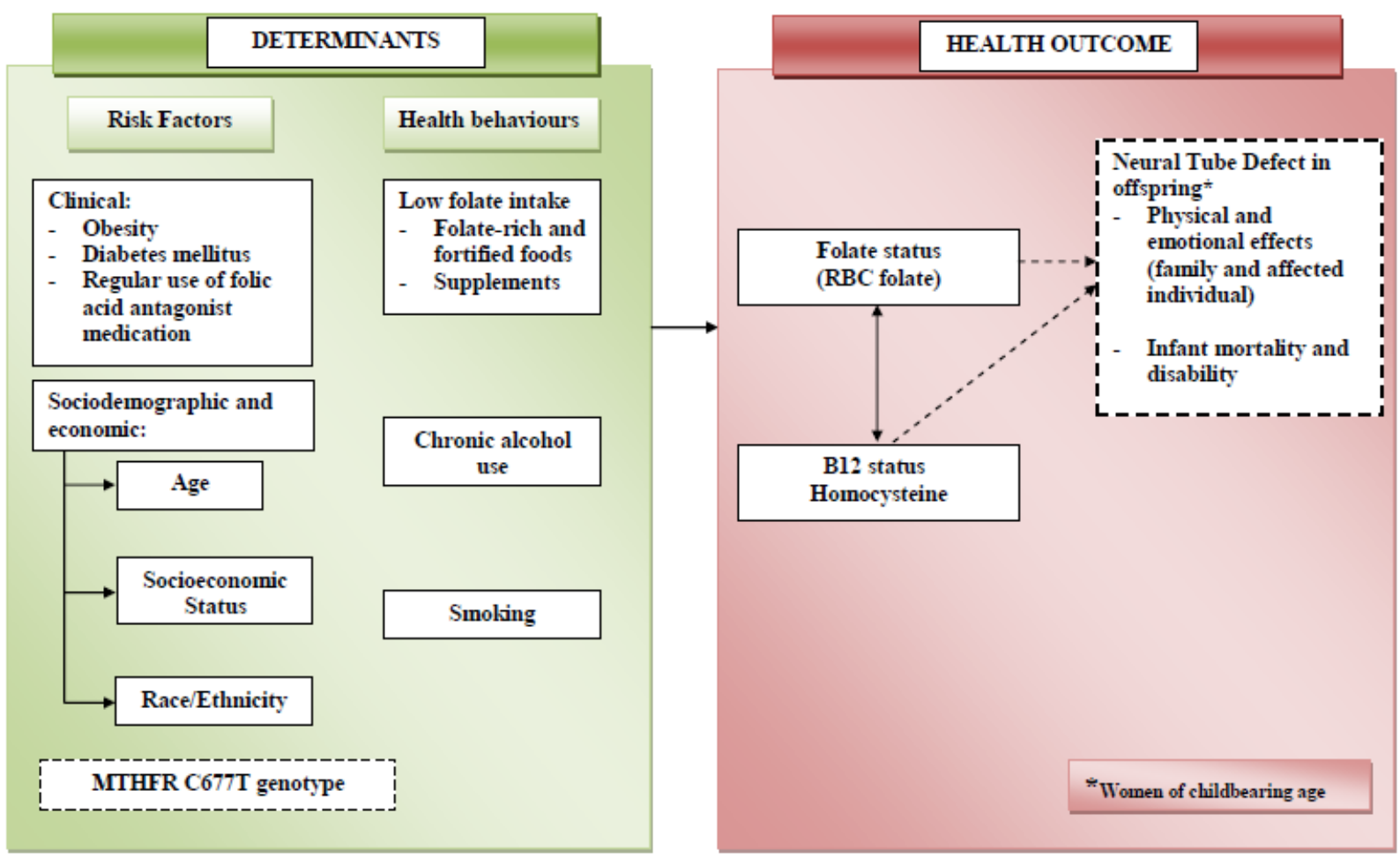

Item not in CHMS dataset

Figure 1: Analytical framework of risk factors for deficient folate status

\section{Behavioural factors:}

Supplement intake: Interviewers collected drug identification and natural health product numbers from containers shared by participants at the household visit. Researchers verified this information at the clinic visit and changes in drug and supplement usage were also collected at this time. ${ }^{14}$ Supplemental folic acid use - whether consumed alone or as a multivitamin - in the 30 days prior to the clinic visit was determined by matching drug identification and natural health product numbers to product information extracted from the 
Health Canada Drug Product and Licensed Natural Health Product databases. ${ }^{14-16}$ This approach was also used to quantify vitamin $\mathrm{B}_{12}$ supplement use - again, whether consumed alone or as a multivitamin.

Intake of folate-rich foods: A brief, non-quantitative food frequency questionnaire was used to examine usual frequency of consumption from the grains and fruit and vegetables categories to assess dietary habits for food sources of folate. ${ }^{14}$ This tool was tested for content and construct validity prior to implementation. Combined, these food groups have been shown to represent $62-78 \%$ of dietary folate intake in the Canadian diet. ${ }^{14,17,18}$ The derived variable for fruit and vegetables included usual intake of fruit, tomato, lettuce, dark greens and other vegetables - not including juices or potatoes. Usual intake of cereal, white bread, brown bread and pasta were combined to formulate the derived variable for grains. Smoking: Self-reported smoking status and history were used to categorize participants as a current, former or never smoker.

Alcohol use: Animal studies have shown that ethanol intake may impair folate absorption and metabolism and cause an increase in renal folate excretion. ${ }^{6}$ Low intake of folate-rich foods is also a likely contributor to low folate status in these populations. Frequency of alcohol use was categorized as never or less than once per month, one to three times per month, or more than 3 times per month.

Physical activity: A physical activity index of active, moderately active or inactive was derived based on average daily energy expenditure values during self-reported leisure time activities in the three months prior to the household visit. ${ }^{19}$

Clinical factors:

Folic acid antagonist medication: Drug identification numbers were matched to data extracts 
from the Drug Product Database to identify folic acid antagonist medication consumption in the 30 days prior to the clinic visit. ${ }^{14,20}$ Drugs known to interfere with folate metabolism were included in the variable: anticonvulsants (carbamazepine, phenytoin, valproic acid, lamotrigine, primidone, Phenobarbital); antifolates (methotrexate, pemetrexed, trimethoprim, pyrimethamine, proguanil, triamterene, sulfasalazine); and levodopa. ${ }^{20}$

Body mass index: Measured height and weight were used to calculate body mass index $\left(\mathrm{BMI}, \mathrm{kg} / \mathrm{m}^{2}\right)$. Participants were classified as neither overweight nor obese or overweight/obese. The BMI status of adults, excluding pregnant women, was classified using Health Canada's guidelines (BMI of 25 to 29.9 indicates overweight, BMI of $\geq 30$ indicates obesity). ${ }^{21}$ For our examination of folic acid supplement intake (Manuscript 2) and women of childbearing age (Manuscript 3), participants aged 6 to 17 years were classified as being normal weight, overweight or obese based on definitions proposed by the International Obesity Task Force. ${ }^{22}$ For our examination of high folate concentration cut-offs (Manuscript 4), participants aged 6-17 years were classified into two categories, neither overweight nor obese or overweight/obese, based on the WHO cut-offs. ${ }^{23}$ BMI was also examined as a separate predictor.

Derived variable for clinical risk factor: A derived variable was created to examine combinations of clinical risk factors - self-reported diabetes mellitus, use of folic acid antagonist medication and overweight/obese - for low folate status. These were categorized as no risk factor, or one or more risk factor.

Vitamin $B_{12}$ concentrations: Serum vitamin $B_{12}$ was assessed using the Immulite 2000 immunoassay (Siemens Canada Ltd., Mississauga), a solid phase, competitive chemiluminescent enzyme immunoassay involving an automated alkaline denaturation 
procedure. The cut-off for marginal vitamin $\mathrm{B}_{12}$ status was determined to be $\leq 221 \mathrm{pmol} / \mathrm{L}{ }^{24}$,

${ }^{25}$ Serum controls had an interassay coefficient of variation of $9.6 \%$ (manufacturer's \%CV) and all analyzed controls were within $10 \%$ of target values.

Hcy concentrations: The Vitros 5,1FS (Ortho Clinical Diagnostics, Markham) was used to measure plasma homocysteine concentration. The quantitative measurement of homocysteine was performed using the VITROS Chemistry Products Homocysteine Reagent - consisting of two dual-chambered reagent packs containing three ready-to-use liquid reagents - in conjunction with the VITROS Chemistry Products Calibrator Kit 27 on VITROS 5,1 FS Chemistry Systems. Normal homocysteine status was determined as $\leq 8 \mu \mathrm{mol} / \mathrm{L}$ for participants 10 years of age and younger, and $\leq 15 \mu \mathrm{mol} / \mathrm{L}$ for participants over 10 years of age. $^{26-28}$ Serum controls (BioRad Homocysteine QC, levels 1 \& 2) had an interassay coefficient within $5 \%$ of targeted values.

\subsection{Analytic strategies}

All data were analysed using SAS 9.1.3 (SAS Institute Inc., Cary, NC) and SUDAAN v. 10.0 (RTI International, Research Triangle Park, NC). DDF=11 was used in the SUDAAN procedure statements for all analyses with the exception of the fifth study, which used $\mathrm{DDF}=26$ due to the increased degrees of freedom granted by combining the CHMS and NHANES datasets. Where 11 degrees of freedom were available for variance estimation, Satterthwaite-adjusted statistics were used to test the significance of each regression model's coefficients. Significance was defined as a p-value of $<0.05$. All estimates were based on weighted data to represent the Canadian population. In the fifth study, weighted NHANES data were also used. Variance estimation ( $95 \%$ confidence intervals) and significance testing 
were based on the bootstrap technique to account for the complex sampling design.

Participants with a missing value for RBC folate were removed from the analysis. Below is a brief overview of the analytical methods used to explore the proposed hypotheses. A description specific to each study can be found in Chapter 4.

\subsubsection{Primary and secondary hypotheses \#1}

Less than $5 \%$ of Canadians demonstrate folate deficiency $(R B C$ folate $<305 \mathrm{nmol} / \mathrm{L})$ and less than 5\% demonstrate high folate (RBC folate $>1360 \mathrm{nmol} / \mathrm{L})$, but proportions vary by age, sex, and socioeconomic status. Adolescents (vs. adults), females (vs. males) and Canadians of low socioeconomic status (vs. higher socioeconomic status) are more likely to be folate deficient.

These hypotheses are addressed in the first study (see Section 4.1). We used Proc Crosstabs to generate descriptive statistics (frequencies, medians, percentiles) to characterize the general population and for RBC folate concentrations. The general population was examined for $\mathrm{RBC}$ folate deficiency ( $<305 \mathrm{nmol} / \mathrm{L})$ and high concentrations $(>1360 \mathrm{nmol} / \mathrm{L})$ by age, sex and socioeconomic status. Cumulative percentile distribution curves were generated using Proc Descript for RBC folate concentrations by age and sex group. We examined differences in median RBC folate between sex and age groups by education level and income quartile using t-tests. A Bonferroni adjustment was applied in cases of multiple comparisons.

\subsubsection{Primary and secondary hypotheses \#2}

At least $40 \%$ of Canadian women of childbearing age demonstrate inadequate folate status for maximal protection against NTDs (RBC folate $<906 \mathrm{nmol} / \mathrm{L})$. Canadian women of childbearing age of low socioeconomic status are more likely to have inadequate folate 
status for maximal protection against NTDs (RBC folate $<906 \mathrm{nmol} / \mathrm{L})$ than those of higher socioeconomic status.

These hypotheses are relevant to the first and third study (see Sections 4.1 and 4.3). We used Proc Crosstabs to examine women of childbearing age for concentrations below those considered optimal for minimizing the risk of NTDs ( $\geq 906 \mathrm{nmol} / \mathrm{L}){ }^{7}$ We examined correlates of folate concentrations $\geq 906 \mathrm{nmol} / \mathrm{L}$ using univariate and separate multivariate logistic regression models, with Proc RLogist, controlling for age and income. For individual analyses, we removed missing values for predictor variables. T-tests were used to study differences between folic acid supplement users and non-users for each correlate.

\subsubsection{Primary and secondary hypotheses \#3}

At least 50\% of Canadian women of childbearing age do not consume folic acid supplements.

- Canadians of low socioeconomic status in general, and Canadian women of childbearing age of low socioeconomic status specifically, will be less likely to consume folic acid supplements than those of higher socioeconomic status.

- Canadian women of childbearing age who do not consume folic acid supplements are less likely to have RBC folate concentrations that are maximally protective against NTD (RBC folate <906 nmol/L).

- Canadian women of childbearing age with clinical risk factors for NTD (ie. obesity, diabetes mellitus, regular use of folic acid antagonist medications) who are noncompliant with high dose folic acid supplement recommendations $(5 \mathrm{mg} / \mathrm{d})$ will be more likely to have inadequate folate status for maximal protection against NTDs (RBC folate $<906 \mathrm{nmol} / \mathrm{L})$ than those who are compliant. 
These hypotheses are addressed in the third study (see Section 4.3). We used Proc Crosstabs to estimate the prevalence of folic acid supplement use among women of childbearing age, as well as the strength of folic acid supplements. T-tests were used to study differences between relevant sociodemographic, behavioural and clinical factors. To examine RBC folate concentration $\geq 906 \mathrm{nmol} / \mathrm{L}$ and other potential correlates of folic acid-containing supplement use we used Proc RLogist with separate multivariate logistic regression models controlling for age and household income. For individual analyses, we removed missing values for predictor variables. The sample sizes for the final secondary hypothesis, related to those consuming $\geq 5 \mathrm{mg} / \mathrm{d}$, were too small to examine.

\subsubsection{Primary and secondary hypotheses \#4}

Canadians in general are less likely to be folate deficient $(R B C$ folate $<305 \mathrm{nmol} / \mathrm{L})$ than Americans. Canadian women of childbearing age are less likely to have inadequate folate for maximal protection against NTDs (RBC folate $<906 \mathrm{nmol} / \mathrm{L})$ than American women of childbearing age.

These hypotheses are examined in the fifth study (see Section 4.5). We stacked the CHMS and NHANES datasets based on strata and PSU and renamed the NHANES variables to correspond with CHMS variables prior to stacking. We applied the crossover equation (See Appendix F) to the CHMS RBC folate data to derive a measure adjusted to microbiologic assay for comparison to the NHANES RBC folate data. Strata were recoded for CHMS as 1 to 4 to avoid cross-over with the NHANES strata numbering. We used Proc Crosstabs to examine relevant factors by country and Proc RLogist to examine country differences in RBC folate. The study used t-tests to examine differences between countries for folate concentrations and supplement intake by age and race/ethnicity. We examined 
concentrations $\geq 906 \mathrm{nmol} / \mathrm{L}$ for women of childbearing age using multivariate logistic regression, adjusted for age, household income, folic acid supplement use and race/ethnicity. Statistics Canada suggested using Taylor linearization for variance estimation after finding that regression analyses conducted using bootstrap weights or Taylor linearization yielded similar results. A procedure statement including design=WR DDF=26 as well as a nest statement containing strata and PSU was recommended. We applied weights to CHMS data using the variable wgt_full and to the NHANES data using the variable wtmec 2 yr from the 2007-2008 NHANES public file.

\subsection{Methodological considerations}

\subsubsection{Limited degrees of freedom for regression analyses:}

The CHMS produced a nationally representative sample of Canadians using 15 collection

sites from five regional strata. ${ }^{29}$ A sample of individuals between age 6 and 79 years were selected from each site. Cost and logistical considerations largely dictated the small number of collection sites. The sampling protocol yielded unbiased national prevalence estimates. In calculating degrees of freedom, the Atlantic region PSUs were collapsed into the four Quebec region PSUs, yielding four regional strata (Quebec, Ontario, Prairies and British Columbia). The number of PSUs and strata limited the degrees of freedom to 11 for variance estimation: Degrees of freedom (11) equals the number of PSUs (15) minus the number of strata (4). Considering the limited degrees of freedom, Statistics Canada had the following recommendations in relation to our analyses:

○ Produce only national estimates since regional estimates will have even fewer than 11 degrees of freedom because fewer PSUs would be involved in variance estimation. 
Avoid fitting models with a large number of coefficients.

- Use analytical methods that are less impacted by the limited degrees of freedom - for example, Satterthwaite-adjusted statistics or Bonferroni adjustment.

\subsubsection{Missing values}

We removed participants with a missing value for RBC folate from the analyses. Those with missing folate were more likely to be younger in age and no association was found for sex, income or education. For income, greater than $6 \%$ of values were missing among those with an RBC folate value, which necessitated the creation of a missing parameter. For all other predictors, we removed missing values from each model separately. Each of these missing values was examined before and after removal and there was little to no impact on the final estimate.

\subsubsection{Pregnant women}

A total of 29 pregnant women provided a blood measure for RBC folate. We considered these women as part of the general population, thus they were not excluded from analyses, unless a derived variable did not apply to this population (e.g. BMI). The median RBC folate for this subgroup was $1679 \mathrm{nmol} / \mathrm{L}$ and $67 \%$ of pregnant women reported taking a folic acid supplement in the 30 days prior to the clinic visit. Removing pregnant women from the analyses had minimal impact on weighted estimates, thus this subgroup was included in all models throughout this thesis.

\subsubsection{Considerations regarding folic acid supplement}

Single source versus folic acid containing supplements: To examine folic acid supplements, we decided that folic acid containing supplements, whether from a single source or as part of a multivitamin, would be included in the analysis. Less than $1 \%$ of the population reported 
consuming a single source folic acid supplement; thus, the sample size was too small to analyse separately.

Reported supplement intake at clinic versus household: The blood draw for RBC folate concentrations occurred at the clinic visit, which took place between one day to six weeks following the household survey. Considering that participants were asked to report supplement intake in the 30 days prior to the visit, and the RBC folate concentrations reflect intake over the last 90-120 days, we decided to include reported folic acid supplement use at clinic, rather than household, to capture the reported supplement use closest to the blood draw. $^{30}$

Folate assay difference between Canada and the United States: The planned RBC folate comparison between Canada and the United States was challenged by methodological differences in RBC folate measurement methods, Immulite 2000 immunoassay (CHMS) and microbiologic assay (NHANES). This was overcome through a methods comparison study (Appendix F). 


\subsection{References}

1. Laboratory procedure manual: Folate. Centres for Disease Control and Prevention. Washington (DC). Available: http://www.cdc.gov/nchs/data/nhanes/nhanes_07_08/FOLATE_E_met.pdf. (Accessed December 9, 2012).

2. About the National Health and Nutrition Examination Survey. Centres for Disease Control and Prevention. Washington (DC). Available: http://www.cdc.gov/nchs/nhanes/about_nhanes.htm. (Accessed May 13, 2013).

3. McNulty B, Pentieva K, Marshall B, et al. Women's compliance with current folic acid recommendations and achievement of optimal vitamin status for preventing neural tube defects. Hum Reprod 2011;26(6):1530-6.

4. Immulite 2000 folic acid insert. Mississauga (ON): Siemans Canada, Ltd.; 2009.

5. Pfeiffer CM, Zhang M, Lacher DA, et al. Comparison of serum and red blood cell folate microbiologic assays for national population surveys. J Nutr 2011;141(7):1402-9.

6. Institute of Medicine. DRI dietary reference intakes for thiamin, riboflavin, niacin, vitamin B6, folate, vitamin B12, pantothenic acid, biotin, and choline. Washington, D.C.: National Academy Press; 1998.

7. Daly LE, Kirke PN, Molloy A, et al. Folate levels and neural tube defects. implications for prevention. JAMA 1995 Dec 6;274(21):1698-702.

8. Tam C, McKenna K, Goh YI, et al. Periconceptional folic acid supplementation: A new indication for therapeutic drug monitoring. Ther Drug Monit 2009; 31(3):319-26.

9. Crider KS, Bailey LB, Berry RJ. Folic acid food fortification-its history, effect, concerns, and future directions. Nutrients 2011;3(3):370-84.

10. Pfeiffer CM, Johnson CL, Jain RB, et al. Trends in blood folate and vitamin B12 concentrations in the United States, 1988 2004. Am J Clin Nutr 2007;86(3):718-27.

11. Selhub J, Morris MS, Jacques PF, et al. Folate-vitamin B-12 interaction in relation to cognitive impairment, anemia, and biochemical indicators of vitamin B12 deficiency. Am J Clin Nutr 2009;89(2):702S-6S.

12. Dietrich M, Brown CJ, Block G. The effect of folate fortification of cereal-grain products on blood folate status, dietary folate intake, and dietary folate sources among adult nonsupplement users in the United States. J Am Coll Nutr 2005;24(4):266-74. 
13. Income trends in Canada: 1980-2003(13F0022XIE). Statistics Canada. Ottawa (ON). Available: http://www.statcan.gc.ca/pub/13f0022x/00003/notedef/5801170eng.htm\#famsize. (Accessed May 13, 2013).

14. Questionnaire(s) and reporting guide(s) - Canadian Health Measures Survey (CHMS). Statistics Canada. Ottawa (ON). Available: http://www.statcan.gc.ca/cgibin/imdb/p2SV.pl?Function=getInstrumentLink\&SurvItem_Id=9353\&Query_Id=10263 $\underline{\& \text { Query }=\text { instance } \& \text { lang }=\mathrm{e} \& \mathrm{db}=\mathrm{imdb} \& \mathrm{adm}=8 \& \mathrm{dis}=2 .}$. (Accessed May 13, 2013).

15. Drug Product Database. Health Canada. Ottawa (ON). Available: http://www.hcsc.gc.ca/dhp-mps/prodpharma/databasdon/index-eng.php. (Accessed May 13, 2013).

16. Licensed Natural Health Products Database. Health Canada. Ottawa (ON). Available: http://www.hc-sc.gc.ca.proxy.bib.uottawa.ca/dhp-mps/prodnatur/applications/licenprod/lnhpd-bdpsnh data extract-eng.php. (Accessed May 13, 2013).

17. Sherwood KL, Houghton LA, Tarasuk V, et al. One-third of pregnant and lactating women may not be meeting their folate requirements from diet alone based on mandated levels of folic acid fortification. J Nutr 2006;136(11):2820-6.

18. Shuaibi AM, House JD, Sevenhuysen GP. Folate status of young Canadian women after folic acid fortification of grain products. J Am Diet Assoc 2008;108(12):2090-4.

19. Canadian Health Measures Survey (CHMS) Cycle 1 Wave 1 Derived Variable (DV) Specifications. Statistics Canada. Ottawa (ON). Available: http://www.statcan.gc.ca/imdb-bmdi/document/5071 D3 T9 V2-eng.pdf. (Accessed May 13, 2013).

20. Stabler S. Clinical folate deficiency. In: Bailey LB, ed. Folate in health and disease. $2^{\text {nd }}$ ed. Boca Raton, FL: Taylor \& Francis Group, LLC; 2010.

21. Health Canada. Canadian guidelines for body weight classification. Ottawa, ON: Health Canada; 2003. Report nr Catalogue H49-179.

22. Cole TJ, Bellizzi MC, Flegal KM, et al. Establishing a standard definition for child overweight and obesity worldwide: International survey. BMJ 2000 6;320(7244):12403.

23. Dietitians of Canada, Canadian Paediatric Society, College of Family Physicians of Canada, Community Health Nurses of Canada, et al. Promoting optimal monitoring of child growth in Canada: Using the new WHO growth charts. Can J Diet Pract Res 2010;71(1):e1-3.

24. Immulite 2000 vitamin B12 package insert \#P1L2KVB-22. Mississauga (ON): Siemans Canada, Ltd.; 2006. 
25. Allen L. How common is vitamin B-12 deficiency? Am J Clin Nut 2009;89(Suppl):693S-696S.

26. Refsum H, Smith AD, Ueland PM, et al. Facts and recommendations about total homocysteine determinations: An expert opinion. Clinical Chemistry 2004;50(1):3-32.

27. Refsum H, Yajnik CS, Gadkari M, et al. Hyperhomocysteinemia and elevated methylmalonic acid indicate a high prevalence of cobalamin deficiency in Asian Indians. Am J Clin Nut 2001;74(2):233-41.

28. VITROS chemistry products homocysteine reagents - instructions for use. Publication number J23410_EN (version 1.0)L. Markham (ON): Ortho-Clinical Diagnostics Inc.; 2006.

29. Roberts G. Some recommendations for doing analysis with data from cycle 1 of CHMS draft. Statistics Canada; 2010.

30. Yetley EA, Johnson CL. Folate and vitamin B12 biomarkers in NHANES: History of their measurement and use. Am J Clin Nutr 2011;94(1):322S-31S. 


\section{CHAPTER 4: RESEARCH RESULTS}

\subsection{Folate status of the population in the Canadian Health Measures Survey}

Authors: Cynthia K. Colapinto ${ }^{1,2}$, Deborah L. O’Connor ${ }^{3,4}$, Mark S. Tremblay ${ }^{1,5}$

1. Healthy Active Living and Obesity Research Group, Children's Hospital of Eastern Ontario Research Institute

2. Institute of Population Health, University of Ottawa

3. Physiology and Experimental Medicine, The Hospital for Sick Children

4. Department of Nutritional Sciences, University of Toronto

5. Department of Pediatrics, University of Ottawa

This manuscript was written and published in accordance with the specifications for the Canadian Medical Association Journal. It was published as an original research article on February 8, 2011 (on-line ahead of print on December 13, 2010) and appears here in its online published format with permission from the publisher.

Suggested citation: Colapinto CK, O’Connor DL, Tremblay MS. Folate status of the population in the Canadian Health Measures Survey. CMAJ, 183(2):E100-E106. 


\title{
Folate status of the population in the Canadian Health Measures Survey
}

\author{
Cynthia K. Colapinto MSc, Deborah L. O'Connor PhD, Mark S. Tremblay PhD
}

\author{
Competing interests: None \\ declared. \\ This article has been peer \\ reviewed. \\ Correspondence to: \\ Dr. Mark Tremblay; \\ mtremblay@cheo.onca \\ CMAJ 2011. DOI:10.1503 \\ /cmaj.100568
}

\begin{abstract}
Background: Low folate concentrations are inversely associated with birth defects, including neural tube defects, congenital heart disease and oral clefts. Conversely, high folate concentrations may be associated with adverse outcomes, including increased risk of colorectal cancer among those with pre-existing neoplasms. The purpose of our study was to investigate the folate status of a nationally representative sample of Canadians, including a subset of women of childbearing age.

Methods: We examined red blood cell folate concentrations among members of the general population aged $6-79$ years $(n=5248)$ and separately among women of childbearing age (15-45 yr, $n=1162)$, as recorded by the Canadian Health Measures Survey and measured by immunologic assay. We assessed the data for significant differences by age, sex and socioeconomic status.

Results: Less than $1 \%$ of Canadians showed folate deficiency (red blood cell folate $<305 \mathrm{nmol} / \mathrm{L}$ ) and $40 \%$ showed high folate con-

centrations (> $1360 \mathrm{nmol} / \mathrm{L})$. Among women of childbearing age, $22 \%$ showed concentrations below those considered optimal for maximal neural tube defect-risk reduction $(<906 \mathrm{nmol} / \mathrm{L})$. Significant differences by age and socio-economic status, but not sex, were evident in median red blood cell folate concentrations, although concentrations in all groups exceeded recommended levels. No differences by age or income were found among women of childbearing age.

Interpretation: Folate deficiency is virtually nonexistent in the Canadian population. although high folate concentrations are evident. Additional research is needed to better understand the determinants of red blood cell folate among women of childbearing age who have concentrations below levels that are maximally protective against neural tube defects. Ongoing monitoring of the folate status of Canadians and the relationship between red blood cell folate and health outcomes is warranted.
\end{abstract}

$\mathrm{F}$ olic acid represents both a public health success and a controversial debate over associated health risks. Fortification with folic acid of Canadian white wheat flou $(150 \mu \mathrm{g} / 100 \mathrm{~g})$ and other selected grains in 1998 has been linked to a $46 \%$ reduction in the prevalence of neural tube defects. ${ }^{1}$ Declines in rates of neural tube defects have also been documented in the United States and Chile after fortification of grains with folic acid. ${ }^{23}$ To further reduce the risk of folate-dependent neural tube defects, women of childbearing age are encouraged to eat folate-rich foods and take a multivitamin supplement containing folic acid $(0.4 \mathrm{mg} / \mathrm{d}){ }^{4}$ Higher-dose supplements $(4-5 \mathrm{mg} / \mathrm{d})$ are recommended for women at increased risk of giving birth to a baby with a neural tube defect (e.g., those who regularly use folic acid antagonist medications or have a family history of neural tube defects). ${ }^{5}$ Although biochemical assessment of the folate status of select subgroups of Canadians has been done, it has not been studied on a nationally representative sample in over 30 years. $^{6-9}$ The recent Canadian Health Measures Survey provides data to fill this gap. The purpose of our study was to describe the current folate status of Canadians, including a suband to assess whether folate concentrations vary by age, sex and socio-economic status.

\section{Methods}

\section{Sources of data}

We used data from the 2007-2009 Canadian Health Measures Survey (Cycle 1), conducted by Statistics Canada in partnership with Health Canada and the Public Health Agency of Canada. The survey methodology is described briefly here and in greater detail elsewhere. ${ }^{7.10}$

Canadian Health Measures Survey sampling

The Canadian Health Measures Survey used a complex, multistage, cluster-sampling protocol group of Canadian women of childbearing age, 
to achieve a nationally representative crosssectional sample. The final sample is representative of approximately $96.3 \%$ of the Canadian population, and included 5604 Canadians aged 6 to 79 years balanced by sex in each of the following age groups: $6-11,12-19,20-39,40-59$ and $60-79$ years.

\section{Survey methods}

Data were collected between March 2007 and February 2009. A Statistics Canada interviewer administered a detailed in-home health questionnaire, which included items about sociodemographic characteristics. One day to six weeks later, blood samples were taken by a certified phlebotomist in a mobile examination centre to measure a variety of analytes, including red blood cell folate. ${ }^{10} \mathrm{Of}$ the 8772 dwellings selected, $69.6 \%$ agreed to participate; $88.3 \%$ participated in the household survey and, of those, $84.9 \%$ attended the mobile clinic. The overall response rate was $51.7 \%$. Implied consent was obtained by household and a comprehensive consent process was employed in the clinic.

Ethics approval for the Canadian Health Measures Survey was obtained from the Health Canada Research Ethics Board and for this secondary data analysis from the Children's Hospital of Eastern Ontario and University of Ottawa Research Ethics Boards.

\section{Blood sampling}

Blood was taken from 5373 participants in the Canadian Health Measures Survey, with 5248 providing a usable sample for red blood cell folate measurement. Participants who refused to participate in the blood draw or did not have a usable sample were excluded $(n=356)$.

\section{Red blood cell folate concentration}

Red blood cell folate allows for an estimate of tissue folate stores. Venipuncture samples were collected in EDTA-treated vacutainers, then immediately processed on-site. After hematocrit measurement, aliquots of whole blood were frozen, stored at $-20^{\circ} \mathrm{C}$ and shipped on dry ice weekly to the Health Canada Nutrition Laboratory. ${ }^{10}$ Samples were thawed, diluted (1-in-26) with $0.5 \%$ ascorbic acid solution, allowed to incubate $\left(180^{\circ} \mathrm{C}\right)$ at room temperature and then analyzed for folate using the Immulite 2000 immunoassay (Siemens Canada Ltd.). ${ }^{11}$ Red blood cell folate concentration was calculated from the measured whole-blood folate concentration adjusting for red blood cell volume, without correction for plasma folate concentration. Accuracy and reproducibility of these procedures were assessed using the manufacturers' serum controls
(Con6: Trilevel multiconstituent control) and whole blood controls (BioRad Lyphochek Trilevel, Biorad Laboratories). Serum controls had an interassay coefficient of variation of less than $5 \%$, and all analyzed controls (serum, whole blood) were within $10 \%$ of target values.

Deficient folate status was defined as a red blood cell folate concentration of less than $305 \mathrm{nmol} / \mathrm{L}(<135 \mathrm{ng} / \mathrm{mL})$, a cut-off defined by the Institute of Medicine based on several studies reporting the appearance of hypersegmented neutrophils, a characteristic of megaloblastic anemia, at red blood cell folate concentrations below this level. ${ }^{12}$

The cut-off for folate status considered optimal for minimizing the risk of neural tube defects among women of childbearing age was set at $906 \mathrm{nmol} / \mathrm{L}$ or greater $(\geq 400 \mathrm{ng} / \mathrm{mL})$ and has been adopted by experts in the field. ${ }^{13.14}$

The concentration of red blood cell folate at which adverse effects occur in association with high intakes of folic acid is unknown, and no universally accepted cut-off is available. Leading researchers in the area have used distribution cut-offs from the National Health and Nutrition Examination Survey data in the United States to establish a high serum folate cut-off, but this has not been done for red blood cell folate. ${ }^{15-17}$ Given that recent national Canadian data are unavailable, a similar but more conservative approach was taken to establish a cut-off for high red blood cell folate concentration from the most recent postfortification national American data. Therefore, a red blood cell folate concentration of greater than $1360 \mathrm{nmol} / \mathrm{L}(>600 \mathrm{ng} / \mathrm{mL})$, which reflects the 97 th percentile from the National Health and Nutrition Examination Survey (1999-2004), was chosen as a cut-off for high red blood cell folate. ${ }^{15}$

\section{Selected socio-demographic factors}

The age groups of the Canadian Health Measures Survey sample were used for analyses, and a variable for women of childbearing age (15-45 years) was created. Socio-economic status was examined by per-person household income equivalents (which grouped respondents into quartiles after adjusting for family size and composition) and by highest level of household education (less than secondary, secondary graduation, some postsecondary, postsecondary graduation). ${ }^{18}$

\section{Statistical analysis}

Descriptive statistics (frequencies, medians, percentiles) were used to describe the population and estimate red blood cell folate concentrations by age, sex and socio-economic status. Red blood cell folate in the general population was 
assessed for deficiency and high concentrations. whereas women of childbearing age were examined for concentrations below those considered optimal for minimizing the risk of neural tube defects. ${ }^{12.13}$ Differences between sex and age groups by education level and income quartile were examined using $t$ tests. All estimates were based on weighted data to represent the Canadian population. Variance estimation ( $95 \%$ confidence intervals) and significance testing ( $t$ test) were based on the bootstrap technique to account for the complex sampling design. ${ }^{19} \mathrm{Sig}$ nificance was defined as a $p$ value of $<0.05$ and a Bonferroni adjustment was applied in cases of multiple comparisons.

\section{Results}

A demographic description of the population by age, sex, income and education can be found in
Table 1. Overall, almost $100 \%$ of Canadians met or exceeded the cut-off level in the general population for deficiency of red blood cell folate concentration $(<305 \mathrm{nmol} / \mathrm{L})$. High red blood cell folate concentrations were found in $40 \%$ $(>1360 \mathrm{nmol} / \mathrm{L})$ of the general population. Among women of childbearing age, $22 \%$ were below the cut-off level for concentration of red blood cell folate considered optimal for minimizing the risk of neural tube defects $(<906 \mathrm{nmol} / \mathrm{L})$.

Median red blood cell folate concentrations were highest among participants aged 60 to 79 years $(1409 \mathrm{nmol} / \mathrm{L})$ and lowest among participants aged 12 to 19 years $(1120 \mathrm{nmol} / \mathrm{L})$ (Table 2). No significant difference in median red blood cell folate concentration between sexes was found. Elevated red blood cell folate concentrations across each percentile were evident, with the 5th percentile consistently above the cut-off level for fo-

Table 1: Demographic characteristics of participants*

\begin{tabular}{|c|c|c|c|c|c|c|c|c|}
\hline \multirow[b]{2}{*}{ Characteristic } & \multicolumn{4}{|c|}{ General population } & \multicolumn{4}{|c|}{ Women of childbearing age ( $15-45 \mathrm{yr})$} \\
\hline & $\begin{array}{l}\text { Sample } \\
\text { size }\end{array}$ & $\begin{array}{l}\text { Weighted } \\
\text { sample size }\end{array}$ & $\%$ & $95 \% \mathrm{Cl}$ & $\begin{array}{c}\text { Sample } \\
\text { size }\end{array}$ & $\begin{array}{l}\text { Weighted } \\
\text { sample size }\end{array}$ & $\%$ & $95 \% \mathrm{Cl}$ \\
\hline \multicolumn{9}{|l|}{ Sex } \\
\hline Female & 2705 & 13910435 & 49.8 & $49.5-50.0$ & 1162 & 6676456 & 100.0 & - \\
\hline Male & 2543 & 14025760 & 50.2 & $50.1-50.5$ & - & - & - & - \\
\hline \multicolumn{9}{|c|}{ Age at time of clinic, $y r$} \\
\hline $6-11$ & 911 & 1830773 & 6.6 & $6.2-6.9$ & - & - & - & - \\
\hline $12-19$ & 945 & 3109972 & 11.1 & $10.8-11.5$ & 290 & 1058456 & 15.9 & $17.5-14.3$ \\
\hline $20-39$ & 1150 & 8748999 & 31.3 & $30.9-31.7$ & 643 & 4300645 & 64.4 & $67.3-61.4$ \\
\hline $40-59$ & 1202 & 9545984 & 34.2 & $33.7-34.6$ & 229 & 1317355 & 19.7 & $22.8-17.0$ \\
\hline 60-79 & 1040 & 4700466 & 16.8 & $16.4-17.2$ & - & - & - & - \\
\hline
\end{tabular}

Highest level of household

education

\begin{tabular}{lrrrrrrrrr} 
Less than secondary & 327 & 1537019 & 5.5 & $4.1-7.4$ & 49 & 234820 & $<7.6 \dagger$ & $1.6-7.6$ \\
\hline Secondary graduation & 550 & 3576116 & 15.8 & $12.6-19.5$ & 105 & 634890 & 9.5 & $6.1-14.6 \ddagger$ \\
\hline Some postsecondary & 334 & 1805058 & 6.5 & $4.7-8.5$ & 78 & 503874 & 7.6 & $4.8-11.6$ \\
\hline Postsecondary graduation & 3900 & 20407347 & 73.0 & $66.3-78.9$ & 906 & 5151621 & 77.2 & $67.4-84.7$ \\
\hline Data unavailable & 137 & 1010655 & 3.6 & $2.7-4.8$ & 24 & 151251 & 2.3 & $1.5-3.5 \ddagger$
\end{tabular}

Income quartile (lowest to

highest)

\begin{tabular}{lrrrrrrrr} 
Q1 $(<\$ 25000)$ & 1368 & 6434838 & 23.0 & $20.6-26.4$ & 322 & 1863287 & 27.9 & $21.2-35.8$ \\
\hline Q2 $(\$ 25000$ to $\$ 39999)$ & 1242 & 6523556 & 23.4 & $20.6-26.4$ & 251 & 1437931 & 21.5 & $17.3-26.4$ \\
\hline Q3 $(\$ 40000$ to \$59 999) & 1196 & 6543379 & 23.4 & $20.0-27.3$ & 272 & 1548858 & 23.2 & $18.9-28.2$ \\
\hline Q4 $(\geq \$ 60000)$ & 1110 & 6546371 & 23.4 & $19.8-27.6$ & 215 & 1230297 & 18.4 & $15.4-21.9$ \\
\hline Data unavailable & 332 & 1888050 & 6.8 & $5.8-7.8$ & 102 & 596082 & 8.9 & $6.5-12.2$ \\
\hline
\end{tabular}

Note: $\mathrm{Cl}=$ confidence interval

*Comprises participants with a measured value of red blood cell folate concentration ( $n=5248$, data unavailable $n=356$ ).

†Estimate was not provided because of extreme sampling variability or small sample size. If the coefficient of variation of the estimate was greater than $33 \%$, the estimate is indicated as being less than the upper limit of $95 \% \mathrm{Cl}$.

¥Data should be interpreted with caution because of high sampling variability (coefficient of variation $\geq 16.6$ and $<33.3$ ). 
late deficiency. Cumulative percent distributions for females and males by age are shown separately in Figure 1.

Significant differences in median red blood cell folate concentrations by income and education were few and inconsistent across age and sex groups (Appendix 1, available at www.cmaj.ca /cgi/content/full/cmaj.100568/DC1). No consistent differences in median red blood cell folate values by age and socio-economic status were evident among women of childbearing age.

\section{Interpretation}

Our study used the recently released Canadian Health Measures Survey data set to examine the folate status of the Canadian population. Folate deficiency was extremely low in the general population, though high concentrations of red blood cell folate were common. More than $20 \%$ of Canadian women of childbearing age had a red blood cell folate concentration below that considered optimal for maximal reduction of risk of neural tube defects. ${ }^{13}$ Differences by age and socio-economic status were seen in the general population but not among women of childbearing age.

Given that comparable national-level Canadian data are unavailable, the Canadian Health Measures Survey was modelled after the National Health and Nutrition Examination Survey. The United States also fortifies grain products with folic acid, making the American survey an appropriate comparator. ${ }^{20}$ In the period of 2005 to 2006 (postfortification), the prevalence of folate deficiency in the American population was similar to that reported herein. Findings from postfortification studies of subgroups of Canadians show comparable results related to deficiency, and increases in circulating folate concentrations. For example, low rates of postfortification deficiency $(<1 \%)$ were found in a retrospective, population-based study involving Ontarian women of childbearing age, with the prefortification geometric mean for red blood cell folate increasing postfortification $(527$ to $741 \mathrm{nmol} / \mathrm{L}){ }^{8}$ In a sample of Newfoundlanders aged 65 years or older, deficiency was less than $1.6 \%$ with a pre- to postfortification increase in red blood cells of 625 to $818 \mathrm{nmol} / \mathrm{L} .{ }^{9}$ In a 2008 Ontario review of laboratory databases, $40 \%$ of women of childbearing age were not achieving a red blood cell folate concentration of $906 \mathrm{nmol} / \mathrm{L}$ or greater. ${ }^{21}$ Further, a recent randomized controlled trial in Toronto involving pregnant women, most of whom were consuming prenatal supplements containing folic acid $(1 \mathrm{mg} / \mathrm{d})$, showed a baseline geometric mean red blood cell folate in three groups that ranged from 2453 to $3635 \mathrm{nmol} / \mathrm{L}^{22}$

Some medical practitioners argue that many women of childbearing age need high-dose folic acid supplements and that doubling the level of folic acid fortification in the food supply should be considered. ${ }^{23.24}$ This argument has sparked considerable debate because folic acid fortification targets women of childbearing age by exposing the entire population to higher levels of folic acid. Given the absence of folate defi-

Table 2: Selected population percentile values for red blood cell folate concentrations ( $\mathrm{nmol} / \mathrm{L}$ ) by sex and age group

\begin{tabular}{|c|c|c|c|c|c|}
\hline \multirow[b]{2}{*}{ Sex } & \multirow[b]{2}{*}{ Age group, yr } & \multicolumn{4}{|c|}{ Percentile $(95 \% \mathrm{Cl})$} \\
\hline & & 5th & 50th & 75th & 97th \\
\hline All & All & 621 (544-699) & $1248(1164-1332)$ & 1619 (1501-1737) & $2580(2363-2797)$ \\
\hline Male & All & 618 (549-687) & $1233(1138-1327)$ & 1566 (1446-1687) & $2410(2196-2624)$ \\
\hline Female & All & $622(526-720)$ & $1261(1164-1357)$ & 1664 (1543-1784) & 2715 (2493-2937) \\
\hline All & $6-11$ & 667 (546-788) & $1212(1132-1292)$ & $1491(1432-1550)$ & 1984 (1859-2108) \\
\hline All & $12-19$ & 592 (547-637) & $1120(1037-1203)$ & 1377 (1266-1488) & 1977 (1843-2112) \\
\hline All & $20-39$ & 629 (498-759) & $1190(1112-1268)$ & $1480(1380-1581)$ & $2269(2066-2472)$ \\
\hline All & $40-59$ & $620(565-676)$ & $1292(1167-1416)$ & $1697(1546-1848)$ & 2676 (2473-2880) \\
\hline All & $60-79$ & $634(481-787)$ & $1409(1260-1558)$ & $1891(1745-2037)$ & 2887 (2678-3097) \\
\hline Female* & $15-45$ & $615(506-724)$ & $1193(1104-1282)$ & 1549 (1399-1700) & $2299(2021-2577)$ \\
\hline Female* & $15-19$ & 606 (515-697) & $1173(1054-1293)$ & $1470(1313-1627)$ & 1978 (1789-2169) \\
\hline Female* & 20-39 & $600(443-758)$ & $1176(1085-1266)$ & $1547(1365-1730)$ & $2318(2009-2627)$ \\
\hline Female* & $40-45$ & $620(498-741)$ & $1247(1056-1438)$ & $1652(1428-1877)$ & $2605(1987-3223)$ \\
\hline
\end{tabular}


ciency in the general population and the apparent shift toward Canadians having high serum folate concentrations, there appears to be little rationale for doubling levels of folic acid fortification in the Canadian food supply. Correction of folate deficiency and improved folate status, in part through fortification, has been associated with positive health outcomes such as the dramatic reduction in neural tube defects. ${ }^{1}$ However, given speculations about the possible

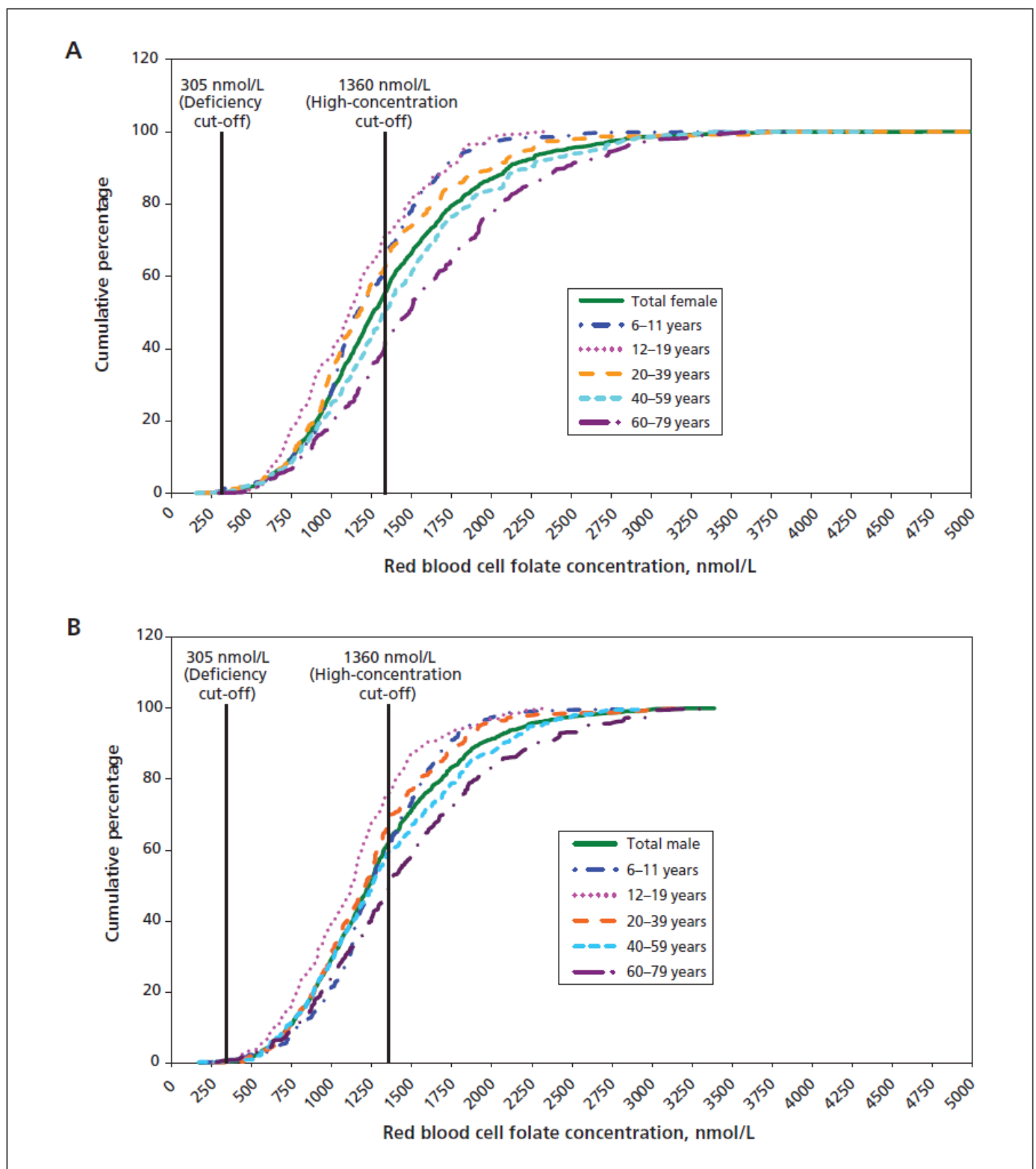

Figure 1: Cumulative percentile distributions of red blood cell folate concentrations by age group among female (A) and male (B) participants in the Canadian Health Measures Survey, 2007-2009. Folate concentrations for deficiency ( $305 \mathrm{nmol} / \mathrm{L})$ and high folate concentrations $(1360 \mathrm{nmol} / \mathrm{L})$ are indicated by vertical lines. 
adverse effects associated with high levels of folic acid, including increased risk of certain cancers among those with pre-existing neoplasms, further attempts to improve the folate status of Canadian women of childbearing age by increasing fortification levels should be approached cautiously. ${ }^{25-28}$

\section{Strengths and limitations}

The main strengths of our study include a large, nationally representative sample and directly measured biomarkers. This research is limited by its inability to establish causation because of the cross-sectional nature of the Canadian Health Measures Survey. Further, although red blood cell folate is defined by the Institute of Medicine as the primary biochemical index to establish dietary reference intakes, there are significant interlaboratory differences in values obtained for red blood cell folate. ${ }^{12,29}$ As such, study-to-study comparisons need to be performed with caution. Although the cut-offs used in our study are undoubtedly assay-dependent, it is standard practice to use the same cut-off values regardless of the method used to measure of red blood cell folate concentration. For example, the US Centres for Disease Control and Prevention reported that at least one competitive binding assay resulted in red blood cell folate concentrations that were about $30 \%$ lower than either microbiological or liquid chromatography-tandem mass spectrometry. ${ }^{30}$ Interestingly, it was with the microbiological assay that the cut-off considered optimal for maximal reduction of risk of neural tube defects was established. To minimize the aforementioned limitation, strict quality control procedures were employed in our investigation to ensure both accuracy and precision of the red blood cell folate measurements.

\section{Conclusion}

Folate deficiency is virtually nonexistent in the Canadian population, regardless of income or education, and high folate concentrations are evident. Many women of childbearing age are still not achieving the concentrations considered optimal for maximal reduction of risk of neural tube defects. Although food insecurity has been identified previously as a risk factor for low folate intake, ${ }^{31}$ the median red blood cell folate concentration among women of childbearing age did not differ by income or education in our study

Investigations into the determinants of suboptimal folate status are needed to develop intervention strategies to further mitigate neural tube defects. Given the high red blood cell folate con- centrations reported herein and speculation that exposure to high concentrations may have undesirable consequences for some, ongoing monitoring of the folate status of Canadians and study of the relation between red blood cell folate and health outcomes is warranted.

\section{References}

1. De Wals $P$, Tairou F, Van Allen MI, et al. Spina bifida before and after folic acid fortification in Canada. Birth Defects Res $A$ Clin Mol Teratol 2008;82:622-6.

2. Bentley TG, Weinstein MC, Willett WC, et al. A cost-effectiveness analysis of folic acid fortification policy in the United States. Public Health Nutr 2009;12:455-67.

3. Llanos A, Hertrampf E, Cortes F, et al. Cost-effectiveness of folic acid fortification program in Chile. Health Policy 2007;83: 295-303.

4. Prenatal nutrition. Ottawa (ON): Health Canada; 2009. Available: www.hc-sc.gc.ca/fn-an/nutrition/prenatal/index-eng.php (accessed 2010 Mar. 31)

5. High dose folic acid supplementation - questions and answer for health professionals. Ottawa (ON): Health Canada; 2010 Available: www hc-sc.gc.ca/fn-an/nutrition/prenatal/fol-qa-qI-eng php\#a2 (accessed 2010 Mar. 30).

6. Nutrition Canada national survey. 1970-1972. Toronto (ON): University of Toronto Data Library Service; 2005. Available: http: datalib.chass.utoronto.ca/codebooks $/ \mathrm{utm} / \mathrm{nutr} 70 \mathrm{htm}$ (accessed 2010 Nov. 24).

7. Tremblay M, Wolfson M, Gorber SC. Canadian Health Measures Survey: rationale, background and overview. Health Rep 2007;18(Suppl):7-20

8. Ray JG, Vermeulen MJ, Boss SC, et al. Increased red cell folate concentrations in women of reproductive age after Canadian folic acid food fortification. Epidemiology 2002;13:238-40.

9. Liu S, West R, Randell E, et al. A comprehensive evaluation of food fortification with folic acid for the primary prevention of neural tube defects. BMC Pregnancy Childbirth 2004;4:20.

10. Bryan S, St-Denis M, Wojtas D. Canadian Health Measures Survey: clinic operations and logistics. Health Rep 2007;18(Suppl) vey: c

11. Immulite 2000 folic acid insert. Mississauga (ON): Siemans Canada, Ltd.; 2009

12. Institute of Medicine DRI dietary reference intakes for thiamin riboflavin, niacin, vitamin $B 6$, folate, vitamin $B 12$, pantothenic acid, biotin, and choline. Washington (DC): National Academy Press; 1998.

13. Daly LE, Kirke PN, Molloy A, et al. Folate levels and neura tube defects. Implications for prevention. JAMA 1995;274 1698-702

14. Tam C, McKenna K, Goh YI, et al. Periconceptional folic acid supplementation: a new indication for therapeutic drug monitoring. Ther Drug Monit 2009;31:319-26.

15. Pfeiffer CM, Johnson CL, Jain RB, et al. Trends in blood folate and vitamin B-12 concentrations in the United States, 1998 to 2004. Am J Clin Nutr 2007;86:718-27.

16. Selhub J, Morris MS, Jacques PF, et al. Folate-vitamin B-12 interaction in relation to cognitive impairment, anemia, and biochemical indicators of vitamin B-12 deficiency. Am J Clin Nutr 2009;89:702S-6S

17. Dietrich M, Brown CJ, Block $\mathrm{G}$. The effect of folate fortification of cereal-grain products on blood folate status, dietary folate intake, and dietary folate sources among adult nonsupplement users in the United States. J Am Coll Nutr 2005;24:266-74.

18. Income trends in Canada: 1980-2003. Ottawa (ON): Statistics Canada; 2008. Cat no 13F0022XIE. Available: www.statcan gc.ca pub/13f0022x/00003/notedef/5801170-eng htm\#famsize (accessed 2010 Mar. 29)

19. Rust KF, Rao JN. Variance estimation for complex surveys using replication techniques. Stat Methods Med Res 1996;5:283-310.

20. National Health and Nutrition Examination Survey. Atlanta (GA): Centers for Disease Control and Prevention; 2010. Available: www.cdc.gov/nchs/nhanes.htm (accessed $2010 \mathrm{Jan} .10$ ).

21. Bar-Oz B, Koren G, Nguyen P, et al. Folate fortification and supplementation - are we there yet? Reprod Toxicol 2008:25: 408-12.

22. Houghton LA, Sherwood KL, Pawlosky R, et al. [6S]-5-methyltetrahydrofolate is at least as effective as folic acid in preventing a decline in blood folate concentrations during lactation. $\mathrm{Am} \mathrm{J}$ Clin Nutr 2006:83:842-50

23. Wilson RD, Johnson JA, Wyatt P, et al. Preconceptional vita- 
RESEARCH

$\min /$ folic acid supplementation 2007: the use of folic acid in combination with a multivitamin supplement for the prevention of neural tube defects and other congenital anomalies. J Obstet Gynaecol Can 2007:29:1003-26.

24 Wald NJ, Law M, Hoftbrand AV. Folic acid fortification in the prevention of neural tube defects. Am J Clin Nutr 2004;80:1665-6.

25. Cole BF, Baron JA, Sandler RS, et al. Folic acid for the prevenCole $\mathrm{BF}$ Bar 2007-297-2351-9.

26. Hirsch S, Sanchez H, Albala C, et al. Colon cancer in Chile before and after the start of the flour fortification program with folic acid. Eur J Gastroenterol Hepatol 2009;21:436-9.

27. Allen LH. How common is vitamin B-12 deficiency? Am J Clin Nutr 2009;89(supp):693S-6S

28. Yajnik CS, Deshpande SS, Jackson AA, et al. Vitamin B12 and folate concentrations during pregnancy and insulin resistance in the offspring: the Pune maternal nutrition study. Diabetologia 2008;51:29-38.

29. Pfeiffer CM, Fazili Z, Zhang M. Folate analytical methodology. In: LB Bailey, editor. Folate in health in disease. 2nd ed. Boca Raton (FL): CRC Press, Taylor \& Francis Group; 2010.

30. Fazili Z, Pfeiffer CM, Zhang M, et al. Influence of 5,10-methyl enetetrahydrofolate reductase polymorphism on whole-blood folate concentrations measured by LC-MS/MS, microbiologic folate concentrations measured by LC-MS/MS, microbio

31. Kirkpatrick SI, Tarasulk V. Food insecurity is associated with nutrient inadequacies among Canadian adults and adolescents. $J$ Nutr 2008;138(3):604-12.
Affiliations: From the Children's Hospital of Easter Ontario Research Institute (Colapinto, Tremblay), Institute of Population Health (Colapinto) and Department of Pediatrics (Tremblay), University of Ottawa, Ottawa, Ont.; and the Hospital for Sick Children and Department of Nutritional Sciences (O'Connor), University of Toronto, Toronto, Ont.

Contributors: All of the authors contributed to the conception and design of the study. Cynthia Colapinto conducted the analysis, and all of the authors assisted in the interpretation of the results. Cynthia Colapinto drafted the manuscript. All of the authors critically reviewed the manuscript for important intellectual content and approved the final version submitted for publication

Funding: This research was supported by a CIHR Health Professionals Fellowship Award in the area of public health (funding reference no. 180375) and by a Statistics Canada Tom Symon's Fellowship Award to Cynthia Colapinto.

Acknowledgements: The authors thank the Health Analysis Division at Statistics Canada, in particular Tracey Bushni and Michelle Rotermann for their support during the analysis stage of this research. The authors also thank Penny Jee for her review of the laboratory methods and Trevor Stewart for his review and feedback on the manuscript. 


\section{Supplementary figures:}

Appendix 1 (as submitted by the authors)

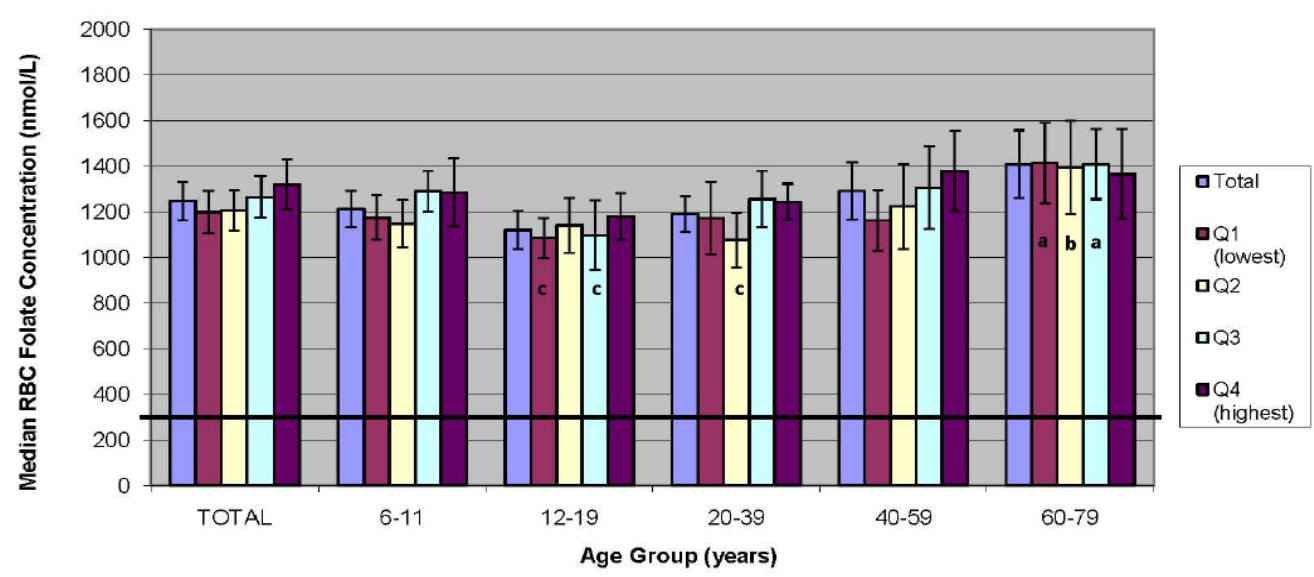

Appendix 1a: Median red blood cell (RBC) folate concentrations

by age group and income quartile among the entire population

from the Canadian Health Measures Survey, 2007-2009.

The solid horizontal line indicates the RBC folate concentration

cut-off for deficiency in the general population (305 nmol/L).

Confidence intervals are indicated by the vertical lines on each

bar.

a: Significantly different from median estimate for the 12-19

year age group of the same quartile

Appendix to: Colapinto CK, O'Connor DL, Tremblay MS. Folate status of adults in the Canadian Health Measures Survey. CMAJ 2010. DOI: $10.1503 / \mathrm{cmaj} .100568$.

Copyright $\odot$ 2010, Canadian Medical Association or its licensors 

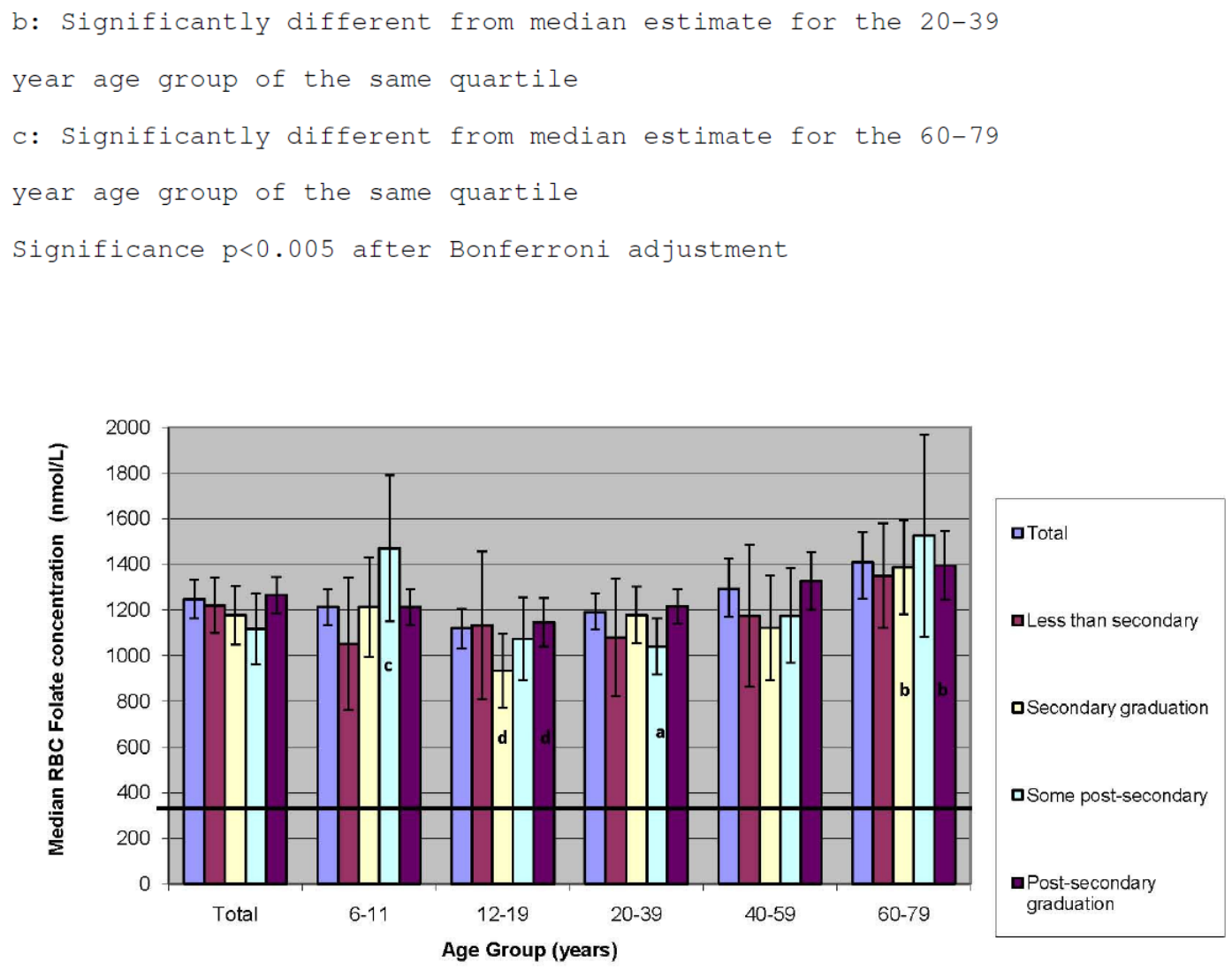

Appendix 1b: Median red blood cell ( $R B C$ ) folate concentrations by age group and highest level of education (household) among the entire population from the Canadian Health Measures Survey, $2007-2009$

The solid horizontal line indicates the RBC folate concentration cut-off for deficiency in the general population (305 nmol/L).

Appendix to: Colapinto CK, O'Connor DL, Tremblay MS. Folate status of adults in the Canadian Health Measures Survey. CMAJ 2010. DOI:10.1503/cmaj.100568.

Copyright $\odot$ 2010, Canadian Medical Association or its licensors 


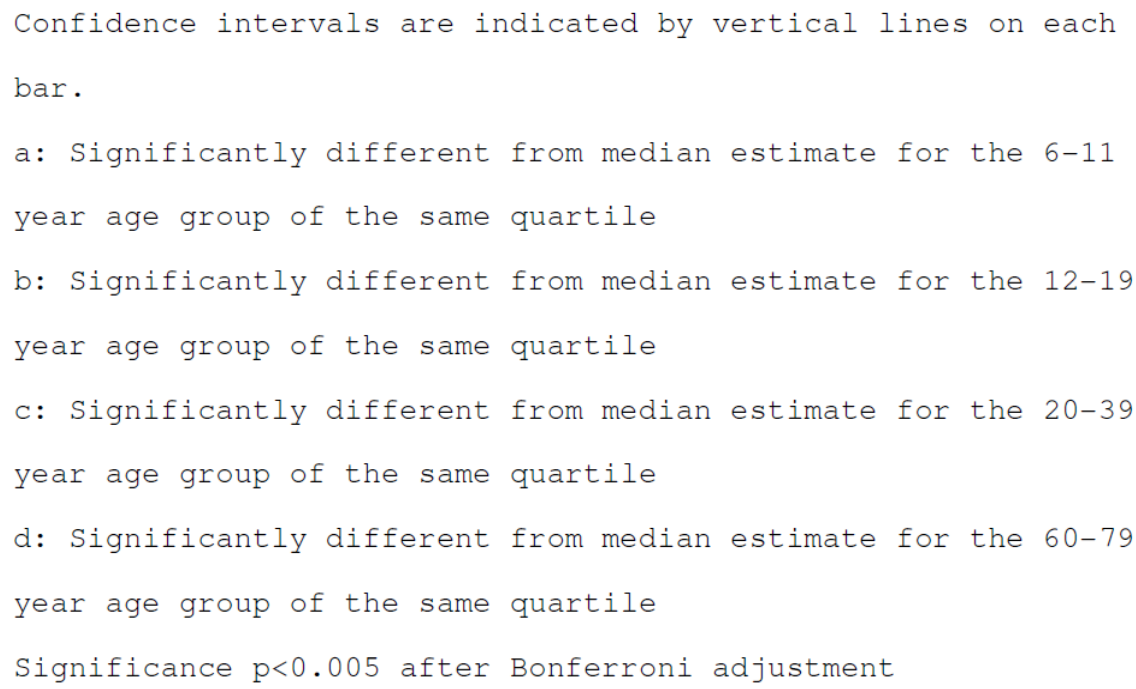

Copyright @ 2010, Canadian Medical Association or its licensors 
on the hazards of cardiac imaging without this crucial information?

I humbly request that $C M A J$ include absolute risk reduction and/or increase in every research article published.

Robert Y. Shaw MD

Internal medicine, Vancouver, BC

\section{References}

1. Wells G, Parkash R, Healey JS, et al. Cardiac resynchronization therapy: a meta-analysis of ran-

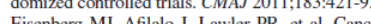
Eisenberg MJ, Afilalo J, Lawler PR, et al. Cancer cardiac imaging in patients after acute myocardie infarction. CMAJ 2011;183:430-6.

CMAJ 2011. DOI:10.1503/cmaj.110-2067

\section{Editor's response}

$C M A J$ is grateful for the reminder that what matters to a patient is the absolute risk. ${ }^{1}$ We should have made this easier for readers to find, especially in the second article to which Shaw refers.

The total mortality on optimal medical therapy was easy to see in Wells and colleagues' article; ${ }^{2}$ in Figure 2 it was $250 / 1013$, or $24.5 \%$. The absolute risk of cancer was less easy to find in Eisenberg and associates' article. ${ }^{3}$ One estimate might be 12020 cancers diagnosed in 82861 patients, as reported in the abstract; these occurred over an average follow-up time of five years according to the results, which suggests about 2.9 cases per 100 person years.
What these summary absolute risks hide, however, is that they may not be appropriate for an individual patient. Risk may vary with characteristics such as age, sex, severity of illness, comorbidity and family history. There is a long tradition of debate about whether to present research findings in terms of relative measures, which tend to be more stable between patient populations, or absolute measures, which have more immediate interpretability for clinicians and patients. ${ }^{4.5}$ We prefer to have both where possible, and we will make renewed efforts to remind authors to provide them.

John Fletcher MB BChir MPH

Deputy Editor, Research, CMAJ

\section{References}

1. Shaw RY. Absolute risk reduction a must. CMAJ 2011;183:151

2. Wells G, Parkash R, Healey JS, et al. Cardiac resynchronization therapy: a meta-analysis of randomized controlled trials. CMAJ 2011;183:421-9.

Eisenberg MJ, Afilalo J, Lawler PR, et al. Cancer risk related to low-dose ionizing radiation from cardiac imaging in patients after acute myocardial

Schwatc LM, Wolotin S, Dvorin E

Schwartz LM, Woloshin S, Dvorin EL, et al. Ratio measures in leading medical journals: structured BMJ 2006:333:1248

5. Naylor CD, Chen E, Strauss B. Measured enthusiasm: Does the method of reporting trial results alter perceptions of therapeutic effectiveness? Ann Intern Med 1992;117:916-21.

CMAJ 2011. DOI:10.1503/cmaj.110-2068

Some letters have been abbreviated for print. See www.cmaj.ca for full versions.

\section{- Correction \\ Folate status of the population in the Canadian Health Measures Survey}

In the February 8, 2011 issue of $C M A J$, two errors occurred in the article by Colapinto and colleagues.' The revised statements are below, with the correction in italics:

"Samples were thawed, diluted (1-in-26) with $0.5 \%$ ascorbic acid solution, allowed to incubate at room temperature for 18 minutes and then analyzed for folate using ..." (Methods section).

"Given the absence of folate deficiency in the general population and the apparent shift toward Canadians having high red blood cell folate concentrations ..." (Interpretation section).

$C M A J$ regrets the errors.

\section{Reference}

1. Colapinto CK, O'Connor DL, Tremblay MS. Folate status of the population in the Canadian Health Mensures Survey. CMAJ 2011;183:E100-6.

CMAJ 2011. DOI:10.1503/cmaj.110-2069 


\subsection{Prevalence and correlates of folic acid supplement use in Canada}

Authors: Cynthia K. Colapinto ${ }^{1,2}$, Deborah L. O’Connor ${ }^{3,4}$, Lise Dubois ${ }^{2}$, Mark S. Tremblay ${ }^{1,5}$

1. Healthy Active Living and Obesity Research Group, Children's Hospital of Eastern Ontario Research Institute

2. Institute of Population Health, University of Ottawa

3. Physiology and Experimental Medicine, The Hospital for Sick Children

4. Department of Nutritional Sciences, University of Toronto

5. Department of Pediatrics, University of Ottawa

This manuscript was written and published in accordance with the specifications for Health Reports. It was published as an original article on June 20, 2012 and appears here in its online published format with permission from the publisher.

Suggested citation: Colapinto CK, O’Connor DL, Dubois L, Tremblay MS. Prevalence and correlates of folate supplement use in the Canada. Health Rep. 2012;183(2):39-44. 


\section{Prevalence and correlates of folic acid supplement use in Canada}

by Cynthia K. Colapinto, Deborah L. O'Connor, Lise Dubois and Mark S. Tremblay

\begin{abstract}
Dietary supplements are an important source of folic acid, a nutrient that is vital in reducing the risk of neural tube defects. As part of the 2007 to 2009 Canadian Health Measures Survey, data were collected on supplement use, and biomarkers were directly measured. Use of supplements that contain folic acid was reported by $25 \%$ of Canadians aged 6 to 79 . Females were more likely than males to report taking folic acid supplements. People who ate fruit and vegetables less than once a day had significantly lower odds of taking folic acid-containing supplements than did those who ate fruit and vegetables at least three times a day. Of those who consumed a folic acid supplement, $91 \%$ reported also taking a supplement that contained vitamin $\mathrm{B}_{12}$. Red blood cell folate concentrations below the median (less than $1,248 \mathrm{nmol} / \mathrm{L})$, low-to-marginal serum vitamin $\mathrm{B}_{12}$ concentrations (221 pmol/L or less ), and high concentrations of plasma homocysteine were negatively correlated with folic acid-containing supplement use.
\end{abstract}

\section{Keywords}

Biological markers, dietary supplements, folate, nutrition, vitamins

\section{Authors}

Cynthia K. Colapinto (colapinto@uottawa.ca) and Mark S. Tremblay are with the Children's Hospita of Eastern Ontario and the University of Ottawa, Ottawa, Ontario. Deborah L. O'Connor is with the University of Toronto and the Hospital for Sick Children, Toronto, Ontario. Lise Dubois is with the University of Ottawa, Ottawa, Ontario.

$\mathrm{F}^{\mathrm{s}}$ olate, one of the B-vitamins, is a key nutrient in reducing the risk of neural tube defects. ${ }^{1}$ It plays an important role in metabolic pathways that involve vitamin $\mathrm{B}_{12}$ and homocysteine. ${ }^{1}$ While folate occurs naturally in many foods, such as dark green vegetables and legumes, the most common synthetic form in fortified foods and supplements is folic acid. Members of the general population do not commonly need supplemental folic acid unless it is recommended by a health care professional for certain medical conditions. In fact, high levels of supplemental folic acid may mask and exacerbate vitamin $\mathrm{B}_{12}$ deficiency, particularly in the elderly, which could result in neurological damage. ${ }^{2-4}$

According to the Institute of Medicine's Dietary Reference Intakes, the Recommended Dietary Allowance for the population older than age 13 is $0.4 \mathrm{mg}$ of folate a day. ${ }^{5}$ For women of childbearing age, an additional $0.4 \mathrm{mg}$ per day from supplements or fortified foods is recommended. ${ }^{5}$ Because up to $50 \%$ of pregnancies are unplanned, and many women of childbearing age report irregular or no consumption of folic acid before pregnancy, in 1998, Canada approved folic acid fortification of white wheat and other selected grains, in addition to previously implemented supplementation recommendations. ${ }^{6}$

This analysis uses data from the 2007 to 2009 Canadian Health Measures Survey (CHMS) to investigate self-reported intake of folic acidcontaining supplements (see The data). Associations with socio-demographic, behavioural and clinical factors were studied, including, for the first time in a nationally representative sample, red blood cell folate concentrations. 
2 Health Reports, Vol. 23, no. 2, June 2012 • Statistics Canada, Catalogue no. 82-003-XPE

Prevalence and correlates of folic acid supplement use in Canada $\cdot$ Health matters

\section{The data}

This study is based on results of cycle 1 of the Canadian Health Measures Survey (CHMS), which collected data from a nationally representative sample of the household population aged 6 to 79 . Residents of Indian Reserves, Crown lands, institutions and certain remote regions, and full-time members of the Canadian Forces, were excluded. Data were collected at 15 sites across the country from March 2007 through February 2009.

A Statistics Canada interviewer administered a detailed in-home health questionnaire, which covered medication and natural health product use. One day to six weeks later, respondents visited a mobile examination centre for a series of physical measurements, including blood samples taken by a certified phlebotomist to measure a variety of analytes. ${ }^{7}$

Of the 8,772 households selected for the CHMS, $69.6 \%$ agreed to participate; $88.3 \%$ of them responded to the in-home survey, and of those, $84.9 \%$ visited the mobile examination centre. The overall response rate was $51.7 \%$. A comprehensive consent process was employed; participation was voluntary and respondents could opt out of any part of the survey at any time. ${ }^{8}$ The final sample consisted of 5,604 respondents aged 6 to 79 and is representative of approximately $96.3 \%$ of the Canadian population. Details about the CHMS are available elsewhere. ${ }^{7,9}$

Drug identification and natural health product numbers were collected from respondents during the in-home interview. This information was verified at the mobile examination centre visit, and changes in drug and supplement use were recorded. ${ }^{10}$ Consumption of folic acid supplements-alone or in a multivitamin - in the 30 days before the mobile examination centre visit was determined by matching drug identification and natural health product numbers to product information extracted from the Health Canada Drug Product and Licensed Natural Health Product databases. ${ }^{10,11,12}$ This approach was also used to quantify vitamin $\mathrm{B}_{12}$ supplement use.

Dietary reference intake age groups were used for this study. These age groups were collapsed into three categories to achieve adequate sample size in the analyses examining doses of folic acid-containing supplements. Socio-economic status was measured by per person household income equivalents (which grouped respondent household income into quartiles after adjusting for household size and composition) and highest level of household education (less than postsecondary graduation and postsecondary graduation) ${ }^{13}$ Immigrant status was defined as born in Canada or not born in Canada.

A brief, non-quantitative questionnaire was used to examine usual frequency of consumption from the grains and fruit and vegetables food groups. Cereal, white bread, brown bread and pasta were combined to formulate the derived variable for grains. Self-reported smoking status and history were used to categorize respondents as daily, former or never smokers. A physical activity index of active, moderately active or inactive was derived based on average daily energy expenditure values during self-reported leisure time activities in the three months before the in-home interview. ${ }^{14}$

Measured height and weight were used to calculate body mass index $\left(\mathrm{wt}(\mathrm{kg}) / \mathrm{ht}(\mathrm{m})^{2}\right)$. The body mass index of adults, excluding pregnant women, was classified using Health Canada's guidelines. ${ }^{15}$ Children aged 6 to 17 were classified as being normal weight, overweight or obese based on definitions proposed by the International Obesity Task Force, which account for both the age and sex of the child. ${ }^{16}$

A clinical risk factor variable was created to combine self-reported diabetes mellitus, use of folic acid antagonist medication, and overweight/obesity. Folic acid antagonist medication was determined by matching drug identification numbers-from medications used in the 30 days before the mobile examination centre visit-to information in the Drug Product Database. ${ }^{11,17}$ The variable identified three parameters: no risk factors, one risk factor, and more than one risk factor.

Blood was taken from 5,373 CHMS respondents. Red blood cell folate was analyzed using the Immulite 2000 immunoassay (Siemens Canada Ltd., Mississauga). ${ }^{18}$ Red blood cell folate concentration was calculated from the measured whole-blood folate concentration adjusting for red blood cell volume, without correction for plasma folate concentration. Serum vitamin $B_{12}$ was also assessed using the Immulite 2000 immunoassay, a solid phase, competitive chemiluminescent enzyme immunoassay involving an automated alkaline denaturation procedure. The cut-off for marginal Vitamin $\mathrm{B}_{12}$ status was $221 \mathrm{pmol} / \mathrm{L}$ or less. ${ }^{2,19}$ The Vitros 5, 1FS (Ortho Clinical Diagnostics, Markham) was used to assess plasma homocysteine concentrations. The quantitative measurement of plasma homocysteine was performed using the VITROS Chemistry Products Homocysteine Reagent, a spectrophotometric method involving three coupled enzymatic reactions (cystathionine synthase, cystathionine lyase and lactate dehydrogenase). Normal plasma homocysteine status was as $8 \mu \mathrm{mol} / \mathrm{L}$ or less for respondents aged 10 or younger, and $15 \mu \mathrm{mol} / \mathrm{L}$ or less for older respondents ${ }^{20-22}$

Descriptive statistics (frequencies, percentiles) were used to characterize the population. Missing values for predictor variables were removed for individual analyses. T-tests were used to study differences between estimates. With separate logistic regression analyses that controlled for age and household income, each co-variate was examined as a correlate of folic acid-containing supplement use. All estimates were based on data weighted to represent the Canadian population. Variance estimation ( $95 \%$ confidence intervals) and significance testing were based on the bootstrap technique to account for the complex CHMS sampling design. ${ }^{23}$ Analyses were conducted in SAS 9.1.3 (SAS Institute Inc., Cary, NC) and SUDAAN v.10.0 (RTI International, Research Triangle Park, NC), using DDF=11 in the SUDAAN procedure statements. Given the 11 degrees of freedom available for variance estimation, Satterthwaite-adjusted statistics were used to test the significance of each regression model's coefficients. ${ }^{24}$ Significance was defined as a p-value of $<0.05$.

The overall response rate to the CHMS was slightly above $50 \%$. Although the survey weights ensured that the sample was representative of the target population, bias might exist if the use of folic acid-containing supplements by non-respondents and respondents differed systematically. The number of independent variables in the regression model was limited by 11 degrees of freedom; future research that combines subsequent CHMS cycles will increase the number of degrees of freedom and permit more complex modelling. The cross-sectional nature of the survey precludes inferences about the temporal ordering of events or causality. As well, the CHMS was not designed to collect information on usual supplement dosage, so precisely how often supplements were consumed could not be determined.

\section{One in four}

Results from the CHMS show that one in four Canadians aged 6 to 79 (an estimated 25\%) reported taking a supplement containing folic acid in the previous 30 days (Table 1). This figure is consistent with data from the 2004 Canadian Community Health Survey, cycle 2.2 (Nutrition). ${ }^{25}$ Females were significantly more likely than males to report taking a supplement that contained folic acid (28\% versus $21 \%)$.
The use of folic acid-containing supplements was highest in the youngest and oldest age groups, and lowest among teenagers and young adults. The greater likelihood of folic acid supplement use among females than males prevailed 
Table 1

Prevalence and adjusted odds of folic acid-containing supplement use, by selected characteristics, household population aged 6 to 79, Canada, 2007 to 2009

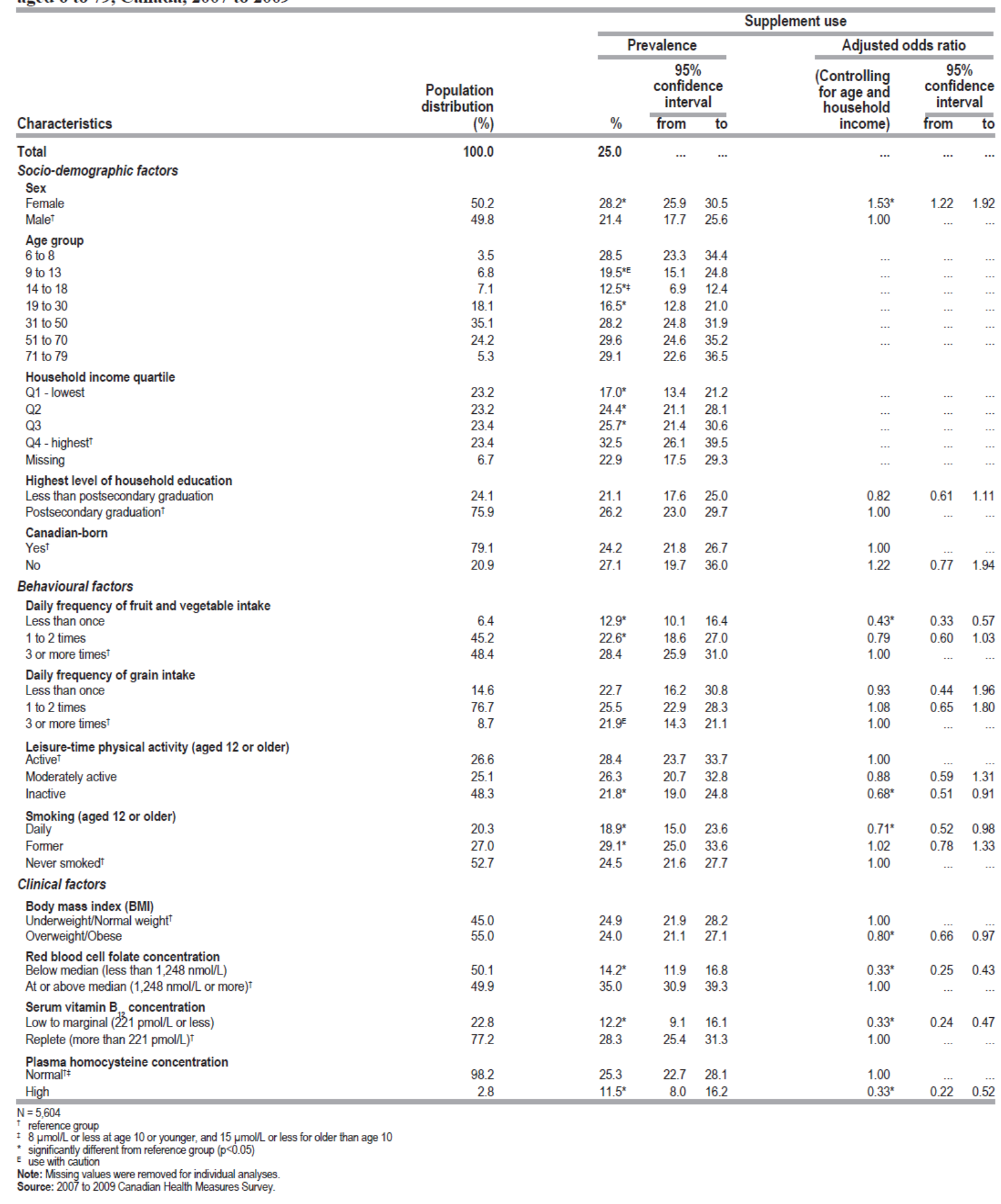


4 Health Reports, Vol. 23, no. 2, June 2012 • Statistics Canada, Catalogue no. 82-003-XPE

Prevalence and correlates of folic acid supplement use in Canada $\bullet$ Health matters

in age groups older than 30 (data not shown). Use peaked among women older than age $70(36 \%)$ and was lowest among boys aged 14 to 18 (11\%) (data not shown).

A positive gradient by household income emerged, with those in the lower income quartiles being significantly less likely than those in the highest quartile to have taken a supplement containing folic acid.

Even when the potential influence of age and household income was taken into account, females were significantly more likely than males to have consumed a folic acid-containing supplement (OR: 1.53; CI: 1.22, 1.92). Household education and country of birth were not significant correlates of folic acid supplement use.

\section{Diet, exercise and smoking}

Together, grains and fruit and vegetables are responsible for $62 \%$ to $78 \%$ of Canadians' dietary folate intake. ${ }^{10,26,27}$ However, people who ate fruit and vegetables relatively infrequently (less than once a day), had significantly low odds (OR: 0.43 ; CI: $0.33,0.57$ ) of taking a supplement that contained folic acid, compared with people who ate fruit and vegetables three or more times a day. Grain intake was not significantly related to folic acid supplement use (Table 1).

People who reported inactive leisure time had significantly low odds of taking folic acid supplements, compared with those whose leisure time was active. As well, the odds of folic acid supplement use were significantly low for daily smokers, compared with people who had never smoked. Having a family physician and the frequency of alcohol consumption were not related to the use of folic acid-containing supplements (data not shown).

The odds of taking a supplement that contained folic acid were significantly low for people whose BMI put them in the overweight/obese category.

\section{Biomarkers}

Red blood cell folate is the best indicator of tissue folate stores. ${ }^{28}$ People whose
Figure 1

Reported dose of folic acid-containing supplement, by sex, household population aged 6 to 79 , Canada, 2007 to 2009

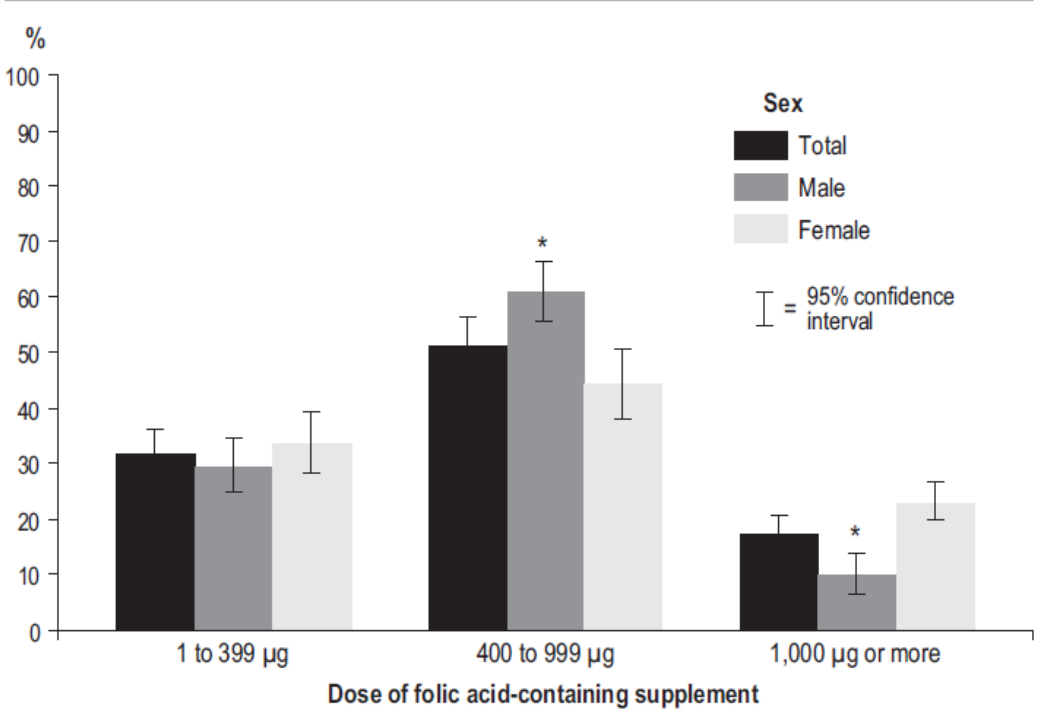

$\mathrm{N}=1,357$

* significantly different from females $(\mathrm{p}<0.05)$

Note: Based on respondents who reported taking folic acid-containing supplement.

Source: 2007 to 2009 Canadian Health Measures Survey.

Figure 2

Reported dose of folic acid-containing supplement, by age group, household population aged 6 to 79, Canada, 2007 to 2009

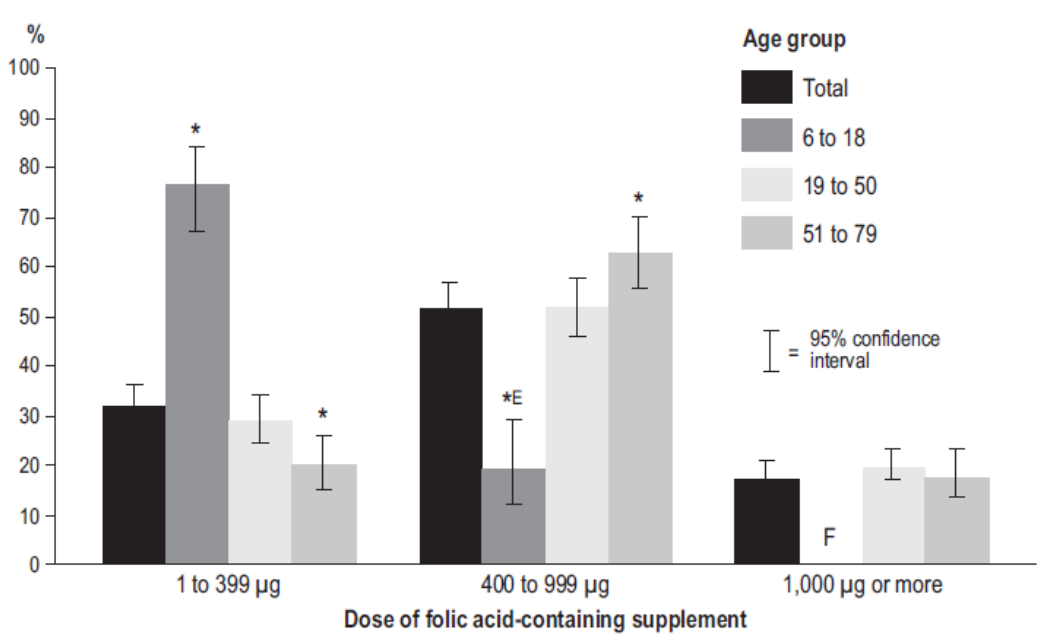

$\mathrm{N}=1,357$

* significantly different from 19 -to-50 age group $(p<0.05)$

E use with caution

$\mathrm{F}$ too unreliable to be published

Note: Based on respondents who reported taking folic acid-containing supplement.

Source: 2007 to 2009 Canadian Health Measures Survey. 
red blood cell folate concentrations were below the median (less than 1,248 $\mathrm{nmol} / \mathrm{L}$ ) were significantly less likely to report taking a folic-acid containing supplement (OR: 0.33; CI: 0.25, 0.43) than were people whose concentrations were at or above the median.

The Tolerable Upper Limit for folate is $1,000 \mu \mathrm{g}$ of the synthetic form a day. Higher amounts may mask a vitamin $\mathrm{B}_{12}$ deficiency. ${ }^{5}$ Overall, $17.4 \%$ of folic acid supplement users consumed 1,000 $\mu \mathrm{g}$ or more (Figures 1 and 2). Canadian prenatal nutrition guidelines and federal natural health product regulations ${ }^{29,30}$ support the combined use of vitamin $\mathrm{B}_{12}$ and folic acid supplements to reduce the risk of masking a vitamin $\mathrm{B}_{12}$ deficiency. A large majority (91\%) of CHMS respondents who took a folic acid-containing supplement also reported taking a supplement that contained vitamin $B_{12}$. Further, individuals with low serum vitamin $B_{12}$ concentrations were less likely to have consumed a folic acid-containing supplement (OR: 0.33 ; CI: $0.24,0.47)$ than were people whose vitamin $B_{12}$ concentrations were higher.

High plasma homocysteine concentrations are a biomarker for low concentrations of both folate and vitamin $\mathrm{B}_{12} \cdot{ }^{20}$ Individuals with high homocysteine concentrations were less likely to consume folic acid-containing supplements (OR: 0.33; CI: 0.22, 0.52 ) than were those whose plasma homocysteine concentrations were in the normal range.

The clinical risk factor variable was not significantly correlated with folic acid-containing supplement use (data not shown).

\section{Dosage}

The amount of folic acid in the supplements used by about half (51\%) of supplements takers ranged from 400 to $999 \mu \mathrm{g}$, and for another third (32\%), the folic acid dose was 1 to $399 \mu \mathrm{g}$ (Figure 1). The remaining $17 \%$ took supplements that contained $1,000 \mu \mathrm{g}$ or more of folic acid: $22 \%$ of females and $10 \%$ of males.

The most common dose of folic acid for children and teenagers aged 6 to 18 was 1 to $399 \mu \mathrm{g}$ (Figure 2). Folic acidcontaining supplements designed for Canadian children contain 100 to 400 $\mu \mathrm{g}^{7} \quad$ At older ages, particularly 51 to 79 , the dosage most frequently reported was 400 to $999 \mu \mathrm{g}$. Around $20 \%$ of people older than 19 reported taking supplements containing at least 1000 $\mu \mathrm{g}$ of folic acid. Such high intake was extremely rare at younger ages.

\section{References}

1. Refsum H. Folate, vitamin B12 and homocysteine in relation to birth defects and pregnancy outcome. British Journal of Nutrition 2001; 85(Suppl. 2): S109-13.

2. Allen L. How common is vitamin B-12 deficiency? American Journal of Clinical Nutrition 2009; 89(Suppl.): 693S-6S.

3. Mason JB, Dickstein A, Jacques PF, et al. A temporal association between folic acid fortification and an increase in colorectal cancer rates may be illuminating important biological principles: A hypothesis. Cancer Epidemiology Biomarkers and Prevention 2007; 16(7): 1325-9
4. Morris MS, Jacques PF, Rosenberg IH, et al. Folate and vitamin $B_{12}$ status in relation to anemia, macrocytosis, and cognitive impairment in older Americans in the age of folic acid fortification. American Journal of Clinical Nutrition 2007; 85(1): 193-200.

5. Institute of Medicine. DRIDietary Reference Intakes for Thiamin, Riboflavin, Niacin, Vitamin B6, Folate, Vitamin B12, Pantothenic Acid, Biotin, and Choline. Washington, D.C. National Academy Press, 1998.

6. Berry RJ, Mulinare J, Hamner H. Folic acid fortification. In: LB Bailey, ed. Folate in Health and Disease. Second edition. Boca Raton, Florida: CRC Press, Taylor and Francis Group, 2010.

\section{Conclusion}

The use of folic acid-containing supplements is associated with a number of factors: socio-demographic (sex, age, household income), behavioural (frequency of consumption of fruit and vegetables, physical activity, smoking, overweight/obesity) and clinical (blood concentrations of $\mathrm{RBC}$ folate, serum vitamin $\mathrm{B} 12$ and plasma homocysteine). The results in this overview can inform fortification and supplementation policy in Canada.

\section{Acknowledgments}

The authors thank the Health Analysis Division at Statistics Canada, in particular, Tracey Bushnik and Michelle Rotermann, for their support during the analysis stage of this research. We further thank the Physical Health Measures Division for preparing and granting special access to the data. This research was supported by a CIHR Health Professionals Fellowship in the Area of Public Health to Cynthia Colapinto (funding reference \#180375) and a CIHR Operating Grant (funding reference \#218776).
7. Bryan S, St-Denis M, Wojtas D. Canadian Health Measures Survey: Clinic operations and logistics. Health Reports 2007; 18(Suppl.): 53-70.

8. Day B, Langlois R, Tremblay et al. Canadian Health Measures Survey: Ethical, legal and social issues. Health Reports 2007; 18(Suppl.): $37-51$.

9. Tremblay M, Wolfson M, Gorber SC. Canadian Health Measures Survey: Rationale, background and overview. Health Reports 2007; 18(Suppl.): 7-20. 
6 Health Reports, Vol. 23, no. 2, June 2012 • Statistics Canada, Catalogue no. 82-003-XPE

Prevalence and correlates of folic acid supplement use in Canada $\bullet$ Health matters

10. Statistics Canada. Questionnaire(s) and Reporting Guide(s) - Canadian Health Measures Survey (CHMS). Available at: http://www.statcan.gc.ca/cgi-bin/imdb/p2SV. pl?Function $=$ getInstrumentLink\&SurvItem Id=9353\&Query_Id $=10263 \&$ Query=insta nce $\&$ lang $=$ en $\& \mathrm{db}=\mathrm{imdb} \& \mathrm{adm}=8 \&$ dis $=2$. Accessed August 15, 2011.

11. Health Canada. Drug Product Database. Available at: http://www.hc-sc.gc.ca/dhp-mps/ prodpharma/databasdon/index-eng.php. Accessed August 15, 2010.

12. Health Canada. Licensed Natural Health Products Database. Available at: http:// www.he-sc.gc.ca.proxy.bib.uottawa.ca/ dhp-mps/prodnatur/applications/licen-prod lnhpd-bdpsnh data extract-eng.php. Accessed August 15, 2010.

13. Statistics Canada. Income Trends in Canada: 1980-2003. Available at: http:// www.statcan.gc.ca/pub/13f0022x/00003/ notedef/5801170-eng.htm\#famsize. Accessed March 29, 2010.

14. Statistics Canada. Canadian Health Measures Survey (CHMS) Cycle 1 Wave 1 Derived Variable (DV) Specifications. Available at: http://www.statcan.gc.ca/imdb-bmdi/ document/5071_D3_T9_V2-eng.pdf. Accessed April 18, $201 \overline{1}$.

15. Health Canada. Canadian Guidelines for Body Weight Classification (Catalogue H49-179) Ottawa: Health Canada, 2003.

16. Cole TJ, Bellizzi MC, Flegal KM, et al Establishing a standard definition for child overweight and obesity worldwide: International survey. British Medical Joumal 2000; 320(7244): 1240-3.
17. Stabler S. Clinical folate deficiency. In: LB Bailey, ed. Folate in Health and Disease. Second edition. Boca Raton, Florida: CRC Press, Taylor and Francis Group, 2010.

18. Siemans Canada. Immulite 2000 Folic Acid Insert. Mississauga, Ontario: Siemans Canada, Ltd., 2009.

19. Siemans Canada. Immulite 2000 Vitamin $B 12$ Package Insert \#P1L2KVB-22. Mississauga, Ontario: Siemans Canada, Ltd., 2006.

20. Refsum $\mathrm{H}$, Smith $\mathrm{AD}$, Ueland $\mathrm{PM}$, et al. Facts and recommendations about total homocysteine determinations: An expert opinion. Clinical Chemistry 2004; 50(1):3-32

21. Refsum H, Yajnik CS, Gadkari M, et al. Hyperhomocysteinemia and elevated methylmalonic acid indicate a high prevalence of cobalamin deficiency in Asian Indians. American Journal of Clinical Nutrition 2001, 74(2): $233-41$

22. Ortho-Clinical Diagnostics. VITROS Chemistry Products Homocysteine Reagents - Instructions for Use. Publication number J23410_EN (version 1.0)L. Markham, Ontario: Ortho-Clinical Diagnostics Inc.; 2006.

23. Rust K, Rao J. Variance estimation for complex surveys using replication techniques. Statistical Methods in Medical Research 1996; 5: 281-310.

24. Statistics Canada. Canadian Health Measures Survey (CHMS) Data User Guide: Cycle 1. Available at: http://www.statcan.gc.ca/ imdb-bmdi/document/5071 D2 T1 V1-eng. pdf. Accessed May 5, 2011.
25. ShakurYA, Garriguet D, Corey P, et al. Folic acid fortification above mandated levels results in a low prevalence of folate inadequacy among Canadians. American Journal of Clinical Nutrition 2010; 92(4): 818-25.

26. Sherwood KL, Houghton LA, Tarasuk V, et al. One-third of pregnant and lactating women may not be meeting their folate requirements from diet alone based on mandated levels of folic acid fortification. Journal of Nutrition 2006; 136(11): 2820-6.

27. Shuaibi AM, House JD, Sevenhuysen GP. Folate status of young Canadian women after folic acid fortification of grain products. Journal of the American Dietetic Association 2008; 108(12): 2090-4.

28. McNulty B, Pentieva K, Marshall B, et al. Women's compliance with current folic acid recommendations and achievement of optimal vitamin status for preventing neural tube defects. Human Reproduction 2011; 26(6): 1530-6.

29. Health Canada. Prenatal Nutrition Guidelines for Health Professionals - Folate Contributes to a Healthy Pregnancy. Available at: http:// www.hc-sc.gc.ca/fn-an/pubs/nutrition/ folate-eng.php. Accessed September 17, 2011.

30. Health Canada. Multi-vitamin/Mineral Supplement Monograph. Available at: http://www.hc-sc.gc.ca/dhp-mps/prodnatur/ applications/licen-prod/monograph/multi vitmin_suppl-eng.php\#table8foot1. Accessed October 14, 2011 


\subsection{Folic acid supplement use is the most significant predictor of folate concentrations in Canadian women of childbearing age}

Authors: Cynthia K. Colapinto ${ }^{1,2}$, Deborah L. O’Connor ${ }^{3,4}$, Lise Dubois ${ }^{2}$, Mark S. Tremblay ${ }^{1,5}$

1. Healthy Active Living and Obesity Research Group, Children's Hospital of Eastern Ontario Research Institute

2. Institute of Population Health, University of Ottawa

3. Physiology and Experimental Medicine, The Hospital for Sick Children

4. Department of Nutritional Sciences, University of Toronto

5. Department of Pediatrics, University of Ottawa

This manuscript was written and published in accordance with the specifications for Applied Physiology, Nutrition and Metabolism. It was published as an original article on April 24, 2012 and appears here in its online published format with permission from the publisher.

Suggested citation: Colapinto CK, O’Connor DL, Dubois L, Tremblay MS. Folic acid supplement use is the most significant predictor of folate concentrations in Canadian women of childbearing age. Appl Physiol Nutr Metab. 2012;37(2):284-92. 


\title{
Folic acid supplement use is the most significant predictor of folate concentrations in Canadian women of childbearing age
}

\author{
Cynthia K. Colapinto, Deborah L. O'Connor, Lise Dubois, and Mark S. Tremblay
}

\begin{abstract}
One-fifth of Canadian women of childbearing age (WCBA) have red blood cell (RBC) folate concentrations below those considered optimal for neural tube defect risk reduction $\left(\geq 906 \mathrm{nmol} \cdot \mathrm{L}^{-1}\right)$. Determinants of optimal concentrations have not been examined in a nationally representative sample of Canadian WCBA since food fortification with folic acid was implemented. This study explored correlates of optimal RBC folate concentrations and characteristics of folic acid supplement users in a sample of Canadian WCBA. RBC folate concentrations from the 2007-2009 Canadian Health Measures Survey were assessed in women aged 15 to 45 years $(n=1162)$. Sociodemographic, behavioural, and clinical determinants of RBC folate $\geq 906 \mathrm{nmol} \cdot \mathrm{L}^{-1}$ were examined using univariate and separate multiple logistic regression models that controlled for age and household income. $t$ tests were used to study differences between folic acid supplement users and nonusers. WCBA not taking folic acid supplements were less likely to achieve a RBC folate concentration $\geq 906 \mathrm{nmol} \cdot \mathrm{L}^{-1}$ compared with folic acid supplement users (odds ratio, $0.47 ; 95 \%$ confidence interval, $0.24,0.92$ ). Twenty-five percent of WCBA reported folic acid supplement use, and there was a higher percentage of folic acid supplement users in the highest income group. Folic acid supplement users were also more frequent consumers of supplemental vitamin $\mathrm{B}_{12}$ and of fruit and vegetables ( $>3$ times per day). Folic acid supplement use was the most significant predictor of WCBA achieving optimal RBC folate concentrations. These results indicate a need for targeted strategies to improve compliance with folic acid supplement recommendations among WCBA.
\end{abstract}

Key words: red blood cell (RBC) folate, folic acid, supplementation, Canadian Health Measures Survey (CHMS).

Résumé : Un cinquième des Canadiennes en âge de procréer (WCBA) présente une concentration érythrocytaire (RBC) de folate sous le seuil considéré optimal pour diminuer le risque d'anomalie du tube neural $\left(\geq 906 \mathrm{nmol} \cdot \mathrm{L}^{-1}\right)$. Il n'y a pas eu d'études sur les déterminants de la concentration optimale dans un échantillon représentatif des WBCA sur le plan national depuis la mise en œuvre de l'enrichissement des produits alimentaires en acide folique. Cette étude analyse les corrélats de la concentration optimale d'acide folique dans les RBC et les caractéristiques des consommatrices de supplément d'acide folique dans un échantillon canadien de WBCA. On évalue la concentration érythrocytaire de folate dans un échantillon de l'Enquête canadienne sur les mesures de la santé 2007-2009 (CHMS) comprenant des femmes âgées de 15 à 45 ans ( $n=$ 1162). On cherche les déterminants sociodémographiques, comportementaux et cliniques d'une concentration érythrocytaire de folate $\geq 906 \mathrm{nmol} \cdot \mathrm{L}^{-1}$ au moyen de modèles de régression univariée et de régression logistique multiple prenant en compte l'âge et le revenu du ménage. On utilise des tests t pour analyser les différences entre les consommatrices de supplément en acide folique et celles qui n'en consomment pas. Les WCBA qui ne prennent pas de supplément en acide folique ont vraisemblablement une probabilité moindre de présenter une concentration érythrocytaire de folate $\geq 906 \mathrm{nmol} \cdot \mathrm{L}^{-1}$ que les consommatrices de supplément (OR 0,47, I C : 0,24-0,92). Vingt-cinq pour cent des WBCA disent consommer des suppléments d'acide folique et chez ces consommatrices, on enregistre un plus haut pourcentage de femmes dans des ménages à plus haut revenu. Les consommatrices de supplément d'acide folique prennent aussi plus souvent des suppléments de vitamine $B_{12}$ de même que des fruits et des légumes soit plus de 3 fois par jour. La prise de supplément d'acide folique est le prédicteur le plus significatif chez les WCBA pour l'atteinte de la concentration optimale de folate dans les érythrocytes. Ces observations soulignent la nécessité de stratégies de concertation pour améliorer la conformité à l'égard des recommandations en matière de supplémentation en acide folique chez les WCBA.

Received 18 October 2011. Accepted 2 December 2011. Published at www.nrcresearchpress.com/apnm on 27 March 2012.

C.K. Colapinto. Healthy Active Living and Obesity Research Group, Children's Hospital of Eastern Ontario Research Institute (CHEO-RI), 401 Smyth Road, Room 242, Ottawa, ON K1H 8L1, Canada; Institute of Population Health, University of Ottawa, Ottawa, ON K1N 6N5, Canada.

D.L. O'Connor. Department of Clinical Dietetics; Physiology and Experimental Medicine Program, The Hospital for Sick Children, Room 8511C, 555 University Avenue, Toronto, ON M5G 1X8, Canada; Department of Nutritional Sciences, University of Toronto, Toronto, ON M5S 3E2, Canada.

L. Dubois. Department of Epidemiology and Community Medicine, Faculty of Medicine, Institute of Population Health, University of Ottawa, 1 Stewart Street, Office 303, Ottawa, ON K1N 6N5, Canada.

M.S. Tremblay. Healthy Active Living and Obesity Research Group, Children's Hospital of Eastern Ontario Research Institute (CHEO-RI), 401 Smyth Road, Room 211, Ottawa, ON K1H 8L1, Canada; Department of Pediatrics, University of Ottawa, Ottawa, ON K1H 8L1, Canada.

Corresponding author: Cynthia K. Colapinto (e-mail: colapinto@uottawa.ca). 
Mots-clés : folate érythrocytaire, acide folique, supplémentation, Enquête canadienne sur les mesures de la santé.

[Traduit par la Rédaction]

\section{Introduction}

The role of folic acid intake in the prevention of neural tube defects (NTDs) is well established (Refsum 2001). While folate occurs naturally in food, folic acid is the most common synthetic form of folate found in fortified foods and supplements. In Canada, women of childbearing age (WCBA) are encouraged to eat folate-rich foods and to take a multivitamin supplement containing folic acid $\left(0.4 \mathrm{mg} \cdot \mathrm{day}^{-1}\right)$ to further reduce the risk of folate-dependent NTDs (Health Canada 2010a). Higher-dose supplements (4-5 mg $\left.\cdot \mathrm{day}^{-1}\right)$ are recommended for women at increased risk of a NTD birth (Health Canada 2010b). Given that up to $50 \%$ of pregnancies are unplanned and that many WCBA report irregular or no consumption of folic acid prior to pregnancy, in 1998, Canadian policymakers approved the fortification of white wheat and other select grains with folic acid, in addition to supplementation recommendations (Berry et al. 2010).

NTD births in Canada have been reduced by $46 \%$ since the implementation of fortification with folic acid, demonstrating the success of this intervention (De Wals et al. 2008). In addition, folate deficiency (red blood cell (RBC) folate $<305 \mathrm{nmol} \cdot \mathrm{L}^{-1}$ ) is virtually nonexistent in the general Canadian population (Colapinto et al. 2011). Despite this absence of deficiency, approximately $22 \%$ of Canadian WCBA are still not achieving a folate concentration considered optimal for NTD risk reduction $\left(\geq 906 \mathrm{nmol} \cdot \mathrm{L}^{-1}\right.$ ) (Daly et al. 1995; Colapinto et al. 2011). Because this segment of the population is the target of fortification and supplementation policies, clarifying the factors associated with achieving optimal folate status is essential to refining interventions.

Although certain factors (e.g., adolescence, low socioeconomic status, low consumption of folate-rich foods, poor compliance with folic acid supplements, smoking, and maternal obesity) are known to be related to NTDs, the association of these factors with folate concentrations $\geq 906 \mathrm{nmol} \cdot \mathrm{L}^{-1}$ has not been investigated on a nationally representative Canadian sample since the implementation of food fortification with folic acid (Tam et al. 2009). This study addresses this knowledge gap by exploring correlates of RBC folate concentrations considered optimal for NTD risk reduction and of folic acid supplement use in Canadian WCBA, using the Canadian Health Measures Survey (CHMS).

\section{Materials and methods}

Data from the 2007-2009 CHMS, conducted by Statistics Canada in partnership with Health Canada and the Public Health Agency of Canada, were used for these analyses. The survey methodology is described briefly here and in detail elsewhere (Bryan et al. 2007).

\section{CHMS sampling}

The CHMS used a complex, multistage, cluster-sampling protocol to achieve a nationally representative cross-sectional sample. The final sample comprised 5604 Canadians aged 6-
79 years, balanced by sex, in each of the following age groups: $6-11,12-19,20-39,40-59$, and $60-79$ years. This is representative of approximately $96.3 \%$ of the Canadian population.

\section{Survey methods}

Data collection occurred between March 2007 and February 2009. An interviewer administered a detailed in-home health questionnaire, which included data on sociodemographic characteristics. One day to 6 weeks later, blood samples were taken by a phlebotomist in a mobile examination centre to measure a variety of analytes, including RBC folate (Bryan et al. 2007). Implied consent occurred in the household, and a comprehensive consent process was employed in the clinic. Ethics approval for the CHMS was obtained from the Health Canada Research Ethics Board and, for this secondary data analysis, from the Children's Hospital of Eastern Ontario and University of Ottawa Research Ethics Boards.

\section{Blood sampling}

Blood was drawn from 5373 CHMS participants, with 1162 WCBA (15-45 years old, including 29 reporting pregnancy) providing a sample for RBC folate measurement, weighted to represent approximately 6676460 Canadians. Participants in this subgroup who refused to participate in the blood draw or who did not have a usable sample were excluded $(n=45)$.

\section{RBC folate concentration}

RBC folate allows for an estimate of tissue folate stores (McNulty et al. 2011). Venipuncture samples were collected in EDTA-treated vacutainers, then immediately processed on site. After hematocrit measurement, aliquots of whole blood were frozen, stored at $-20{ }^{\circ} \mathrm{C}$, and shipped weekly to the Health Canada nutrition laboratory on dry ice (Bryan et al. 2007). Samples were thawed, diluted (1-in-26) with $0.5 \%$ ascorbic acid solution, allowed to incubate for $180 \mathrm{~min}$ at room temperature, and then analyzed for RBC folate, using the Immulite 2000 immunoassay (Siemens Canada Ltd., Mississauga, Ont., Canada) (Siemans Canada 2009). RBC folate concentration was calculated from the measured whole-blood folate concentration, adjusted for RBC volume, without correction for plasma folate concentration. Accuracy and reproducibility of these procedures was assessed using the manufacturers' serum controls (Con6: Tri-level multiconstituent control) and whole-blood controls (BioRad Lyphochek Tri-level; BioRad Laboratories, Hercules, Calif., USA). Serum controls had an interassay coefficient of variation of $<5 \%$, and all analyzed controls (serum, whole blood) were within $10 \%$ of target values.

The folate concentration considered optimal for NTD risk reduction among WCBA was set at $\geq 906 \mathrm{nmol} \cdot \mathrm{L}^{-1}$, which was derived from a large Irish case-control study of antenatal 
women from 1986 to 1990 that demonstrated a continuous, inverse dose-response relationship between RBC folate concentration (up to $1292 \mathrm{nmol} \cdot \mathrm{L}^{-1}$ ) and NTD risk (Daly et al. 1995). The cut-off of $906 \mathrm{nmol} \cdot \mathrm{L}^{-1}$ represents the lower boundary of the uppermost RBC folate concentration group in this study population, as well as the category with the lowest risk of a NTD birth. This cut-off has been widely adopted by experts in the field (Daly et al. 1995; Institute of Medicine 1998).

Correlates of optimal RBC folate concentration for NTD risk reduction

\section{Sociodemographic factors}

A variable for WCBA (aged 15 to 45 years) was derived. Socioeconomic status was examined by per-person household-income equivalents (which grouped respondents into quartiles after adjustment for family size and composition) and the highest level of household education (less than postsecondary graduation and postsecondary graduation) (Statistics Canada 2008). Participants were categorized dichotomously as born or not born in Canada.

\section{Behavioural factors}

\section{Supplement intake}

Drug identification and natural health product numbers were collected from containers shared by participants during the household visit. This information was verified during the clinic visit; changes in drug and supplement usage were also collected at this time (Statistics Canada 2011a). Supplemental folic acid use - whether consumed alone or as a multivitamin - in the 30 days prior to the clinic visit was determined by matching drug identification and natural health product numbers to product information extracted from the Health Canada Drug Product and Licensed Natural Health Product databases (Statistics Canada 2011a; Health Canada 2011a, 2011b). This approach was also used to quantify vitamin $B_{12}$ supplement use - again, whether consumed alone or as a multivitamin.

\section{Intake of folate-rich foods}

A brief, nonquantitative food frequency questionnaire was used to examine the usual frequency of consumption from the grains and fruit and vegetables categories to assess dietary habits for food sources of folate (Statistics Canada 2011a). Combined, these food groups have been shown to represent $62 \%$ to $78 \%$ of dietary folate intake in the Canadian diet (Sherwood et al. 2006; Shuaibi et al. 2008; Statistics Canada 2011a). The derived variable for fruit and vegetables included usual intake of fruit, tomatoes, lettuce, dark greens, and other vegetables - not including juices or potatoes. Usual intake of cereal, white bread, brown bread, and pasta were combined to formulate the derived variable for grains.

\section{Smoking}

Self-reported smoking status and history were used to categorize participants as current, former, or never smokers.

\section{Physical activity}

A physical activity index of active, moderately active, or inactive was derived on the basis of average daily energy ex- penditure values during self-reported leisure time activities in the 3 months prior to the household visit (Statistics Canada 2011b).

\section{Clinical factors}

Derived variable for clinical risk factor

A derived variable was created to combine self-reported diabetes mellitus, use of folic acid antagonist medication, and overweight/obese. Drug identification numbers were matched to data extracts from the Drug Product Database to identify folic acid antagonist medication consumption in the 30 days prior to the clinic visit (Stabler 2010; Statistics Canada 2011a). Measured height and weight were used to calculate body mass index (BMI; $\mathrm{kg} \cdot \mathrm{m}^{-2}$ ), which was then used to classify participants as neither overweight nor obese, or overweight/obese. The BMI status of adults, excluding pregnant women, was classified using Health Canada's guidelines (BMI of 25 to $29.9 \mathrm{~kg} \cdot \mathrm{m}^{-2}$ indicates overweight; BMI of $>30 \mathrm{~kg} \cdot \mathrm{m}^{-2}$ indicates obesity) (Health Canada 2003). Participants aged 15 to 17 years were classified as being norma weight, overweight, or obese, based on definitions proposed by the International Obesity Task Force (Cole et al. 2000) BMI was also examined as a separate predictor.

\section{Vitamin $B_{12}$ concentrations}

Serum vitamin $B_{12}$ was assessed using the Immulite 2000 immunoassay, a solid-phase, competitive chemiluminescent enzyme immunoassay involving an automated alkaline denaturation procedure. The cut-off for marginal vitamin $\mathrm{B}_{12}$ status was determined to be $\leq 221 \mathrm{pmol} \cdot \mathrm{L}^{-1}$ (Siemans Canada 2006; Allen 2009).

\section{Statistical analysis}

Descriptive statistics (frequencies, percentiles) were used to characterize the population. Missing values for predictor variables were removed for individual analysis. Univariate logistic regression analysis was used to examine each covariate as a correlate of folate concentrations $\geq 906 \mathrm{nmol} \cdot \mathrm{L}^{-1}$; it was followed by a separate logistic regression analysis that controlled for age and income. $t$ tests were used to study the differences between folic acid supplement users and nonusers for each correlate. All estimates were based on data weighted to represent the Canadian population. Variance estimation (95\% confidence intervals) and significance testing were based on the bootstrap technique to account for the complex sampling design (Rust and Rao 1996). Analyses were conducted with SAS 9.1.3 (SAS Institute Inc., Cary, N.C., USA) and SUDAAN v.10.0 (RTI International, Research Triangle Park, N.C., USA), using DDF $=11$ in the SUDAAN procedure statements. Given the 11 degrees of freedom available for variance estimation, Satterthwaite-adjusted statistics were used to test the significance $(p<0.05)$ of each regression model's coefficients, rather than testing the significance of individual parameters (Bushnik et al. 2010).

\section{Results}

Prevalence of RBC folate concentrations $\geq 906 \mathrm{nmol} \cdot \mathrm{L}^{-1}$

The greatest proportion of RBC folate concentrations $\geq 906 \mathrm{nmol} \cdot \mathrm{L}^{-1}$ occurred in the highest income quartile (Table 1). The 2 older age groups (20-45 years of age) had a 
Table 1. Associations between red blood cell folate $\geq 906 \mathrm{nmol} \cdot \mathrm{L}^{-1}$ and sociodemographic, behavioural, and clinical factors in Canadian women of childbearing age

\begin{tabular}{|c|c|c|c|c|c|c|}
\hline \multirow[b]{2}{*}{ Factors } & \multirow[b]{2}{*}{$n$} & \multirow[b]{2}{*}{ Weighted $n(\%)$} & \multicolumn{2}{|l|}{ Percentage $(95 \% \mathrm{CI})$} & \multirow{2}{*}{$\begin{array}{l}\text { Crude OR } \\
(95 \% \mathrm{CI})\end{array}$} & \multirow{2}{*}{$\begin{array}{l}\text { Adjusted OR* } \\
(95 \% \text { CI })\end{array}$} \\
\hline & & & $<906 \mathrm{nmol} \cdot \mathrm{L}^{-1}$ & $\geq 906 \mathrm{nmol} \cdot \mathrm{L}^{-1}$ & & \\
\hline \multicolumn{7}{|l|}{ Sociodemographic factors ${ }^{8}$} \\
\hline \multicolumn{7}{|l|}{ Age $(y)$} \\
\hline $15-19$ & 290 & $1058500(15.9)$ & $30.0(19.5,43.1)^{\dagger}$ & $70.0(56.9,80.5)$ & & \\
\hline $20-39$ & 643 & $4300600(64.4)$ & $20.4(12.3,31.9)^{\dagger}$ & $79.6(68.1,87.7)$ & & \\
\hline $40-45$ & 229 & $1317400(19.7)$ & $19.2(9.04,36.3)^{\dagger}$ & $80.8(63.7,91.0)$ & & \\
\hline \multicolumn{7}{|l|}{ Income quartile } \\
\hline Q1 & 322 & $1863300(27.9)$ & $25.3(12.7,44.1)^{\dagger}$ & $74.7(55.9,87.3)$ & & \\
\hline Q2 & 251 & $1437900(21.5)$ & $23.2(12.2,39.7)^{\dagger}$ & $76.8(60.3,87.8)$ & & \\
\hline Q3 & 272 & $1548900(23.2)$ & $19.8(13.9,27.5)$ & $80.2(72.5,86.1)$ & & \\
\hline Q4 & 215 & $1230300(18.4)$ & $<28.4(5.96,28.4)^{\ddagger}$ & $86.3(71.6,94.0)$ & & \\
\hline Missing & 102 & $596100(8.9)$ & $27.7(17.7,40.7)^{\dagger}$ & $72.3(59.3,82.3)$ & & \\
\hline \multicolumn{7}{|l|}{ Household education } \\
\hline Less than postsecondary graduation & 232 & $1373600(21.1)$ & $31.0(20.9,43.4)^{\dagger}$ & $69.0(56.6,79.1)$ & $0.52(0.33,0.82)$ & $0.65(0.41,1.02)$ \\
\hline Postsecondary graduation & 906 & $5151600(78.9)$ & $18.9(11.2,30.1)^{\dagger}$ & $81.1(69.9,88.8)$ & 1 & 1 \\
\hline \multicolumn{7}{|l|}{ Canadian born } \\
\hline No & 221 & $1353500(20.3)$ & $15.8(8.48,27.6)^{\dagger}$ & $84.2(72.4,91.5)$ & $1.60(0.92,2.80)$ & $1.84(1.03,3.30)$ \\
\hline Yes & 940 & $5320900(79.7)$ & $23.2(14.3,35.2)^{\dagger}$ & $76.8(64.8,85.7)$ & 1 & 1 \\
\hline \multicolumn{7}{|l|}{ Behavioural factors ${ }^{8}$} \\
\hline \multicolumn{7}{|l|}{ Folic acid supplement (last $30 \mathrm{~d}$ ) } \\
\hline Yes (at least 1) & 276 & $1653500(24.8)$ & $12.1(5.51,24.6)^{\dagger}$ & $87.9(75.4,94.5)$ & 1 & 1 \\
\hline No & 886 & $5023000(75.2)$ & $<24.8(15.6,37.0)^{\ddagger}$ & $75.2(63.0,84.4)$ & $0.42(0.22,0.81)$ & $0.47(0.24,0.92)$ \\
\hline \multicolumn{7}{|l|}{ Vitamin $B_{12}$ supplement (last $30 \mathrm{~d}$ ) } \\
\hline Yes (at least 1) & 282 & $4961000(74.3)$ & $12.2(5.41,25.1)^{\dagger}$ & $87.8(74.9,94.6)$ & 1 & 1 \\
\hline No & 880 & $1715500(25.7)$ & $<37.0(15.8,37.0)^{\ddagger}$ & $75.1(63.0,84.2)$ & $0.42(0.22,0.80)$ & $0.46(0.24,0.89)$ \\
\hline \multicolumn{7}{|l|}{ Clinical factors ${ }^{8}$} \\
\hline \multicolumn{7}{|l|}{ Vitamin $B_{12}$ concentrations } \\
\hline Marginal $\left(\leq 221 \mathrm{pmol} \cdot \mathrm{L}^{-1}\right)$ & 327 & $104300(29.7)$ & $26.6(16.8,39.5)^{\dagger}$ & $73.4(60.5,83.2)$ & $0.68(0.47,0.98)$ & $0.68(0.46,0.99)$ \\
\hline Replete $\left(>221 \mathrm{pmol} \cdot \mathrm{L}^{-1}\right.$ & 793 & $151600(70.3)$ & $19.7(11.6,31.7)^{\dagger}$ & $80.3(68.3,88.4)^{\dagger}$ & 1 & 1 \\
\hline
\end{tabular}

Replete $\left(>221 \mathrm{pmol} \cdot \mathrm{L}^{-1}\right.$

Satterthwaite $F$ statistic $(p<0.05)$. OR, odds ratio

controlling for age and income.

Fen vampling variability; coefficient of variation $\geq 16.6 \%$ and $<33.3 \%$ ).

limit of the $95 \%$ confidence interval (CI).

sOnly determinants that demonstrated significance in the adjusted model are shown in the table $(p<0.05)$ 
higher prevalence of $\mathrm{RBC}$ folate $\geq 906 \mathrm{nmol} \cdot \mathrm{L}^{-1}$ than the youngest age group. A total of $24.8 \%$ of the study population reported taking a folic acid supplement in the 30 days prior to the clinic visit. Folic acid supplement users had a greater prevalence of RBC folate concentration $\geq 906 \mathrm{nmol} \cdot \mathrm{L}^{-1}$ $(87.9 \%)$ than nonusers $(75.2 \%)$.

\section{Correlates of RBC folate concentrations $\geq 906 \mathrm{nmol} \cdot \mathrm{L}^{-1}$}

Participants who did not report folic acid supplement consumption were significantly less likely to have a folate concentration $\geq 906 \mathrm{nmol} \cdot \mathrm{L}^{-1}$ (Table 1), after controlling for age and income. For example, WCBA who did not report taking a folic acid supplement were less likely to have folate concentrations $\geq 906 \mathrm{nmol} \cdot \mathrm{L}^{-1}$ than folic acid supplement users (odds ratio (OR) $0.47 ; 95 \%$ CI $0.24,0.92$; Satterthwaite $F$ statistic $<0.05$ ). Participants not born in Canada were more likely than Canadian-born participants to have folate concentrations $\geq 906 \mathrm{nmol} \cdot \mathrm{L}^{-1}$ (OR 1.84; $95 \%$ CI 1.03, 3.30). Participants who consumed supplements containing vitamin $\mathrm{B}_{12}$ were also more likely than nonconsumers to have a RBC folate concentration $\geq 906 \mathrm{nmol} \cdot \mathrm{L}^{-1}$ (OR $0.46 ; 95 \%$ CI 0.24 , 0.89 ). Participants with marginal vitamin $B_{12}$ status were significantly less likely to have optimal folate concentrations than those who were vitamin $\mathrm{B}_{12}$ replete (OR $0.68 ; 95 \%$ CI $0.46,0.99)$.

\section{Differences between folic acid supplement users and nonusers}

Twenty-five percent of Canadian WCBA reported consuming a folic acid supplement. A higher prevalence of folic acid supplement users than nonusers were in the highest income quartile $(28.8 \%$ (95\% CI $22.5,36.1)$ and $15.0 \%$ (95\% CI $12.7,17.7$ ), respectively) (Table 2). Conversely, nonusers were more prevalent than users in the lowest income quartile (30.9\% (95\% CI 23.9, 38.8) and 18.9 (95\% CI 10.3, 32.1), respectively). Folic acid supplement users were more prevalent in association with vitamin $\mathrm{B}_{12}$ supplement use. A higher percentage of folic acid supplement use was evident among participants who consumed fruit and vegetables 3 or more times per day, and lower in participants who consumed fruit and vegetables less than once per day.

The cumulative percent distributions for supplement users and nonusers are shown in Fig. 1. The median RBC folate concentration for folic acid supplement users was significantly higher than that for nonusers, although both groups had a median $\mathrm{RBC}$ folate $\geq 906 \mathrm{nmol} \cdot \mathrm{L}^{-1}\left(1470 \mathrm{nmol} \cdot \mathrm{L}^{-1}\right.$ and $1141 \mathrm{nmol} \cdot \mathrm{L}^{-1}$, respectively) (Fig. 1).

\section{Discussion}

This study provides new information on the correlates of RBC folate concentrations considered optimal for NTD reduction in Canadian WCBA since fortification of the food supply with folic acid began. The most significant correlate of optimal RBC folate concentration for this subgroup was folic acid supplement intake, which in turn was significantly related to income, with a greater percentage of folic acid supplement users in the highest income group.

Studies of subgroups of WCBA have demonstrated comparable results, showing folic acid supplement intake as a strong, modifiable factor associated with $\mathrm{RBC}$ folate concen- trations $\geq 906 \mathrm{nmol} \cdot \mathrm{L}^{-1}$. For example, 40 healthy women, aged 18-45 years, from Toronto, who did not use supplements, were randomly assigned to consume supplements of $5.0 \mathrm{mg}$ or $1.1 \mathrm{mg}$ for 30 weeks. This resulted in an increase in mean RBC folate concentrations, from $1121 \pm$ $410 \mathrm{nmol} \cdot \mathrm{L}^{-1}$ and $1035 \pm 273 \mathrm{nmol} \cdot \mathrm{L}^{-1}$ to $2339 \pm$ $782 \mathrm{nmol} \cdot \mathrm{L}^{-1}$ and $1625 \pm 339 \mathrm{nmol} \cdot \mathrm{L}^{-1}$, respectively (Nguyen et al. 2009). In the United States, postfortification data showed that in a prospective sample of primarily white women, aged 22 to 25 years, supplement use was a strong predictor of RBC folate concentration, and folic acid supplement users had a higher mean RBC folate $\left(983 \pm 65 \mathrm{nmol} \cdot \mathrm{L}^{-1}\right)$ than nonusers (Brown et al. 1997). Another sample of nonsupplementing WCBA from the National Health and Nutrition Examination Survey (NHANES) was examined before and after the fortification of the food supply with folic acid, revealing that $90 \%$ of the sample participants were not achieving levels associated with NTD risk reduction (Dietrich et al. 2005). Further, a study of a sample of healthy pregnant women from Northern Ireland revealed that the proportion of women with RBC folate concentrations $<906 \mathrm{nmol} \cdot \mathrm{L}^{-1}$ increased if they started taking folic acid later in the prenatal period, from $27 \%$ at preconception, to $38 \%$ at $0-6$ gestational weeks, to $53 \%$ at $\geq 6$ gestational weeks (McNulty et al. 2011).

A recent study of the CHMS data showed that one-fifth of Canadian WCBA are not achieving optimal concentrations of $\mathrm{RBC}$ folate, although this subgroup is not folate deficient (RBC folate $<305 \mathrm{nmol} \cdot \mathrm{L}^{-1}$ ) (Colapinto et al. 2011); median folate concentrations were greater than the cut-off of $906 \mathrm{nmol} \cdot \mathrm{L}^{-1}$ for both supplement users and nonusers. Folic acid supplement use in our study population was comparable to another nationally representative study of Canadians (the 2004 Canadian Community Health Survey), which demonstrated consumption in $15 \%, 23 \%$, and $29 \%$ of women aged 14-18, 19-30, and 31-50 years, respectively (Shakur et al. 2010). The 2006 Maternity Experiences Survey, which examined women giving birth in Canada, found that $58 \%$ of these women reported taking folic acid at some point during the 3 months before conception (Chalmers et al. 2008). Further, in the United States, similar population-level data (20032006 NHANES) demonstrated that $25 \%$ of WCBA consumed a folic acid supplement (Tinker et al. 2010). The correlation between lower income and decreased prevalence of folic acid supplement use was also reflected in a systematic review of international research (1989 to 2006) on folic acid supplement intake, as well as in a study of the 2004 Canadian Community Health Survey data (Stockley and Lund 2008; Vatanparast et al. 2010). Considering the possible income disparity related to folate concentration and supplement intake established in our study, and the similar inequality that has been identified for NTD risk, low-income WCBA may be an important target population for folic acid supplement interventions. Interestingly, participants who are not Canadian born were more likely to have folate concentrations $\geq 906 \mathrm{nmol} \cdot \mathrm{L}^{-1}$, but no significant relationship was found between birth place and folic acid supplement intake. Factors such as specific dietary habits, country of origin, and length of time since immigration to Canada - the study of which are beyond the scope of this analysis - may provide insight into this finding. 
Table 2. Folic acid supplement use in Canadian women of childbearing age.

\begin{tabular}{|c|c|c|}
\hline Variables & $\begin{array}{l}\text { All women, \% } \\
(95 \% \mathrm{CI})\end{array}$ & $\begin{array}{l}\text { Supplement users, \% } \\
(95 \% \mathrm{CI})\end{array}$ \\
\hline \multicolumn{3}{|l|}{ RBC folate concentration } \\
\hline Suboptimal $\left(<906 \mathrm{nmol} \cdot \mathrm{L}^{-1}\right)$ & $21.7(13.4,33.1)$ & $<24.6(5.51,24.6)^{\ddagger}$ \\
\hline Optimal $\left(\geq 906 \mathrm{nmol} \cdot \mathrm{L}^{-1}\right)$ & $78.3(66.9,86.6)$ & $87.9(75.4,94.5)$ \\
\hline \multicolumn{3}{|l|}{ Sociodemographic factors* } \\
\hline \multicolumn{3}{|l|}{ Income quartile } \\
\hline Q1 & $27.9(21.2,35.8)$ & $18.9(10.3,32.1)^{\dagger}$ \\
\hline Q2 & $21.5(17.3,26.4)$ & $18.5(12.4,26.7)$ \\
\hline Q3 & $23.2(18.9,28.2)$ & $25.0(17.6,34.2)$ \\
\hline Q4 & $18.4(15.4,21.9)$ & $28.8(22.5,36.1)$ \\
\hline Missing & $8.93(6.48,12.2)$ & $<20.3(3.57,20.3)^{\ddagger}$ \\
\hline \multicolumn{3}{|l|}{ Behavioural factors* } \\
\hline \multicolumn{3}{|c|}{ Vitamin $\mathrm{B}_{12}$ supplement (last $30 \mathrm{~d}$ ) } \\
\hline Yes (at least 1) & $74.3(71.4,77.0)$ & $97.7(95.8,97.9)$ \\
\hline No & $25.7(23.0,28.6)$ & $2.98(2.14,4.15)$ \\
\hline \multicolumn{3}{|l|}{ Daily fruit and vegetable intake } \\
\hline Less than once per day & $5.71(3.42,9.37)^{\dagger}$ & $<6.22(1.40,6.22)^{\ddagger}$ \\
\hline 1 to 2 times per day & $40.7(34.8,46.8)$ & $32.8(21.5,46.4)^{\dagger}$ \\
\hline 3 or more times per day & $53.6(45.7,61.4)$ & $64.3(50.9,75.7)$ \\
\hline \multicolumn{3}{|l|}{ Clinical factor* } \\
\hline \multicolumn{3}{|l|}{ Vitamin $\mathrm{B}_{12}$ concentration } \\
\hline Marginal $\left(\leq 221 \mathrm{pmol} \cdot \mathrm{L}^{-1}\right)$ & $29.7(26.4,22.3)$ & $16.4(10.2,25.4)^{\dagger}$ \\
\hline Replete $\left(>221 \mathrm{pmol} \cdot \mathrm{L}^{-1}\right)$ & $70.3(66.7,73.6)$ & $83.6(74.6,89.8)$ \\
\hline \multicolumn{3}{|c|}{$\begin{array}{l}\text { Note: These analyses are for participants with a value for } \mathrm{RBC} \text { folate }(n=1162 \text {, missing } n=45) \text {. Bo } \\
\text { type indicates significance at Satterthwaite } F \text { statistic }(p<0.05) \text {. }\end{array}$} \\
\hline \multirow{2}{*}{\multicolumn{3}{|c|}{$\begin{array}{l}\text { *Only determinants that demonstrated significance in the } t \text { test are shown in the table. } \\
\text { Interpret with caution (high sampling variability; coefficient of variation } \geq 16.6 \% \text { and }\langle 33.3 \% \text { ). } \\
{ }^{\dagger} \text { Estimate not provided because of extreme sampling variability or small sample size; if the coefficie }\end{array}$}} \\
\hline & & \\
\hline \multicolumn{3}{|c|}{$\begin{array}{l}\text { variation of the estimate is greater than } 33 \% \text {, the estimate is indicated as being less than the upper limit of } \\
\text { the } 95 \% \text { confidence interval. }\end{array}$} \\
\hline
\end{tabular}

Fig. 1. Cumulative percentile distributions of red blood cell folate concentrations by folic-acid supplement use from the 2007-2009 Canadian Health Measures Survey. Folate concentrations considered optimal for maximal neural tube defect risk reduction $\left(906 \mathrm{nmol} \cdot \mathrm{L}^{-1}\right)$ is indicated by the vertical line. The median folate concentration for each group is indicated by the dashed horizontal line. *, Significant difference in medians.

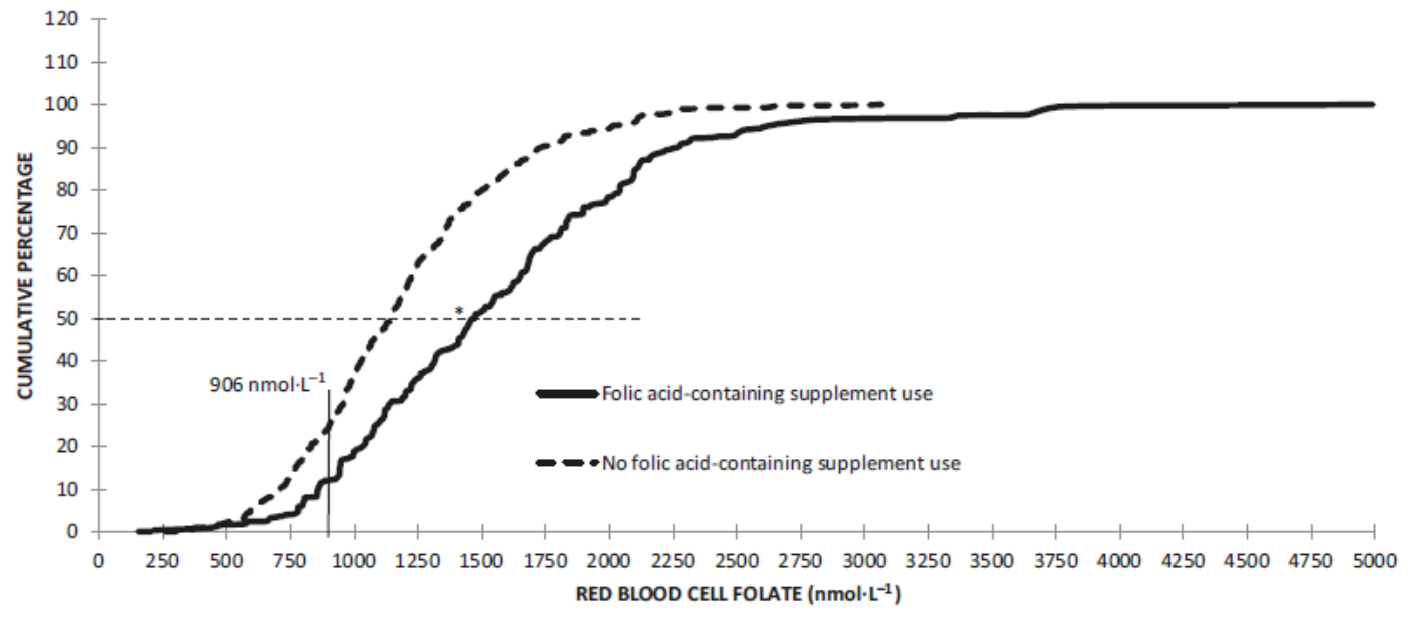

Conflicting findings regarding the health impact of consuming folic acid may lead women to become disenchanted with periconceptional folic acid supplement use, regardless of the undisputed benefit of NTD risk reduction and the important link between optimal folate concentration and lower risk of congenital heart disease and oral clefts. Fuelling this 
controversy is a recent study suggesting that supplement use does not offer an additional benefit for NTD risk reduction when taken with grains that are fortified with folic acid (Ahrens et al. 2011). Further, an association between folic acid supplement use and adverse health outcomes - including an increased risk of asthma, obesity, insulin resistance, and breast cancer in offspring - has been hypothesized, and there is speculation that there is a link between the high intake of folic acid and an increased risk of cancer in those with pre-existing neoplasms, and the potential for vitamin $\mathrm{B}_{12}$ masking (Mason et al. 2007; Cole et al. 2007; Yajnik et al. 2008; Allen 2009; Hirsch et al. 2009; Ly et al. 2011). It is notable that in our study, the participants with marginal vita$\min B_{12}$ status were less likely to have optimal RBC folate concentrations. This may be due to a lower intake of supplements containing vitamin $\mathrm{B}_{12}$, which in our sample often appeared to be taken in combination with folic-acid-containing supplements, a behaviour that is supported by Canadian guidelines (Health Canada 2010b). This study reinforces the importance of taking folic acid supplements to achieve optimal concentrations.

This research used a nationally representative study, which included a large sample size, directly measured biomarkers, and access to drug identification numbers and natural health product numbers. The cross-sectional nature of the CHMS does not allow for causal inferences, and the number of independent variables included in the regression model was limited by the 11 degrees of freedom. Future cycles of the CHMS would benefit from the inclusion of more detailed nutrition information to complement RBC folate concentration data, so that the impact of folate-related policies can be more thoroughly examined over time. WCBA incapable of becoming pregnant, for reasons of physiology or medication use, were not examined separately in this study.

It has been established that interlaboratory differences in values for RBC folate exist, although RBC folate is defined by the Institute of Medicine as the primary biochemical index to formulate the dietary reference intakes (Institute of Medicine 1998; Pfeiffer et al. 2010). As a result, study-to-study comparisons need to be performed with caution. It is acknowledged that the cut-off used in our study is assay dependent; however, it is standard practice to use the same cutoff values, regardless of RBC folate methods. For example, the US Centres for Disease Control and Prevention reported that at least 1 competitive binding assay resulted in RBC folate concentrations approximately $30 \%$ lower than either microbiological or liquid chromatography-tandem mass spectrometry (Fazili et al. 2008). Notably, the RBC folate cut-off of $906 \mathrm{nmol} \cdot \mathrm{L}^{-1}$ used in this study was initially established by Daly et al. (1995), using a microbiological assay, except in our study, no correction was made for serum folate concentration. We employed strict quality-control procedures to ensure both the accuracy and precision of the RBC folate measurements to minimize this limitation.

The RBC folate cut-off of $906 \mathrm{nmol} \cdot \mathrm{L}^{-1}$ represents the upper limit of the continuous, inverse dose-response relationship between RBC folate concentration and folate-dependent NTDs theorized by Daly et al. (1995), and should not be considered an absolute determinant of folate-dependent NTD risk. Future research investigating the incidence of folatedependent NTDs, optimal RBC folate concentration, and folic acid supplement use is needed to provide insight into this relationship.

In conclusion, folic acid supplement use was the most significant predictor of WCBA achieving optimal RBC folate concentrations for maximal NTD risk reduction. The importance of folic acid supplementation for WCBA must be distinguished from the needs of the general population. Future research is needed to investigate the dose and duration of intake that is most favourable for achieving optimal concentrations in different populations. These data indicate a need for targeted strategies to improve compliance with folic acid supplement recommendations to assist WCBA in achieving desired folate concentrations.

\section{Acknowledgements}

The authors thank the Health Analysis Division at Statistics Canada, in particular Tracey Bushnik and Michelle Rotermann for their support during the analysis stage of this research, and the Physical Health Measures Division at Statistics Canada for preparing and granting special access to data. The authors also thank Trevor Stewart for his review and feedback on the manuscript. This research was supported by a CIHR Health Professionals Fellowship in the area of public health to Cynthia Colapinto (funding reference no. 180375) and a CIHR Operating Grant (funding reference no. 218776). Authors statement of contributions: All of the authors contributed to the conception and design of the study. Cynthia Colapinto conducted the analysis, and all authors assisted in the interpretation of the results. Cynthia Colapinto drafted the manuscript, and all authors critically reviewed the manuscript for important intellectual content and approved the final version submitted for publication.

\section{References}

Ahrens, K., Yazdy, M.M., Mitchell, A.A., and Werler, M.M. 2011. Folic acid intake and spina bifida in the era of dietary folic acid fortification. Epidemiology, 22(5): 731-737. doi:10.1097/EDE. 0b013e3182227887. PMID:21659881.

Allen, L. 2009. How common is vitamin B-12 deficiency? Am. J. Clin. Nutr. 89(2 Supp): 693S-696S. doi:10.3945/ajen.2008. 26947A. PMID:19116323.

Berry, R.J., Mulinare, J., and Hamner, H. 2010. Folic acid fortification: Neural tube defect risk reduction - A global perspective. In Folate in health and disease. 2nd ed. Edited by L.B. Bailey. CRC Press; Taylor \& Francis Group. Boca Raton, Fla., USA. pp. 179-204.

- Brown, J.E., Jacobs, D.R., Jr, Hartman, TJ., Barosso, G.M., Stang, J.S., Gross, M.D., and Zeuske, M.A. 1997. Predictors of red cell folate level in women attempting pregnancy. JAMA, 277(7): 548552. doi:10.1001/jama.1997.03540310046033. PMD:9032161.

- Bryan, S., St-Denis, M., and Wojtas, D. 2007. Canadian Health Measures Survey: clinic operations and logistics. Health Rep. 18(Suppl.): 53-70. PMID:18210870.

Bushnik, T., Haines, D., Levallois, P., Levesque, J., Van Oostdam, J., and Viau, C. 2010. Lead and bisphenol A concentrations in the Canadian population. Health Rep. 21(3): 7-18. PMID:20973429.

Chalmers, B., Dzakpasu, S., Heaman, M., and Kaczorowski, J. 2008. The Canadian Maternity Experiences Survey: An overview of findings. J. Obstet. Gynaecol. Can. 30(3): 217-228. PMID: 18364099.

Colapinto, C.K., O’Connor, D.L., and Tremblay, M.S. 2011. Folate 
status of the population in the Canadian Health Measures Survey. CMAJ, 183(2): E100-E106. doi:10.1503/cmaj.100568. PMID: 21149516.

-Cole, B.F., Baron, J.A., Sandler, R.S., Haile, R.W., Ahnen, D.J. Bresalier, R.S., et al.Polyp Prevention Study Group. 2007. Folic acid for the prevention of colorectal adenomas: A randomized clinical trial. JAMA, 297(21): 2351-2359. doi:10.1001/jama.297. 21.2351. PMID: 17551129

-Cole, TJ., Bellizzi, M.C., Flegal, K.M., and Dietz, W.H. 2000. Establishing a standard definition for child overweight and obesity worldwide: International survey. BMJ, 320(7244): 1240-1243. doi:10.1136/bmj.320.7244.1240. PMID:10797032.

Daly, L.E., Kirke, P.N., Molloy, A., Weir, D.G., and Scott, J.M. 1995 Folate levels and neural tube defects. Implications for prevention. JAMA, 274(21): 1698-1702. doi:10.1001/jama.1995. 03530210052030 . PMID:7474275.

-De Wals, P., Tairou, F., Van Allen, M.I., Lowry, R.B., Evans, J.A., Van den Hof, M.C., et al. 2008. Spina bifida before and after folic acid fortification in Canada. Birth Defects Res. A Clin. Mol Teratol. 82(9): 622-626. doi:10.1002/bdra.20485. PMID 18655127.

Dietrich, M., Brown, C.J., and Block, G. 2005. The effect of folate fortification of cereal-grain products on blood folate status, dietary folate intake, and dietary folate sources among adult nonsupplement users in the United States. J. Am. Coll. Nutr. 24(4): 266-274. PMID:16093404.

-Fazili, Z., Pfeiffer, C.M., Zhang, M., Jain, R.B., and Koontz, D. 2008. Influence of 5,10-methylenetetrahydrofolate reductase polymorphism on whole-blood folate concentrations measured by LC-M.S M.S., microbiologic assay, and bio-rad radioassay. Clin. Chem. 54(1): 197-201. doi:10.1373/clinchem.2007.096545. PMID: 18160726.

Health Canada. 2003. Canadian guidelines for body weight classification in adults. Cat no.: H49-179. Ottawa, Ont., Canada.

Health Canada. 2010a. Prenatal nutrition. Available from http://www. hc-sc.gc.ca/fn-an/nutrition/prenatal/index-eng.php. [Accessed 30 August 2011.]

Health Canada. 2010b. High dose folic acid supplementation questions and answers for health professionals. Available from http://www.hc-sc.gc.ca/fn-an/nutrition/prenatal/fol-qa-qr-eng. php\#a2. [Accessed 30 August 2011.]

Health Canada. 2011a. Drug Product Database. Ottawa, Ont., Canada. Available from http://www.hc-sc.gc.ca/dhp-mps/prodpharma/databasdon/index-eng.php. [Accessed 15 Aug 2011.

Health Canada. 2011b. Licensed Natural Health Products Database. Ottawa, Ont., Canada. Available from http://www.hc-sc.gc.ca/ dhp-mps/prodnatur/applications/licen-prod/nnhpd-bdpsnh-eng.php. [Accessed 15 August 2011.]

Hirsch, S., Sanchez, H., Albala, C., Maza, M.P., Barrera, G., Leiva, L., and Bunout, D. 2009. Colon cancer in Chile before and after the start of the flour fortification program with folic acid. Eur. J. Gastroenterol. Hepatol. 21(4): 436-439. doi:10.1097/MEG. Ob013e328306ccdb. PMID:19190501.

Institute of Medicine. 1998. DRI dietary reference intakes for thiamin, riboflavin, niacin, vitamin $\mathrm{B}_{6}$, folate, vitamin $\mathrm{B}_{12}$, pantothenic acid, biotin, and choline. National Academy Press, Washington, D.C., USA.

-Ly, A., Lee, H., Chen, J., Sie, K.K., Renlund, R., Medline, A., et al. 2011. Effect of maternal and postweaning folic acid supplementation on mammary tumor risk in the offspring. Cancer Res. 71(3): 988-997. doi:10.1158/0008-5472.CAN-10-2379. PMID: 21135116.

-Mason, J.B., Dickstein, A., Jacques, P.F., Haggarty, P., Selhub, J., Dallal, G., and Rosenberg, I.H. 2007. A temporal association between folic acid fortification and an increase in colorectal cancer rates may be illuminating important biological principles: A hypothesis. Cancer Epidemiol. Biomarkers Prev. 16(7): 13251329. doi:10.1158/1055-9965.EPI-07-0329. PMID:17626997.

McNulty, B., Pentieva, K., Marshall, B., Ward, M., Molloy, A.M., Scott, J.M., and McNulty, H. 2011. Women's compliance with current folic acid recommendations and achievement of optimal vitamin status for preventing neural tube defects. Hum. Reprod. 26(6): 1530-1536. doi:10.1093/humrep/der078. PMID:21441543.

-Nguyen, P., Tam, C., O'Connor, D.L., Kapur, B., and Koren, G. 2009. Steady state folate concentrations achieved with 5 compared with $1.1 \mathrm{mg}$ folic acid supplementation among women of childbearing age. Am. J. Clin. Nutr. 89(3): 844-852. doi:10. 3945/ajen.2008.26878. PMID:19158211.

Pfeiffer, C.M., Fazili, Z, and Zhang, M. 2010. Folate analytical methodology. In LB Bailey, editor. Folate in health in disease. 2nd ed. CRC Press, Taylor \& Francis Group. Boca Raton, Fla., USA.

-Refsum, H. 2001. Folate, vitamin B12 and homocysteine in relation to birth defects and pregnancy outcome. Br. J. Nutr. 85(Suppl. 2): S109-S113. doi:10.1079/BJN2000302. PMID:1 1509098.

Rust, K.F., and Rao, J. 1996. Variance estimation for complex surveys using replication techniques. Stat. Methods Med. Res. 5(3): 283310. doi:10.1177/096228029600500305. PMID:8931 197.

- Shakur, Y.A., Garriguet, D., Corey, P., and O'Connor, D.L. 2010. Folic acid fortification above mandated levels results in a low prevalence of folate inadequacy among Canadians. Am. J. Clin. Nutr. 92(4): 818-825. doi:10.3945/ajen.2010.29696. PMID: 20739423 .

-Sherwood, K.L., Houghton, L.A., Tarasuk, V., and O'Connor, D.L. 2006. One-third of pregnant and lactating women may not be meeting their folate requirements from diet alone based on mandated levels of folic acid fortification. J. Nutr. 136(11): 2820 2826. PMID:17056807.

-Shuaibi, A.M., House, J.D., and Sevenhuysen, G.P. 2008. Folate status of young Canadian women after folic acid fortification of grain products. J. Am. Diet. Assoc. 108(12): 2090-2094. doi:10. 1016/j.jada.2008.09.007. PMID:19027414.

Siemans Canada. 2006. Immulite 2000 vitamin $B_{12}$ package insert \#P1L2KVB-22. 2006. Siemans Canada Ltd. Mississauga, Ont., Canada.

Siemans Canada. 2009. Immulite 2000 folic acid insert. Siemans Canada Ltd., Mississauga, Ont., Canada.

Stabler, S., Clinical folate deficiency. 2010. In Folate in health and disease. 2nd ed. Edited by L.B. Bailey. CRC Press, Taylor \& Francis Group. Boca Raton, Fla., USA. pp. 409-428.

Statistics Canada. 2008. Income trends in Canada: 1980-2003. Ottawa, Ont., Canada. Cat no. 13F0022XIE. Available from http:// www.statcan.gc.ca/pub/13f0022x/00003/notedef/5801 170-eng. htm\#famsize. [Accessed 29 March 2011.]

Statistics Canada. 2011a. Questionnaire $(s)$ and reporting guide $(s)-$ Canadian Health Measures Survey (CHMS). Ottawa, Ont., Canada. Available from http://www.statcan.gc.ca/cgi-bin/imdb/ p2SV.pl?Function=getInstrumentLink\&SurvItem_Id=9353\&Query_Id $=10263 \&$ Query $=$ instance\&lang=en \&db=imdb\&adm $=8 \&$ dis $=2$. [Accessed 4 April 2011.]

Statistics Canada. 2011 b. Canadian Health Measures Survey (CHMS) Cycle 1 Wave 1 Derived Variable (DV) Specifications. Ottawa, ON. Available from http://www.statcan.gc.ca/imdb-bmdi/document/ 5071_D3_T9_V2-eng.pdf. [Accessed 18 April 2011.]

-Stockley, L., and Lund, V. 2008. Use of folic acid supplements, particularly by low-income and young women: A series of systematic reviews to inform public health policy in the UK. Public Health Nutr. 11(8): 807-821. doi:10.1017/ S1368980008002346. PMID: 18457601.

Published by NRC Research Press 
- Tam, C., McKenna, K., Goh, Y.I., Klieger-Grossman, C., O’Connor, D.L., Einarson, A., and Koren, G. 2009. Periconceptional folic acid supplementation: A new indication for therapeutic drug monitoring. Ther. Drug Monit. 31(3): 319-326. doi:10.1097/FTD. Ob013e31819f3340. PMID:19349928.

Tinker, S.C., Cogswell, M.E., Devine, O., and Berry, R.J. 2010. Folic acid intake among U.S. women aged 15-44 years, National Health and Nutrition Examination Survey, 2003-2006. Am. J. Prev. Med. 38(5): 534-542. doi:10.1016/j.amepre.2010.01.025. PMID: 20347553.
-Vatanparast, H., Adolphe, J.L., and Whiting, SJ. 2010. Socioeconomic status and vitamin/ mineral supplement use in Canada. Health Rep. 21(4): 19-25. PMID:21269008.

Yajnik, C.S., Deshpande, S.S., Jackson, A.A., Refsum, H., Rao, S., Fisher, D.J., et al. 2008. Vitamin $\mathrm{B}_{12}$ and folate concentrations during pregnancy and insulin resistance in the offspring: The Pune maternal nutrition study. Diabetologia, 51(1): 29-38. doi:10.1007/ s00125-007-0793-y. PMID:17851649. 


\subsection{Prevalence of high RBC folate concentration using three proposed cut-offs}

Authors: Cynthia K. Colapinto ${ }^{1,2}$, Deborah L. O’Connor ${ }^{3,4}$, Lise Dubois ${ }^{2}$, Mark S. Tremblay ${ }^{1,5}$

1. Healthy Active Living and Obesity Research Group, Children's Hospital of Eastern Ontario Research Institute

2. Institute of Population Health, University of Ottawa

3. Physiology and Experimental Medicine, The Hospital for Sick Children

4. Department of Nutritional Sciences, University of Toronto

5. Department of Pediatrics, University of Ottawa

This manuscript was written in accordance with the specifications for submission to the European Journal of Clinical Nutrition. 


\section{ABSTRACT}

\section{Background:}

A distinct shift towards higher RBC folate concentrations has emerged in Canadians. These higher concentrations have known benefits, including neural tube defect prevention, but concerns have been raised regarding potential associations with adverse health outcomes. A universal definition of high $\mathrm{RBC}$ folate concentration does not exist. The aim of this research is to create dialogue by examining hypothetical cut-offs for high RBC folate concentrations.

Methods:

The research examined biochemical measures of RBC folate - adjusted from Immulite 2000 immunoassay to microbiologic assay - using Canadian Health Measures Survey data, a nationally representative, cross-sectional sample of Canadians $(\mathrm{N}=5248)$, aged 6 to 79 years. High RBC folate cut-offs were proposed to capture a range of postulated high folate values from the literature. Where sample size allowed, we used t-tests to examine differences between age, sex, income and body mass index groups and logistic regression to explore folic acid supplement use at each proposed cut-off.

Results:

Participants had 16\%, 6\% and 2\% prevalence of having high RBC folate cut-offs of 1450 $\mathrm{nmol} / \mathrm{L}, 1800 \mathrm{nmol} / \mathrm{L}$ and $2150 \mathrm{nmol} / \mathrm{L}$, respectively. Females, participants aged 60 to 79 years and those who were overweight or obese had the greatest prevalence of having high RBC folate at each cut-off. Folic acid supplement users were more likely than non-users to have high RBC folate.

Interpretation:

Folic acid supplement use is a correlate of high RBC folate concentration. A universal definition 
for high RBC folate will advance the field towards consistent measurement and reporting of high folate status and related health outcomes.

Keywords: folic acid, folate, red blood cell folate, RBC folate, high folate, Canadian Health Measures Survey, CHMS

\section{INTRODUCTION}

Folate is a nutrient with a significant population health impact. While best known for its role in reducing neural tube defects, folate has also been implicated in the etiology of other beneficial health outcomes, such as decreased risk of congenital heart defects and oral cleft and, at adequate levels, lower risk of breast, lung and prostate cancer. ${ }^{1-3}$ Folate deficiency (RBC folate $<305$ $\mathrm{nmol} / \mathrm{L}$ ) is virtually non-existent in Canada, likely due to the 1998 introduction of mandatory fortification of certain grain products with folic acid and increased use of folic acid-containing multivitamin and mineral supplements. ${ }^{4-7}$ Mandatory folic acid fortification has been associated with a $46 \%$ reduction in neural tube defect births. ${ }^{8}$

Women of childbearing age were the target of folic acid enhancement interventions; however, fortification strategies expose the entire population. ${ }^{5}$ Amidst this public health success story are speculations that high intake may lead to adverse health outcomes. Dissipating interest in deficiency has been replaced with concerns that population folate concentrations may be elevated. ${ }^{6,9,10}$ Proposed adverse effects include increased risk of colorectal cancer in those with pre-existing neoplasms and cognitive impairment in older adults with unmetabolized folic acid in their serum. ${ }^{3,11-14}$

Studies proposing adverse health outcomes have been refuted by others. For example, recent systematic reviews and meta-analyses have demonstrated a beneficial or neutral effect in 
the etiology of cancer. ${ }^{15,16}$ The lack of consensus in this field confirms that the study of high folate concentrations is an important area of investigation that will ultimately inform future clinical practice, research on health outcomes and folic acid policies. A universal definition of high folate status does not exist. The aim of this research is to create dialogue by examining three hypothetical cut-offs for high RBC folate concentrations.

\section{METHODS}

Data from the 2007-09 Canadian Health Measures Survey (CHMS) were used for these analyses. The survey methodology is described briefly here and in greater detail elsewhere. ${ }^{17,18}$

CHMS sampling: The CHMS used a complex, multi-stage, cluster sampling protocol to achieve a nationally representative cross-sectional sample. The final sample included 5604 Canadians aged 6 to 79 years balanced by sex in each of the following age groups: 6 to 11,12 to 19,20 to 39, 40 to 59, and 60 to 79 years and is representative of approximately $96 \%$ of the Canadian population. People living in institutions, on Indian reserves or Crown lands, full-time members of the Canadian Armed Forces, and residents of certain remote regions were excluded.

Survey methods: A Statistics Canada interviewer administered a detailed in-home health questionnaire that included sociodemographic characteristics. One day to six weeks later, blood samples were taken by a certified phlebotomist in a mobile examination centre for later determination of a variety of analytes, including RBC folate. ${ }^{18}$ Of the 8,772 dwellings selected, $70 \%$ agreed to participate; $88 \%$ participated in the household survey and of those, $85 \%$ attended the mobile clinic. The overall response rate was $52 \%$. Implied consent occurred in the household and a comprehensive consent process was employed in the clinic. ${ }^{19}$

Ethics approval for the CHMS was obtained from the Health Canada Research Ethics Board 
and we obtained institutional ethics approval for this secondary data analysis.

Determination of $R B C$ folate content and high RBC folate cut-offs: Blood was taken from 5373 CHMS participants with 5248 providing a usable sample for RBC folate measurement, weighted to represent 28 million Canadians who met the CHMS inclusion criteria. Participants who refused to participate in the blood draw or did not have a usable sample were excluded $(n=356)$. RBC folate allows for an estimate of tissue folate stores. ${ }^{4}$ Venipuncture samples were collected in EDTA-treated vacutainers, then immediately processed on-site. After hematocrit measurement, aliquots of whole blood were frozen, stored at $-20^{\circ} \mathrm{C}$ and shipped weekly to the Health Canada Nutrition Laboratory on dry ice. ${ }^{18}$ Samples were thawed, diluted (1-in-26) with $0.5 \%$ ascorbic acid solution, allowed to incubate for 180 minutes at room temperature and then analyzed for RBC folate using the Immulite 2000 immunoassay (Siemens Canada Ltd., Mississauga). ${ }^{20} \mathrm{RBC}$ folate was calculated from the measured whole-blood folate concentration adjusting for RBC volume, without correction for plasma folate. Accuracy and reproducibility of these procedures was assessed using the manufacturers' serum controls (Con6: Tri-level multiconstituent control and tri-level BioRad ImmunoassayPlus) and whole blood controls (BioRad Lyphochek Whole Blood, 2 levels; BioRad Laboratories, Hercules, CA). Serum controls had an inter-assay coefficient of variation of $<8 \%$ and all analyzed controls (serum, whole blood) were within $10 \%$ of target values.

As it was reported that the Immulite 2000 immunoassay measures RBC folate higher than the microbiologic assay, RBC folate data were adjusted to be comparable to the microbiologic assay in the laboratory of one of the authors (DLO). ${ }^{21}$ The microbiologic assay in this laboratory was conducted using an assay medium containing Lactobacillus rhamnosus (NCIB 10463) and a calibration curve generated using 5-methyltetrahydrofolate, as per the method of Molloy et al., 
with modification. ${ }^{22,23}$ Microbiological assay is considered the gold standard for determining RBC folate concentration. ${ }^{24}$ A methods comparison study between the CHMS Immulite 2000 immunoassay and microbiologic assay was used to generate the following conversion equation. ${ }^{25}$ Predicted microbiologic assay $=-22.95+0.81 *$ Immulite 2000 immunoassay. We applied this equation to the CHMS data, generating adjusted RBC folate values.

No universally accepted cut-off for high RBC folate is available and a scan of the literature revealed that few studies have examined high $\mathrm{RBC}$ folate concentrations, though definitions for high serum folate have been suggested. ${ }^{11,26-32}$ Table 1 outlines the 14 postulated RBC folate concentrations that informed our cut-offs. Three cut-offs were calculated by estimating the difference between the highest and lowest cut-off in Table 1 (rounded to the nearest hundred) divided by four $((2500 \mathrm{nmol} / \mathrm{L}-1100 \mathrm{nmol} / \mathrm{L}) / 4=350 \mathrm{nmol} / \mathrm{L})$ to capture the range of postulated high values. The three final cut-offs for RBC folate were $1450 \mathrm{nmol} / \mathrm{L}, 1800 \mathrm{nmol} / \mathrm{L}$ and 2150 nmol/L. The lowest of the two cut-offs proposed by Clarke et al. was not considered in our estimation. $^{28}$

\section{Potential correlates of high folate concentrations:}

Selected sociodemographic factors: The CHMS sample age groups were used for these analyses. ${ }^{18}$ Socioeconomic status was examined by per person household income equivalents that grouped respondent income into quartiles after adjusting for family size and composition.

Behavioural factors: The CHMS collected drug identification and natural health product numbers from supplement containers during household interviews and at the mobile clinic visit. ${ }^{33}$ Folic acid supplement use in the 30 days prior to the clinic visit and the supplement dose were determined by matching the drug and national health product numbers with the supplement composition information found in the Health Canada Drug Product Database and Licensed 
Natural Health Product Database. ${ }^{33-35}$ This process required a special request to access drug identification and natural health product number data that are not available on the CHMS master file.

Clinical factors: Measured height and weight were used to calculate body mass index (BMI, $\mathrm{kg} / \mathrm{m}^{2}$ ), by which participants were then classified as neither overweight nor obese or overweight/obese. The BMI status of adults, excluding pregnant women, was classified using Health Canada's guidelines ( 25 to 29.9 indicates overweight, $\geq 30$ indicates obesity). ${ }^{36}$ Participants aged 6 to 17 years were classified into two categories, neither overweight nor obese or overweight or obese, based on the World Health Organization cut-offs. ${ }^{37}$ Serum vitamin $B_{12}$ was assessed using the Immulite 2000 immunoassay (Siemens Canada Ltd., Mississauga), a solid phase, competitive chemiluminescent enzyme immunoassay involving an automated alkaline denaturation procedure. The cut-off for marginal Vitamin $\mathrm{B}_{12}$ status was determined to be $\leq 221 \mathrm{pmol} / \mathrm{L} \cdot{ }^{38,39}$ Serum controls had an interassay coefficient of variation of 9.6\% (manufacturer's \%CV) and all analyzed controls were within $10 \%$ of target values.

Statistical Analysis: Descriptive statistics (frequencies, percentiles) were used to characterize the population. The proportion of Canadians with high $\mathrm{RBC}$ folate was assessed at each of the three proposed cut-offs. Where sample sizes were adequate, we used t-tests to examine differences between sociodemographic, behavioural and clinical factors and logistic regression analyses to examine folic acid supplement use as a correlate of high folate concentrations. All estimates were based on weighted data to represent the Canadian population. Variance estimation (95\% confidence intervals) and significance testing were based on the bootstrap technique to account for the complex sampling design. ${ }^{40}$ Analyses were conducted in SAS 9.1.3 (SAS Institute Inc., Cary, NC) and SUDAAN v.10.0 (RTI International, Research Triangle Park, 
$\mathrm{NC}$ ), using DDF=11 in the SUDAAN procedure statements. Given the 11 degrees of freedom available for variance estimation, Satterthwaite-adjusted statistics were used to test the significance of each regression model's coefficients. ${ }^{41}$ Significance was defined as a p-value of $<0.05$.

\section{RESULTS}

Prevalence at each proposed high cut-off

Prevalence data for the population are presented in Table 2. In the general population, $16 \%, 6 \%$ and $2 \%$ of participants reached high RBC folate concentrations of $1450 \mathrm{nmol} / \mathrm{L}, 1800 \mathrm{nmol} / \mathrm{L}$ and $2150 \mathrm{nmol} / \mathrm{L}$, respectively. Higher prevalence of being above the RBC folate cut-offs occurred in females, participants 60 to 79 years, those who were overweight or obese, and folic acid supplement users. No consistent difference was found for income in the general population. Those with replete vitamin $\mathrm{B}_{12}$ concentrations had a higher prevalence of $\mathrm{RBC}$ folate concentrations above the $1450 \mathrm{nmol} / \mathrm{L}$ and $1800 \mathrm{nmol} / \mathrm{L}$ cut-offs than those who with low to marginal vitamin $\mathrm{B}_{12}$ concentrations.

Achieving high cut-off with supplement use

As we previously reported, $17 \%$ of the population consumed $\geq 1000 \mu \mathrm{g} / \mathrm{d}$ of folic acid as a

supplement. ${ }^{42}$ Less than $1 \%$ of the population reported use of a folic acid supplement $\geq 5000$ $\mu \mathrm{g} / \mathrm{d}$. Further, approximately $51 \%$ of the general population reported consuming doses of folic acid in the range of 400 to $999 \mu \mathrm{g} / \mathrm{d}$. Folic acid supplement users were more likely than nonusers to have high RBC folate, regardless of the cut-off (Figure 1). Supplement users had 5.6 times the odds of having folate concentrations $>1450 \mathrm{nmol} / \mathrm{L}$ than non-supplement users $(95 \% \mathrm{CI}$ 3.96, 7.82). Folic acid supplement users were also more likely than non-users to be above the 
proposed high cut-off at $1800 \mathrm{nmol} / \mathrm{L}(\mathrm{OR} 7.54 ; 95 \% \mathrm{CI} 4.22,13.46)$ and $2150 \mathrm{nmol} / \mathrm{L}(\mathrm{OR} 7.03$; 95\%CI 3.37, 14.65). These odds persisted after controlling for age, sex and income at 1450 $\mathrm{nmol} / \mathrm{L}$, though the sample size was too small to conduct multivariate analysis at $1800 \mathrm{nmol} / \mathrm{L}$ and $2150 \mathrm{nmol} / \mathrm{L}$. The small sample size also did not support an analysis of folic acid supplement dose at each cut-off.

\section{INTERPRETATION}

This study provides important information to characterize high RBC folate concentrations in the Canadian population. Using the proposed cut-offs of 1450,1800 and $2150 \mathrm{nmol} / \mathrm{L}$ it was determined that $16 \%, 6 \%$ and $2 \%$ of Canadians, respectively, may have high folate status. The proposed high $\mathrm{RBC}$ folate concentration cut-offs can be used by researchers and policy makers as a starting point to investigate and confirm the most appropriate definition for high folate status. This will also allow for the examination of relationships between high RBC folate concentrations and adverse health outcomes.

In these analyses, folic acid supplement use was a strong modifiable risk factor for high RBC folate concentrations, regardless of the proposed cut-off selected. Of note, the proposed high folate cut-offs are similar to the RBC folate concentrations - recently reported by ourselves and others - of participants consuming folic acid as a supplement at or above the Institute of Medicine's Tolerable Upper Intake Level (UL) of $1000 \mu \mathrm{g} /$ day. By definition the UL is the highest intake of a nutrient thought to pose no adverse health effects in healthy individuals. For folate, the UL is set at $1000 \mu \mathrm{g} / \mathrm{d}$ of synthetic folic acid based on the lowest observed adverse effect level $(5000 \mu \mathrm{g} / \mathrm{d})$, a dose that could potentially mask neurological symptoms of vitamin 
$\mathrm{B}_{12}$ deficiency and an uncertainty factor of 5 , which accounts for the limited evidence and uncertainty in the process of defining a UL. ${ }^{43}$

For example, we previously reported the RBC folate concentrations in a sample of healthy women, (18-45 years) from Toronto, randomly assigned to consume daily supplements of 1100 $\mu \mathrm{g} / \mathrm{d}$ or $5000 \mu \mathrm{g} / \mathrm{d}$ (a dose approximately equal to the UL and the lowest observed adverse effect level, respectively) for 30 weeks. At the end of the study period the mean RBC folate concentrations (measured by microbiologic assay) rose from $1035 \pm 273 \mathrm{nmol} / \mathrm{L}$ and $1121 \pm 410$ $\mathrm{nmol} / \mathrm{L}$ to $1625 \pm 339 \mathrm{nmol} / \mathrm{L}$ and $2339 \pm 782 \mathrm{nmol} / \mathrm{L}$, among women randomized to the 1100 $\mu \mathrm{g} / \mathrm{d}$ and $5000 \mu \mathrm{g} / \mathrm{d}$ folic acid supplement respectively. ${ }^{44}$ Adults $>65$ years of age in New Zealand ( $\mathrm{n}=276$ ) were given a daily placebo or $1 \mathrm{mg} / \mathrm{d}$ folic acid supplement over a two year period as part of a double-blind randomized controlled trial (RCT) to examine time to achieve steady-state concentrations. The supplemented group demonstrated considerable increases in $\mathrm{RBC}$ folate concentrations (measured by microbiologic assay) from $980 \mathrm{nmol} / \mathrm{L}$ at baseline to 2750 at 6 months and $3230 \mathrm{nmol} / \mathrm{L}$ at 24 months. ${ }^{45}$ It is notable at the time of this latter study there was no mandatory folic acid fortification program in New Zealand. Nonetheless, the Toronto and New Zealand studies together suggest that supplemental folic acid doses in the range of the UL elicit RBC folate concentrations similar to or above our proposed high cut-offs of 1800 and $2150 \mathrm{nmol} / \mathrm{L}$.

The primary strengths of this study include a large, nationally representative sample, directly measured biomarkers and in-person collection of folic acid supplement information. Further, the CHMS data were harmonized with the proposed cut-offs by adjusting the RBC folate concentrations from Immulite 2000 immunoassay to microbiologic assay. Interassay differences in $\mathrm{RBC}$ folate measures can be profound and harmonizing results to a common assay method 
should be considered when formulating a universal definition of high folate concentrations. The overall response rate for the CHMS was slightly above $50 \%$. While the survey weights ensured that the sample was representative of the target population, bias might exist if the RBC folate concentrations of non-respondents differed systematically from those of respondents.

It is paramount to consider that concerns regarding high folate concentrations for the general population should not overshadow the health benefit of women of childbearing age achieving adequate folate concentrations for optimal protection against neural tube defects $(\geq 906 \mathrm{nmol} / \mathrm{L})$. The risk of neural tube defect birth is reduced when women consume folic acid three months prior to conception and continue this behaviour for 21 to 28 days into their pregnancy. ${ }^{46}$ Considering that an estimated $50 \%$ of pregnancies are unplanned, Canadian guidelines recommend that women capable of becoming pregnant consume a folic acid (400 $\mu / d)$ containing multivitamin supplement, in addition to folate-rich foods. In the present paper, three high RBC folate concentration cut-offs are proposed (1450, 1800 and $2150 \mathrm{nmol} / \mathrm{L})$. The lowest cut-off selected is more than four times the cut-off for folate deficiency $(305 \mathrm{nmol} / \mathrm{L})$ and the highest two cut-offs are similar to recent controlled trials where a folic acid supplement was provided at the UL proposed by the U.S. Institute of Medicine. Universal cut-off values for defining high RBC folate will advance the field towards consistent measurement and reporting of high folate status and related health outcomes. Future research may reveal that a range of RBC folate values, rather than a specific cut-off, may promote maximal health benefits for the population at minimal risk. This definition will ultimately inform the debate on appropriate public health interventions and clinical guidelines for folic acid. 
Table 1: Proposed high red blood cell (RBC) folate cut-offs from literature scan

\begin{tabular}{|c|c|c|c|c|c|}
\hline & $\begin{array}{l}\text { RBC } \\
\text { folate cut- } \\
\text { off } \\
(\mathrm{nmol} / \mathrm{L})\end{array}$ & $\begin{array}{l}\text { 2007-2008 National } \\
\text { Health and Nutrition } \\
\text { Examination Survey } \\
\text { (NHANES) serum } \\
\text { folate percentile* }\end{array}$ & $\begin{array}{l}\text { Pre or Post } \\
\text { fortification }\end{array}$ & Rationale & Citation \\
\hline & \multicolumn{5}{|c|}{ Based on American population distribution percentile } \\
\hline $\mathbf{1}$ & 1360 & N/A & Post & $\begin{array}{l}\text { Examination of Canadian Health Measures Survey } \\
\text { (CHMS) folate data using a cut-off based on the } 97^{\text {th }} \\
\text { percentile of BioRad 1999-2004 NHANES, as recent } \\
\text { national Canadian data were unavailable. }{ }^{47}\end{array}$ & Colapinto CK et al., $2011^{6}$ \\
\hline 2 & 1370 & N/A & Pre & $\begin{array}{l}\text { Represents the } 90^{\text {th }} \text { percentile } 1988-1994 \text { NHANES } \\
\text { adjusted to microbiologic assay }\end{array}$ & Pfeiffer CM, et al. 2012. ${ }^{48}$ \\
\hline 3 & $1460 *$ & $\begin{array}{l}\text { RBC folate at the } 76^{\text {th }} \\
\% \text { ile }\end{array}$ & Post & $\begin{array}{l}\text { The authors used a serum folate of } 59 \mathrm{nmol} / \mathrm{L} \text {, which } \\
\text { was based on the } 80^{\text {th }} \text { percentile from early post- } \\
\text { fortification (1999-2002) NHANES data. For this table, } \\
\text { the cut-off of } 59 \mathrm{nmol} / \mathrm{L} \text { is assessed as a percentile using } \\
\text { the } 2007-2008 \mathrm{NHANES} \mathrm{data.} \\
\text { Authors found an inverse association with cognitive test } \\
\text { performance was demonstrated. }\end{array}$ & $\begin{array}{l}\text { Selhub J, et al. } 2009 .^{26} \\
\text { Morris MC, et al. } 2005 .^{27} \\
\text { Morris MS, et al. } 2010 .^{11}\end{array}$ \\
\hline 4 & $1540^{*}$ & $\begin{array}{l}\text { RBC folate at the } 80^{\text {th }} \\
\text { percentile }\end{array}$ & Post & $\begin{array}{l}\text { As above, but corresponding RBC folate to the } 80^{\text {th }} \\
\text { percentile of the } 2007-2008 \text { NHANES data. }\end{array}$ & As above for \#3 \\
\hline 5 & 1630 & N/A & Pre & $\begin{array}{l}\text { Represents the } 95^{\text {th }} \text { percentile 1988-1994 NHANES } \\
\text { adjusted to microbiologic assay. }\end{array}$ & Pfeiffer CM, et al. 2012. ${ }^{48}$ \\
\hline 6 & 1820 & N/A & Late Post & $\begin{array}{l}\text { Represents the } 90^{\text {th }} \text { percentile } 2005-2010 \text { NHANES } \\
\text { adjusted to microbiologic assay. }\end{array}$ & As above \\
\hline 7 & 1880 & N/A & Pre & $\begin{array}{l}\text { Represents the } 97.5^{\text {th }} \text { percentile } 1988-1994 \text { NHANES } \\
\text { adjusted to microbiologic assay. }\end{array}$ & As above \\
\hline 8 & 2140 & N/A & Late Post & $\begin{array}{l}\text { Represents the } 95^{\text {th }} \text { percentile } 2005-2010 \text { NHANES } \\
\text { adjusted to microbiologic assay. }\end{array}$ & As above \\
\hline
\end{tabular}




\begin{tabular}{|c|c|c|c|c|c|}
\hline & $\begin{array}{l}\text { RBC } \\
\text { folate cut- } \\
\text { off } \\
(\mathbf{n m o l} / \mathrm{L})\end{array}$ & $\begin{array}{l}\text { 2007-2008 National } \\
\text { Health and Nutrition } \\
\text { Examination Survey } \\
\text { (NHANES) serum } \\
\text { folate percentile* }\end{array}$ & $\begin{array}{l}\text { Pre or Post } \\
\text { fortification }\end{array}$ & Rationale & Citation \\
\hline 9 & 2490 & N/A & Late Post & $\begin{array}{l}\text { Represents the } 97.5^{\text {th }} \text { percentile } 2005-2010 \text { NHANES } \\
\text { adjusted to microbiologic assay. }\end{array}$ & As above \\
\hline & \multicolumn{5}{|c|}{ Association with cognitive impairment in seniors (in addition to those cited by \#3, \#4 and \#12) } \\
\hline 10 & $913^{*}$ & $\begin{array}{l}\text { Lower of two cut-offs } \\
\text { proposed by Clarke et al } \\
\text { RBC folate at the } 30^{\text {th }} \\
\% \text { ile }\end{array}$ & $\begin{array}{l}\text { Voluntary fort } \\
\text { in UK }\end{array}$ & $\begin{array}{l}\text { Cut-off of } 30 \mathrm{nmol} / \mathrm{L} \text { serum, corresponds to the } 30^{\text {th }} \\
\text { percentile of the } 2007-2008 \text { NHANES. } \\
\text { Authors found no evidence of modification by high } \\
\text { folate status of the associations } \\
\text { of low } B_{12} \text { with anaemia or cognitive impairment. }\end{array}$ & Clarke, R, et al. $2008{ }^{28}$ \\
\hline 11 & $1480 *$ & $\begin{array}{l}\text { RBC folate at the } 77^{\text {th }} \\
\text { \%ile }\end{array}$ & As above & $\begin{array}{l}\text { Cut-off of } 60 \mathrm{nmol} / \mathrm{L} \text { serum, which corresponds to the } \\
77^{\text {th }} \text { percentile of the 2007-2008 NHANES. } \\
\text { The authors found no evidence of modification by high } \\
\text { folate status of the associations } \\
\text { of low } B_{12} \text { with anaemia or cognitive impairment }\end{array}$ & As above \\
\hline & \multicolumn{5}{|c|}{ Estimated based on relationship between DFEs and RBC folate } \\
\hline 12 & 1090 & N/A & Post & $\begin{array}{l}\text { This cut-off was estimated in correspondence to a } \\
\text { relationship between DFEs and RBC folate determined } \\
\text { by Quinlivan and Gregory, here representing } 2.1 \text { DFEs, } \\
\text { or a combined intake of the recommended daily } \\
\text { allowance for the general population ( } 0.4 \mathrm{mg} \text { DFEs) and } \\
\text { a } 1 \mathrm{mg} \text { folic acid supplement }\end{array}$ & MacFarlane AJ, et al. 2011.49 \\
\hline & \multicolumn{5}{|c|}{ Folate above calibration of machine or where unmetabolized folic acid appears in the serum } \\
\hline 13 & $1200^{*}$ & $\begin{array}{l}\text { RBC folate at the } 58^{\text {th }} \\
\text { \%ile }\end{array}$ & Post & $\begin{array}{l}\text { Pfeiffer et al. and Fazilli et al. arbitrarily assigned this } \\
\text { cut-off because of the upper end of the calibration curve } \\
\text { is } 45 \mathrm{nmol} / \mathrm{L} \text { for serum, which corresponds to the } 58^{\text {th }} \\
\text { percentile for the } 2007-2008 \text { NHANES. } \\
\text { Fazili et al. also noted an appreciable increase in folic } \\
\text { acid concentrations greater than } \sim 50 \mathrm{nmol} / \mathrm{L} \text { total folate. } \\
\text { Miller et al. found that low vitamin } B_{12} \text { is associated with }\end{array}$ & $\begin{array}{l}\text { Pfeiffer CM, et al. } 2005 .{ }^{29} \\
\text { Fazili A, et al., 2007. }{ }^{30} \\
\text { Miller JW, et al. 2009. }{ }^{31} \\
\text { Hirsch, S., et al. 2008. }{ }^{32}\end{array}$ \\
\hline
\end{tabular}




\begin{tabular}{|c|c|c|c|c|c|}
\hline & $\begin{array}{l}\text { RBC } \\
\text { folate cut- } \\
\text { off } \\
(\mathbf{n m o l} / \mathrm{L})\end{array}$ & $\begin{array}{l}\text { 2007-2008 National } \\
\text { Health and Nutrition } \\
\text { Examination Survey } \\
\text { (NHANES) serum } \\
\text { folate percentile* }\end{array}$ & $\begin{array}{l}\text { Pre or Post } \\
\text { fortification }\end{array}$ & Rationale & Citation \\
\hline & & & & $\begin{array}{l}\text { more pronounced metabolic evidence of vitamin } \mathrm{B}_{12} \\
\text { deficiency when folate is elevated above this cut-off than } \\
\text { when folate is not elevated. No difference in cognitive } \\
\text { function or dementia. } \\
\text { Hirsch et all used } 45 \mathrm{nmol} / \mathrm{L} \text {, but rationalized as the } \\
\text { upper quintile }\end{array}$ & \\
\hline & \multicolumn{5}{|c|}{ No rationale given } \\
\hline 14 & 1700 & N/A & Post & No rationale provided & Bor MV, et al. 2008. ${ }^{50}$ \\
\hline
\end{tabular}

* derived from percentile curves for serum and RBC folate from 2007-2008 NHANES 
Table 2: Prevalence of the Canadian population above proposed high RBC folate cut-offs by sociodemographic, behavioural and clinical factors $(n=5248$, unless otherwise indicated)

\begin{tabular}{|c|c|c|c|c|c|c|}
\hline & & & Population & \multicolumn{2}{|c|}{ Prevalence (\% (95\% CI)) } & \\
\hline & $\mathbf{N}$ & Weighted $\mathbf{N}^{\mathbb{\pi}}$ & $\%$ & $>1450 \mathrm{nmol} / \mathrm{L}$ & $>1800 \mathrm{nmol} / \mathrm{L}$ & $>2150 \mathrm{nmol} / \mathrm{L} * *$ \\
\hline Total population & 5248 & & 100 & $16.4(12.6,21.0)$ & $5.86(4.1,8.4)^{\dagger}$ & $2.41(1.5,3.9)^{\dagger}$ \\
\hline \multicolumn{7}{|l|}{ Sociodemographic factors } \\
\hline \multicolumn{7}{|l|}{ Age (years) } \\
\hline $6-11$ & 911 & 1830800 & 17.4 & $6.0(3.9,9.1)^{* \dagger}$ & suppressed $^{\dagger}$ & suppressed $^{\dagger}$ \\
\hline $12-19$ & 945 & 3110000 & 18.0 & $5.6(3.2,9.5)^{* \dagger}$ & suppressed $^{\dagger}$ & suppressed $^{\dagger}$ \\
\hline 20-39 & 1150 & 8749000 & 21.9 & $12.0(8.7,16.4)^{*}$ & $3.6(1.8,6.9)^{* \dagger}$ & $1.4(0.7,2.7)^{* \dagger}$ \\
\hline 40-59 & 1202 & 9546000 & 22.8 & $20.0(14.7,26.6)^{*}$ & $7.3(5.2,10.3)^{* \dagger}$ & $2.98(1.4,5.7)^{\dagger}$ \\
\hline $60-79$ & 1040 & 4700500 & 19.8 & $28.2(21.4,36.2)^{8}$ & $12.5(7.7,19.5)^{\S}$ & $5.8(2.8,11.3)^{\S \dagger}$ \\
\hline \multicolumn{7}{|l|}{ Income quartile } \\
\hline Q1 & 1368 & 6434800 & 26.1 & $13.0(9.1,18.2) *$ & $5.0(3.1,8.0)^{\dagger}$ & $2.7(1.3,5.5)^{\dagger}$ \\
\hline Q2 & 1242 & 6523600 & 23.7 & $16.3(11.0,23.4)^{\dagger}$ & $5.9(2.8,11.9)^{\dagger}$ & suppressed $^{\ddagger}$ \\
\hline Q3 & 1196 & 6543400 & 22.9 & $15.5(10.6,22.1)^{\dagger}$ & $5.3(2.7,10.1)^{\dagger}$ & suppressed ${ }^{\ddagger}$ \\
\hline Q4 & 1110 & 6546400 & 21.6 & $20.8(15.2,27.8)^{\S}$ & $7.1(4.2,11.6)^{8 \dagger}$ & suppressed ${ }^{\ddagger}$ \\
\hline Missing & 332 & 1888100 & 6.12 & $15.4(8.9,25.4)^{\dagger}$ & $6.5(3.2,12.9)^{\dagger}$ & suppressed $^{\ddagger}$ \\
\hline \multicolumn{7}{|l|}{ Sex } \\
\hline Female & 2705 & 13910400 & 51.5 & $18.4(13.7,24.3)^{*}$ & $7.6(5.16,11.2)^{*^{\dagger}}$ & $3.3(2.0,5.6)^{*}$ \\
\hline Male & 2543 & 14025800 & 48.5 & $14.3(11.0,18.5)^{\S}$ & $4.2(2.5,7.0)^{\$ \dagger}$ & $1.59(0.7,3.0)^{\S \dagger}$ \\
\hline \multicolumn{7}{|l|}{ Behavioural factors } \\
\hline \multicolumn{7}{|l|}{ Folic acid supplement (last 30 days) } \\
\hline Yes (at least one) & 1258 & 6869500 & 24.0 & $37.1(30.4,44.4) *$ & $16.2(11.4,22.4)^{* \dagger}$ & $6.7(4.3,10.4)^{\S \dagger}$ \\
\hline No & 3990 & 21066700 & 76.0 & $9.6(6.6,13.7)^{8 \dagger}$ & $2.5(1.4,4.4)^{\S \dagger}$ & suppressed $^{\ddagger}$ \\
\hline \multicolumn{7}{|l|}{ Clinical factors } \\
\hline \multicolumn{7}{|l|}{ Body mass index $(\mathrm{BMI})(\mathrm{N}=5217)$} \\
\hline Neither overweight nor obese & 2524 & 12172550 & 43.9 & $13.1(9.8,17.2)^{*}$ & $4.4(2.7,7.1)^{* \dagger}$ & $1.5(0.8,2.7)^{* \dagger}$ \\
\hline Overweight/Obese & 2693 & 15570370 & 56.1 & $18.5(14.0,24.1)^{\S}$ & $7.0(5.0,9.8)^{\S}$ & $3.1(1.9,5.2)^{8 \dagger}$ \\
\hline \multicolumn{7}{|l|}{ Vitamin $B_{12}$ concentrations $(\mathrm{N}=\mathbf{4 9 8 8})$} \\
\hline Low to marginal $(\leq 221 \mathrm{pmol} / \mathrm{L})$ & 1013 & 6150600 & 20.3 & $9.0(5.6,14.3))^{\dagger}$ & $1.5(0.8,2.6)^{* \dagger}$ & suppressed $^{\dagger}$ \\
\hline Replete (>221 pmol/L) & 3975 & 20611200 & 79.7 & $17.8(14.1,22.3)^{8}$ & $6.6(4.6,9.40)^{\S}$ & $2.9(1.8,4.8)^{\S \dagger}$ \\
\hline
\end{tabular}

* Significantly different from the reference group

Interpret with caution (high sampling variability; coefficient of variation $\geq 16.6$ and $<33.3$ )

Estimate suppressed because of extreme sampling variability or small sample size.

${ }^{\S}$ Reference group

"Estimates rounded to the nearest hundred 


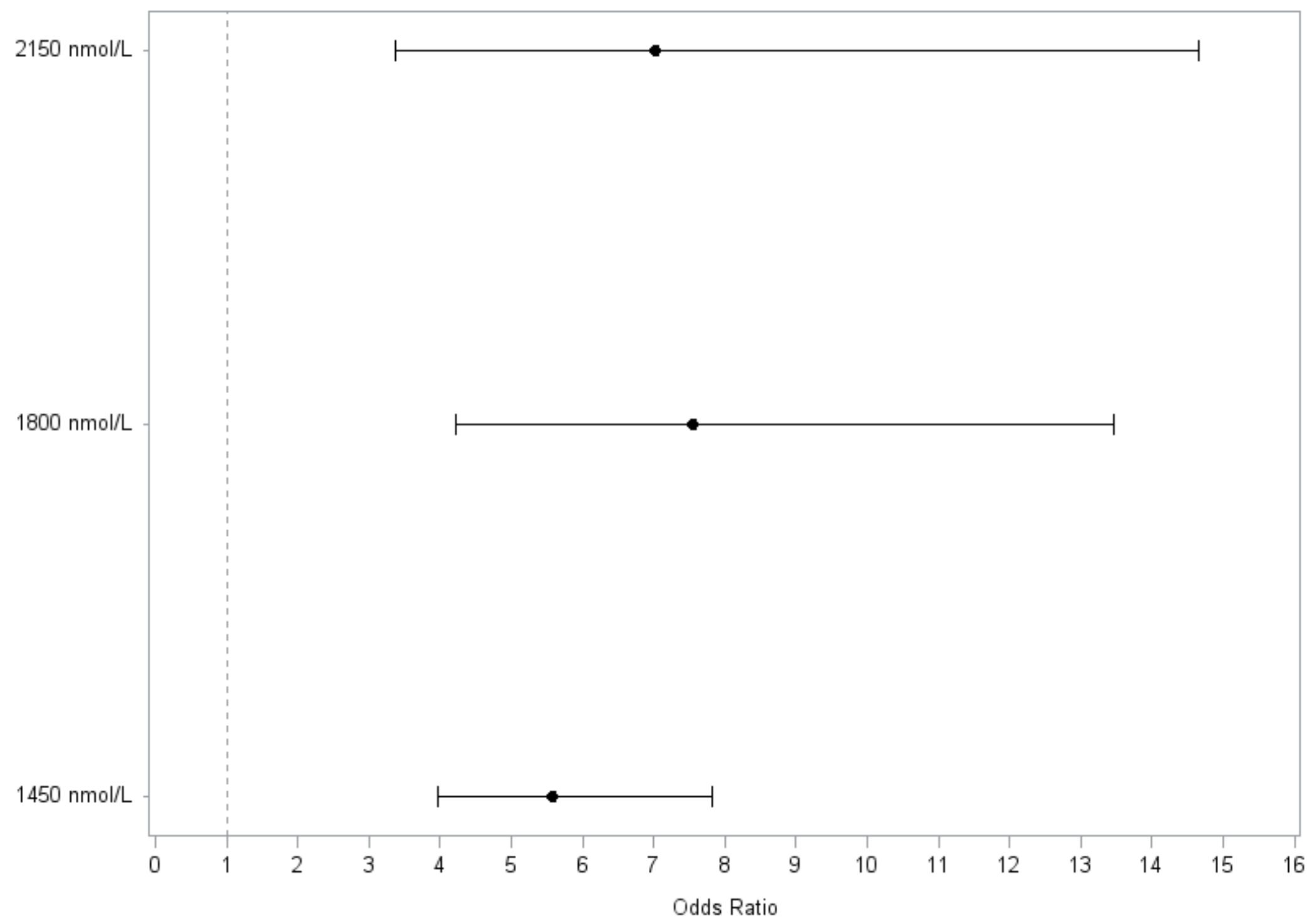




\section{LEGEND FOR FIGURE}

FIGURE 1: Forest plot of univariate logistic regression (Odds Ratio (OR), 95\% Confidence Interval (CI)) of proposed cut-offs for high $\mathrm{RBC}$ folate concentrations and folic acid supplement use in the general population $(\mathrm{N}=5248)$. 


\section{References}

1. Goh YI, Koren G. Folic acid in pregnancy and fetal outcomes. J Obstet Gynaecol 2008;28(1):3-13.

2. De-Regil LM, Fernandez-Gaxiola AC, Dowswell T, Peña-Rosas JP. Effects and safety of periconceptional folate supplementation for preventing birth defects (Review). In: The Cochrane Library, Issue 10, 2010. Chichester: Wiley.

3. Mason JB. Unraveling the complex relationship between folate and cancer risk. Biofactors $2011 ; 37(4): 253-60$.

4. Institute of Medicine. DRI dietary reference intakes for thiamin, riboflavin, niacin, vitamin B6, folate, vitamin B12, pantothenic acid, biotin, and choline. Washington, D.C.: National Academy Press; 1998.

5. Berry RJ, Mulinare J, Hamner H. Folic acid fortification. In: LB Bailey, editor. Folate in health and disease. $2^{\text {nd }}$ ed. Boca Raton, FL: CRC Press, Taylor \& Francis Group; 2010.

6. Colapinto CK, O'Connor DL, Tremblay MS. Folate status of the population in the Canadian Health Measures Survey. CMAJ 2011;183(2):E100-6.

7. Shakur YA, Garriguet D, Corey P, O'Connor DL. Folic acid fortification above mandated levels results in a low prevalence of folate inadequacy among Canadians. Am J Clin Nutr 2010;92(4):818-25.

8. De Wals P, Tairou F, Van Allen MI, Lowry RB, Evans JA, Van den Hof MC, et al. Spina bifida before and after folic acid fortification in Canada. Birth Defects Res A Clin Mol Teratol 2008;82(9):622-6.

9. Crider KS, Bailey LB, Berry RJ. Folic acid food fortification-its history, effect, concerns, and future directions. Nutrients $2011 \mathrm{Ma} ; 3(3): 370-84$.

10. Kim YI. Folic acid fortification and supplementation-good for some but not so good for others. Nutr Rev 2007;65(11):504-11.

11. Morris MS, Jacques PF, Rosenberg IH, Selhub J. Circulating unmetabolized folic acid and 5methyltetrahydrofolate in relation to anemia, macrocytosis, and cognitive test performance in American seniors. Am J Clin Nutr 2010;91(6):1733-44.

12. Fife J, Raniga S, Hider PN, Frizelle FA. Folic acid supplementation and colorectal cancer risk: A meta-analysis. Colorectal Dis 2011;13(2):132-7.

13. Baggott JE, Oster RA, Tamura T. Meta-analysis of cancer risk in folic acid supplementation trials. Cancer Epidemiol 2012;36(1):78-81.

14. Wien TN, Pike E, Wisloff T, Staff A, Smeland S, Klemp M. Cancer risk with folic acid supplements: A systematic review and meta-analysis. BMJ Open 2012;2(1):e000653.

15. Vollset SE, Clarke R, Lewington S, Ebbing M, Halsey J, Lonn E, et al. Effects of folic acid supplementation on overall and site-specific cancer incidence during the randomised trials: Meta-analyses of data on 50000 individuals. Lancet 2013;9871(381):1029-1036.

16. Science and Risk Directorate of the Ministry for Primary Industries. Voluntary folic acid fortification: Monitoring and evaluation report. New Zealand Government. Wellington, New Zealand, 2012.

17. Tremblay M, Wolfson M, Gorber SC. Canadian Health Measures Survey: Rationale, background and overview. Health Rep 2007;18 Suppl:7-20.

18. Bryan S, St-Denis M, Wojtas D. Canadian Health Measures Survey: Clinic operations and logistics. Health Rep 2007;18 Suppl:53-70. 
19. Day B, Langlois R, Tremblay M, Knoppers BM. Canadian Health Measures Survey: Ethical, legal and social issues. Health Rep 2007;18 Suppl:37-51.

20. Immulite 2000 folic acid insert. Mississauga (ON): Siemans Canada, Ltd.; 2009.

21. Icke GC, Dennis M, Sjollema S, Nicol DJ, Eikelboom JW. Red cell N5methyltetrahydrofolate concentrations and C677T methylenetetrahydrofolate reductase genotype in patients with stroke. J Clin Pathol 2004;57(1):54-7.

22. Molloy AM, Scott JM. Microbiological assay for serum, plasma, and red cell folate using cryopreserved, microtiter plate method. Methods Enzymol 1997;281:43-53.

23. Pfeiffer CM, Zhang M, Lacher DA, Molloy AM, Tamura T, Yetley EA, et al. Comparison of serum and red blood cell folate microbiologic assays for national population surveys. J Nutr 2011;141(7):1402-9.

24. Yetley EA, Coates PM, Johnson CL. Overview of a roundtable on NHANES monitoring of biomarkers of folate and vitamin $\mathrm{B}_{12}$ status: Measurement procedure issues. Am J Clin Nutr 2011;94(1):297S-302S.

25. Aufreiter S, Colapinto CK, Tremblay MT, Bushnik T, Pfeiffer CM, O'Connor DL. Comparison study between RBC folate measured by microbiologic assay and immulite 2000 immunoassay [Abstract]. The FASEB Journal 2013;27:1077.4.

26. Selhub J, Morris MS, Jacques PF, Rosenberg IH. Folate-vitamin $\mathrm{B}_{12}$ interaction in relation to cognitive impairment, anemia, and biochemical indicators of vitamin $\mathrm{B}_{12}$ deficiency. Am $\mathrm{J}$ Clin Nutr 2009;89(2):702S-6S.

27. Morris MC, Evans DA, Bienias JL, Tangney CC, Hebert LE, Scherr PA, et al. Dietary folate and vitamin B12 intake and cognitive decline among community-dwelling older persons. Arch Neurol 2005;62(4):641-5.

28. Clarke R, Sherliker P, Hin H, Molloy AM, Nexo E, Ueland PM, et al. Folate and vitamin $B_{12}$ status in relation to cognitive impairment and anaemia in the setting of voluntary fortification in the UK. Br J Nutr 2008;100(5):1054-9.

29. Pfeiffer CM, Caudill SP, Gunter EW, Osterloh J, Sampson EJ. Biochemical indicators of B vitamin status in the US population after folic acid fortification: Results from the National Health and Nutrition Examination Survey 1999-2000. Am J Clin Nutr 2005;82(2):442-50.

30. Fazili Z, Pfeiffer CM, Zhang M. Comparison of serum folate species analyzed by LCMS/MS with total folate measured by microbiologic assay and bio-rad radioassay. Clin Chem 2007;53(4):781-4.

31. Miller JW, Garrod MG, Allen LH, Haan MN, Green R. Metabolic evidence of vitamin B $B_{12}$ deficiency, including high homocysteine and methylmalonic acid and low holotranscobalamin, is more pronounced in older adults with elevated plasma folate. Am J Clin Nutr 2009;90(6):1586-92.

32. Hirsch S, Ronco AM, Guerrero-Bosagna C, de la Maza MP, Leiva L, Barrera G, et al. Methylation status in healthy subjects with normal and high serum folate concentration. Nutrition 2008;24(11-12):1103-9.

33. Statistics Canada. Questionnaire(s) and reporting guide(s) - Canadian Health Measures Survey (CHMS) Ottawa, ON Available from: http://www.statcan.gc.ca/cgibin/imdb/p2SV.pl?Function=getInstrumentLink\&SurvItem_Id=9353\&Query_Id=10263\&Q uery=instance \&lang=en $\& d b=i m d b \& a d m=8 \& d i s=2$. (accessed March 25, 2013).

34. Health Canada. Drug Product Database. Ottawa, ON. Available from: http://www.hcsc.gc.ca/dhp-mps/prodpharma/databasdon/index-eng.php. (accessed August 15, 2010). 
35. Health Canada. Licensed Natural Health Products Database Ottawa, ON. Available from: http://www.hc-sc.gc.ca.proxy.bib.uottawa.ca/dhp-mps/prodnatur/applications/licenprod/lnhpd-bdpsnh_data_extract-eng.php. (accessed August 15, 2010).

36. Health Canada. Canadian guidelines for body weight classification. Ottawa, ON: Health Canada; 2003. Report nr Catalogue H49-179.

37. Dietitians of Canada, Canadian Paediatric Society, College of Family Physicians of Canada, Community Health Nurses of Canada, Secker D. Promoting optimal monitoring of child growth in Canada: Using the new WHO growth charts. Can J Diet Pract Res 2010;71(1):e13.

38. Allen L. How common is vitamin $B_{12}$ deficiency? Am J Clin Nutr 2009;89(supp):693S-696S.

39. Immulite 2000 vitamin B12 package insert \#P1L2KVB-22. Mississauga (ON): Siemans Canada, Ltd.; 2006.

40. Rust K, Rao J. Variance estimation for complex surveys using replication techniques. Stat Methods Med Res 1996;5:281-310.

41. Statistics Canada. Canadian Health Measures Survey (CHMS) Data User Guide: Cycle 1. Available from: http://www.statcan.gc.ca/imdb-bmdi/document/5071 D2 T1 V1-eng.pdf. (accessed March 25, 2011).

42. Colapinto CK, O'Connor DL, Dubois L, Tremblay MS. Prevalence and correlates of folic acid supplement use in Canada. Health Rep 2012;23(2):39-44.

43. Zlotkin S. A critical assessment of the upper intake levels for infants and children. J Nutr 2006;136(2):502S-6S.

44. Nguyen P, Tam C, O'Connor DL, Kapur B, Koren G. Steady state folate concentrations achieved with 5 compared with $1.1 \mathrm{mg}$ folic acid supplementation among women of childbearing age. Am J Clin Nutr 2009;89(3):844-52.

45. Bradbury KE, Williams SM, Green TJ, McMahon JA, Mann JI, Knight RG, et al. Differences in erythrocyte folate concentrations in older adults reached steady-state within one year in a two-year, controlled, $1 \mathrm{mg} / \mathrm{d}$ folate supplementation trial. J Nutr 2012;142(9):1633-7.

46. Health Canada. Prenatal nutrition guidelines for health professionals - Folate contributes to a healthy pregnancy. Ottawa, ON: c2009. Available from: http://www.hc-sc.gc.ca/fnan/pubs/nutrition/folate-eng.php. (accessed March 25, 2013).

47. Pfeiffer CM, Johnson CL, Jain RB, Yetley EA, Picciano MF, Rader JI, et al. Trends in blood folate and vitamin $B_{12}$ concentrations in the United States, 1988-2004. Am J Clin Nutr 2007;86(3):718-27.

48. Pfeiffer CM, Hughes JP, Lacher DA, Bailey RL, Berry RJ, Zhang M, et al. Estimation of trends in serum and RBC folate in the U.S. population from pre- to postfortification using assay-adjusted data from the NHANES 1988-2010. J Nutr 2012;142(5):886-93.

49. MacFarlane AJ, Greene-Finestone LS, Shi Y. Vitamin $B_{12}$ and homocysteine status in a folate-replete population: Results from the Canadian Health Measures Survey. Am J Clin Nutr 2011;94(4):1079-87.

50. Bor MV, Wulff AM, Nexo E, Karup H. Infrequency of low red blood cell (RBC) folate levels despite no folate fortification program: A study based on results from routine requests for RBC folate. Clin Chem Lab Med 2008;46(3):401-4. 


\subsection{Comparison of Canadian and American red blood cell folate concentrations}

Authors: Cynthia K. Colapinto ${ }^{1,2}$, Mark S. Tremblay ${ }^{1,3}$, Susanne Aufreiter ${ }^{4}$, Tracey Bushnik ${ }^{5}$, Christine M. Pfeiffer ${ }^{6}$, Deborah L. O’Connor ${ }^{4,7}$

${ }^{1}$ Healthy Active Living and Obesity Research Group, Children's Hospital of Eastern Ontario Research Institute

${ }^{2}$ Institute of Population Health, University of Ottawa

${ }^{3}$ Department of Pediatrics, University of Ottawa

${ }^{4}$ Physiology and Experimental Medicine, The Hospital for Sick Children

${ }^{5}$ Health Analysis Division, Statistics Canada

${ }^{6}$ National Center for Environmental Health, CDC

${ }^{7}$ Department of Nutritional Sciences, University of Toronto

This manuscript was written in accordance with the specifications for submission to the Journal of Nutrition. 


\begin{abstract}
Fortification of certain grains with folic acid and guidelines for prenatal supplementation are designed to improve folate status and reduce the incidence of neural tube defects. Since these policies vary by country, this research aimed to compare nationally representative RBC folate concentrations from the 2007-2009 Canadian Health Measures Survey (CHMS) and the 20072008 US NHANES. RBC folate was assessed in participants aged 6 to 79 y (CHMS, $n=5248$; NHANES, $n=7070$ ) and a subset of women of childbearing age (WCBA), 15 to 45 y old (CHMS, $n=1162$; NHANES, $n=1456$ ). Two different folate assay methods were employed - Immulite 2000 immunoassay (CHMS) and microbiologic assay (NHANES) - necessitating the application of a conversion equation to adjust the CHMS RBC folate data. T-tests were used to examine country differences. RBC folate concentrations $\geq 906 \mathrm{nmol} / \mathrm{L}$ (considered optimal for neural tube defect risk reduction) were explored with a multiple logistic regression model. Median Canadian RBC folate (adjusted) were lower than those of Americans $(988 \mathrm{nmol} / \mathrm{L}$ and $1106 \mathrm{nmol} / \mathrm{L}$, respectively), but unadjusted Canadian median RBC folate values were higher $(1248 \mathrm{nmol} / \mathrm{L})$. Canadian WCBA (adjusted RBC folate) were less likely than American WCBA to have RBC folate $\geq 906 \mathrm{nmol} / \mathrm{L}$ (OR 0.58; 95\% CI 0.37, 0.92), though Canadian WCBA with unadjusted RBC folate values were more likely to achieve this cut-off than American WCBA (OR 1.90; 95\% CI 1.03, 3.49). Caution must be exercised in comparing RBC folate data from different countries since the use of analytical methods that have not been harmonized may lead to incorrect data interpretation. Harmonization of folate measurement procedures in future surveillance efforts would support comparisons and inform policy directions.
\end{abstract}




\section{Introduction}

Fortification of certain grains with folic acid and guidelines for prenatal supplementation are designed to improve folate status and reduce the incidence of poor birth outcomes. The United States and Canada were among the first countries to implement mandatory policies specific to the fortification of certain grain products with folic acid, in 1996 and 1998 respectively. ${ }^{1,2}$ Monitoring the impact and effectiveness of an intervention accompanies any population-level policy to assess the need for modifications. Though folic acid policies are somewhat different between Canada and the United States, these have been credited with similar reductions in neural tube defect rates since the programs were implemented. ${ }^{3-5}$ Folic acid is added to all enriched cereal grain products in the United States - including flour, corn grits, cornmeal, rice and pasta at a level of $0.14 \mathrm{mg} / 100 \mathrm{~g}$, whereas Canada fortifies white wheat flour and cornmeal with folic acid at a level of $0.15 \mathrm{mg} / 100 \mathrm{~g}$, and pasta labelled enriched at a level of $0.20 \mathrm{mg} / 100 \mathrm{~g} .{ }^{6}$ Discretionary fortification of ready-to-eat breakfast cereals allow up to $0.40 \mathrm{mg} / \mathrm{serving}$ in the United States, and up to $0.06 \mathrm{mg} / \mathrm{serving}$ in Canada. More than 50 countries have reported a requirement to add folic acid to flour, however, regulations may not be implemented in all countries. ${ }^{7,8}$ The United States has adopted the Institute of Medicine guidelines recommending that women of childbearing age consume $0.4 \mathrm{mg} / \mathrm{d}$ of folic acid from fortified foods, supplements or both in addition to natural food sources of folate. ${ }^{6,9,10}$ In Canada, this amount is recommended in the form of a multivitamin supplement, in addition to folate-rich foods. ${ }^{6,9,10}$

RBC folate concentrations have been monitored regularly in the United States through the NHANES since the 1976; however, the RBC folate concentrations of Canadians have only recently been examined through the Canadian Health Measures Survey (CHMS). ${ }^{11,12}$ While these national studies have reported that folate deficiency is virtually non-existent in both countries 
since folic acid fortification of the food supply, there has never been a national-level comparison of folate concentrations between Canada and the United States. ${ }^{11,13}$ Such a comparison is complicated by the fact that the assay methods used for measuring RBC folate concentration the 2007-2009 CHMS used the Immulite 2000 immunoassay (Siemans Canada Ltd., Mississauga) and the 2007-2008 NHANES used a microbiologic assay - are not harmonized. It is well known that blood folate concentrations vary depending on which assay is employed. ${ }^{14,15}$ A direct country-to-country comparison of RBC folate values without consideration of methodological differences may lead to erroneous conclusions. This study aimed to generate a conversion equation through a methods comparison experiment and - once the equation was applied to the CHMS data - compare the folate concentrations of the Canadian and the American populations.

\section{Methods}

These analyses included data from the 2007-2009 CHMS, conducted by Statistics Canada in partnership with Health Canada and the Public Health Agency of Canada, and the 2007-2008 NHANES, from the National Center for Health Statistics (NCHS) at the United States Centers for Disease Control and Prevention. The methodology for each survey is described briefly here and in greater detail elsewhere. ${ }^{16,17}$

Sampling and survey methods:

CHMS: The CHMS used a complex, multi-stage, cluster sampling protocol to achieve a nationally representative cross-sectional sample. The final sample included 5604 Canadians aged 6-79 y balanced by sex in each of the following age groups: 6-11, 12-19, 20-39, 40-59, and 6079 y and was representative of approximately $96 \%$ of the Canadian population. CHMS sampling 
excludes full-time members of the Canadian Forces and residents of Indian reserves, institutions and certain remote areas. Data collection occurred between March 2007 and February 2009. An interviewer administered a detailed health questionnaire, in participant's homes, which included questions on sociodemographic characteristics and dietary supplement use. A certified phlebotomist collected blood samples one day to six weeks later in a Mobile Examination Center to measure a variety of analytes, including RBC folate. ${ }^{16}$ Implied consent occurred in the household and a comprehensive consent process took place in the clinic. ${ }^{18}$ The Health Canada Research Ethics Board approved the CHMS protocol and the Children's Hospital of Eastern Ontario and University of Ottawa Research Ethics Boards approved the secondary data analysis. NHANES: The 2007-2008 NHANES is a 2-year cycle release from the continuous NHANES survey. This survey employed a complex, multi-stage design to represent the American population on the basis of age, sex and race/ethnicity. In 2007-2008, the survey oversampled African-Americans, Hispanics, persons with low income, and $\geq 60$ y old to obtain reliable estimates for these population subgroups. ${ }^{17}$ This research included a final sample of 6-79 y olds ( $n=7996$ ), from a total sample of 10149 participants, to match the age range for the CHMS. Similar to the CHMS, participants completed an in-home interviewer-administered survey, which included information on sociodemographic characteristics and dietary supplement use, followed by a physical examination and blood collection in a Mobile Examination Center one to two weeks later. All respondents provided informed consent, and the NHANES protocol was reviewed and approved by the NCHS Research Ethics Review Board.

\section{RBC Folate concentration:}

A total of 5248 CHMS participants, with 1162 women of childbearing age, and 7070 NHANES participants, with 1456 women of childbearing age (15 to 45 y) had RBC folate data available. 
RBC folate allows for an estimate of tissue folate stores. ${ }^{19}$ Both CHMS and NHANES collected venipuncture samples in EDTA-treated vacutainers that were immediately processed on-site. After hematocrit measurement, aliquots of whole blood were frozen, stored at $-20^{\circ} \mathrm{C}$ and shipped weekly to the Health Canada Nutrition Laboratory (CHMS) on dry ice or the CDC laboratory (NHANES). ${ }^{16,20}$ The NHANES diluted whole blood (1/11) with a $10 \mathrm{~g} / \mathrm{L}$ ascorbic acid solution prior to freezing. Ascorbate is not typically added to the serum specimen prior to storage.

CHMS Immunoassay: Researchers thawed and then diluted samples (1/26) with a $5 \mathrm{~g} / \mathrm{L}$ ascorbic acid solution, allowed to incubate for $180 \mathrm{~min}$ at room temperature, and then analyzed for folate using the Immulite 2000 immunoassay. ${ }^{21}$ Researchers calculated RBC folate concentration from the measured whole-blood folate concentration adjusting for RBC volume, without correction for serum folate concentration. The CHMS laboratory assessed the accuracy and reproducibility of these procedures using the manufacturers' serum controls (Con6: Tri-level multi-constituent control) and whole blood controls (BioRad Lyphochek Tri-level; BioRad Laboratories, Hercules, CA). Serum controls had an inter-assay coefficient of variation of 6-8.5\% and $8 \%$ for whole blood. All analyzed controls (serum, whole blood) were within $10 \%$ of target values. NHANES microbiologic assay: The NHANES laboratory thawed then prepared samples by diluting serum 1/100 and whole blood lysate $1 / 140$ with $5 \mathrm{~g} / \mathrm{L}$ sodium ascorbate. ${ }^{20,22}$ These dilution factors are appropriate for a population consuming folic acid fortified foods. Researchers added diluted samples to a 96-well plate together with assay medium containing chloramphenicol-resistant Lactobacillus Rhamnosus (ATCC number 27773; National Collection of Industrial Bacteria [NCIB] 10463) and all of the nutrients necessary for the growth of $L$. Rhamnosus, with the exception of folate, then incubated for $45 \mathrm{~h}$ at $37^{\circ} \mathrm{C}$. The total folate 
concentration was assessed by measuring the turbidity of the inoculated medium at $590 \mathrm{~nm}$ in a PowerWave microplate reader (Bio-Tek Instrument). The NHANES laboratory calculated RBC folate concentration from the measured whole-blood folate concentration adjusting for RBC volume, correcting for serum folate concentration. ${ }^{23}$ The researchers generated a calibration curve for this assay with 5-methyltetrahydrofolate (5-methylTHF) from Merck Cie (Schaffhausen, Switzerland). ${ }^{20,22}$ Long-term CVs from three whole blood lysate quality control pools analyzed in every run were $8.0 \%-14 \%$ at $402-1570 \mathrm{nmol} / \mathrm{L}$. The NIBSC WHO reference material (lyophilized) for whole blood folate (95/528, established 1996) was analyzed several times a year to verify comparability of results over time. The mean (SD) obtained was 11.5 (1.15) ng/ampoule, $12 \%$ lower than the assigned content of $13 \mathrm{ng} / \mathrm{ampoule}$. This is an expected result as it has been previously demonstrated that calibration with 5-methylTHF versus folic acid produces lower results and the assigned content was obtained by calibration with folic acid. ${ }^{20}$ Cut-offs: We used a RBC folate of $<305 \mathrm{nmol} / \mathrm{L}(<140 \mathrm{ng} / \mathrm{mL})$ to determine deficient folate status, a cut-off defined by the Institute of Medicine based on several studies demonstrating the appearance of hypersegmented neutrophils, a characteristic of megaloblastic anemia, at RBC folate below this concentration. ${ }^{9}$

We defined folate insufficiency for the prevention of neural tube defects as a RBC folate concentration $\geq 906 \mathrm{nmol} / \mathrm{L}(\geq 400 \mathrm{ng} / \mathrm{mL})$. Due to lack of an internationally recognized value, this value was drawn from a prospective study that found that the prevalence of neural tube defects in an Irish population was lowest when RBC folate concentrations, determined by microbiologic assay, were $\geq 906 \mathrm{nmol} / \mathrm{L}^{24}$

Selected sociodemographic factors of interest: Both surveys used self-reported sociodemographic characteristics. Analyses used the CHMS sample age groups, and we derived 
a variable for women of childbearing age (aged 15 to $45 \mathrm{y}$ ). We examined socioeconomic status by per person household income equivalents (which grouped respondents into quintiles after adjusting for family size and composition) for each country separately. We defined race/ethnicity as non-Hispanic white or all other responses for race/ethnicity and included missing responses for race/ethnicity in the largest parameter (non-Hispanic white) as less than $3 \%$ of responses were missing, which when tested did not impact the findings.

Supplement use: CHMS interviewers collected drug identification and natural health product numbers from containers shared by participants at the household visit. Researchers verified this information at the clinic visit and collected any changes in drug and supplement usage at this time. ${ }^{25}$ We determined supplemental folic acid use - whether consumed alone or as a multivitamin - in the 30 days prior to the clinic visit by matching drug identification and natural health product numbers to product information extracted from the Health Canada Drug Product and Licensed Natural Health Product databases. ${ }^{25-27}$ We used the derived variable in the NHANES public data file for use of folic acid containing supplement in the last 30 days. NHANES participants showed the supplement container at the household interview, or if this was unavailable, named the supplement verbally. Trained nutritionists reviewed these data and matched entries to the in-house NCHS Product Label Database. If no match was available, the product was added or an appropriate alternative was sought.

\section{Crossover equation sub-study:}

We conducted a RBC folate methods comparison study to compare the immunoassay used in CHMS to a microbiological assay similar to the one used in NHANES. We generated a conversion equation to predict a microbiologic assay result from the CHMS immunoassay data. A convenience sample of 152 healthy men and women, aged 16 to $79 \mathrm{y}$, was recruited from the 
Hospital for Sick Children (SickKids) and general Toronto area. Participants attended the Clinical Investigation Unit at SickKids where blood was drawn. We obtained signed consent at the time of the blood draw. Following determination of hematocrit, we aliquoted each whole blood sample with (microbiologic assay) and without (Immulite 2000 immunoassay) a 1:11 mixture of $10 \mathrm{~g} / \mathrm{L}$ ascorbic acid solution. We determined folate concentrations by Immulite 2000 immunoassay at the Health Canada CHMS laboratory using the methods described above and by microbiologic assay at SickKids. The microbiologic assay used at SickKids was specifically modified to replicate that of the NHANES laboratory - using the chloramphenicol-resistant microorganism (L. Rhamnosus) with 5-methylTHF as the calibrator. ${ }^{22} \mathrm{~A} \mathrm{CV}$ of $13 \%$ was confirmed using the 95/528 NIBSC whole blood reference standard (mean (SD) of 12.7 (1.7) ng/ampoule, expected $13 \mathrm{ng} / \mathrm{ampoule})$.

We analysed the data using Analyse-it, version 2.26 Excel 12+ software (Analyse-it Software, Ltd., Leeds, UK). Values were deemed outliers and removed $(n=6)$ where the absolute difference between the two method values for a given blood sample (immunoassay - microbiologic assay) was greater than 2 SDs $(\geq 1000 \mathrm{nmol} / \mathrm{L})$. Plotting the two sets of remaining values against each other resulted in a Pearson correlation coefficient, $r$, of 0.67, which guided the choice of regression technique to estimate the crossover equation.

A correlation coefficient below 0.80 indicates the need to use Deming regression methods as Ordinary Least Squares regression routinely underestimates the actual slope of the data, and can have a large impact on the results. ${ }^{28}$ As a result, lower adjusted value may be estimated. Deming regression accounts for the random error present in both the values of $\mathrm{X}$ and $\mathrm{Y}$. Ordinary Least Squares assumes random error for only the $\mathrm{Y}$ values, which is rarely fulfilled in method 
comparison studies. ${ }^{29,30}$ Weighted Deming regression was performed to account for proportional error. ${ }^{31}$ The final weighted Deming regression equation was as follows (Supplemental Figure 1): Predicted microbiologic assay $=-22.95+0.81 *$ Immunoassay.

We assessed the goodness-of-fit by estimating the mean absolute percentage error (MAPE) resulting from the model. This statistic: ${ }^{i}$

$$
\text { MAPE }=\frac{1}{n} \sum_{k=1}^{n} \frac{\left(y_{k}-\text { pred_y } y_{k}\right)}{y_{k}}
$$

indicates that there is $23 \%$ error in the model. To validate the model, the whole sample was randomly split into two groups, one for estimation and the other for validation. The estimation sample was used to fit the model, and the validation sample was used to obtain the MAPE. A similar MAPE (23\%) was obtained, indicating robustness in the precision of the model's predicted values.

As a final examination of the model, we conducted a boundary assessment by generating equations using the lower and upper $95 \% \mathrm{CI}$ of the conversion equation. We applied these equations to the CHMS and NHANES data to examine the cumulative distributions for the bottom and top $95 \% \mathrm{CI}$ of the conversion equation. The equations were as follows: Lower 95\% CI: Predicted microbiologic assay $=-155.68+0.81 *$ Immunoassay Upper 95\% CI: Predicted microbiologic assay $=109.78+0.81 *$ Immunoassay

Ethics approval for the crossover study was obtained from the Children's Hospital of Eastern Ontario, the Hospital for Sick Children, the University of Ottawa and the Health Canada Research Ethics Boards.

\footnotetext{
${ }^{\mathrm{i}} \mathrm{k}=$ dummy index or the range for a quantity from $\mathrm{k}$ up to, and including, $\mathrm{n} ; \mathrm{y}=$ actual value for microbiologic assay; pred_y = predicted value for microbiologic assay; $n=$ number of fitted points
} 


\section{Statistical Analysis:}

The crossover equation was applied to the CHMS RBC folate data to derive an adjusted measure for comparison to the NHANES RBC folate data. We stacked the CHMS and NHANES datasets based on regional strata and primary sampling unit. Descriptive statistics (frequencies, medians, percentiles) were used to characterize the population. Differences between countries for folate concentrations and supplement intake by age and race/ethnicity were examined using t-tests. Multivariate logistic regression was conducted to examine concentrations $\geq 906 \mathrm{nmol} / \mathrm{L}$ for women of childbearing age, adjusted for age, household income, folic acid supplement use and race/ethnicity. All estimates were based on weighted data to represent the population. Variance estimation (95\% confidence intervals) and significance testing (t-tests, logistic regression) were based on Taylor linearization. ${ }^{32}$ Significance was defined as a p-value of $<0.05$. Analyses were conducted in SAS 9.1.3 (SAS Institute Inc., Cary, NC) and SUDAAN v.10.0 (RTI International, Research Triangle Park, NC).

\section{Results}

\section{Adjusted RBC folate}

A summary description of the population demographics and folic acid supplement use can be found in Table 1. Folate deficiency (RBC folate $<305 \mathrm{nmol} / \mathrm{L}$ ) was not evident in Canada or the United States. For women of childbearing age, $55 \%$ of Canadians - using adjusted values - met or were above the RBC folate cut-off considered optimal for minimizing the risk of neural tube defects $(906 \mathrm{nmol} / \mathrm{L})$ compared to $66 \%$ of Americans. Logistic regression analysis demonstrated that Canadian women of childbearing age had 0.61 times the odds of having folate concentrations $\geq 906 \mathrm{nmol} / \mathrm{L}$ (95\% CI 0.41, 0.90). This significant difference persisted (OR 0.58; 
95\%CI $0.37,0.92$ ) when the model was controlled for folic acid supplement use and race/ethnicity.

The adjusted median RBC folate concentrations of Canadians was lower than the median value for Americans (988 nmol/L vs. $1106 \mathrm{nmol} / \mathrm{L}$, respectively) (Table 2). The $5^{\text {th }}$ percentile for RBC folate was consistently above the deficiency cut-off for each country. Cumulative percent distributions by country are shown for the general population (Figure 1A) and women of childbearing age (Figure 1B).

A significant country difference existed, with Canadian folic acid supplement users having lower median RBC folate concentrations than Americans.(Table 3) This difference persisted for the youngest age groups (6-11 y and 12-19 y) and oldest age group, as well as for non-Hispanic whites.

The boundary assessment, using the lower and upper 95\% CI for the conversion equation, demonstrated that for both the general population and women of childbearing age, the cumulative distribution for the upper 95\% CI was similar to the United States. The lower 95\% CI was much lower than the United States.

\section{Unadjusted RBC folate}

The unadjusted RBC folate also did not demonstrate folate deficiency (RBC folate $<305$ $\mathrm{nmol} / \mathrm{L})$ in the Canadian population. Previously reported unadjusted values for women of childbearing age indicate that $22 \%$ met or were above the RBC folate cut-off of $906 \mathrm{nmol} / \mathrm{L} .{ }^{11}$ Logistic regression analysis using unadjusted Canadian values showed that Canadian women of childbearing age were more likely than American women of childbearing age to have folate concentrations $\geq 906 \mathrm{nmol} / \mathrm{L}(\mathrm{OR} 1.84,95 \% \mathrm{CI}: 1.07,3.18)$, and these odds were similar when 
the model was controlled for folic acid supplement use and race/ethnicity (OR 1.90; 95\% CI $1.03,3.49)$.

The median of the unadjusted Canadian data (1248 nmol/L) was higher than the American median (Table 2). This was also true for the unadjusted median for Canadian women of childbearing age. Similar to the adjusted data, the $5^{\text {th }}$ percentile for the unadjusted Canadian RBC folate was above the deficiency cut-off (Figures 1) and this population did not show any folate deficiency (<305 nmol/L). Median RBC folate concentrations were higher for Canadians, using unadjusted RBC folate, who were folic acid supplement users, not non-Hispanic white, and for aged 12-59 y.

The boundary assessment demonstrated that the cumulative distribution for the upper 95\% CI did not approach the unadjusted Canadian values except at the $5^{\text {th }}$ percentile. The lower $95 \%$ CI was far below the unadjusted Canadian data.

\section{Discussion}

This study presents the first national-level comparison of RBC folate status between Canada and the United States. The inter-laboratory differences in RBC folate assay methods were addressed by generating a conversion equation that was then applied to the CHMS data. Though folate deficiency is no longer an issue in either country, the proportion of women of childbearing age achieving optimal RBC folate concentrations for neural tube defect prevention is lower in Canada. Our results also highlight the problematic nature of directly comparing different RBC folate measurement methods. While Canadians appear to have lower median concentrations of RBC folate than Americans when the conversion equation is applied, Canadians had higher median concentrations than Americans when the unadjusted data were compared. 
Separate studies examining the CHMS and NHANES data have also reported that folate deficiency is virtually non-existent in both the United States and Canada. ${ }^{11,13,33}$ The current analyses confirm that few Canadians are folate deficient regardless of whether data were adjusted to microbiologic assay. The overall lack of deficiency may be a demonstration of the success of folic acid-related public health efforts in both countries. This comparison also shows that Canadian women of childbearing age are less likely than American women of childbearing age to achieve folate concentrations considered optimal for the prevention of neural tube defects (906 nmol/L). Previous estimates of folate status in the Canadian population reported that $22 \%$ of women were below the cut-off of $906 \mathrm{nmol} / \mathrm{L} .{ }^{11,24}$ However, the current estimate of $45 \%$, generated from data adjusted to microbiologic assay, is likely more accurate since the 906 nmol/L cut-off was established using a microbiologic assay method. ${ }^{34}$ A Toronto, Canada study of 1537 reproductive age women reported that, in 2006, an estimated $40 \%$ of participants did not achieve optimal RBC folate concentrations, analysed using a protein-binding assay (nonradioassay) method (Beckman-Coulter, Instrument-Dxl). ${ }^{35}$ A 2001 study of 135 women, aged 18 to $45 \mathrm{y}$, in Southern California determined, using microbiologic assay, that $22 \%$ had RBC folate $<906 \mathrm{nmol} / \mathrm{L}^{36}$ In an analysis of the 1999-2000 NHANES, notably with RBC folate determined by Bio-Rad radioassay, approximately $90 \%$ of women of childbearing age did not achieve $906 \mathrm{nmol} / \mathrm{L} .{ }^{37}$ Both of these studies occurred post-fortification of grains with folic acid and only included a non-supplementing population in the analysis. These data suggest that folic acid interventions may be benefiting the target population more effectively in the United States than in Canada. ${ }^{13}$ In the current study, a smaller proportion of Canadians, including women of childbearing age, reported taking folic acid supplements - a primary predictor of folate status than Americans. Past examinations of nationally representative Canadian and American data 
found similar proportions for folic acid supplement consumption in women of childbearing age. ${ }^{38,39}$ A detailed comparison of folic acid promotion programs between the United States and Canada would provide insight into the source of this discrepancy.

In addition to folic acid supplementation, a number of factors are known to impact folate status, including age and race/ethnicity..$^{40-42}$ In the United States, disparities based on race/ethnicity are considered primary determinants of folate status. Post-fortification, 2005-2006 NHANES data showed that the non-Hispanic white population had a higher RBC folate than Mexican Americans and non-Hispanic black participants, and this was also true for women of childbearing age.${ }^{33}$ All subgroups demonstrated virtually no folate deficiency. ${ }^{13}$ Since a significant difference in RBC folate status between Canada and the United States persisted in this study, regardless of controlling for race/ethnicity and supplement use, it is likely that other factors may be driving the disparity between countries. Dietary intake of folic acid may be one of these factors since fortification policies differ between the two countries. Most significantly, the United States mandates a greater number of foods to be fortified and Canada allows lower fortification levels for breakfast cereals. ${ }^{1,2}$ This study was not able to control for potential differences in dietary intake.

There is growing support for harmonization of biochemical measurement methods in national-level studies. In clinical chemistry, the term harmonization is used to indicate that the measures for all laboratories are congruent. ${ }^{43}$ When comparing biochemical measures, inter- and intra-assay variation must be considered as this difference can have a strong impact on the interpretation of data. Vitamin D is an example of a nutrient currently undergoing methodological scrutiny as numerous and varying measurement methods have impeded the ability to formulate evidence-based guidelines and surveillance efforts. ${ }^{43}$ It has been suggested 
that standardized measures are needed to determine appropriate levels in the population that are comparable to other countries. Similarly, folate measurement would benefit from harmonization to improve the accuracy of surveillance and monitoring. A direct comparison of the unadjusted CHMS data to the NHANES data would have indicated that the median folate status of Canadians was higher than that of Americans. Considering the difference between the unadjusted and adjusted estimates presented in our study, a comparison between the CHMS and NHANES data - without using a conversion equation to adjust for different assay methods - would lead to inaccurate conclusions and has the potential to misinform policy decisions. Collaborative efforts towards harmonization may yield stronger outputs allowing for the impact of folic acid fortification policies to be assessed on a global level.

It is notable that both countries demonstrate median folate concentrations that are much higher than the deficiency cut-off of $305 \mathrm{nmol} / \mathrm{L}$. Harmonized folate concentrations between Canada and the United States would allow for effective monitoring to assess the longitudinal trajectory of elevated levels and to determine the need for modification to current programs. ${ }^{44-49}$ This data would inform countries that are currently fortifying as well as those considering folic acid fortification programs.

This is the first comparison of RBC folate concentrations between two nationally representative North American datasets using harmonized data. Another key strength of this study is the use of directly measured biomarkers. Though it is imperative to harmonize methods prior to making comparisons, method comparison studies are not without limitations that must be considered in order to apply the results in different contexts. The MAPE of the model was $23 \%$, which indicates a certain level of error in the model. Further, the microbiologic assay in this study was run at the SickKids laboratory, not the CDC laboratory, thus there is potential for 
some inter-laboratory variation. However, a boundary assessment was conducted as a final examination of the conversion equation model. The lower and upper 95\% confidence intervals of the conversion equation were used to generate two equations representing the lower and upper boundary of the adjusted data (see Supplementary figure 2A/B). These equations were applied to the CHMS and NHANES data to examine the cumulative distributions for the extreme boundaries of the model. The upper value generated by the model produced estimates similar to the NHANES data, and these estimates did not approach the unadjusted CHMS data, except at the $5^{\text {th }}$ percentile. Potential methodological issues in the crossover study were explored; for example, unlike the NHANES microbiologic assay, the CHMS immunoassay does not correct for serum in its calculation of RBC folate. Whole blood data were examined (Supplemental Table 1) and it was determined that the adjusted whole blood yielded comparable results to the adjusted RBC folate. It is also noted that, generally, immunoassay yields lower measures of RBC folate than microbiologic assay. Separate studies of whole blood have demonstrated that the Immulite 2000 immunoassay measures approximately three times higher, and microbiologic assay measures $45 \%$ higher, than Bio-Rad radioassay. ${ }^{15,50}$ Further, a small, hospital-based Australian study focusing on folate status in stroke patients found that Immulite 2000 immunoassay provided higher estimates than the microbiologic assay. ${ }^{51}$ The limited CHMS dietary data made it impossible to examine dietary intake as a factor in this discrepancy between countries.

This study found that, after adjusting for different assay methods, Canadian folate concentrations appear to be significantly lower than those of Americans. Comparing RBC folate data across time and countries is an important step in evaluating the success of current interventions and will advance future dialogue and research on folic acid fortification and 
supplementation policies. Caution must be exercised in comparing RBC folate data from different countries since the use of analytical methods that have not been harmonized may lead to incorrect data interpretation. Adjusting laboratory data to make methods comparable allows for a comparison of RBC folate data; however, it is important to consider the limitations of the method comparison study. Harmonization of folate measurement methods in future surveillance efforts would facilitate comparisons and inform policy directions.

\section{Acknowledgments}

The authors thank the Health Analysis Division at Statistics Canada, in particular Julie Bernier for her support during the generation of the conversion equation, and the Physical Health Measures Division at Statistics Canada for preparing and granting special access to data. The authors also thank Penny Jee for her analysis of the blood at the CHMS laboratory for the conversion equation sub-study and Trevor Stewart for his review and feedback on the manuscript. The authors thank all participants in the conversion equation sub-study, the CHMS and the NHANES. This research was supported by a CIHR Health Professionals Fellowship in the Area of Public to C.K.C. (funding reference \#180375) and a CIHR Operating Grant to M.S.T., D.L.O. and C.K.C. (funding reference \#218776).

\section{Statement of Author's Contributions to Manuscript}

C.K.C., M.S.T. and D.L.O. conceptualized and designed the study and crossover equation substudy. S.A. and D.L.O. conducted the data collection and blood analysis for the sub-study. C.K.C. generated the crossover equation with the assistance of T.B., M.S.T., C.M.P. and D.L.O. C.K.C. conducted all analyses and T.B., M.S.T., C.M.P. and D.L.O. assisted in the interpretation 
of the results. C.K.C. drafted the manuscript. All of the authors critically reviewed the manuscript for important intellectual content and approved the final version submitted for publication. 
Table 1: Summary description of population demographics and folic acid supplement use, by country

\begin{tabular}{|c|c|c|c|c|c|c|c|c|}
\hline & \multicolumn{4}{|c|}{ General Population } & \multicolumn{4}{|c|}{ Women of Childbearing Age (15-45 y) } \\
\hline & \multicolumn{2}{|c|}{ Canada $(n=5248)$} & \multicolumn{2}{|c|}{ United States $(n=7070)$} & \multicolumn{2}{|c|}{ Canada $(n=1162)$} & \multicolumn{2}{|c|}{ United States $(n=1456$} \\
\hline & $\begin{array}{l}\text { Sample } \\
\text { Size }\end{array}$ & $\begin{array}{l}\text { Weighted } \\
\text { distribution (\%) } \\
(95 \% \mathrm{CI})\end{array}$ & $\begin{array}{l}\text { Sample } \\
\text { size }\end{array}$ & $\begin{array}{l}\text { Weighted } \\
\text { distribution (\%) } \\
(95 \% \text { CI) }\end{array}$ & $\begin{array}{l}\text { Sample } \\
\text { size }\end{array}$ & $\begin{array}{l}\text { Weighted } \\
\text { distribution (\%) } \\
(\mathbf{9 5 \%} \mathrm{CI})\end{array}$ & $\begin{array}{l}\text { Sample } \\
\text { size }\end{array}$ & $\begin{array}{l}\text { Weighted } \\
\text { distribution } \\
(95 \% \mathrm{CI})\end{array}$ \\
\hline \multicolumn{9}{|c|}{$\begin{array}{l}\text { RBC folate concentrations } \\
\text { (adjusted for Canada) }\end{array}$} \\
\hline$<906 \mathrm{nmol} / \mathrm{L}^{1}$ & - & - & - & - & 529 & $45.5(37.9,53.3)$ & 571 & $33.7(28.7,39.2)$ \\
\hline$\geq 906 \mathrm{nmol} / \mathrm{L}$ & - & - & - & - & 633 & $54.5(46.7,62.1)$ & 885 & $66.3(60.8,71.3)$ \\
\hline \multicolumn{9}{|l|}{ Sociodemographic factors } \\
\hline \multicolumn{9}{|l|}{ Age $(y)$} \\
\hline $6-11$ & 911 & $6.55(5.89,7.29)$ & 1010 & $8.03(7.42,8.68)$ & - & - & - & - \\
\hline $12-19^{3}$ & 945 & $11.1(10.0,12.3)$ & 1073 & $12.2(11.0,13.4)$ & 290 & $15.9(13.1,19.1)$ & 302 & $15.4(12.6,18.6)$ \\
\hline 20-39 & 1150 & $31.3(27.6,35.2)$ & 1705 & $30.7(28.5,33.1)$ & 643 & $64.4(60.1,68.5)$ & 874 & $63.4(59.1,67.5)$ \\
\hline $40-59^{3}$ & 1202 & $34.2(31.9,36.6)$ & 1722 & $32.9(31.1 .34 .7)$ & 229 & $19.7(17.4,22.3)$ & 280 & $21.2(18.2,24.5)$ \\
\hline $60-79$ & 1040 & $16.8(13.8,20.3)$ & 1560 & $16.2(14.4,18.3)$ & - & - & - & - \\
\hline \multicolumn{9}{|l|}{ Sex } \\
\hline Female & 2705 & $49.8(46.7,52.9)$ & 3546 & $50.7(49.7,51.7)$ & - & - & - & - \\
\hline Male & 2543 & $50.2(47.1,53.3)$ & 3524 & $49.3(48.3,50.3)$ & - & - & - & - \\
\hline \multicolumn{9}{|l|}{ Income quintile } \\
\hline Q1 & 1125 & $18.5(15.2,22.3)$ & 1908 & $17.6(14.8,20.8)$ & 264 & $20.9(14.9,28.4)$ & 407 & $20.2(16.6,24.4)$ \\
\hline Q2 & 1130 & $20.8(18.3,23.6)$ & 1625 & $18.4(15.9,21.1)$ & 246 & $22.2(17.5,27.7)$ & 328 & $18.1(15.3,21.4)$ \\
\hline Q3 & 838 & $16.8(14.8,19.1)$ & 1384 & $20.7(18.8,22.8)$ & 179 & $17.0(12.1,23.4)$ & 302 & $22.1(19.2,25.5)$ \\
\hline Q4 & 980 & $18.8(15.9,22.1)$ & 905 & $20.1(17.0,23.8)$ & 197 & $16.2(12.2,21.2)$ & 206 & $21.4(17.5,25.8)$ \\
\hline Q5 & 843 & $18.3(14.9,22.4)$ & 726 & $16.7(14.6,19.1)$ & 174 & $14.9(11.6,18.8)$ & 120 & $12.9(10.0,16.5)$ \\
\hline Missing & 332 & $6.76(5.86,7.78)$ & 522 & $6.41(4.92,8.31)$ & 102 & $8.93(6.76,11.7)$ & 93 & $5.21(3.61,7.45)^{2}$ \\
\hline \multicolumn{9}{|l|}{ Race/ethnicity } \\
\hline Non-Hispanic white & 4499 & $84.6(73.8,91.4)$ & 4155 & $67.3(59.4,74.4)$ & 969 & $81.7(69.7,89.7)$ & 671 & $65.1(56.4,72.9)$ \\
\hline Other & 749 & $15.4(8.58,26.2)^{2}$ & 2915 & $32.7(25.6,40.6)$ & 193 & $18.3(10.3,30.3)^{2}$ & 574 & $34.9(27.1,43.6)$ \\
\hline \multicolumn{9}{|l|}{ Supplement use } \\
\hline \multicolumn{9}{|c|}{ Folic acid supplement (last 30 days) } \\
\hline Yes (at least one) & 1258 & $24.6(22.3,27.0)$ & 1873 & $32.0(28.7,35.5)$ & 276 & $24.8(22.0,27.8)$ & 369 & $32.0(26.7,37.8)$ \\
\hline No & 3990 & $75.4(73,77.7)$ & 5197 & $68.0(64.5,71.3)$ & 886 & $75.2(72.2,78.0)$ & 1087 & $68.0(62.2,73.3)$ \\
\hline
\end{tabular}


Strength of folic acid supplement (total dose) 0 ug (did not $\mu \mathrm{g}$ (did not take in last 30 days) $400-999 \mu \mathrm{g}$

$\geq 1000 \mu \mathrm{g}$
$3990 \quad 75.4(73.0,77.7)$ 496 568

194 $7.47(6.49,8.59)$

$13.0(11.1,15.2)$

$4.08(3.29,5.04)$

$\begin{array}{ll}5197 & 68.0(64.5,71.3) \\ 847 & 13.8(12.3,15.4) \\ 976 & 17.3(15.4,19.5) \\ 50 & 0.84(0.58,1.21)\end{array}$

886

78

130

$75.2(72.2,78.0)$

$8.56(6.48,11.2)$

$10.3(8.60,12.2)$

$5.94(4.36,8.04)$
$1087 \quad 68.0(62.2,73.3)$
$185-15.6(12.8,19.0)$
$14.9(11.7,18.8)$
$20 \quad 1.45(0.78,2.67)^{2}$

${ }^{1}$ The value $\geq 906 \mathrm{nmol} / \mathrm{L}$ is specific to women of childbearing age and is considered to be the optimal folate concentration for maximal protection against neural tube defects in offspring.

${ }^{2}$ Interpret with caution (high sampling variability; coefficient of variation $\geq 16.6$ and $<33.3$ )

${ }^{3}$ For women of childbearing age, these groups are aged 15 to $19 \mathrm{y}$ and aged 40 to $45 \mathrm{y}$, respectively. 
Table 2: Selected percentiles for RBC folate concentrations by country ${ }^{1}$

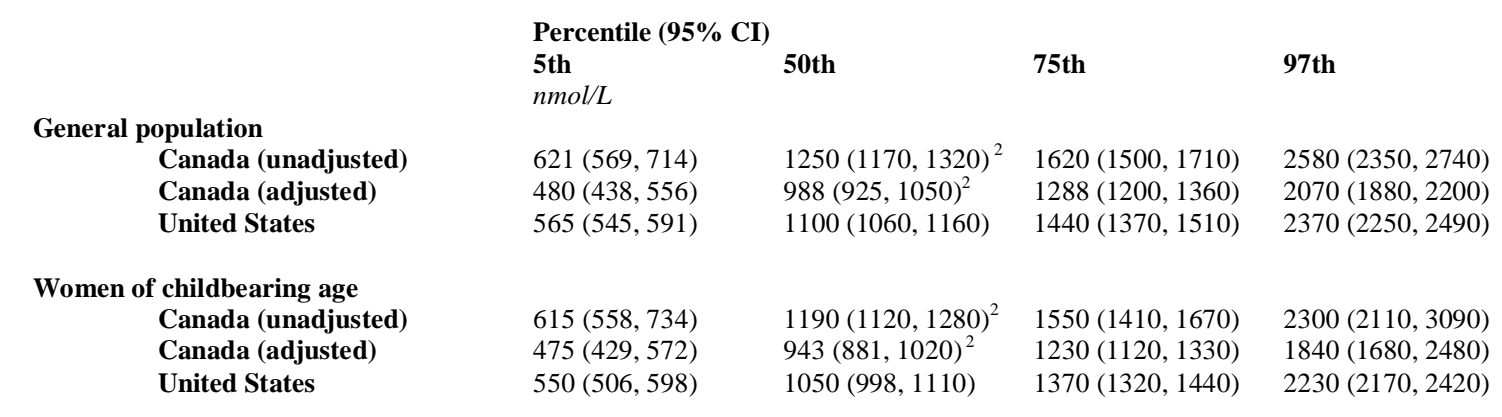

${ }^{1}$ Values represent RBC folate concentration at the $5^{\text {th }}, 50^{\text {th }}, 75^{\text {th }}$ and $97^{\text {th }}$ percentile. Unadjusted Canadian RBC folate concentrations are from the 2007-2009 Canadian Health Measures Survey and were measured by Immulite 2000 immunoassay, these values were adjusted to be comparable to the microbiologic assay used in the 2007-2008 NHANES. ${ }^{20}$

${ }^{2} \mathrm{p}<0.05$ for tests comparing unadjusted and adjusted Canadian concentrations at the $50^{\text {th }}$ percentile to the United States $(\mathrm{p}<0.05)$. Tests were not conducted at the $5^{\text {th }}, 75^{\text {th }}$ and $97^{\text {th }}$ percentile. 
Table 3: Median RBC folate for country by age, race/ethnicity and folic acid supplement use for the general population

\begin{tabular}{|c|c|c|c|}
\hline & $\begin{array}{l}\text { Canada (adjusted) } \\
\mathrm{nmol} / \mathrm{L}\end{array}$ & $\begin{array}{l}\text { Median }(\mathbf{9 5 \%} \mathbf{C I})^{1} \\
\text { United States } \\
\text { nmol/L }\end{array}$ & $\begin{array}{l}\text { Canada (unadjusted) } \\
\mathrm{nmol} / \mathrm{L}\end{array}$ \\
\hline \multicolumn{4}{|l|}{ General population } \\
\hline \multicolumn{4}{|l|}{ Age (y) } \\
\hline 6-11 & $959(902,1033)^{2}$ & $1127(1096,1186)$ & $1212(1142,1304)$ \\
\hline $12-19$ & $884(788,941)^{2}$ & $974(933,1044)$ & $1120(1001,1189)^{2}$ \\
\hline 20-39 & $941(871,993)$ & $1013(976,1073)$ & $1190(1103,1254)^{2}$ \\
\hline 40-59 & $1023(933,1142)$ & $1145(1074,1223)$ & $1292(1180,1438)^{2}$ \\
\hline $60-79$ & $1118(1035,1224)^{2}$ & $1422(1312,1529)$ & $1409(1306,1539)$ \\
\hline \multicolumn{4}{|l|}{ Race/ethnicity } \\
\hline Non-Hispanic white & $994(926,1062)^{2}$ & $1174(1112,1238)$ & $1255(1171,1340)$ \\
\hline Other & $941(893,1029)$ & $975(930,1030)$ & $1190(1130,1299)^{2}$ \\
\hline \multicolumn{4}{|c|}{ Folic acid supplement use (last 30 days) } \\
\hline Yes (at least one) & $1261(1179,1351)^{2}$ & $1372(1332,1439)$ & $1585(1484,1696)^{2}$ \\
\hline No & $930(861,993)$ & $998(964,1048)$ & $1176(1092,1254)^{2}$ \\
\hline
\end{tabular}

${ }^{1}$ Values represent RBC folate concentration at the $50^{\text {th }}$ percentile. Unadjusted Canadian RBC folate concentrations are from the $2007-2009$ Canadian Health Measures Survey and were measured by Immulite 2000 immunoassay, these values were adjusted to be comparable to the microbiologic assay used in the 2007-2008 NHANES

${ }^{2} \mathrm{p}<0.05$ for tests comparing unadjusted and adjusted Canadian concentrations at the $50^{\text {th }}$ percentile to the United States ( $\mathrm{p}<0.05$ ). 


\section{Figure legends:}

Figure 1: A) Cumulative percentile distributions of red blood cell (RBC) folate concentrations by country from the Canadian Health Measures Survey, 2007-2009 and the National Health and Nutrition Examination Survey 2007-2008. Values exceeding $3500 \mathrm{nmol} / \mathrm{L}$ are not shown $(n=32)$. Cumulative percentile distributions of red blood cell (RBC) folate concentrations by country from the Canadian Health Measures Survey, 2007-2009 (adjusted for microbiologic assay comparison and unadjusted) and the National Health and Nutrition Examination Survey 20072008. The median folate concentration is indicated by the horizontal line. Values exceeding 3500 nmol/L are not shown $(n=32)$. B) Cumulative percentile distributions of red blood cell (RBC) folate concentrations by country among women of childbearing age (15-45 y) from the Canadian Health Measures Survey, 2007-2009 (adjusted for microbiologic assay comparison and unadjusted) and the National Health and Nutrition Examination Survey, 2007-2008. The folate concentration considered optimal for maximal neural tube defect risk reduction $(906 \mathrm{nmol} / \mathrm{L})$ is indicated by the vertical line. Values exceeding $3500 \mathrm{nmol} / \mathrm{L}$ are not shown $(n=7)$. 


\section{Figure 1:}

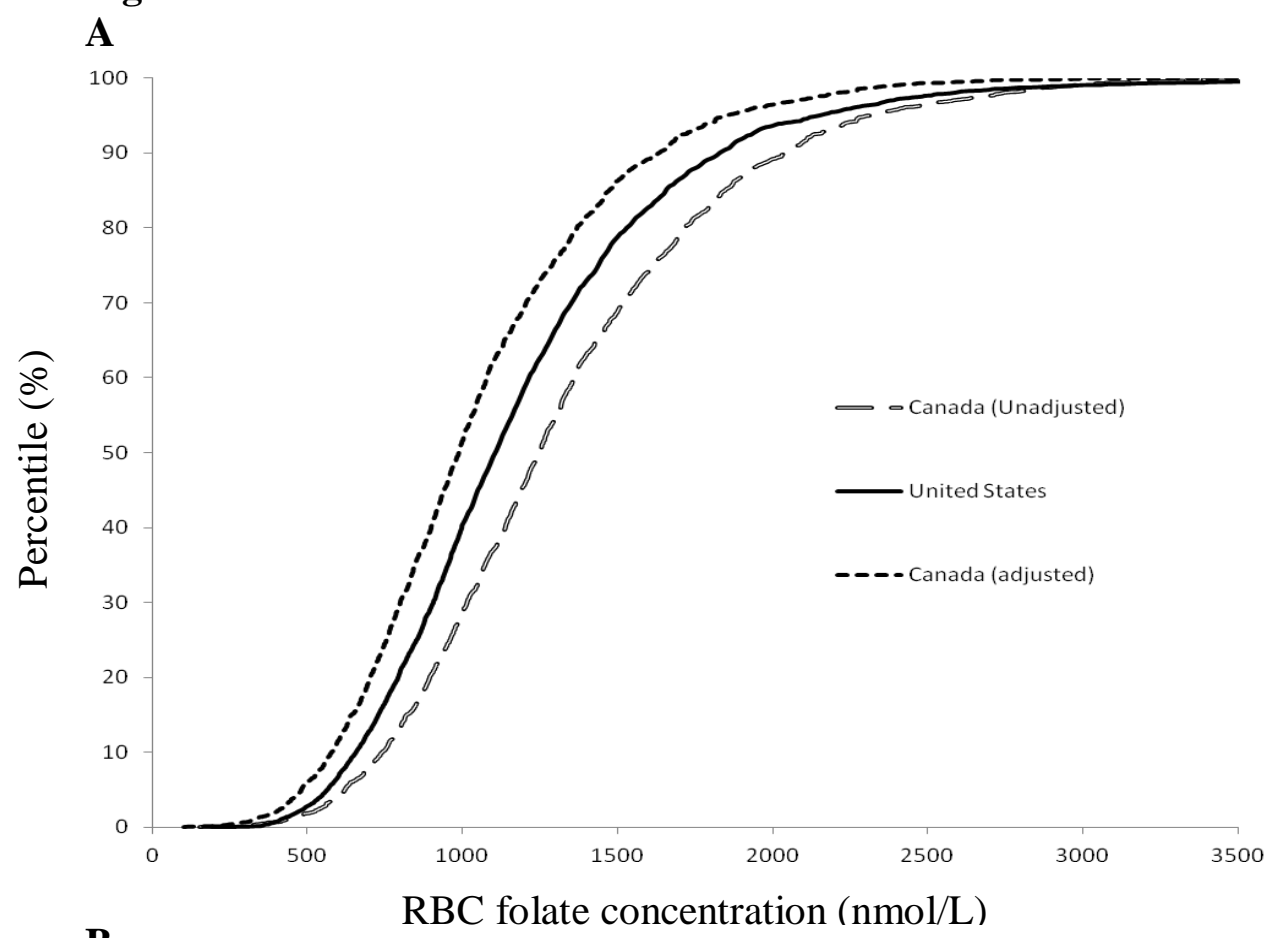

B

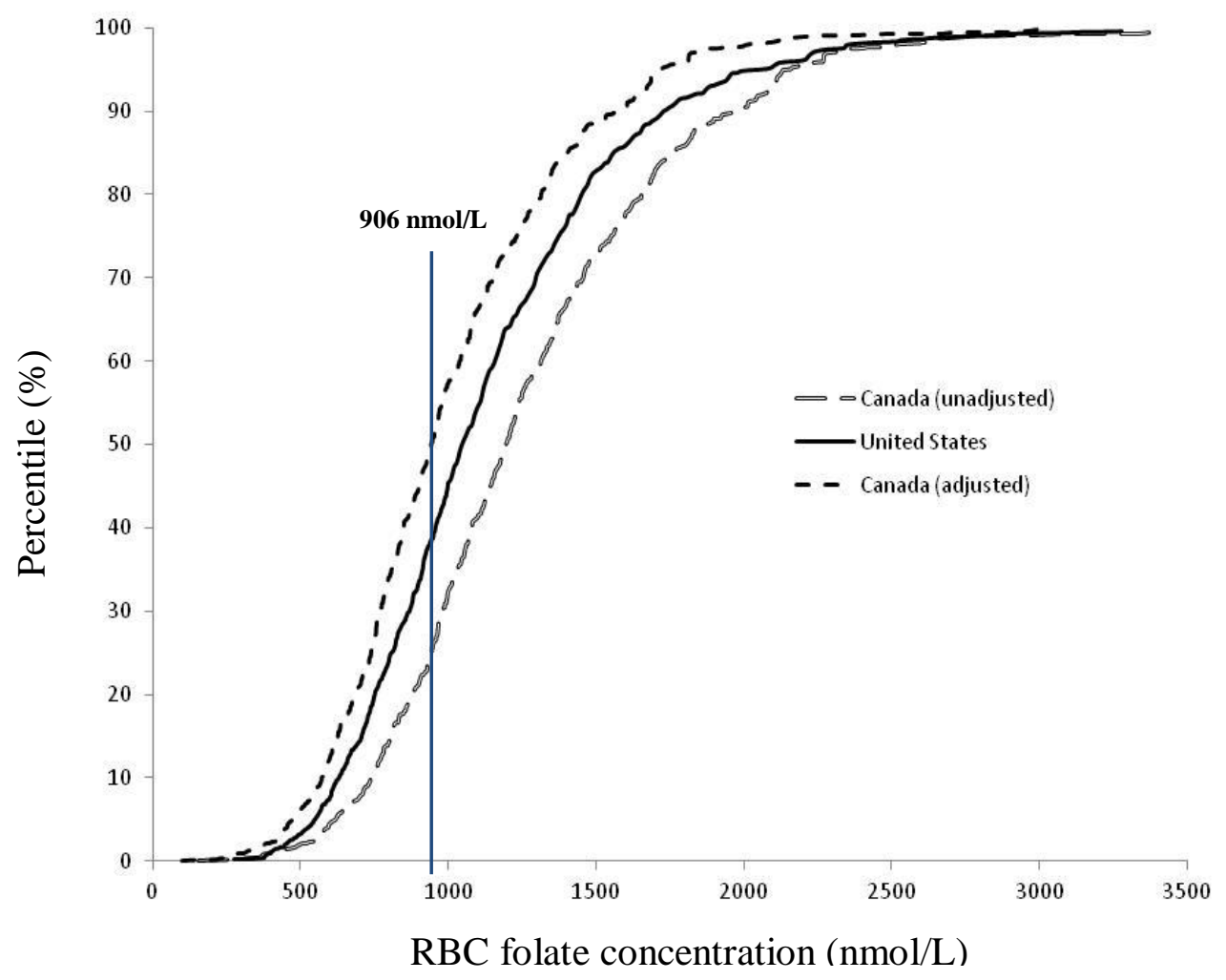


Supplemental Table 1: Selected percentiles for whole blood folate by country

\section{Whole blood folate}

\begin{tabular}{|c|c|c|c|c|}
\hline & \multicolumn{4}{|c|}{ Percentile (95\% CI) } \\
\hline & $\begin{array}{l}\text { 5th } \\
\mathrm{nmol} / \mathrm{L}\end{array}$ & 50th & 75th & 97th \\
\hline \multicolumn{5}{|l|}{ General population } \\
\hline Canada (unadjusted) & $256(233,295)$ & $517(483,552)$ & $666(623,712)$ & $1063(993,1130)$ \\
\hline Canada (adjusted) & $221(203,252)$ & $430(402,458)^{1}$ & $549(514,586)$ & $866(811,922)$ \\
\hline United States & $243(232,257)$ & $482(459,508)$ & $627(587,664)$ & $1020(952,1100)$ \\
\hline \multicolumn{5}{|l|}{ Women of childbearing age } \\
\hline Canada (unadjusted) & $239(207,288)$ & $460(427,491)$ & $605(562,658)$ & $833(912,1020)$ \\
\hline Canada (adjusted) & $207(182,247)$ & $384(358,409)^{1}$ & $500(465,542)$ & $745(682,833)$ \\
\hline United States & $223(204,243)$ & $432(407,453)$ & $562(532,592)$ & $910(873,992)$ \\
\hline
\end{tabular}

${ }^{1}$ Indicates significant in comparison to the United States in the same category $(\mathrm{p}<0.05) .5^{\text {th }}, 75^{\text {th }}$ and $97^{\text {th }}$ percentiles not tested for significant differences.

Note: whole blood folate sample size: General population NHANES, $n=7025$ (45 missing); Women of childbearing age NHANES, $n=1451$ (5 missing) 


\section{Supplemental Figure legends:}

Supplemental Figure 1: A) Altman Bland difference plot. The thin solid line marks the line of identity, the thick solid line marks the bias and the dashed lines mark the $95 \%$ limits of agreement. B) Scatterplot of microbiologic assay results by Immulite 2000 immunoassay results with weighted Deming regression fit. Outliers were removed $(n=6)$. The thin solid line marks the line of identity, the thick solid line marks the weighted Deming fit $(-22.95+0.81 x)$.

Supplemental Figure 2: Boundary assessment examining the lower and upper 95\% CI for the conversion equation for the A) general population and B) women of childbearing age. For reference, figures also include lines indicating the unadjusted and adjusted Canadian values, as well as the American data. 


\section{Supplemental Figure 1:}

A

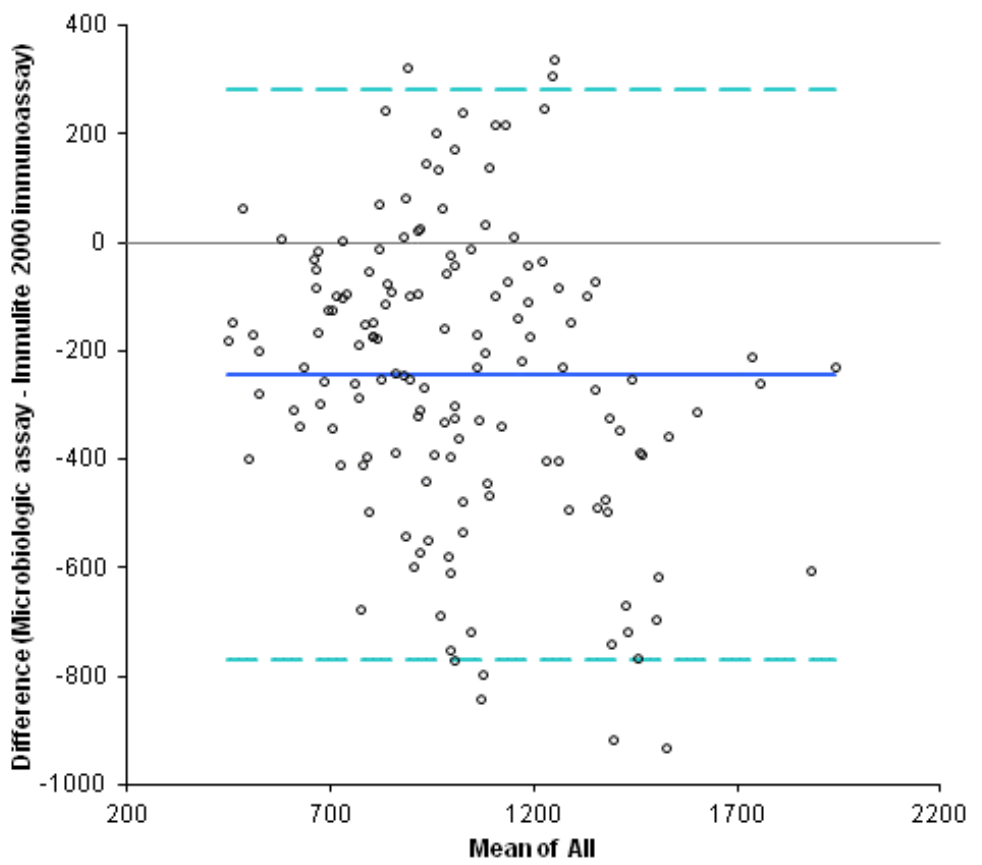

B

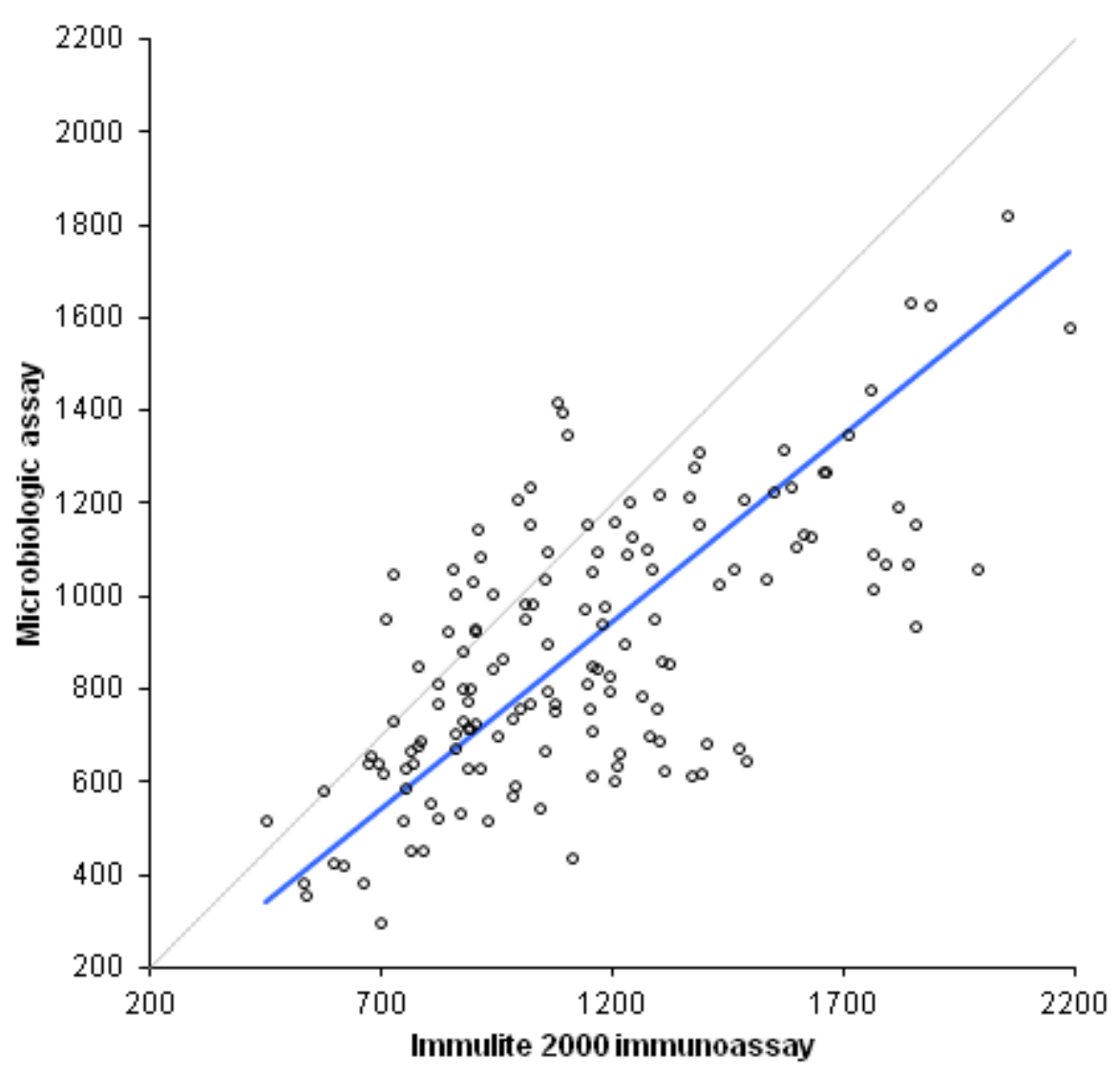




\section{Supplemental Figure 2:}

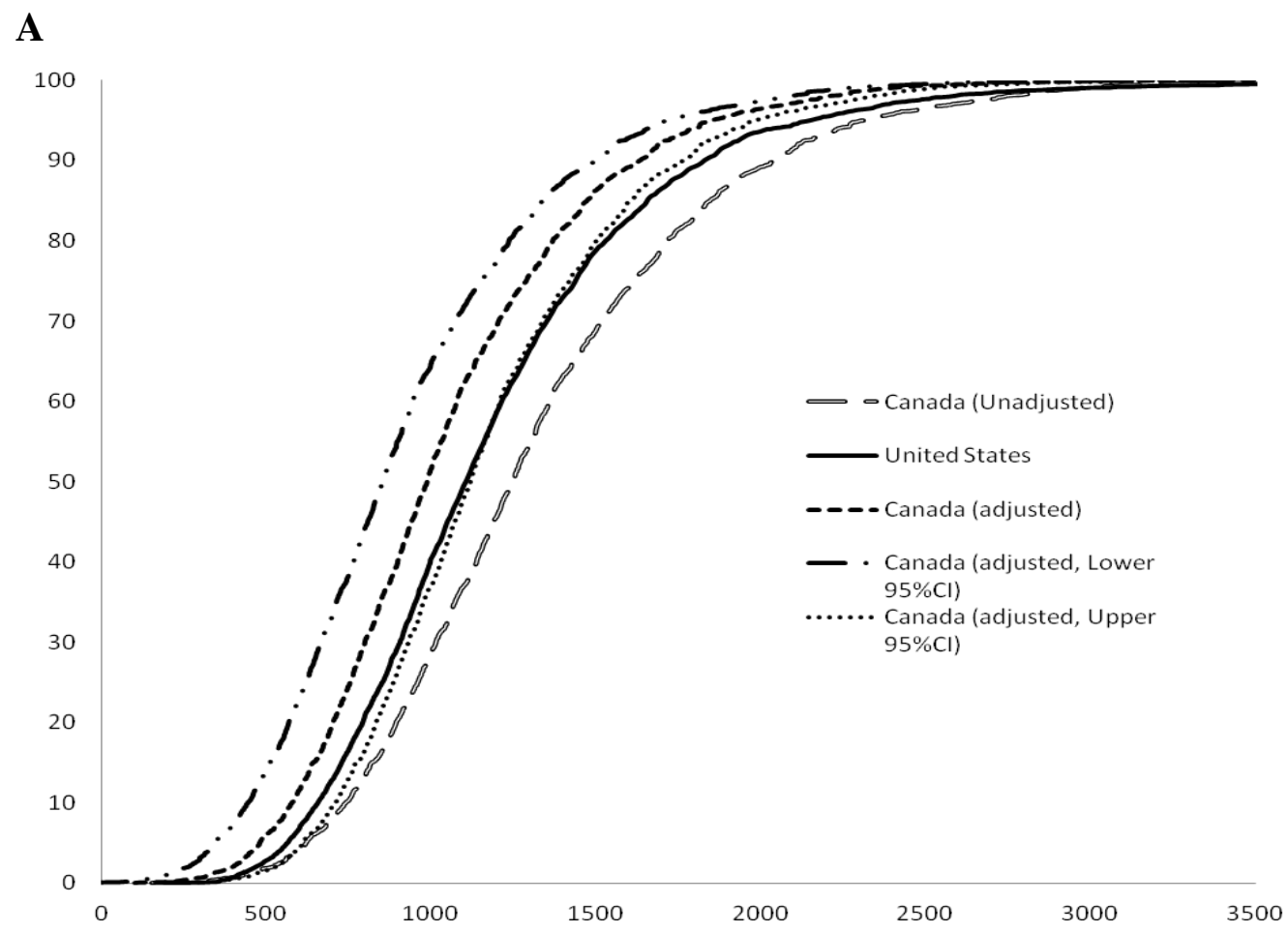

\section{B}

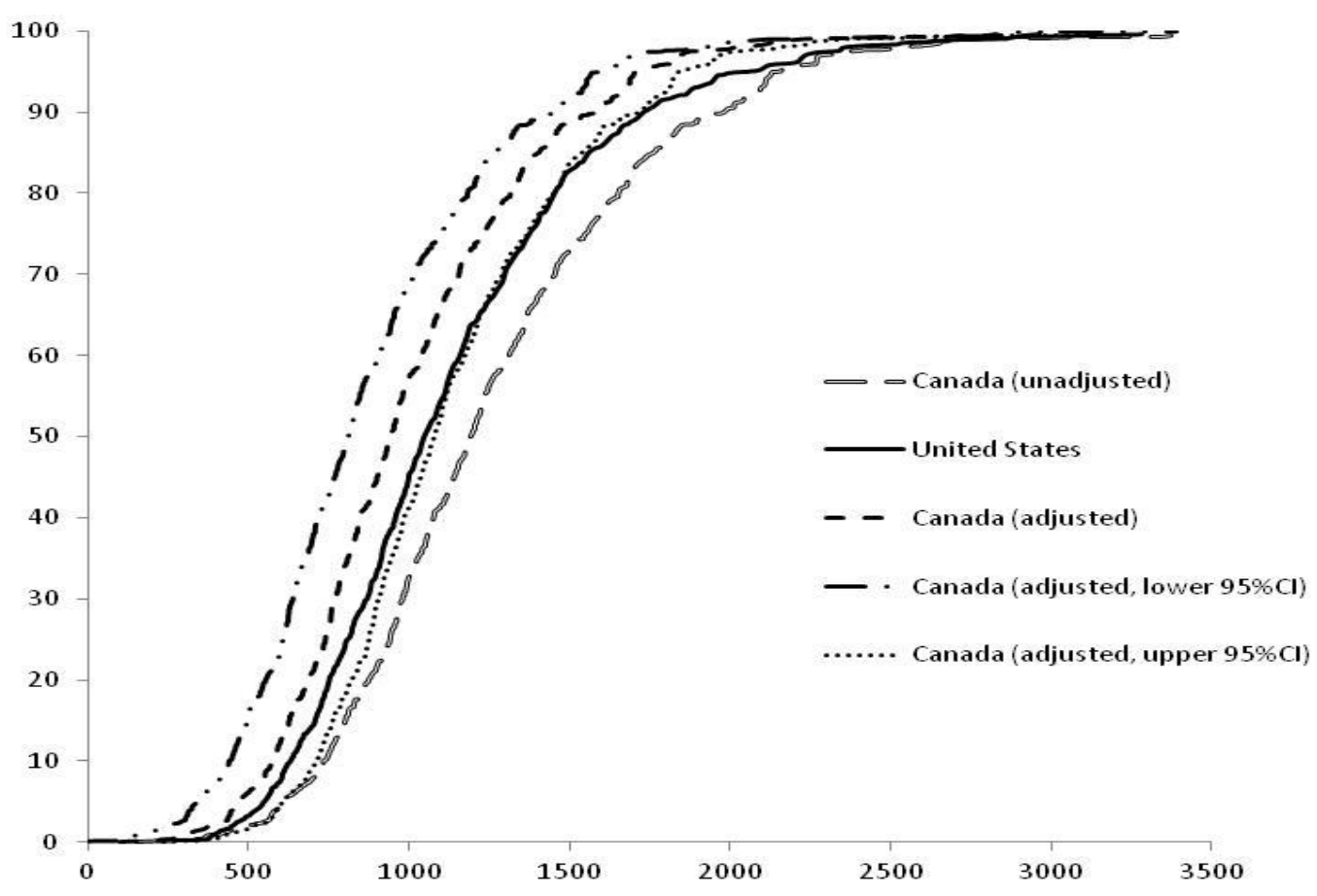




\section{References}

1. Food and Drug Administration. Food standards: amendment of standards of identity for enriched grain products to require addition of folic acid. Final Rule. 21 CFR Parts 136, 137, and 139. Federal Register. 1996;61:8781-8789.

2. Food and drug regulations - amendment SOR/96-527. Canada Gazette Part II; 1996.

3. De Wals P, Tairou F, Van Allen MI, et al. Reduction in neural-tube defects after folic acid fortification in Canada. N Engl J Med 2007;357(2):135-42.

4. Williams LJ, Rasmussen SA, Flores A, et al. Decline in the prevalence of spina bifida and anencephaly by race/ethnicity: 1995-2002. Pediatrics 2005;116(3):580-6.

5. Centers for Disease Control and Prevention (CDC). CDC grand rounds: Additional opportunities to prevent neural tube defects with folic acid fortification. MMWR Morb Mortal Wkly Rep 2010;59(31):980-4.

6. Berry RJ, Mulinare J, Hamner H. Folic acid fortification. In: Bailey, LB. ed. Folate in health and disease. $2^{\text {nd }}$ ed. Boca Raton, FL: CRC Press, Taylor \& Francis Group; 2010.

7. Global progress mandatory wheat flour fortification legislation - August 2012. Ottawa (ON): Flour Fortification Initiative; 2012. Available:

http://www.ffinetwork.org/global progress/index.php (Accessed December 11, 2012).

8. Crider KS, Bailey LB, Berry RJ. Folic acid food fortification-its history, effect, concerns, and future directions. Nutrients 2011;3(3):370-84.

9. Institute of Medicine. DRI dietary reference intakes for thiamin, riboflavin, niacin, vitamin B6, folate, vitamin B12, pantothenic acid, biotin, and choline. Washington, D.C.:

National Academy Press; 1998.

10. Nutrition for a healthy pregnancy - National guidelines for the childbearing years. Ottawa (ON): Health Canada, 2009. Available from: http://www.hc-

sc.gc.ca.proxy.bib.uottawa.ca/fn-an/pubs/nutrition/folate-eng.php (Accessed October 10, 2009).

11. Colapinto CK, O'Connor DL, Tremblay MS. Folate status of the population in the Canadian health measures survey. CMAJ 2011;183(2):E100-6.

12. Yetley EA, Johnson CL. Folate and vitamin $B_{12}$ biomarkers in NHANES: History of their measurement and use. Am J Clin Nutr 2011;94(1):322S-31S. 
13. Pfeiffer CM, Hughes JP, Lacher DA, et al. Estimation of trends in serum and RBC folate in the U.S. population from pre- to postfortification using assay-adjusted data from the NHANES 1988-2010. J Nutr 2012;142(5):886-93.

14. Gunter EW, Bowman BA, Caudill SP, et al. Results of an international round robin for serum and whole-blood folate. Clin Chem 1996;42(10):1689-94.

15. Owen WE, Roberts WL. Comparison of five automated serum and whole blood folate assays. Am J Clin Pathol 2003;120(1):121-6.

16. Bryan S, St-Denis M, Wojtas D. Canadian Health Measures Survey: Clinic operations and logistics. Health Rep 2007;18 Suppl:53-70.

17. About the National Health and Nutrition Examination Survey. Centres for Disease Control and Prevention. Washington (DC). Available:

http://www.cdc.gov/nchs/nhanes/about_nhanes.htm. (Accessed May 13, 2013).

18. Day B, Langlois R, Tremblay M, et al. Canadian Health Measures Survey: Ethical, legal and social issues. Health Rep 2007;18 Suppl:37-51.

19. McNulty B, Pentieva K, Marshall B, et al. Women's compliance with current folic acid recommendations and achievement of optimal vitamin status for preventing neural tube defects. Hum Reprod 2011;26(6):1530-6.

20. Laboratory procedure manual: Folate. Centres for Disease Control and Prevention. Washington (DC). Available: http://www.cdc.gov/nchs/data/nhanes/nhanes_07_08/FOLATE_E_met.pdf. (Accessed May 13, 2013).

21. Immulite 2000 folic acid insert. Mississauga (ON): Siemans Canada, Ltd.; 2009.

22. Pfeiffer CM, Zhang M, Lacher DA, et al. Comparison of serum and red blood cell folate microbiologic assays for national population surveys. J Nutr 2011;141(7):1402-9.

23. National Health and Nutrition Examination Survey: 2007-2008 Data documentation, codebook, and frequencies: RBC folate and serum folate. Centres for Disease Control and Prevention. Washington (DC). Available from: http://www.cdc.gov/nchs/nhanes/nhanes2007-2008/FOLATE_E.htm\#LBXRBFSI. (Accessed May 13, 2013).

24. Daly LE, Kirke PN, Molloy A, et al. Folate levels and neural tube defects. implications for prevention. JAMA 1995 Dec 6;274(21):1698-702. 
25. Questionnaire(s) and reporting guide(s) - Canadian Health Measures Survey (CHMS). Statistics Canada. Ottawa (ON). Available: http://www.statcan.gc.ca/cgibin/imdb/p2SV.pl?Function=getInstrumentLink\&SurvItem Id=9353\&Query Id=10263 $\&$ Query $=$ instance $\&$ lang $=$ en $\& \mathrm{db}=\mathrm{imdb} \& \mathrm{adm}=8 \& \mathrm{dis}=2 .($ Accessed May 13, 2013).

26. Drug Product Database. Health Canada. Ottawa (ON). Available: http://www.hcsc.gc.ca/dhp-mps/prodpharma/databasdon/index-eng.php. (Accessed May 13, 2013).

27. Licensed Natural Health Products Database. Health Canada. Ottawa (ON). Available: http://www.hc-sc.gc.ca.proxy.bib.uottawa.ca/dhp-mps/prodnatur/applications/licen$\mathrm{prod} / \mathrm{lnhpd}-\mathrm{bdpsnh}$ data_extract-eng.php. (Accessed May 13, 2013).

28. Good, PI, Hardin, JW. Common errors in statistics (and how to avoid them). New Jersey, USA: John Wiley and Sons, Inc.; 2009.

29. Ludbrook J. Statistical techniques for comparing measurers and methods of measurement: A critical review. Clin Exp Pharmacol Physiol 2002;29(7):527-36.

30. Linnet K. Evaluation of regression procedures for methods comparison studies. Clin Chem 1993;39(3):424-32.

31. Linnet K. Estimation of the linear relationship between the measurements of two methods with proportional errors. Stat Med 1990;9(12):1463-73.

32. Rust K, Rao J. Variance estimation for complex surveys using replication techniques. Stat Methods Med Res 1996;5:281-310.

33. McDowell MA, Lacher DA, Pfeiffer CM, et al. Blood folate levels: The latest NHANES results. NCHS Data Brief 2008;(6)(6):1-8.

34. O'Broin S, Kelleher B. Microbiological assay on microtitre plates of folate in serum and red cells. J Clin Pathol 1992;45(4):344-7.

35. Bar-Oz B, Koren G, Nguyen P, et al. Folate fortification and supplementation--are we there yet? Reprod Toxicol 2008;25(4):408-12.

36. Caudill MA, Le T, Moonie SA, et al. Folate status in women of childbearing age residing in southern California after folic acid fortification. J Am Coll Nutr 2001;20(2 Suppl):129-34.

37. Dietrich M, Brown CJ, Block G. The effect of folate fortification of cereal-grain products on blood folate status, dietary folate intake, and dietary folate sources among adult nonsupplement users in the United States. J Am Coll Nutr 2005;24(4):266-74. 
38. Tinker SC, Cogswell ME, Devine O, Berry RJ. Folic acid intake among U.S. women aged 15-44 years, National Health and Nutrition Examination Survey, 2003-2006. Am J Prev Med 2010;38(5):534-42.

39. Shakur YA, Garriguet D, Corey P, et al. Folic acid fortification above mandated levels results in a low prevalence of folate inadequacy among Canadians. Am J Clin Nutr 2010 ;92(4):818-25.

40. Colapinto CK, O'Connor DL, Dubois L, et al. Prevalence and correlates of folic acid supplement use in Canada. Health Rep 2012;23(2):39-44.

41. Colapinto CK, O'Connor DL, Dubois L, et al. Folic acid supplement use is the most significant predictor of folate concentrations in Canadian women of childbearing age. Appl Physiol Nutr Metab 2012;37(2):284-92.

42. Yang Q, Cogswell M, Hamner H, et al. Folic acid source, usual intake, and folate and B12 status in U.S. adults: National Health and Nutrition Examination Survey (NHANES) 2003-2006. Am J Clin Nutr 2010;91(1):64-72.

43. Sempos CT, Vesper HW, Phinney KW, et al. Vitamin D status as an international issue: National surveys and the problem of standardization. Scand J Clin Lab Invest Suppl 2012;243:32-40.

44. Mason JB, Dickstein A, Jacques PF, et al. A temporal association between folic acid fortification and an increase in colorectal cancer rates may be illuminating important biological principles: A hypothesis. Cancer Epidemiol Biomarkers Prev 2007;16(7):1325-9.

45. Cole BF, Baron JA, Sandler RS, et al. Folic acid for the prevention of colorectal adenomas: A randomized clinical trial. JAMA 2007;297(21):2351-9.

46. Wien TN, Pike E, Wisloff T, et al. Cancer risk with folic acid supplements: A systematic review and meta-analysis. BMJ Open 2012;2(1):e000653.

47. Fife J, Raniga S, Hider PN, et al. Folic acid supplementation and colorectal cancer risk: A meta-analysis. Colorectal Dis 2011;13(2):132-7.

48. Baggott JE, Oster RA, Tamura T. Meta-analysis of cancer risk in folic acid supplementation trials. Cancer Epidemiol 2012;36(1):78-81.

49. Vollset SE, Clarke R, Lewington S, et al. Effects of folic acid supplementation on overall and site-specific cancer incidence during the randomised trials: Meta-analyses of data on 50000 individuals. Lancet 2013;381(9871):1029-36. 
50. Fazili Z, Pfeiffer CM, Zhang M, et al. Influence of 5,10-methylenetetrahydrofolate reductase polymorphism on whole-blood folate concentrations measured by LCMS/MS, microbiologic assay, and Bio-Rad radioassay. Clin Chem 2008;54(1):197-201.

51. Icke GC, Dennis M, Sjollema S, et al. Red cell N5-methyltetrahydrofolate concentrations and C677T methylenetetrahydrofolate reductase genotype in patients with stroke. J Clin Pathol 2004;57(1):54-7. 


\section{CHAPTER 5: DISCUSSION}

This Chapter presents a summary of the results and additional reflections to complement the fourth chapter's discussion sections. Here, the results are interpreted through the Total Environmental Assessment Model for Early Child Development (TEAM-ECD), the socioecological framework used to conceptualize this research (see Section 1.3.3). Answers to key questions, a summary of the strengths and limitations, and evidence-based policy and research recommendations follow the interpretation.

\subsection{Summary of results by hypothesis}

1. Less than 5\% of Canadians demonstrate folate deficiency (red blood cell [RBC] folate $<305 \mathrm{nmol} / \mathrm{L})$ and less than 5\% demonstrate high folate (RBC folate $>1360 \mathrm{nmol} / \mathrm{L})$, but proportions vary by age, sex, and socioeconomic status. Adolescents (vs. adults), females (vs. males) and Canadians of low socioeconomic status (vs. higher socioeconomic status) are more likely to be folate deficient.

We found that folate deficiency was virtually non-existent in the Canadian population, and, conversely, that elevated folate concentrations were evident. Differences in median folate concentrations by age and socioeconomic status were seen in the general population. The shift from concerns regarding folate deficiency towards higher RBC folate concentrations led to the examination of three hypothesized high folate cut-offs, which were significantly associated with folic acid supplement intake, older age groups, females, overweight and obese participants and replete vitamin $\mathrm{B}_{12}$ status.

2. At least $40 \%$ of Canadian women of childbearing age demonstrate inadequate folate status for maximal protection against NTDs (RBC folate $<906 \mathrm{nmol} / \mathrm{L})$. Canadian 
women of childbearing age of low socioeconomic status are more likely to have inadequate folate status for maximal protection against neural tube defects (NTDs) (RBC folate $<906 \mathrm{nmol} / \mathrm{L})$ than those of higher socioeconomic status.

It was demonstrated that more than $20 \%$ of women of childbearing age were below optimal folate concentrations for maximal protection against NTD births ( $\geq 906 \mathrm{nmol} / \mathrm{L})$. Differences in median folate concentrations by age and socioeconomic status were not seen among women of childbearing age.

An investigation of women of childbearing age revealed that folic acid supplement intake was a primary predictor of $\mathrm{RBC}$ folate concentrations and $25 \%$ of this subgroup reported folic acid supplement use. A higher percentage of women of childbearing age who used folic acid supplements were in the upper income group.

\section{At least $50 \%$ of Canadian women of childbearing age do not consume folic acid} supplements.

- Canadians of low socioeconomic status in general, and Canadian women of childbearing age of low socioeconomic status specifically, will be less likely to consume folic acid supplements than those of higher socioeconomic status.

- Canadian WCBA who do not consume folic acid supplements are less likely to have $R B C$ folate concentrations that are maximally protective against NTD births (RBC folate $<906 \mathrm{nmol} / \mathrm{L})$.

- Canadian socioeconomic status with clinical risk factors for NTD births (ie. obesity, diabetes mellitus, regular use of folic acid antagonist medications) who are noncompliant with high dose folic acid supplement recommendations $(5 \mathrm{mg} / \mathrm{d})$ will be 
more likely to have inadequate folate status for maximal protection against NTDs (RBC folate $<906 \mathrm{nmol} / \mathrm{L})$ than those who are compliant.

One-quarter of the Canadian population reported folic acid supplement consumption. The youngest and oldest age groups demonstrated the highest use of folic acid supplements, teenagers and young adults proved lowest. Further, females were more likely to use a folic acid supplement than males. A positive gradient by household income emerged as those in the lower income quartiles were significantly less likely than those in the highest quartile to have taken a folic acid supplement.

4. Canadians in general are less likely to be folate deficient (RBC folate $<305 \mathrm{nmol} / \mathrm{L})$ than Americans. Canadian WCBA are less likely to have inadequate folate for maximal protection against NTDs (RBC folate $<906 \mathrm{nmol} / \mathrm{L})$ than American WCBA. When the Canadian Health Measures Survey (CHMS) RBC folate concentration data were compared to similar American National Health and Nutrition Examination Survey (NHANES) data, it appeared that Canadians had lower folate concentrations than Americans. Though folate deficiency was no longer an issue in either country, the proportion of women of childbearing age achieving optimal RBC folate concentrations for NTD prevention was lower in Canada. While Canadians appeared to have lower median concentrations of RBC folate than Americans when a methods conversion equation was applied, Canadians had higher median concentrations than Americans when the unadjusted data were compared. 


\subsection{Interpretation within a socioecological framework}

The TEAM-ECD model (described in detail in Section 1.3.3) provided a conceptual framework for this research. This model is based in socioecological theory, which incorporates the interrelated, contextual factors that exert influence at different societal levels across the lifecourse so relevant levers for action can be identified. The study development was based on two theoretical assumptions: 1) A socioeconomic status gradient in folate status exists, with those of lower socioeconomic status having diminished folate status, and 2) Policies intended to improve the folate status of the population may lead to high folate status in certain subgroups or may not be accessible to all Canadians.

The lifecourse approach is at the core of the TEAM-ECD model. Women of childbearing age are the origin of early child development as they can provide a healthy environment where a fetus can grow and develop. One component of fostering fetal health is folic acid consumption periconceptionally for NTD prevention in the offspring. During this examination, more than one-fifth of Canadian women of childbearing age had RBC folate concentrations that were not considered optimal for NTD risk reduction. Further, only $25 \%$ of women of childbearing age were consuming a folic acid supplement, which was a primary predictor of folate status.

The prevalence of folic acid supplement intake was comparable to the 2004 Canadian Community Health Survey (CCHS), which demonstrated folic acid supplement use in 15\%, $23 \%$ and $29 \%$ of women aged $14-18,19-30$ and $31-50$ years, respectively. ${ }^{1}$ Further, $25 \%$ of American women of childbearing age reported consuming a folic acid supplement in the 2003-2006 NHANES. ${ }^{2}$ Studies of subgroups of women of childbearing age also concurred that folic acid supplement intake was a strong, modifiable factor associated with RBC folate 
concentrations $\geq 906 \mathrm{nmol} / \mathrm{L}$. For example, 40 healthy women, aged $18-45$ years, from Toronto, who did not use supplements, were randomly assigned to consume supplements of $1.1 \mathrm{mg}$ or $5.0 \mathrm{mg}$ for 30 weeks. This resulted in an increase in mean RBC folate concentrations, from $1035 \pm 273 \mathrm{nmol} / \mathrm{L}$ to $1121 \pm 410 \mathrm{nmol} / \mathrm{L}$ and $1625 \pm 339 \mathrm{nmol} / \mathrm{L}$ to $2339 \pm 782 \mathrm{nmol} / \mathrm{L}$, respectively. ${ }^{3}$ Though it is unknown how many of the women of childbearing age in the CHMS were capable of getting pregnant, it is evident that many were not consuming the amount of folic acid supplement recommended by Health Canada (Appendix B). ${ }^{4}$ Further, a study of 361 pregnant women in Montreal, Quebec, found that adherence to the Society of Obstetricians and Gynecologists Canada (SOGC)/Motherisk guidelines was low (27\%). ${ }^{5}$ Barriers to compliance have been explored, ranging from women deeming supplementation unnecessary to poor access. ${ }^{6-8}$ This dissertation corroborates the need for targeted strategies to support compliance with folic acid supplementation guidelines.

The social determinants of health, a component of the TEAM-ECD, guide strategies to improve access to folic acid supplements for women of childbearing age. This thesis established a relationship between low income quartiles and folic acid supplement intake, in addition to a correlation between optimal RBC folate concentrations for women of childbearing age and folic acid supplement intake. Considering a similar inequality has been identified for NTD risk, low income women of childbearing age may be an important target population for folic acid supplement interventions. The correlation between the lower income quartiles and decreased prevalence of folic acid supplement use was also reflected in a systematic review of international research (1989-2006) on folic acid supplement intake, as well as in a study of the 2004 CCHS data. ${ }^{9}{ }^{10}$ Strategies to improve access to folic acid 
supplements for low income women who are capable of becoming pregnant - such as supplying these supplements at no cost to those demonstrating financial need - may be appropriate. Further, many women in the lower income quartile may not have access to a family doctor who could provide education on folic acid supplements or prescribe higher dose supplements for women at risk of NTD birth. Supporting these women in accessing folic acid may further reduce the risk of NTDs in this subgroup and improve the ability for children to develop, prosper and contribute to society throughout their lifespan.

At the other end of the lifecourse spectrum are older adults. These individuals were more likely to have RBC folate concentrations above the median than the younger age groups. This population also had a higher prevalence of RBC folate concentrations above the proposed high cut-offs and were more likely to consume supplements than other age groups. NHANES data also demonstrated higher mean RBC folate concentrations, post-fortification, among American older adults than other age groups. ${ }^{11}$ Folic acid supplements are not generally recommended for this population, unless there is an identified clinical need. Considering the current literature that demonstrates conflicting results as to the existence of an association between high intake of folic acid and speculated adverse health outcomes including increased risk of cancer in those with pre-existing neo-plasms and cognitive impairment in older adults - and that older adults are at increased risk of malignancy, elevated folate concentrations require further investigation in this subgroup. ${ }^{12-17}$ Those with elevated RBC folate concentrations may also have unmetabolized folic acid in the serum, which has been implicated in cognitive impairment in older adults. ${ }^{18}$ Future research into the cause of this elevated folate status in older adults would help clarify if it is due to intake of fortified foods and supplements, metabolism, physiology or a combination of these factors. 
In the interim, it appears that multivitamin supplements formulated for older adults should contain nutrients required by this subgroup, for example vitamin D and calcium, but not include folic acid.

Our comparison of RBC folate concentration between Canada and the United States explored disparities based on race/ethnicity as primary determinants of folate status. NHANES data (2005-2006, post-fortification) showed that the non-Hispanic white population had a higher RBC folate than Mexican Americans and non-Hispanic black participants. Further, non-Hispanic white women had significantly higher folate concentrations than non-Hispanic black and Mexican-American women. ${ }^{19}$ In our study, nearly all subgroups, in both countries, were folate replete. ${ }^{11}$ Since a significant difference in RBC folate status between Canada and the United States persisted in this study, regardless of controlling for race/ethnicity and supplement use, it is likely that other factors may be driving the difference between countries. Dietary intake of folic acid may be one of these factors since fortification policies differ between the two countries. Most significantly, the United States mandates a greater number of foods to be fortified and Canada allows lower fortification levels for breakfast cereals. ${ }^{20,21}$ Our study was not able to control for potential differences in dietary intake. Further, the RBC folate measurement method used in the CHMS is not considered a gold standard, and limits comparisons both domestically and internationally.

The policy implications of this research can be explored through the multiple spheres of influence, described in the TEAM-ECD. These spheres capture the social determinants of health and the lifecourse approach by illustrating the complexity of the child's environment and the various structures that exert influence on periconceptional and prenatal health. This 
framework highlights how healthy child development, and health across the lifecourse, is influenced by the introduction and refinement of policies over time. It is important to adapt these policies based on current evidence and population needs. Key policy considerations (e.g. fortification of certain grain products with folic acid; amendments to discretionary folic acid fortification policy; and the dose and availability of folic acid supplements) are captured in the outermost spheres with their impact resonating in the innermost levels. In examining the policy environment, the needs of the general population were considered separately from those of women of childbearing age. Our results demonstrated elevated RBC folate concentrations in the general population and that folic acid supplement intake was a primary correlate of high folate status. Synthetic folic acid was found to be responsible for folic acid intake above the tolerable upper intake level (UL) ${ }^{\mathrm{i}}$, in both Canadian and American nationallevel studies. ${ }^{1,22}$ Thus, folic acid supplement use appears to be an important lever for policy reform. Eliminating or lowering the dose of folic acid in supplements that do not target women of childbearing age may be appropriate as these are used by a folate-replete population with access to folic acid fortified foods. Policy makers may consider elevated $\mathrm{RBC}$ folate concentrations in the general population prior to augmenting the amount of folic acid in the food supply, whether through increasing the dose in currently fortified products or allowing more products to be fortified through amendments to discretionary fortification policy. It appears that such increases are not necessary. A study of fortified foods in Canada identified 92 commonly consumed foods and revealed that the folic acid content was $151 \%$ +/- 63 of Canadian Nutrient File values. These folic acid overages, in addition to the

\footnotetext{
${ }^{\mathrm{i}}$ The UL is the highest average daily dose that is likely to pose no risk of adverse health effects in healthy individuals. For folic acid a conservative UL value was set $(1000 \mu \mathrm{g} / \mathrm{d})$ based on a dose that could potentially mask neurological symptoms of vitamin $B_{12}$ deficiency $(5000 \mu \mathrm{g} / \mathrm{d})$ divided by an uncertainty factor of five. ${ }^{41}$
} 
knowledge that synthetic folic acid is a primary contributor to elevated blood folate levels, suggests the need for an amendment to folic acid policies to specify and enforce a maximum level for folic acid fortification. The New Zealand Ministry for Primary Industries has one such policy that limits bread to include no more than $2.5 \mathrm{mg} / \mathrm{kg}(0.25 \mathrm{mg} / 100 \mathrm{~g})$ of folic acid..$^{23,24}$

Many prenatal supplements for women of childbearing age contain $1 \mathrm{mg}$ of folic acid, which is the UL. Taking these supplements in addition to foods fortified with folic acid will lead to intake that exceeds the UL. The amounts in these supplements could be reconsidered and policy efforts re-focused on improved access and education regarding appropriate supplement use for both women of childbearing age, in particular for those of lower income, and the general population.

It appears that folic acid fortification and supplementation policies have succeeded in eliminating much of the inequality related to folate deficiency. A socioeconomic status gradient in folate concentrations was demonstrated in the general population; however, those of lower socioeconomic status did not have low folate status. Supplemental doses of folic acid are vitally important for women of childbearing age, though the strength and necessity of supplements - in addition to consumption of fortified grains - for the general population should be assessed carefully by clinicians and policy makers. Continued surveillance of folic acid policies and related health implications for women of childbearing age, their offspring, and the general population, will allow for trends in the impact of influential policies and programs on healthy child development to be measured. Folate surveillance would be improved, in terms of accuracy and domestic and international comparability, if the CHMS adopted the gold standard for folate analysis, currently microbiologic assay. 


\subsection{Responses to policy relevant questions}

\subsubsection{Do doses of folic acid in the food supply or supplements need to be increased?}

The initial stimulus for this research was the 2007 SOGC/Motherisk guidelines, which included recommendations that suggest an increased dose of folic acid supplement for many women of childbearing age and that the Federal government should consider evaluating the need to double the level of folic acid in currently fortified food products. ${ }^{25}$ This has sparked considerable debate because folic acid fortification targets women of childbearing age by exposing the entire population to higher levels of folic acid. Correction of folate deficiency and improved folate status, in part through fortification, has been associated with positive health outcomes. In addition to a dramatic reduction in NTDs, folic acid has been implicated in the etiology of other beneficial health outcomes, such as decreased risk of congenital heart defects and oral cleft and, at adequate levels, lower risk of breast, lung and prostate

cancer. ${ }^{26-28}$ However, speculations of the possible adverse effects associated with high levels of folic acid, including increased risk of certain cancers among those with pre-existing neoplasms - though the results are conflicting - suggest caution prior to making further attempts to improve the folate status of Canadian women of childbearing age by increasing fortification levels. ${ }^{13-17,28-32}$ Further, amendments to national discretionary fortification policy currently being considered in Canada - which would allow for a broader variety of foods to be fortified with folic acid at the discretion of industry - do not appear to be necessary. ${ }^{33}$ Two recent investigations of folate intake in Canadians demonstrated that inadequate intake was rare in the general population and intake of discretionarily fortified foods was associated with lower nutrient intakes and suboptimal food intake patterns. ${ }^{1,34}$ Increasing the availability of folic acid through discretionary folic acid fortification may 
assist more women of childbearing age to achieve levels considered optimal for NTD risk reduction ( $\geq 906 \mathrm{nmol} / \mathrm{L}$ ); however, this would also increase folate concentrations in other subgroups that are already exhibiting high folate status.

Folic acid supplements are a primary determinant of folate concentrations. Both Canadian and American studies have demonstrated that the only participants that exceed the UL for folate were synthetic folic acid supplement users. ${ }^{1,2}$ Canadian women of childbearing age who use folic acid supplements are more likely than non-users to achieve the $906 \mathrm{nmol} / \mathrm{L}$ cut-off. Current Canadian guidelines recommend a multivitamin supplement containing $0.4 \mathrm{mg} / \mathrm{d}$ of folic acid for women of childbearing age, in addition to folate rich foods. ${ }^{35}$ Many studies of women of childbearing age have documented the dose-response relationship between folic supplement intake and folate status. For example, the study by Nguyen et al. demonstrated a greater increase in mean $\mathrm{RBC}$ folate with daily intake of $5 \mathrm{mg}$, as compared to $1.1 \mathrm{mg}$, over 30 weeks. ${ }^{3}$ In a New Zealand study, adults $>65$ years of age $(\mathrm{n}=276)$ were given a daily placebo or $1 \mathrm{mg}$ folic acid supplement over a two-year period as part of a double-blind RCT to examine time to achieve steady-state concentrations. The supplemented group demonstrated considerable increases in RBC folate concentrations (measured by microbiologic assay) from $980 \mathrm{nmol} / \mathrm{L}$ at baseline to 2750 at six months and $3230 \mathrm{nmol} / \mathrm{L}$ at 24 months. ${ }^{36}$ It is notable at the time of this latter study there was no mandatory folic acid fortification program in New Zealand. Nonetheless, the Toronto and New Zealand studies together suggest that supplemental folic acid doses in the range of the UL elicit RBC folate concentrations similar to or above our proposed high cut-offs of 1800 and $2150 \mathrm{nmol} / \mathrm{L}$.

Further exploration is needed to determine the need for the large doses of folic acid (often $1 \mathrm{mg}$ ) found in many prenatal supplements, consumed in addition to folic acid fortified 
(estimated at $200 \mu \mathrm{g} / \mathrm{d}$ ) and folate-rich foods, in those who are not considered at risk of NTD

birth. ${ }^{37}$ Where the general population is the target of a multivitamin supplement, for example older adults, children and men, the folic acid dose could be lowered as Canadians are folate replete and consume folic acid fortified foods.

\subsubsection{Are folate concentrations of particular concern for any population subgroups?}

At the onset of this research, the literature identified a number of subgroups at increased risk of NTD birth and, subsequently investigated these subgroups for folate deficiency. It was evident that the general population had shifted towards elevated folate status, and women of childbearing age were not achieving optimal levels. Regardless of the lack of deficiency, the risk factors for NTD birth were also correlated with folate concentrations. Individuals in the lower age and income groups were more likely to fall below the median $\mathrm{RBC}$ folate; however, older age groups were more likely to have elevated folate status. Overweight or obese participants also appeared to be at particular risk of reaching the high $\mathrm{RBC}$ folate cut-offs proposed in this dissertation (see Section 4.4). The overweight or obese population in the CHMS was less likely than those who were not overweight or obese to report folic acid supplement use; thus, exploration is needed to determine the cause of these elevated concentrations (e.g. biased reporting, intake of folic acid fortified foods or physiology).

An income gradient in RBC folate concentrations was evident among women of childbearing age. Further, women of low income and younger age groups were less likely to consume folic acid supplements, a primary predictor of RBC folate concentrations. It appears that this subgroup warrants further investigation - including a determination of whether women who are not consuming folic acid supplements are capable of before pregnant - as 
well as targeted interventions.

\subsubsection{Is Vitamin $B_{12}$ masking a concern for the Canadian population?}

High levels of supplemental folic acid may mask and exacerbate vitamin $\mathrm{B}_{12}$ deficiency, particularly in the elderly and people who consume small amounts of meat, which could result in neurological damage if not addressed. ${ }^{12,13,29-31}$ Our results demonstrated that a high proportion of the Canadian population was vitamin $\mathrm{B}_{12}$ replete. Further, the majority of those above the high $\mathrm{RBC}$ folate cut-offs were vitamin $\mathrm{B}_{12}$ replete. Vitamin $\mathrm{B}_{12}$ supplement use was also correlated with intake of folic acid supplements, which may explain the association with blood concentrations for both nutrients. Supplemental folic acid doses in the range of the UL elicit RBC folate concentrations similar to or above our proposed high cut-offs of 1800 and $2150 \mathrm{nmol} / \mathrm{L} .{ }^{3,36}$ Vitamin $\mathrm{B}_{12}$ masking does not appear to be a concern for the general Canadian population; however, the potential for this adverse health effect should be reviewed on a case-by-case basis in clinical settings. Further, we should continue to support regulations that require the addition of vitamin $\mathrm{B}_{12}$ at the recommended dietary allowance (RDA) dosage where a product contains folate at doses $>200 \mu \mathrm{g} / \mathrm{d}^{38}$

\subsubsection{Should Canada continue to monitor RBC folate concentrations?}

This thesis provides evidence that folate deficiency is virtually non-existent in the Canadian population. Considering the observed shift towards elevated concentrations - and the associated adverse health outcomes that have been speculated - it is evident that monitoring of blood folate concentrations should continue regardless of major changes in folic acid fortification or supplementation policy. There is evidence that in the United States, RBC folate concentrations trended upwards post-fortification. ${ }^{11}$ Therefore, the current CHMS data provides a snapshot of the RBC folate status of Canadians, but continued monitoring will 
allow trends to emerge and the trajectory of RBC folate concentrations to be understood. Further, access to more CHMS cycles, which can be combined, will increase the degrees of freedom and the sample size and allow for more sophisticated analyses. Monitoring would also be improved if RBC folate concentration was measured using a gold standard method, currently microbiologic assay.

\subsubsection{Is a cut-off needed to define "high" folate status?}

Canadian RBC folate concentrations are elevated and a cut-off for defining high folate concentrations is needed. A universal cut-off for high RBC folate, whether it is more or less conservative than those proposed in this dissertation, will advance the field towards consistent measurement and reporting of high folate status and related health outcomes. Future research may reveal that a range of $\mathrm{RBC}$ folate values, rather than a specific cut-off, may promote maximal health benefits for the population at minimal risk. This definition will ultimately inform the debate on appropriate public health interventions and clinical guidelines for folic acid. Convening a meeting of the experts to explore a definition for high folate status and to consider multiple issues, including the need for a harmonized assay method for RBC folate data, is an essential next step.

\subsection{Summary of limitations and strengths of the research}

\subsubsection{Strengths}

The studies in this thesis were designed to address a significant knowledge gap in the folate status of Canadians. This research used nationally representative survey data, and a large sample size. Drug identification and natural health product numbers were collected in the participant's home and at the clinic, minimizing self-reporting bias. The study included 
directly measured $\mathrm{RBC}$ folate. This research also permitted the comparison of Canada to the United States by conducting a methods comparison study between the Immulite 2000 immunoassay and microbiologic assay to adjust the CHMS RBC folate data. This significantly strengthened our understanding of the two folate assay methods and confirmed that a direct comparison would have led to erroneous conclusions.

\subsubsection{Limitations}

We identified several limitations during the course of this research. The cross-sectional nature of the CHMS does not allow for causal inferences. The overall response rate to the CHMS was slightly above 50\%. Although the survey weights ensured that the sample was representative of the target population, bias might exist if the use of folic acid-containing supplements by non-respondents and respondents differed systematically. As outlined in Section 3.6, the number of independent variables included in the regression model was limited by the 11 degrees of freedom. The CHMS provides concise data on drug identification and natural health product numbers; however, the survey was not designed to collect information on usual supplement dosage, so precisely how often supplements were consumed could not be determined. Future cycles of the CHMS would also benefit from the inclusion of more detailed nutrition information, which would allow the RBC folate concentration data to be used in studying folic acid from dietary sources. The impact of folate-related policies could then be more thoroughly examined over time. All women of childbearing age (15-45 years of age) were included in this subgroup, thus women of childbearing age incapable of becoming pregnant, for reasons of physiology or use of birth control, were not examined separately. However, it is unlikely that the sample size would have been adequate to analyse this subgroup. 
Limitations were also present for the crossover sub-study. The microbiologic assay was not conducted at the Centres for Disease Control and Prevention NHANES laboratory, which may lead to interlaboratory variation in the microbiologic assay. To address this limitation, a boundary assessment demonstrated that, overall, Canadian RBC folate values were lower than those of Americans, even when a conversion equation generated using the upper $95 \%$ confidence interval was applied to the CHMS RBC folate data. Further, unlike the NHANES microbiologic assay, the CHMS immunoassay does not correct for serum folate in its calculation of RBC folate. Whole-blood data were examined in the methods comparison study to examine this potential limitation. It was determined that the adjusted whole-blood data yielded comparable results to RBC folate (see Section 4.5 for more detail on RBC folate results). Thus, the lack of correction for serum folate did not appear to be a limitation of the comparison.

\subsection{Generalizability of the results}

International generalizability of these results may be limited to similar populations, for example the United States. However, any between-laboratory comparison, regardless of country, must consider the comparability of the folate assay methods employed. We suggest caution in using the conversion equation generated in this dissertation in a different context. The equation is limited to data from the CHMS laboratory Immulite 2000 immunoassay for comparison to microbiologic assay, which was conducted using the same methodology described for the 2007-2008 NHANES. ${ }^{39}$ The equation will apply to CHMS Cycle 2 RBC folate data, but for CHMS Cycle 3 the Advia Centaur XP (Bayer Diagnostics, Tarry-town, NY) was introduced. This change in assay machine needs to be examined prior to combining 
RBC folate data from multiple CHMS cycles. The most appropriate procedure may be to adjust the Advia Centaur XP RBC folate data to microbiologic assay then compare this data with the Immulite 2000 immunoassay RBC folate data adjusted to microbiologic assay for CHMS Cycles 1 and 2.

\subsection{Knowledge translation strategy}

Publications, presentations and collaboration have been the primary means of knowledge translation for this research. The article Examining the folate status of Canadians, was published in CMAJ. This publication was accompanied by a press release which received substantial international media attention, including from CBC's The National, The Globe and Mail and The Times of India (Appendix E). This work was presented to the Health Analysis Division at Statistics Canada (June, 2010) at the Canadian Association for Health Services and Policy Research conference in Halifax (May, 2011). The article Prevalence and correlates of folic acid supplement use in Canada was published in Health Reports as a Health Matters article. The article Folic acid supplement use is the most significant predictor of folate concentrations in Canadian women of childbearing age was published in Applied Physiology, Nutrition and Metabolism, and received media attention from Metro Ottawa. This work was presented at the World Congress of Epidemiology in Edinburgh, Scotland (August, 2011). The study Prevalence of high red blood cell folate concentration in the Canadian population using three proposed cut-offs will be submitted to the European Journal of Clinical Nutrition. Part of this work was presented at the World Congress of Epidemiology in Edinburgh, Scotland (August, 2011). The study Comparison of Canadian and American red blood cell folate concentrations was presented the Experimental Biology 
conference along with a presentation of the methods comparison study (April, 2013) and will be submitted to the Journal of Nutrition. Each publication was shared with colleagues at Health Canada, the Public Health Agency of Canada, Statistics Canada and the U.S. Centres for Disease Control.

\subsection{Core evidence-based policy and research recommendations}

The following recommendations flow directly from the results of this research. These recommendations are not presented in order of importance, but represent coordinated, multilevel efforts to improve folic acid interventions, primarily policy and research, and in turn population health.

1) Continue to monitor and evaluate: The CHMS is a well-designed and comprehensive survey. Continued monitoring of the population blood concentrations in future CHMS cycles is recommended to allow researchers to map trends in population folate status, as well as relevant correlates. Though separate national-level data exist for directly measured biomarkers of RBC folate and folate intake, future cycles of the CHMS would benefit from the inclusion of more detailed nutrition information - from food and supplements - to complement RBC folate concentration data, so the impact of folate related policies can be more thoroughly examined over time. Understanding the time constraints associated with large surveys, these questions could take the form of quantitative food frequency questions focused on intake of folic acid fortified grain products. Questions that measure a participant's usual dose and frequency of folic acid supplement use would also provide a more in-depth understanding of intake. In the absence of a more comprehensive dataset, it may be useful to explore microsimulation 
models to combine and examine several key datasets to estimate the impact of intake, folate status and health outcomes. Future research efforts that assess folic acid intake, folate concentrations and health outcomes longitudinally would provide data imperative to understanding the associations of these factors over time.

Survey questions could be developed to facilitate a better understanding of the relationship between folic acid intake and the need for the dose consumed, if any, in Canadian women of childbearing age. For example, data could be gathered on family history of NTD birth and, for parous women, periconceptional folic acid supplement use. It would also be of interest to identify women of childbearing age who are incapable of becoming pregnant, for reasons of physiology or birth control, so we could assess the need for optimal RBC folate concentrations for the prevention of NTD birth in a segment of the target population that may actually be at risk.

2) Harmonize CHMS folate measures with a gold standard: It is recommended that harmonization of the folate assay methods used for surveillance be a critical consideration in comparisons to the CHMS, both domestically and internationally. Microbiologic assay is currently considered the gold standard for measuring RBC folate. ${ }^{40}$ This method could be explored as the method to be employed in future CHMS cycles.

3) Ensure timely policy amendments: The folate status surveillance data offered through the CHMS provide insight into areas where folic acid policies may be refined. The lengthy process for policy change may hinder concise and timely decision-making regarding folic acid policy. The results presented in this thesis support the need to exercise caution when considering increased doses of folic acid in the food supply. The 
lack of folate deficiency, and the shift towards elevated folate concentrations, in the general population and studies on folic acid overages in fortified products, indicate the need to investigate, implement and enforce maximum levels for mandatory fortification with folic acid. Members of the general population do not commonly need supplemental folic acid in addition to fortified foods unless this is recommended by a health care professional for certain medical conditions.

It may be prudent to ensure the folic acid dose found in supplements that target women of childbearing age is below the UL, since these supplements are consumed in combination with fortified foods. Larger doses of folic acid may assist more women in achieving optimal concentrations for NTD risk reduction; however, minimal harm to the general population may not be guaranteed.

4) Determine cut-offs for high folate concentrations: A universal cut-off for high folate concentration is not available; however, several potential cut-offs have been hypothesized in this thesis. This is an unexplored and uncharted area of study. An expert meeting is needed to investigate and gain consensus on a definition that will allow the study of high folate concentrations and health outcomes to occur, and to provide clinicians with direction on how to assess patients at risk of high folate status. A universal cut-off for high RBC folate, whether it is more or less conservative than those proposed, will advance the field towards consistent measurement and reporting of high folate status and related health outcomes. This definition will ultimately inform the debate on appropriate public health interventions and clinical guidelines for folic acid.

5) Target women of childbearing age: Disparities in access to folic acid supplements may be a concern among women of childbearing age. Folic acid fortification of grain products 
has proven to be a policy that is cost-effective and successful in reducing NTDs;

however, the core population-health concerns (e.g. lack of access and ability to afford proper nutrition; poor access to education for women; and lack of access to prenatal care) are not addressed. Efforts to tackle the disparities at the root of non-compliance are of primary importance.

6) Examine folate and older adults: It became evident during this study that older adults in Canada exhibit the highest median RBC folate levels. Though this did not appear to be accompanied by low vitamin $\mathrm{B}_{12}$, which would mean a risk for vitamin $\mathrm{B}_{12}$ masking, it does raise questions as to the etiology of these elevated levels and concerns following speculations of increased risk for cognitive impairment and colorectal cancer in those with pre-existing neo-plasms. Folic acid supplement use was reported most often in the highest age groups (51-79 years). It is not understood whether the elderly metabolise synthetic folic acid differently. Future research is needed to understand if these high levels are an issue of dietary intake, metabolism of synthetic folic acid, physiology or other factors. In the interim, it appears appropriate to implement regulations that support the removal of folic acid from multivitamins that target older adults.

\subsection{Conclusion}

Not only is folate deficiency virtually nonexistent in the Canadian population, our research exposed a shift towards elevated concentrations. Regardless, many women of childbearing age are still not achieving the concentrations considered optimal for maximal NTD risk reduction. These discoveries indicate that future research and policy related to RBC folate status and health outcomes require separate approaches to tackle the differing issues: 
sub-optimal concentrations in women of childbearing age and elevated folate status in the general population. Our data show a need for targeted strategies to improve compliance with folic acid supplement recommendations to assist women of childbearing age, in particular those in lower income groups, in achieving desired folate concentrations. Conversely, a universal cut-off for high RBC folate, whether it is more or less conservative than those proposed, will advance the field towards consistent measurement and reporting of high folate status and related health outcomes in the general population. Furthermore, harmonization of folate measurement methods in future surveillance efforts is essential to facilitate comparisons and more accurately inform policy directions. Ongoing monitoring of the folate status of Canadians, including the associations between RBC folate and health outcomes, is needed to identify the optimal dose and duration of folic acid to achieve folate concentrations that lead to maximal benefit with a minimal amount of harm to the population. Folic acid fortification and supplementation policies and guidelines could then be refined accordingly. 


\subsection{References}

1. Shakur YA, Garriguet D, Corey P, et al. Folic acid fortification above mandated levels results in a low prevalence of folate inadequacy among Canadians. Am J Clin Nutr 2010;92(4):818-25.

2. Tinker SC, Cogswell ME, Devine O, et al. Folic acid intake among U.S. women aged 1544 years, National Health and Nutrition Examination Survey, 2003-2006. Am J Prev Med 2010;38(5):534-42.

3. Nguyen P, Tam C, O'Connor DL, et al. Steady state folate concentrations achieved with 5 compared with $1.1 \mathrm{mg}$ folic acid supplementation among women of childbearing age. Am J Clin Nutr 2009;89(3):844-52.

4. Prenatal nutrition guidelines for health professionals - Folate contributes to a healthy pregnancy. Health Canada. Ottawa (ON). Available: http://www.hc-sc.gc.ca/fnan/pubs/nutrition/folate-eng.php. (Accessed May 13, 2013).

5. Richard-Tremblay AA, Sheehy O, Audibert F, et al. Concordance between periconceptional folic acid supplementation and Canadian clinical guidelines. J Popul Ther Clin Pharmacol 2012;19(2):e150-9.

6. Koren G, Goh I. Increasing folate supplementation for selected groups of Canadian women. J Obstet Gynaecol Can 2007;29(12):992-6.

7. Kallen B. Congenital malformations in infants whose mothers reported the use of folic acid in early pregnancy in Sweden. A prospective population study. Congenit Anom (Kyoto) 2007;47(4):119-24.

8. Bar-Oz B, Koren G, Nguyen P, et al. Folate fortification and supplementation--are we there yet? Reprod Toxicol 2008;25(4):408-12.

9. Stockley L, Lund V. Use of folic acid supplements, particularly by low income and young women: A series of systematic reviews to inform public health policy in the UK. Public Health Nutr 2008;11(8):807-21.

10. Vatanparast H, Adolphe JL, Whiting SJ. Socio-economic status and vitamin/ mineral supplement use in Canada. Health Rep 2010;21(4):19-25.

11. Pfeiffer CM, Hughes JP, Lacher DA, et al. Estimation of trends in serum and RBC folate in the U.S. population from pre- to postfortification using assay-adjusted data from the NHANES 1988-2010. J Nutr 2012;142(5):886-93.

12. Mason JB, Dickstein A, Jacques PF, et al. A temporal association between folic acid fortification and an increase in colorectal cancer rates may be illuminating important 
biological principles: A hypothesis. Cancer Epidemiol Biomarkers Prev 2007;16(7):1325-9.

13. Cole BF, Baron JA, Sandler RS, et al. Folic acid for the prevention of colorectal adenomas: A randomized clinical trial. JAMA 2007;297(21):2351-9.

14. Wien TN, Pike E, Wisloff T, et al. Cancer risk with folic acid supplements: A systematic review and meta-analysis. BMJ Open 2012;2(1):e000653.

15. Fife J, Raniga S, Hider PN, et al. Folic acid supplementation and colorectal cancer risk: A meta-analysis. Colorectal Dis 2011;13(2):132-7.

16. Baggott JE, Oster RA, Tamura T. Meta-analysis of cancer risk in folic acid supplementation trials. Cancer Epidemiol 2012;36(1):78-81.

17. Vollset SE, Clarke R, Lewington S, et al. Effects of folic acid supplementation on overall and site-specific cancer incidence during the randomised trials: Meta-analyses of data on 50000 individuals. Lancet 2013;381(9871):1029-36.

18. Morris MS, Jacques PF, Rosenberg IH, et al. Circulating unmetabolized folic acid and 5methyltetrahydrofolate in relation to anemia, macrocytosis, and cognitive test performance in American seniors. Am J Clin Nutr 2010;91(6):1733-44.

19. McDowell MA, Lacher DA, Pfeiffer CM, et al. Blood folate levels: The latest NHANES results. NCHS Data Brief 2008;(6)(6):1-8.

20. Canada Gazette Part II. Regulatory impact analysis statement. In: Bureau of Food Regulatory IaIA, Health Canada, ed. 1998:3029-33. (SOR/98-550.)

21. Food and Drug Administration. Food standards: amendment of standards of identity for enriched grain products to require addition of folic acid. Final Rule. 21 CFR Parts 136, 137, and 139. Federal Register. 1996;61:8781-8789.

22. Yang Q, Cogswell M, Hamner H, et al. Folic acid source, usual intake, and folate and B12 status in U.S. adults: National health and nutrition examination survey (NHANES) 2003-2006. Am J Clin Nutr 2010;91(1):64-72.

23. Shakur YA, Rogenstein C, Hartman-Craven B, et al. How much folate is in Canadian fortified products 10 years after mandated fortification? Can J Public Health 2009;100(4):281-4.

24. Ministry for Primary Industries. Food standard: New Zealand (permitted fortification of bread with folic acid) food standard 2012. Wellington, (NZ): Ministry for Primary Industries; 2012. 
25. Wilson RD, Johnson JA, Wyatt P, et al. Pre-conceptional vitamin/folic acid supplementation 2007: The use of folic acid in combination with a multivitamin supplement for the prevention of neural tube defects and other congenital anomalies. $\mathbf{J}$ Obstet Gynaecol Can 2007;29(12):1003-26.

26. Goh YI, Koren G. Folic acid in pregnancy and fetal outcomes. J Obstet Gynaecol 2008;28(1):3-13.

27. De-Regil LM, Fernandez-Gaxiola AC, Dowswell T, et al. Effects and safety of periconceptional folate supplementation for preventing birth defects (Review). In: The Cochrane Library, Issue 10, 2010. Chichester: Wiley.

28. Mason JB. Unraveling the complex relationship between folate and cancer risk. Biofactors 2011;37(4):253-60.

29. Morris MS, Jacques PF, Rosenberg IH, et al. Folate and vitamin B12 status in relation to anemia, macrocytosis, and cognitive impairment in older Americans in the age of folic acid fortification. Am J Clin Nutr 2007;85(1):193-200.

30. Hirsch S, Sanchez H, Albala C, et al. Colon cancer in Chile before and after the start of the flour fortification program with folic acid. Eur J Gastroenterol Hepatol 2009;21(4):436-9.

31. Allen L. How common is vitamin B12 deficiency? Am J Clin Nutr 2009;89(supp):693S$696 \mathrm{~S}$.

32. Yajnik CS, Deshpande SS, Jackson AA, et al. Vitamin B12 and folate concentrations during pregnancy and insulin resistance in the offspring: The Pune maternal nutrition study. Diabetologia 2008;51(1):29-38.

33. Health Canada. Addition of vitamins and minerals to foods: Health Canada's proposed policy and implementation plans. Ottawa (ON): Health Canada; 2005.

34. Sacco JE, Tarasuk V. Discretionary addition of vitamins and minerals to foods: Implications for healthy eating. Eur J Clin Nutr 2011;65(3):313-20.

35. Nutrition for a healthy pregnancy - National guidelines for the childbearing years. Ottawa (ON): Health Canada, 2009. Available from: http://www.hcsc.gc.ca.proxy.bib.uottawa.ca/fn-an/pubs/nutrition/folate-eng.php (Accessed October 10, 2009).

36. Bradbury KE, Williams SM, Green TJ, et al. Differences in erythrocyte folate concentrations in older adults reached steady-state within one year in a two-year, controlled, $1 \mathrm{mg} / \mathrm{d}$ folate supplementation trial. J Nutr 2012;142(9):1633-7. 
37. Institute of Medicine. DRI dietary reference intakes for thiamin, riboflavin, niacin, vitamin B6, folate, vitamin B12, pantothenic acid, biotin, and choline. Washington, (DC): National Academy Press; 1998.

38. Multivitamin/mineral supplement monograph. Health Canada. Ottawa (ON). Available: http://www.hc-sc.gc.ca/dhp-mps/prodnatur/applications/licen$\mathrm{prod} / \mathrm{monograph} / \mathrm{multi}$ vitmin_suppl-eng.php\#table8foot1. (Accessed May 5, 2013).

39. Laboratory procedure manual: Folate. Centres for Disease Control and Prevention. Washington (DC). Available:

http://www.cdc.gov/nchs/data/nhanes/nhanes_07_08/FOLATE_E_met.pdf. (Accessed December 9, 2012).

40. Yetley EA, Coates PM, Johnson CL. Overview of a roundtable on NHANES monitoring of biomarkers of folate and vitamin B12 status: Measurement procedure issues. Am J Clin Nutr 2011;94(1):297S-302S.

41. Zlotkin S. A critical assessment of the upper intake levels for infants and children. J Nutr 2006;136(2):502S-6S. 


\title{
APPENDICES
}

\section{Appendix A: Two Canadian agency definitions of population health}

\author{
Canadian Institutes of Health Research Institute of Population and Public Health: ${ }^{1}$
}

Population health: A population health perspective looks at health in broad terms and addresses questions such as what are the most important factors affecting people's health; why are some people healthier than others; and what can be done to improve the health of all peoples and communities.

Population health intervention research: Population health intervention research examines the impacts of policies, programs and resource distribution approaches on the health of whole populations. It is an emerging field of research that is critical in advancing efforts to reduce health inequities. Population health intervention research builds on several decades of research in important areas such as health promotion, health education and community interventions.

\section{Public Health Agency of Canada: ${ }^{2}$}

Population health: Population health is an approach to health that aims to improve the health of the entire population and to reduce health inequities among population groups. In order to reach these objectives, it looks at and acts upon the broad range of factors and conditions that have a strong influence on our health.

1. Canadian Institutes of Health Research - Institute of Population and Public Health, Canadian Institute for Health Information - Canadian Population Health Initiative. Population Health Intervention Research Casebook, 2011.

2. What is the population health approach? Ottawa (ON): Public Health Agency of Canada. Available: http://www.phac-aspc.gc.ca/ph-sp/approach-approche/ (accessed 2013 May. 11). 


\section{Appendix B: Dietary reference intake table for folate}

\begin{tabular}{|c|c|c|c|}
\hline \multirow[t]{2}{*}{ Unit } & \multicolumn{3}{|c|}{$\begin{array}{c}\text { Folate }^{1} \\
1 \mu \mathrm{g} / \text { day DFE }\end{array}$} \\
\hline & EAR & RDA/AI & $\mathrm{UL}^{2}$ \\
\hline \multicolumn{4}{|l|}{ Infants } \\
\hline $0-6 \mathrm{mo}$ & $N D$ & $65^{*}$ & ND \\
\hline $7-12 \mathrm{mo}$ & $N D$ & $80 *$ & ND \\
\hline \multicolumn{4}{|l|}{ Children } \\
\hline $1-3 y$ & 120 & 150 & 300 \\
\hline $4-8 \mathrm{y}$ & 160 & 200 & 400 \\
\hline \multicolumn{4}{|l|}{ Males } \\
\hline $9-13 y$ & 250 & 300 & 600 \\
\hline $14-18 \mathrm{y}$ & 330 & 400 & 800 \\
\hline $19-30 y$ & 320 & 400 & 1000 \\
\hline $31-50 y$ & 320 & 400 & 1000 \\
\hline $51-70 y$ & 320 & 400 & 1000 \\
\hline$>70 y$ & 320 & 400 & 1000 \\
\hline \multicolumn{4}{|l|}{ Females } \\
\hline $9-13 y$ & 250 & 300 & 600 \\
\hline $14-18 \mathrm{y}$ & 330 & $400^{a}$ & 800 \\
\hline $19-30 \mathrm{y}$ & 320 & $400^{a}$ & 1000 \\
\hline $31-50 y$ & 320 & $400^{a}$ & 1000 \\
\hline $51-70 y$ & 320 & 400 & 1000 \\
\hline$>70 y$ & 320 & 400 & 1000 \\
\hline \multicolumn{4}{|l|}{ Pregnancy } \\
\hline$\leq 18 \mathrm{y}$ & 520 & $600^{b}$ & 800 \\
\hline $19-30 \mathrm{y}$ & 520 & $600^{b}$ & 1000 \\
\hline $31-50 y$ & 520 & $600^{b}$ & 1000 \\
\hline \multicolumn{4}{|l|}{ Lactation } \\
\hline$\leq 18 \mathrm{y}$ & 450 & 500 & 800 \\
\hline $19-30 y$ & 450 & 500 & 1000 \\
\hline $31-50 \mathrm{y}$ & 450 & 500 & 1000 \\
\hline
\end{tabular}

This table presents Estimated Average Requirements (EAR) in italics, Recommended Dietary Allowances (RDA) in bold and Adequate Intake (AI) in ordinary type followed by an asterisk (*).

Tolerable Upper Intake Levels (UL) are in the shaded columns.

1. As dietary folate equivalents (DFE)

$1 \mathrm{DFE}=1 \mu \mathrm{g}$ food folate

$1 \mathrm{DFE}=0.6 \mu \mathrm{g}$ folic acid from fortified food or from a supplement consumed with food

$1 \mathrm{DFE}=0.5 \mu \mathrm{g}$ folic acid from a supplement taken on an empty stomach

2. The UL for folate applies only to synthetic forms found in supplements, fortified foods, or a combination of the two.

a. In view of evidence linking the use of supplements containing folic acid before conception and during early pregnancy with reduced risk of neural tube defects in the fetus, it is recommended that all women capable of becoming pregnant take a supplement containing $400 \mu \mathrm{g}$ of folic acid every day, in addition to the amount of folate found in a healthy diet.

b. It is assumed that women will continue consuming $400 \mu \mathrm{g}$ folic acid from supplements until their pregnancy is confirmed and they enter prenatal care. The critical time for formation of the neural tube is shortly after conception.

Source: Health Canada. Dietary Reference Intake Tables. http://www.hc-sc.gc.ca/fn-an/alt_formats/hpfbdgpsa/pdf/nutrition/dri_tables-eng.pdf accessed: Mar. 3, 2013. 


\section{Appendix C: Sources of dietary folate}

\begin{tabular}{|c|c|c|}
\hline Food & $\begin{array}{l}1 \text { Canada's Food } \\
\text { Guide Serving }\end{array}$ & $\begin{array}{l}\text { Micrograms } s^{\mathrm{a}} \text { of folate as dietary } \\
\text { folate equivalents ( } \mu \mathrm{g} \text { DFEs) }\end{array}$ \\
\hline Lentils and romano beans & $175 \mathrm{~mL}$ & $265-270$ \\
\hline Black beans & $175 \mathrm{~mL}$ & 190 \\
\hline Okra & $125 \mathrm{~mL}$ & 140 \\
\hline White beans & $175 \mathrm{~mL}$ & 125 \\
\hline Asparagus and spinach, cooked & $125 \mathrm{~mL}$ & 120 \\
\hline $\begin{array}{l}\text { Salad greens, such as Romaine lettuce, } \\
\text { mustard greens and endive }\end{array}$ & $250 \mathrm{~mL}$ & $80-110$ \\
\hline $\begin{array}{l}\text { Pinto beans, kidney beans and } \\
\text { chickpeas }\end{array}$ & $175 \mathrm{~mL}$ & $70-100$ \\
\hline Pasta made with enriched wheat flour & $125 \mathrm{~mL}$ & 90 \\
\hline Avocado & $1 / 2$ fruit & 80 \\
\hline Sunflower seeds, shelled & $60 \mathrm{~mL}$ & 80 \\
\hline Bagel made with enriched wheat flour & $1 / 2$ bagel $(45 \mathrm{~g})$ & $60-75$ \\
\hline $\begin{array}{l}\text { Brussels sprouts, beets and broccoli, } \\
\text { cooked }\end{array}$ & $125 \mathrm{~mL}$ & 70 \\
\hline $\begin{array}{l}\text { Bread made with enriched wheat flour } \\
\text { or enriched corn meal }\end{array}$ & $\begin{array}{l}1 \text { slice or } 1 / 2 \text { pita or } \\
1 / 2 \text { tortilla }(35 \mathrm{~g})\end{array}$ & $45-65$ \\
\hline Spinach, raw & $250 \mathrm{~mL}$ & 60 \\
\hline Orange juice from concentrate & $125 \mathrm{~mL}$ & 60 \\
\hline Parsley & $125 \mathrm{~mL}$ & 50 \\
\hline Parsnips & $125 \mathrm{~mL}$ & 50 \\
\hline Peanuts, shelled & $60 \mathrm{~mL}$ & 45 \\
\hline Eggs & 2 large & 45 \\
\hline Corn & $125 \mathrm{~mL}$ & 40 \\
\hline Seaweed & $125 \mathrm{~mL}$ & 40 \\
\hline Orange & 1 medium & 40 \\
\hline Green peas & $125 \mathrm{~mL}$ & 40 \\
\hline Raspberries, strawberries, blackberries & $125 \mathrm{~mL}$ & $15-35$ \\
\hline Enriched ready to eat cereal & $30 \mathrm{~g}$ & $10-35$ \\
\hline Broccoli and cauliflower, raw & $125 \mathrm{~mL}$ & 30 \\
\hline Snow peas & $125 \mathrm{~mL}$ & 30 \\
\hline Pineapple juice & $125 \mathrm{~mL}$ & 30 \\
\hline $\begin{array}{l}\text { Walnuts, almonds and hazelnuts, } \\
\text { shelled }\end{array}$ & $60 \mathrm{~mL}$ & $20-30$ \\
\hline Baby carrots & $125 \mathrm{~mL}$ & 25 \\
\hline Kiwifruit & 1 large & 20 \\
\hline Clementine & 1 fruit & 20 \\
\hline
\end{tabular}

a. Amounts are approximate based on Canadian Nutrient File, 2007b.

b. Source: Health Canada. Prenatal Nutrition Guidelines for Health Professionals - Folate Contributes to a Healthy Pregnancy. http://www.hc-sc.gc.ca/fn-an/pubs/nutrition/folate-eng.php accessed: Feb. 8, 2013. 


\title{
Appendix D: Research Ethics Board approval documents
}

\author{
Centre hospitalier pour enfants de l'est de l'Ontario
}

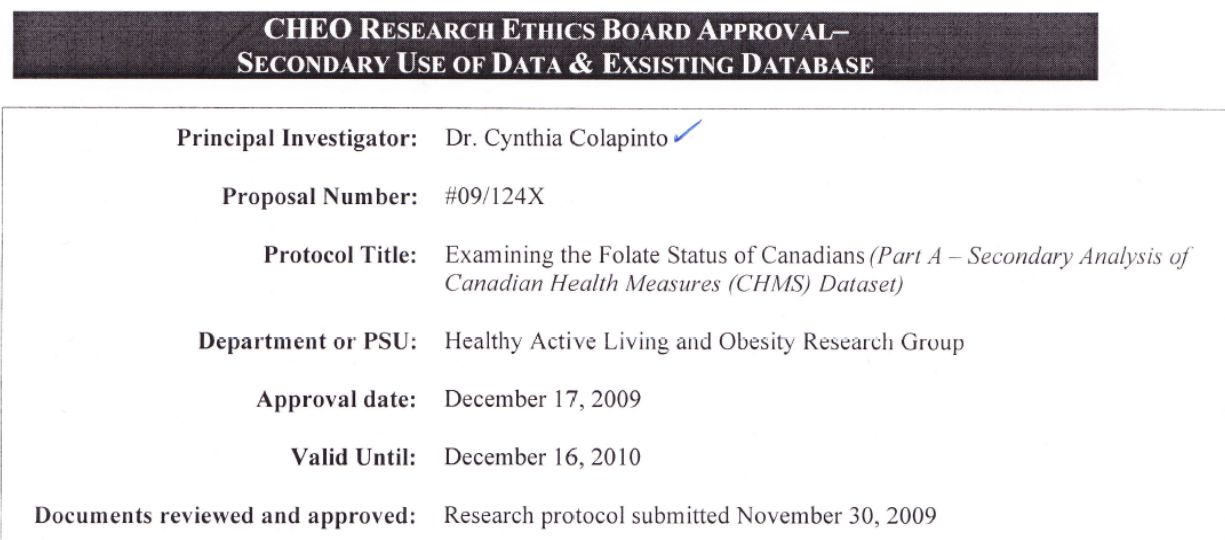

This is to notify you that the Children's Hospital of Eastern Ontario Research Ethics Board has granted approval to the above named research study on the date noted above. Your project was reviewed under the expedited stream, which is reserved for projects that involve no more than minimal risk to human subjects.

Please submit an annual renewal report and a final study report when it becomes available.

Wishing you success in your project.

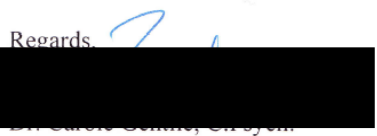

Chair, Research Ethics Board
CG/na $12 / 17 / 2009$
c.c. CHEO RI Administration
Dr. Mark Tremblay, Research Institute

40I Smych Road, Ottawa, ON KIH 8LI, Canada
Tel: (613) 737.7600 www.cheo.on.ca
Making a difference in the lives of children and youth
40I, chemin Smyth, Ottawa (ON) KIH 8LI, Canada

Tél. : (613) 737.7600 www.cheo.on.ca

Faire une diffërence dans la vie des enfants et des adolescents 


\section{Université d'Ottawa University of Ottawa \\ Service de subventions de recherche et déontologie Research Grants and Ethics Services}

January 13,2009

Dr. Cynthia Colapinto

Re: $\quad$ U of O Ethics file no. H 11-09-17 - "Examining the Folate Status of Canadians (Part A - Secondary Analysis of Canadian Health Measures)"

Dear Dr. Colapinto,

Thank you for the protocol documents and the Certificate of Approval from CHEO.

This is to confirm that, in accordance with the agreement between the University of Ottawa and CHEO the University of Ottawa has authorized the CHEO REB to act as Board of Record for the review and oversight of research involving human subjects conducted at or through the hospital.

Copies of annual reports and renewals of CHEO REB approvals, as well as certificates and reports for any other study sites must be provided to our office.

We remind you of your obligation to:

Follow all procedures of the CHEO REB including reporting and renewal procedures;

Submit to the authority of the CHEO REB and that you are subject to CHEO REB requirements, including, without limitation, the requirement to modify or stop the research on demand of the CHEO REB.

If you have any questions, please contact our ethics office at 562-5841.

Sincerely yours,

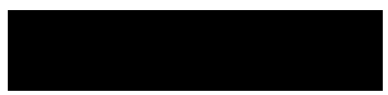

Catherine Paquet

Assistant Director (Ethics)

CC:

Dr. Mark tremblay, Director, Healthy Active Living and Obesity Research Group

\footnotetext{
550 , rue Cumberland 550 Cumberland Street

Ottawa (Ontario) K1N 6N5 Canada $\quad$ Ottawa, Ontario K1N 6N5 Canada

(613) 562-5841 • Téléc./Fax (613) 562-5338

http://www.uottawa.ca/services/research/rge/index.html
} 


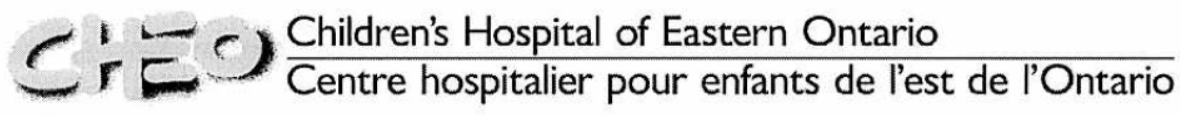

\section{CHEO RESEARCH ETHICS BOARD APPROVAL - DELEGATED REVIEW}

Principal Investigator: Leynthia Colapinto/Dr. Mark Tremblay

Proposal Number: \#10/92X

Protocol Title: Examining the Folate Status of Canadians (Part B - Conversion Study)

Department or PSU: HALO Research

Approval date: November 9, 2010

Valid Until: November 8, 2011

Documents reviewed and approved: Research protocol submitted August 17, 2010

This is to notify you that the Children's Hospital of Eastern Ontario Research Ethics Board has granted approval to the above named research study on the date noted above. Your project was reviewed under the delegated review stream, which is reserved for projects that involve no more than minimal risk to human subjects.

Final approval is granted for the above noted study, with the understanding that the investigator agrees to comply with the following requirements:

- The investigator must conduct the study in compliance with the protocol and any additional conditions set out by the Board.

- The investigator must not implement any deviation from, or changes to, the protocol without the approval of the REB, or when the change involves only logistical or administrative aspects of the study (e.g., change of telephone number or research staff).

- The investigator must, prior to use, submit to the Board changes to the study documentation, e.g., changes to the informed consent letters, recruitment materials.

- For all other research studies, investigators must promptly report to the REB all unexpected and untoward occurrences (including the loss or theft of study data and other such privacy breaches).

- Investigators must submit an annual renewal report to the REB 30 days prior to the expiration date stated above.

- Investigators must submit a final report at the conclusion of the study.

- Investigators must provide the Board with French versions of the consent form, unless a waiver has been granted.

For complete procedures relating to these modifications, please refer to the REB website at

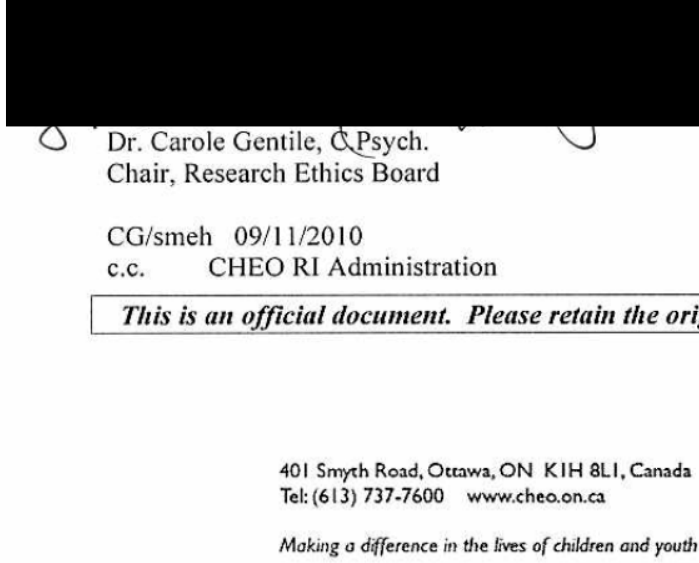

401, chemin Smyth, Ottawa (ON) KIH 8LI, Canada

Tél. : (613) 737.7600 www.cheo.on.ca

Faire une diffërence dans la vie des enfonts et des adolescents 


\title{
Université d'Ottawa University of Ottawa \\ Bureau d'éthique et d'intégrité de la recherche office of Research Ethics and Integrity
}

February 8, 2011

\section{Dr. Cynthia Colapinto}

\section{Re: $\quad U$ of O Ethics file no. H 11-09-17B - "Examining the Health Status of Canadians (Part B - Conversion Study)" CHEO REB \#10/92X}

Dear Dr. Colapinto,

Thank you for the protocol documents and the Certificate of Approval from CHEO for your project.

This is to confirm that, in accordance with the agreement between the University of Ottawa and CHEO the University of Ottawa has authorized the CHEO REB to act as Board of Record for the review and oversight of research involving human subjects conducted at or through the hospital.

Copies of annual reports and renewals of CHEO REB approvals, as well as certificates and reports for any other study sites must be provided to our office.

We remind you of your obligation to:

- $\quad$ Follow all procedures of the CHEO REB including reporting and renewal procedures;

- $\quad$ Submit to the authority of the CHEO REB and that you are subject to CHEO REB requirements, including, without limitation, the requirement to modify or stop the research on demand of the CHEO REB.

If you have any questions, please contact our ethics office at 562-5800 ext. 1787.

Sincerely yours,

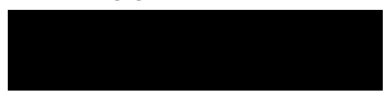

Catherine Paquet

Director, Office of Research Ethics and Integrity

cc:

Dr. Mark tremblay, Director, Healthy Active Living and Obesity Research Group

\author{
$\begin{aligned} 550, \text { rue Cumberland } & 550 \text { Cumberland Street } \\ \text { Ottawa (Ontario) K1N 6N5 Canada } & \text { Ottawa, Ontario K1N 6N5 Canada }\end{aligned}$ \\ (613) 562-5841 • Téléc./Fax (613) 562-5338 \\ http://www.recherche.uottawa.ca/deontologie \\ http://www.research.uottawa.ca/ethics/
}




\section{SickKids}

\section{Research Ethics Board (REB)}

The Research Ethics Board for The Hospital for Sick Children is organized and operates according to the principles and practices outlined in the Tri-Council Policy Statement, the ICH Harmonized Tripartite Guidelines: Good Clinical Practice, and Division 5 and the Medical Devices Regulations of the Food and Drug Act as well as the Natural Health Products Regulations of Health Canada. This signed document is in lieu of the Health Canada Research Ethics Board Attestation Form.

\section{Approval \& Terms of Agreement}

Investigators: Dr. Deborah O'Connor, C.Colapinto, M.Tremblay, L.Dubois

Study Title: Examining the Folate Status of Canadians: A conversion study for Canadian-American comparison

REB File number: $1000021108 \quad$ Level of Continuing Review: II D

Protocol Version Date: CIHR grant \#218776*modified to exclude children without capacity to consent for themselves Consent \& Assent Form Version Date(s): Subject Consent (January 18, 2011); Genetic consent form (September 30, 2010)

Investigator's Brochure Version Date: NA

Other Approved Recruitment Document Dates: Recruitment poster (January 17, 2011); Questionnaire; Telephone script (September 30, 2010); Introduction letter to participants; Introduction letter to HCP (July 20, 2010)

I agree to carry out the proposed research involving human subjects in accordance with the above-noted guidelines and regulations (as applicable) and using only the REB-approved study protocol and consent/assent form(s). I shall notify the division/department head and the REB prior to implementing any amendments in the protocol and consent/assent forms and of any deviations or any changes in study activity. I shall also notify the REB of any unexpected adverse events as per REB guidelines. As applicable, I certify that the research contract and corresponding protocol are consistent and will inform the contract manager of any protocol amendments as required.

I agree that, in accordance with the Personal Health Information Protection Act of Ontario, I am responsible for adhering to all conditions and restrictions imposed by the REB governing the use, security, disclosure, return and disposal of the research subjects ' personal health information. I am also responsible for reporting immediately any privacy breaches to the REB Chair and to Janice Campbell, the Sick Kids privacy officer. I will ensure that the personal health information is used, only as necessary, to fulfill the specific research objectives and related research questions described in this application and approved by the REB.

Signature of Principal Investigator

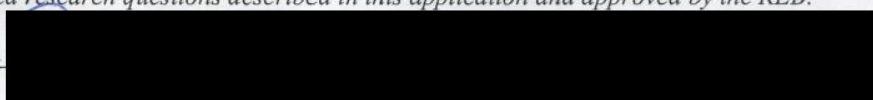

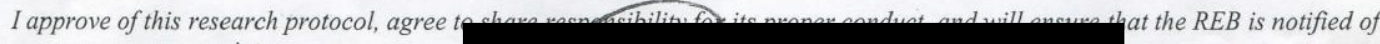
concerns, as appropriate.

Signature of Division/Department Head

The REB of the Hospital for Sick Children has reviewed and approved the above-named research study.

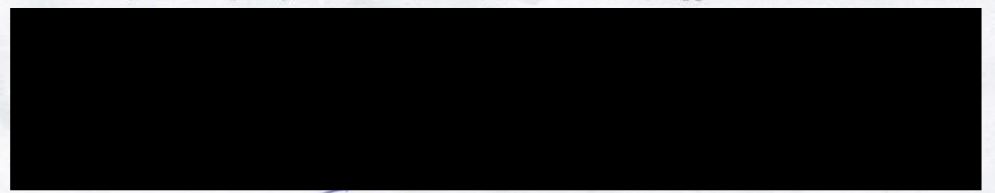

DATE OF APPROVAL TEB.3,201 EXPIRY DATE Feb 2012 


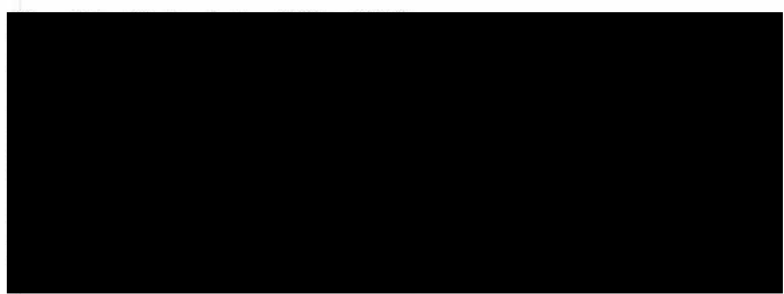

Dear Dr. Colapinto:

Protocol Number:

REB-2010-0033

Protocol Title:

\section{Examining the Folate Status of Canadians}

\section{Departmental Approval}

This letter will inform you of the results of Health Canada and Public Health Agency of Canada's Research Ethics Board's (REB) ethics review of your application which took place on September 16, and November 23, 2010.

The REB members are providing their approval for the project to proceed and in accordance with the protocol submitted to the REB Secretariat on August 6 and November 12, 2010.

Please be informed that, following the receipt of this approval to proceed with the project, Principal Investigators of Health Canada and Public Health Agency of Canada must:

- obtain an annual certificate of ethical approval until the research is complete (the approval is given for one year and will expire on November 23, 2011);

- seek re-approval of the Research Ethies Board for any amendment or modification of the approved research protocol or consent form;

- report immediately to the REB Secretariat, any adverse or unexpected events resulting from the research on human subjects; and

- notify the REB Secretariat, upon termination or completion of the project.

\section{Canadă}


Health Canada and Public Health Agency of Canada

Research

Ethics Board
Santé Canada et l'Agence

de la santé publique du Canada

Comité d'éthique

de la recherche

\section{CERTIFICATE OF ETHICS APPROVAL}

Principal Investigator:

Name: Cynthia Colapinto

Title:

Project Title: Examining the Folate Status of Canadians

Project File Number: REB-2010-0033

Previously approved by another REB: Hospital for Sick Children REB

Contact Department/Agency: Steve Brooks, HECSB

Funding:
Available:
Scientific Peer Review:
Document Name:
List of all documents submitted to the REB on:
1. Application
2. Hospital for Sick Children REB application
3. List of References
4. CIHR Grant Application
5. CIHR Decision Letter
6. Letters of Support
7 \& 8. Assent Forms
9- 14 Consent Forms
15. Recruitment Poster
16. Telephone Script
17. Questionnaire
18. Template for reporting of outlying results

\section{ETHICS REVIEW:}

The application for ethics revicw for the above-referenced research project has been reviewed by the Health Canada and Public Health Agency of Canada's Research Ethics Board (REB) on September 16 November 23, 2010. The documents (listed above) submitted to the REB Secretariat on August $6^{\text {(1) }}$ were found to be acceptable on ethical grounds for research involving human subjects. The REB is recommending that the project proceed:

\section{Canadă}

Page 1 of 2 
as submitted

$\square$ under the conditions stipulated by the REB (attached)

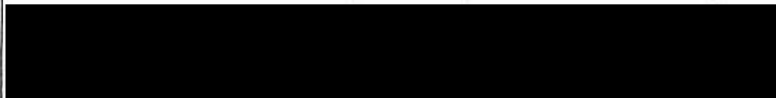

Janet Storch, RN, BScN, MHSA, PhD, DSc (Hon)

NOV 232010

Chair, Research Ethics Board

\section{Certificate Expiry Date:}

November 23,2011

\section{Principal Investigator's responsibilities:}

I confirm that I will:

1. Carry-out the research in accordance with the approved protocol by the REB;

2. Obtain an annual REB approval until the research is complete (the approval is given for one year);

3. Seek approval of the Research Ethics Board for any amendment or modification of the approved research protocol or consent form;

4. Report immediately to the REB Secretariat, any adverse or unexpected events resulting from the research on human subjects; and

5. Notify the REB Secretariat, upon termination or completion of the project.

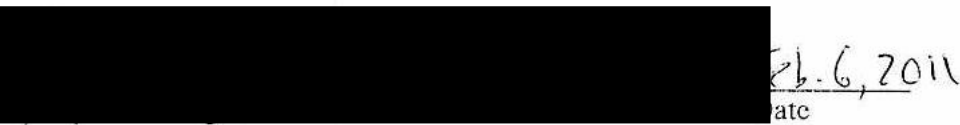

Once signed, please return a copy of this certificate to the REB Secretariat.

Research Ethics Board Secretariat

Holland Cross Building, Tower B

AL \#3104A

\#410 - 1600 Scott, Ottawa, ON KIA OK9

Tel: (613) $941-5199$

Fax: (613) 948-6781

Web: http://www.healthcanada.gc.ca/reb

http://www.santecanada.gc.ca/cer 


\section{Appendix E: Media coverage following release of first manuscript}

CMAJ MEDIA: Below are links to selected coverage from various news agencies. The Canadian Press and Reuters articles, as well as the media release, were picked up by multiple newspapers and websites, domestically and internationally.

\section{CBC}

http://www.cbc.ca/news/health/story/2010/12/13/folic-acid-folate-canadians-fortify.html (includes television interview with the National)

\section{Canadian Press}

http://www.colorectal-cancer.ca/en/news-and-resources/most-canadians-study/

\section{CTV News}

http://www.ctvnews.ca/canadians-blood-levels-of-folic-acid-now-high-study-1.585459

\section{Reuters US}

http://www.reuters.com/article/2010/12/14/us-folic-acid-idUSTRE6BD5M120101214

\section{LA Times}

http://articles.latimes.com/2010/dec/13/news/la-heb-folate-20101213

\section{Times of India}

http://timesofindia.indiatimes.com/life-style/health-fitness/health/High-folic-acid-intakelinked-to-cancer/articleshow/7099298.cms (link now broken) 


\section{Appendix F: Supplementary detail regarding the methods comparison study}

We conducted a methods comparison study to generate a conversion equation so the CHMS RBC folate data measured by Immulite 2000 immunoassay could be adjusted to correlate with microbiologic assay, measured using similar methodology to the 2007-2008 NHANES. This section includes details on subject recruitment, data collection tools and the equation generation.

\section{Subject recruitment}

We used a Bland-Altman approach to estimate sample size. ${ }^{1,2}$ In this method, $95 \%$ limits of agreement for the difference between the measurements from two methods are computed, allowing the researchers to understand how well the two methods agree. A sample size of at least 100 is recommended for a method comparison study, allowing for a confidence interval for the limits of agreement of $+/-0.34 \mathrm{~s}$, which is the standard deviation of the difference between the measurements. The larger sample size of 152 was used in this study provided a smaller confidence interval.

For the crossover study, we recruited 152 men, women and children (aged 18 to 75 years) by posters and word of mouth from the Hospital for Sick Children and the general Toronto area. Potential participants who responded to the advertisements contacted the researchers by telephone. Researchers informed the prospective subjects of the purpose, conduct of the trial, their time commitment and any potential harm or benefits of the study. Study eligibility was also confirmed. The study coordinator reiterated this information and obtained informed verbal consent if the subject was agreeable. Those who agreed came to the hospital clinical investigation unit to read and sign the written consent prior to answering a few demographic 
questions, such as age and supplement usage, and the blood draw by the study nurse.

Subjects fasted from $10 \mathrm{pm}$ the evening before and refrained from taking their usual supplements (if applicable) either the night before or the morning of their visit. Researchers allowed folate-devoid beverages such as water and/or herbal teas such as ginger, citrus peel, lemon balm and rose hip.

\section{Data collection tools}

We created a number of tools for the data collection phase of the sub-study (Appendix G). Researchers posted a recruitment flyer at the Hospital for Sick Children, with contact information. A script ensured consistency in initial participant contact. Participants completed several forms at the Clinical Investigation Unit, including consent forms for the folate analysis and genetic testing as well as a short demographic questionnaire. Eleven percent of subjects were found to have the homozygous form of methylenetetrahydrofolate reductase (MTHFR) C677T or were found to be folate deficient. Researchers notified these participants and sent a letter for the participants to show their health care provider for further assessment and information. (Appendix G).

\section{Demographic information}

The methods comparison study population was 18 to 75 years of age and $26 \%$ male and $74 \%$ female. The majority of the population was born in Canada (64\%). Of those not born in Canada, $35 \%$ were residents for 5 years, $15 \%$ for 5 to 10 years and $51 \%$ for more than 10 years. Non-smokers represented $95 \%$ of the sample. Twenty percent of the sample reported folic acid supplement intake, which is similar to that of the Canadian population $(24 \%) .^{3}$ 


\section{Step-by-step generation of the conversion equation}

We have outlined the steps taken to generate the conversion equation in Appendix H. We used Analyse-it, version 2.26 Excel 12+ software (Analyse-it Software, Ltd., Leeds, UK) to analyse the data. Where the absolute difference between the two method values for a given blood sample (immunoassay - microbiologic assay) was greater than 2 SDs ( $\geq 1000 \mathrm{nmol} / \mathrm{L})$ the value was deemed an outlier and removed $(n=6)$. Plotting the two sets of remaining values against each other resulted in a Pearson correlation coefficient, $r$, of 0.67 , which was used to guide the choice of regression technique to estimate the crossover equation.

A correlation coefficient below 0.80 indicates the need to use Deming regression methods as Ordinary Least Squares regression routinely underestimates the actual slope of the data, and can have a large impact on the results. ${ }^{4}$ As a result, a lower adjusted value may be estimated. Deming regression accounts for the random error present in both the values of $\mathrm{X}$ and Y. Ordinary Least Squares assumes random error for only the Y values, which is rarely fulfilled in method comparison studies. ${ }^{5,6}$ Weighted Deming regression was performed to account for proportional error. ${ }^{7}$ The final weighted Deming regression equation was as follows:

Predicted microbiologic assay $=-22.95+0.81 *$ Immunoassay.

The goodness-of-fit was assessed by estimating the mean absolute percentage error (MAPE) resulting from the model. This statistic: ${ }^{\mathrm{i}}$

$$
\text { MAPE }=\frac{1}{n} \sum_{k=1}^{n} \frac{\left(y_{k}-\text { pred_. } y_{k}\right)}{y_{k}}
$$

\footnotetext{
${ }^{\mathrm{i}} \mathrm{k}=$ dummy index or the range for a quantity from $\mathrm{k}$ up to, and including, $\mathrm{n} ; \mathrm{y}=$ actual value for microbiologic assay; pred_y $=$ predicted value for microbiologic assay; $n=$ number of fitted points
} 
indicated that there was $23 \%$ error in the model. To validate the model, the whole sample was randomly split into two groups, one for estimation and the other for validation. The estimation sample was used to fit the model, and the validation sample was used to obtain the MAPE. A similar MAPE (23\%) was obtained, indicating robustness in the precision of the model's predicted values.

As a final examination of the model, we conducted a boundary assessment. The bottom and top $95 \%$ confidence intervals of the conversion equation were used to generate two equations representing the lower and upper boundary of the adjusted data:

Bottom 95\% CI: Predicted microbiologic assay $=-155.68+0.81 *$ Immunoassay

Top 95\% CI: Predicted microbiologic assay $=109.78+0.81 *$ Immunoassay

These equations were applied to the CHMS and NHANES data to examine the cumulative distributions for the bottom and top $95 \% \mathrm{CI}$ of the conversion equation.

\section{MTHFR genotyping and the conversion equation}

MTHFR is an enzyme that is imperative in folate metabolism. ${ }^{8}$ A common genetic variant in this enzyme is called MTHFR C677T. If a person consumes low levels of folate in their diet, and does not consume a folic acid supplement, the activity of this enzyme is reduced.

Individuals have two copies of the MTHFR gene, one from each parent. Therefore, it is possible to have one or two copies of the variant form of the gene and having one copy is prevalent in about $50 \%$ of the population. Having two copies of the variant varies widely by region and ethnic group. For example, it has been reported in $8 \%$ to $14 \%$ of Caucasians in North America, $6 \%$ to $14 \%$ of northern Europeans and $15 \%$ to $24 \%$ of southern Europeans. ${ }^{9}$ The highest frequencies have been reported among Mexicans and other Hispanic populations (15\% to $35 \%$ ). In Asia, the frequencies range from $12 \%$ to $18 \%$. Two copies of the variant 
and low folate intake can be of concern if a woman becomes pregnant, as it may increase the risk of birth defects, specifically neural tube defects. In the methods comparison experiment, one-factor ANOVA was used to test the difference in RBC folate concentration by genotype for each method. No significant difference in RBC folate concentration by genotype was found for Immulite 2000 immunoassay or microbiologic assay.

\section{References}

1. Bland JM, Altman DG. Statistical methods for assessing agreement between two methods of clinical measurement. Lancet 1986;1(8476):307-10.

2. Bland JM, Altman DG. Measuring agreement in method comparison studies. Stat Methods Med Res 1999;8(2):135-60.

3. Colapinto CK, O'Connor DL, Dubois L, et al. Prevalence and correlates of folic acid supplement use in Canada. Health Rep 2012;23(2):39-44.

4. Good, PI, Hardin, JW. Common errors in statistics (and how to avoid them). New Jersey, USA: John Wiley and Sons, Inc.; 2009..

5. Ludbrook J. Statistical techniques for comparing measurers and methods of measurement: A critical review. Clin Exp Pharmacol Physiol 2002;29(7):527-36.

6. Linnet K. Evaluation of regression procedures for methods comparison studies. Clin Chem 1993;39(3):424-32.

7. Linnet K. Estimation of the linear relationship between the measurements of two methods with proportional errors. Stat Med 1990;9(12):1463-73.

8. Blom HJ, Shaw GM, den Heijer M, et al. Neural tube defects and folate: Case far from closed. Nat Rev Neurosci 2006;7(9):724-31.

9. Christensen, KE, Rozen, R. Genetic variation: Effect on folate metabolism and health. In: Bailey LB, ed. Folate in health and disease. 2nd ed. Boca Raton (FL): Taylor \& Francis Group, L.L.C.; 2010. 
Appendix G: Conversion equation study documents

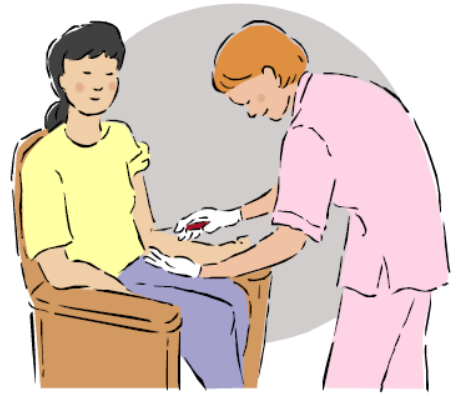

Participants needed 2o

The Hospital for Sick Children SickKids

We are looking for people, $\mathbf{1 6}$ to $\mathbf{7 9}$ years old, to participate in a study looking at the amount of folate in blood.

Folate is very important since it helps to produce new cells. Low amounts of folate in the diet have been linked to birth defects in babies.

We will ask you to fill out a short questionnaire about yourself and your intake of folate-containing supplements. We will also measure the amount and types of folate in your red blood cells. Your participation would take approximately 30 minutes.

We will reimburse you for parking and travel expenses.

To learn more about the study, please contact:

XXXX (XXX) XXX-XXXX ext. XXXX 


\section{SickKids}

THE HOSPITAL FOR
SICK CHILDREN

Research Ethics Board

\section{Telephone Script \\ Examining the Folate Status of Canadians}

Hello, my name is returning your call regarding the folate study at the Hospital for Sick Children. Do you have time to talk now, or would you prefer I call back at a more convenient time? I am calling on behalf of the researchers, myself (research assistant), Deborah O'Connor (a nutrition researcher at Sick Kids), Mark Tremblay, Cynthia Colapinto and Lise Dubois (who are members of the research team in Ottawa). I am now going to explain the purpose of the research. Please feel free to ask me questions at any time.

\section{Purpose of the Research}

Folate, also called folic acid, is a B vitamin. Folate is an important vitamin found in many foods, especially green leafy vegetables, orange juice, broccoli and wheat germ. Our bodies use this vitamin to make sure our cells grow properly and make new cells. Low amounts of folate in the diet have been linked to birth defects in the baby. In this study, we are also interested in looking at whether Canadians and Americans have similar red blood cell folate using data from two sources the Canadian Health Measures Survey (CHMS) and the National Health and Nutrition Examination Survey (NHANES). These surveys measure folate differently. In order to compare the folate status of the Canadian population to the American population, we need to create find out more about this difference. In this study, we will use the blood collected to measure red blood cell folate in two ways. Two ways to measure red blood cell folate will be used. We will then create an equation that will help explain the difference in results between the two ways of measuring red blood cell folate.

\section{Description of the Research:}

We will study 200 people, 6 to 79 years of age. If you (or your child) is eligible to participate in the study you will be asked to come to the Clinical Investigation Unit (5D12 Atrium) at the Hospital for Sick Children in the morning. We would ask you (or your child) not to eat or drink anything (except for water) from about $10 \mathrm{pm}$ the night before. We would also ask that your child not take any of their usual supplements either the night before or the morning of their visit. We will then take about 10 millilitres of blood from a vein in your (or your child's) arm. This blood sample will be used to measure the total amount and form of folate in their blood. This blood sample will also be used for DNA testing to determine whether you (or your child) have a common genetic variant which can alter the amounts of the forms of folate in the blood. If you (or your child) is found to have this variant we will contact you and inform you of the results. At this time, possible risks and inconveniences of genetic testing will be discussed with you, as well as the need to repeat testing in a clinical laboratory to confirm the results. You can discuss these results with your healthcare provider. Results will only be used by the researchers for the purposes of this study.

In order to ensure you (or your child) are eligible to participate, I have a few questions. Your response will not be recorded, this is just to be sure you are eligible to participate before making an appointment:

1) How old are you (or your child)?

2) How healthy are you (or your child) in general? 
3) Are you pregnant or breastfeeding (if potential participant is female and over 13 years of age)?

4) Will you (or your child) be taking any antibiotics in the two weeks prior to participating in the survey?

5) Do you (or your child) have a history of any of the following disorders or conditions that may affect the level of folate in your blood?

- Gastrointestinal disease (chronic diarrhea, inflammitory bowel disease, partial gastrectomy)

- Unresolved GI symptoms(diarrhea/vomiting), steatorrhea or other conditions that interfere with absorption, distribution, metabolism or excretion of folic acid.

- Epilepsy

- Diabetes Mellitus (includes maternal, insulin-dependent and non-insulin dependent)

- Previous child with neural tube disorder (NTD), spina bifida, cleft palate or heart defects

NOTE: If response is under 12 years or over 79 years of age, and/or they are not healthy in general and/or 'yes' to any of the subsequent questions, the researcher will thank the caller for considering the study but they are not eligible to participate at this time. If the participant is eligible, the researcher will continue with the following script:

We will also ask you (or your child) the following personal information at your appointment.

- Age, sex, ethnicity and cultural/racial background

- What medications are currently being taken?

- Have you/they taken antibiotics in the last two weeks?

- How often you/they smoke or drinks alcohol? (for those over 13 years of age)

- Do you/they use supplements and, if so, what kind and how often you/they take them and why?

This research will involve a couple of steps that I will explain to you right now. First, you will be asked to come to SickKids Clinical Investigation Unit. You will be asked to respond to a short questionnaires, with questions as described. You (or your child) will then be asked to provide a blood sample. You (or your child) do not have to answer a question if you (or your child) do not know the answer or choose not to answer. In fact, you (or your child) do not have to participate at all, and this decision will not affect the care received by you or your family at Sick Kids.

This study will take about 30 minutes of your time. We will pay for your expenses for taking part in the study. For example, your meals, babysitters, parking, and getting to and from Sick Kids. If you stop taking part in our study, we will still pay for your expenses. The blood withdrawl might cause some physical discomfort (bruising, bleeding or infections at the site of the needle stick) and/or anxiety in participants, particularly young children. You may request an analgesic (numbing or pain blocking) cream to decrease the pain and discomfort of blood tests. Further, if you are uncomfortable at any time during the study, you (or your child) may stop the study and leave without any penalty, including loss of reimbursement.

Please be assured that the services you receive from Sick Kids will not be affected in any way by whether you take part in this study and if you are a Sick Kids employee, their participation will not impact your employment status.

Consent Form Version: September 30, 2010, Version \#2 
If you would like a copy of the results of the blood draw you can contact the research staff and these will be made available to you. All of the results will be kept confidential. Your name will never be associated with a blood sample. A study number will be assigned instead. All information will be reported together, so your individual results will never be made available to the public. Access to personal information will be strictly limited to members of the research team, and clinical research monitors.

Do you still agree to be part of the study? If so, I will give you directions to the SickKids Clinical Research Unit and then we can discuss a date and time that is convenient for you to come in. If not, thank you for considering taking part. 


\title{
Research Consent Form
}

\section{Title of Research Project:}

Examining the folate status of Canadians

\section{Investigator(s):}

Principal Investigator Deborah L. O'Connor $\mathrm{PhD}, \mathrm{RD}$

Co-Investigators:

\author{
Mark Tremblay, $\mathrm{PhD}$ \\ Lise Dubois, $\mathrm{PhD}, \mathrm{RD}$
}

Cynthia Colapinto, MSc, $\mathrm{RD}, \mathrm{PhD}$ (c)

You are being invited to participate in this research study.

The researcher will explain the purpose of the study. He or she will explain how the study will be carried out and what you will be asked to do. The researcher will also explain the possible risks and benefits of being in the study. You should ask the researcher any questions you have about any of these things before you decide whether you want to take part in the study. This process is called informed consent.

This form also explains the research study. Please read the form and talk to the researcher about any questions you may have. Then, if you decide to be in the study, please sign and date this form in front of the researcher. You will be given a copy of this form to keep.

\section{Purpose of the Research}

Folate, also called folic acid, is a B vitamin. Folate is an important vitamin found in many foods, especially green leafy vegetables, orange juice, broccoli and wheat germ. Our bodies use this vitamin to make sure our cells grow properly and make new cells. Low amounts of folate in the diet have been linked to birth defects in the baby. In this study, we are also interested in looking at whether Canadians and Americans have similar red blood cell folate using data from two sources the Canadian Health Measures Survey (CHMS) and the National Health and Nutrition Examination Survey (NHANES). These surveys measure folate differently. In order to compare the folate status of the Canadian population to the American population, we need to find out more about this difference. In this study, we will use the blood collected to measure red blood cell folate. Two ways to measure red blood cell folate will be used. We will then create an equation that will help explain the difference in results between the two ways of measuring red blood cell folate.

\section{Description of the Research:}

We will study 200 people. If you are eligible to participate in the study you will asked to come to the Clinical Investigation Unit (5D12 Atrium) at the Hospital for Sick Children in the morning. Participating will take around 30 minutes. Please do not eat or drink anything (except for water and beverages that do not contain folate, such as ginger, lemon balm and rose hip herbal teas) from 


\section{SickKids}

THE HOSPITAL FOR

\section{SICK CHILDREN}

\section{Research Ethics Board}

about $10 \mathrm{pm}$ the night before. Also, please do not take any of your usual supplements either the night before or the morning of your visit.

We will then take about 10 millilitres or 2 teaspoons of blood from a vein in your arm. This blood sample will be used to measure the total amount and form of folate in your blood. This blood sample will also be used for DNA testing to determine whether you have a common genetic variant which can change the amounts or forms of folate in your blood. The genetic testing is explained further in the attached Genetic Testing consent form. If you are found to have two copies of this variant (homozygous), or are found to be folate deficient, we will contact you and inform you of the results. Repeat testing in a clinical laboratory will also be recommended to confirm these results.

- We will also ask you the following personal questions:

- How old you are

- Place of birth and cultural/racial background

- Whether you smoke

- How often you drink alcohol

- If you are using oral contraceptives and what level of dosage is the prescription

- Have you taken antibiotics in the last two weeks

- How healthy you are in general

- Pregnancy status

- If you use supplements, what kind and how often you take them and why

\section{Potential Harms:}

There may be a small amount of bleeding when blood is taken from a vein and there may be slight discomfort and bruising or redness that will usually disappear in a few days. There is also a small risk for infection, but efforts will be made to reduce this risk. The nurse will try to take blood a maximum of three times, but if are upset by this at any time you can stop and leave without any penalty. You can also ask for a numbing cream to decrease any pain.

\section{Potential Benefits:}

There is no direct health benefit to you for participating in this study. However what we learn from this study will help us understand how the folate status of Canadians compares to that of Americans. This will help us inform important policies, including folate supplementation recommendations for women who may become pregnant. Also, the creation of an equation for comparing the results of folate measured in two different ways will allow other researchers to compare folate results.

\section{Confidentiality:}

No information that discloses your identity will be released or published without consent unless required by law. This legal requirement includes a number of situations, such as suspected child abuse, infectious disease or expression of suicidal ideas where research documents are ordered to be provided by a court of law and where researchers must report to the appropriate authorities. By 


\section{SickKids}

\section{THE HOSPITAL FOR \\ SICK CHILDREN}

\section{Research Ethics Board}

signing this consent form, you agree to let these people look at your child's study records if necessary. We will put a copy of this research consent form in your child's study records. We will give you a copy for your child's files. Health records identifying the patient may be given to and inspected by the Sickkids Clinical Research Monitors. The SickKids and Children's Hospital of Eastern Ontario Research Ethics Boards may have access to your child's study records for auditing purposes. The data from this study will be stored in a secure, locked location. Only members of the research team (and maybe those people described above) will have access to the data. This could include external research team members. At the end of the research study, the data will be kept for 7 years after publication and then destroyed as required by Sick Kids policy. Published study results will never reveal your identity.

\section{Reimbursement:}

We will give you $\$ 25$ for your expenses for taking part in the study. For example, your meals, babysitters, parking, and getting to and from Sick Kids. If you stop taking part in our study, we will still pay your for expenses. A certificate of volunteer hours will also be provided to recognize your time.

\section{Participation:}

It is your choice to take part in this study. You can stop at any time. The care you get at Sick Kids will not be affected in any way by whether you take part in this study. If you are a Sick Kids employee, this will not impact your employment status. Study results will be accessible to you on request once they become available.

This study has been reviewed and approved by the SickKids and CHEO Research Ethics Boards. These are hospital committees that include people from different professional backgrounds. These Boards review all human research that takes place at their hospitals. Their goal is to ensure the protection of the rights and welfare of people participating in research. The Board's work is not intended to replace a parent or child's judgment about what decisions and choices are best for them. You may contact the Chair of either Research Ethics Board, for information regarding patient's rights in research studies at (416) $813-5718$ or (613) $737-7600$ extension 3272 . This person cannot provide any health-related information about the study, please contact the study investigators for this information.

\section{Compensation:}

During this study we may create new tests, new medicines, or other things that may be worth some money. Although we may make money from these findings, we cannot give you any of this money now or in the future because you took part in this study. If you become ill or are harmed because of study participation, we will treat you for free. Your signing this consent form does not interfere with your legal rights in any way. The study staff, any people who gave money for the study, or the hospital are still responsible, legally and professionally, for what they do. 


\section{SickKids}

THE HOSPITAL FOR

\section{SICK CHILDREN}

Research Ethics Board

\section{Conflict of Interest:}

Dr. O'Connor, and the other research team members, have no conflict of interest to declare

\section{Sponsorship}

This study is funded by the Canadian Institutes of Health Research and sponsored by Dr. O'Connor and the SickKids Department of Physiology and Experimental Medicine.

\section{Consent:}

By signing this form, I agree that:

1) You have explained this study to me. You have answered all my questions.

2) You have explained the possible harms and benefits (if any) of this study.

3) I know what I could do instead of taking part in this study. I understand that I have the right not to take part in the study and the right to stop at any time. My decision about taking part in the study will not affect my health care at Sick Kids.

4) I am free now, and in the future, to ask questions about the study.

5) I have been told that my medical records will be kept private except as described to me.

6) I understand that no information about who I am will be given to anyone or be published without first asking my permission.

7) I have read and understood pages 1 to 3 of this consent form. I agree, or consent, to take part in this study.

Printed Name of Participant \& Age

Participant's signature \& date

Printed Name of person who explained consent

Signature \& date

Printed Witness' name

Witness' signature \& date

(only needed if participant does not read English)

If you have any questions about this study, please call any of the investigators:

Consent Form Version: September 30, 2010, Version \#2 


\section{SickKids}

THE HOSPITAL FOR

SICK CHILDREN

Research Ethics Board

For day to day study issues call: Research Assistant (name TBA) Telephone (TBA)

If you have questions about your rights as a participant in a study or for information on whom to contact in the event of injuries during a study, please call the SickKids Research Ethics Manager at 416-813-5718 or the CHEO Research Ethics Manager at (613) 737-7600 extension 3272. 


\title{
SickKids
}

THE HOSPITAL FOR

SICK CHILDREN

Research Ethics Board

\section{Research Consent for Genetic Testing}

Title of Research Project: Examining the folate status of Canadians

\author{
Investigators: \\ Principal Investigator: Deborah L. O'Connor $\mathrm{PhD}, \mathrm{RD}$ \\ Co-Investigators: \\ Mark Tremblay, $\mathrm{PhD}$ \\ Lise Dubois, $\mathrm{PhD}, \mathrm{RD}$ \\ Cynthia Colapinto, MSc, $\mathrm{RD}, \mathrm{PhD}(\mathrm{c})$
}

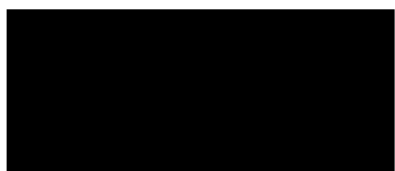

You are being invited to participate in this research study.

The researcher will explain the purpose of the study. He or she will explain how the study will be carried out and what you will be asked to do. The researcher will also explain the possible risks and benefits of being in the study. You should ask the researcher any questions you have about any of these things before you decide whether you want to take part in the study. This process is called informed consent.

This form also explains the research study. Please read the form and talk to the researcher about any questions you may have. Then, if you decide to be in the study, please sign and date this form in front of the researcher. You will be given a copy of this form to keep.

\section{Purpose of the Research}

Folate, also called folic acid, is a B vitamin. Folate is an important vitamin found in many foods, especially green leafy vegetables, orange juice, broccoli and wheat germ. Our bodies use this vitamin to make sure our cells grow properly and produce new cells. Low amounts of folate in the diet have been linked to birth defects in the baby. In this study, we are also interested in looking at whether Canadians and Americans have similar red blood cell folate using data from two sources the Canadian Health Measures Survey (CHMS) and the National Health and Nutrition Examination Survey (NHANES). These surveys measure folate differently. In order to compare the folate status of the Canadian population to the American population we need to find out more about this difference. In this study, we will use the blood collected to measure red blood cell folate. Two ways to measure red blood cell folate will be used. We will then create an equation that will help explain the difference in results between the two ways of measuring red blood cell folate.

We will also use your blood sample to determine whether you have a very common genetic variant in an enzyme called methylenetetrahydrofolate reductase (short form MTHFR). The variant is called MTHFR C677T. The MTHFR enzyme is required for your body to best process folate in your food. If you eat very little folate this enzyme changes, to some degree, how your body processes folate. All individuals have two copies of the MTHFR gene, one from each parent. Therefore, it is possible to have one or two copies of the variant form of the gene. Having one copy is seen in about $50 \%$ of people. Having two copies is seen in $10-15 \%$ of those who are of Caucasian and Asian descent, approximately $20 \%$ of those of Italian heritage, and between 2-3 percent of those of African descent. If 


\section{SickKids}

THE HOSPITAL FOR

\section{SICK CHILDREN}

\section{Research Ethics Board}

you have two copies, and you eat low amounts of folate you will have a lower activity of the MTHFR enzyme in your body. Two copies of the variant and low folate intake can be of concern if you become pregnant, as it may increase the risk of birth defects, specifically neural tube defects. Currently one pregnancy in 1,100 in Canada is affected by this birth defect. Some researchers have shown that two copies of the variant and low folate intake may be related to heart disease but other researchers do not find this.

By testing you for the MTHFR C677T variant, we will know if you have one or two copies of the variant. We will then use this information to help us understand your blood folate levels.

\section{Description of the Research:}

We will study 200 people. If you are eligible to participate in the study you will asked to come to the Clinical Investigation Unit (5D12 Atrium) at the Hospital for Sick Children in the morning. Participating will take around 30 minutes. We will then take about 10 millilitres or 2 teaspoons of blood from a vein in your arm. This blood sample will be used to measure the total amount and form of folate in your blood. This blood sample will also be used for DNA testing to determine whether you have a common genetic variant which can change the amounts or forms of folate in your blood. If you are found to have the most serious form of this variant (homozygous), or are found to be folate deficient, we will contact you and inform you of the results. At this time, possible risks and inconveniences of genetic testing will be discussed with you, as well as the need to repeat testing in a clinical laboratory to confirm the results. Results will only be used by the researchers for the purposes of this study.

I confirm that the researcher has explained the genetic tests that I am [professional's name]

about to have done with respect to C677T MTHFR [name of genetic condition] , and that any questions that I

have asked have been answered to my satisfaction. The discomforts, consequences and possible risks associated with these tests have been explained to me. I understand that it is my choice whether or not to have this testing. I understand that the researchers will only contact me with the results of this test if my child demonstrates the MTHFR C677T variant or folate deficiency. Results will be explained to me and I will be given a letter that I can share with professionals involved in my medical care, including our family physician. I have been assured that records relating to me or my child and the care that we received will be kept confidential, and that no information will be released or printed that will reveal my identity without my permission or unless required by law.

I understand that although genetic testing is usually accurate, as with all testing some inaccuracies may occur. Also genetic testing is ongoing and new research may mean that the interpretation of the test results may change over time. On occasion, in the process of testing for one genetic condition, another genetic alteration may be identified. Such findings would be reported to you for discussion with your health care provider. I understand that if I apply for insurance and provide consent, information in my medical records, including the results of genetic testing will be available to the company.. To clarify 


\section{SickKids}

THE HOSPITAL FOR

SICK CHILDREN

Research Ethics Board

the researchers will not be putting information about genetic testing into your medical record but your health care professional may insert the letter you share with them about your study results into your medical record.

If I want to find out my results, I understand that it is my responsibility to contact the _ Clinical Dietetics_[department name] department.

\section{Closed Consent:}

Closed consent means that any tissue or DNA obtained from me will be analyzed and then destroyed. Specifically, I give my consent for a blood/tissue sample to be taken for testing related only to the verification of the C677T MTHFR genotype; this testing will be undertaken in a accredited clinical service laboratory and/or a research laboratory and that the sample and any DNA extracted from it will be destroyed once the results of the testing are available. I also understand that if I want any further genetic testing to be done in the future, I will need to have another sample taken from me.

Printed Name of Participant

Printed Name of person who explained consent

Printed Witness' name

(only needed if participant does not read English)
Participant's signature \& date

Signature \& date

Witness' signature \& date

If you have any questions about this study, please call any of the investigators: 


\section{Questionnaire: Examining the folate status of Canadians}

Date:

Assigned ID Number:

\section{General Socio-demographic Questions}

1. Age:

2. Sex:
i. Male
ii. Female

3. [Were/Was] [you/your child] born a Canadian citizen?

iii. Yes (Go to Qu.5)

iv. No (Go to Qu. 4)

v. DK, RF (Go to Qu. 4)

4. How many years have [you/he/she] lived in Canada?

i. Enter number of years:

ii. $\quad$ DK, RF (Go to Qu.5)

5. People living in Canada come from many different cultural and racial backgrounds. [Are/Is] [you/your child]: (Read categories to respondent. Mark all that apply)

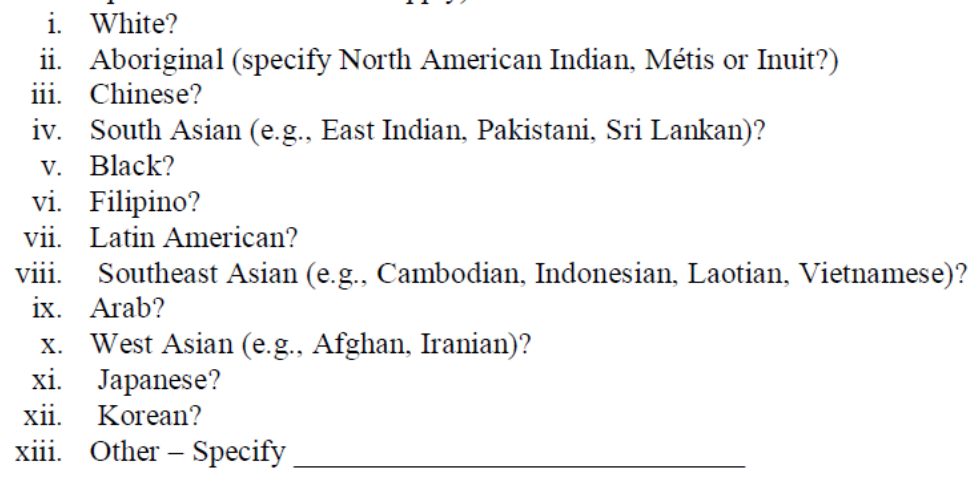

Questionnaire Version: September 30, 2010, Version \#6 
Questions related to folate intake(If under 14 years of age, select N/A for Qu. 6 to8)

6. Do you smoke?

$\begin{aligned} \text { i. } & \text { Yes } \\ \text { ii. } & \text { No } \\ \text { iii. } & \text { Not applicable }\end{aligned}$

7. How often do you have an alcoholic drink?

$$
\begin{aligned}
\text { i. } & \text { I don't drink } \\
\text { ii. } & <1 \text { per week } \\
\text { iii. } & 1 \text { per week } \\
\text { iv. } & 2-4 \text { per week } \\
\text { v. } & 5-7 \text { per week } \\
\text { vi. } & >1 \text { per day } \\
\text { vii. } & \text { Not applicable }
\end{aligned}
$$

\section{General Medical Questions}

8. Do you use birth control or contraceptives? (If male select $N / A$ )
i. Yes
ii. No
iii. Not applicable

If so what kind?

9. Are you currently on any medications?

$$
\begin{array}{ll}
\text { i. } & \text { Yes } \\
\text { ii. } & \text { No }
\end{array}
$$

If so what medications are you on? List below:-

10. Do you have a medical history that includes any of the following conditions:

i. A history or presence of any clinically sign gastrointestinal pathology (such as chronic diarrhea, IBD, partial gastrectomy) Yes/No

ii. Any unresolved GI symptoms (diarrhea/vomiting) Yes/No

iii. Any steatorrhea or other conditions that interfere with absorption, distribution, metabolism or excretion of folic acid. Yes/No 
11. Are you pregnant? (If male and/or under 14 years of age select $N / A$ )

i. Yes

ii. No

iii. Not applicable

Folic Acid Containing Supplement Use and Adherence

12. Have you taken a folic acid containing supplement(s) in the past 30 days?

i. Yes

ii. No

11 a. If so, what brand(s) and dose(s) do you take? Brand: (list if more than one taken)

Dose:

$11 \mathrm{~b}$. If so, how often do you take your folic acid containing supplements?

i.Everyday

ii.Every second day

iii.1-2 per week

iv.less than 1 per week

13. Do you use any meal replacement/power bars or shakes?

$$
\begin{array}{cc}
\text { i. } & \text { Yes } \\
\text { ii. } & \text { No }
\end{array}
$$

14. Why would you/do you use folic acid containing supplements?

$\begin{aligned} \text { i. } & \text { Not eat right } \\ \text { ii. } & \text { Make sure get enough of a vitamin(s) } \\ \text { iii. } & \text { Believe it makes you healthier } \\ \text { iv. } & \text { Good for helping baby grow } \\ \text { v. } & \text { Doctor recommended it } \\ \text { vi. } & \text { Other reason }\end{aligned}$

15. If you don't take your folic acid containing supplements every day, what is the reason?
i. Forget
ii. Nausea or vomiting-morning sickness-from supplement
iii. Pill too big
iv. Don't like take supplements
v. Not important
vi. Other reason

Questionnaire Version: September 30, 2010, Version \#0 


\section{SickKidśs}

\section{THE HOSPITAL FOR}

SICK CHILDREN

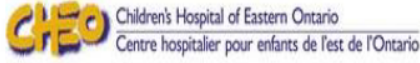

\section{Research Ethics Board}

Dear [Enter Participant name here],

Thank you/your child for your/their participation in the study "Examining the Folate Status of Canadians" at the Hospital for Sick Children. We are writing to inform you that our research results suggest that you/your child may have [enter folate deficiency and/or a common genetic mutation which can change the amounts or forms of folate in your blood].

Folate deficiency:[include if found to be folate deficient]

Folate, also called folic acid, is a B vitamin. Folate is an important vitamin found in many foods, especially green leafy vegetables, orange juice, broccoli and wheat germ. Our bodies use this vitamin to make sure our cells grow properly and produce new cells. Low amounts of folate in the diet have been linked to birth defects in the baby. Low amounts of folate in the diet have been connected to an increased risk for neural tube defects, spina bifida, cleft palate or heart defects in a baby during pregnancy and may also increase the risk of certain cancers and heart disease if folate intake is low.

Common genetic mutation - MTHFR C677T:[include if found to have mutation]

This is a common genetic variant in an enzyme called methylenetetrahydrofolate reductase (short form MTHFR). The variant is called MTHFR C677T. The MTHFR enzyme is required for the body to best process the folate in the food you eat, but even if this enzyme is changed you/your child will still be able to process folate to some degree but not as well. All individuals have two copies of the MTHFR gene, one from each parent. Therefore, it is possible to have one or two copies of the variant form of the gene. Having one copy is seen in about $50 \%$ of people. Having two copies is seen in $10-15 \%$ of those who are of Caucasian and Asian descent, approximately $20 \%$ of those of Italian heritage, and between 2-3 percent of those of African descent. You/your child has two copies, so they will have a lower activity of the MTHFR enzyme in their body. This can affect the way folate is used and can be of concern when they have a low amount of folate in their blood. This is of most concern in pregnant women, or women who may become pregnant, as this may increase the risk for neural tube defects, spina bifida, cleft palate or heart defects in a developing baby and may also increase the risk for heart disease in adults if folate intake is low.

You may wish to visit your health care provider to discuss clinical testing so this result may be assessed further. We will provide you with a letter to take to your health care provider explaining the results. If you do not have a health care provider you can find health services near your home by contacting the City of Toronto information line by calling 311 .

Thank you again for your participation in the study.

Sincerely,

Dr. Deborah O'Connor

Version: July 20, 2010 


\section{SickKids}

THE HOSPITAL FOR

SICK CHILDREN

Research Ethics Board

If you have any questions about this study, please call any of the investigators:

For day to day study issues call: Research Assistant (name TBA) Telephone (TBA)

If you have questions about your rights as a participant in a study or for information on whom to contact in the

Version: July 20, 2010 


\section{SickKids}

THE HOSPITAL FOR

SICK CHILDREN

\section{Dear Health Care Provider,}

Your patient recently participated in a research study, Examining the Folate Status of Canadians. This study took place at the Hospital for Sick Children and is being conducted in collaboration with the Children's Hospital of Eastern Ontario.

In this study, we measured the total amount and folate in their blood. We also did DNA testing to determine whether they have a common genetic variant in an enzyme called methylenetetrahydrofolate reductase (short form MTHFR). The variant is called MTHFR C677T. The MTHFR enzyme is required in the body to metabolize folate. If a person consumes low levels of folate in their diet, and doesn't consume a folic acid supplement, the activity of this enzyme is reduced. As you know, individuals will have two copies of the MTHFR gene, one from each parent. Therefore, it is possible to have one or two copies of the variant form of the gene. Having one copy is seen in about $50 \%$ of the population. Having two copies is seen in $10-15 \%$ of those who are of Caucasian and Asian descent, approximately $20 \%$ of those of Italian heritage, and between 2-3 percent of those of African descent.

Two copies of the variant and low folate intake can be of concern if a woman becomes pregnant, as it may increase the risk of birth defects, specifically neural tube defects. In Canada, one pregnancy in 1,100 is affected by this birth defect. Some researchers have shown that two copies of the variant and low folate intake may also be related to heart disease but other researchers do not find this.

Your patient was found to have (indicated with an $\mathbf{X}$ ):

_ A red blood cell folate concentration indicative of deficiency $(<305 \mathrm{nmol} / \mathrm{L})$.

For females, a red blood cell folate concentration below that maximally protective against a neural tube defect $(<906 \mathrm{nmol})$.

Two copies of the MTHFR variant, which indicates that they will have a lower activity of the MTHFR enzyme in their body if they also have a low folate intake (diet and supplements).

Since these results were found in a research laboratory, we recommend that the results be confirmed in a clinical laboratory.

\section{Suggested Guidance for Females Capable of Becoming Pregnant:}

Health Canada recommends all women capable of becoming pregnant, regardless of their MTHFR C6677T genotype to consume a folic acid containing (400 ug/d) multi-vitamin supplement for the prevention of neural tube defects. Details of this guidance can be found at: http://www.hc-sc.gc.ca/fnan/pubs/nutrition/folate-eng.php 


\section{SickKids}

THE HOSPITAL FOR

SICK CHILDREN

In the event your patient has a red blood cell folate concentration $<906 \mathrm{nmol} / \mathrm{L}$ and/or has other risk factors for birth defects, you may wish to refer to the Health Canada document entitled, "High Dose Folic Acid Supplementation: Questions and Answers for Health Professionals" that can be found at: http://www.hc-sc.gc.ca/fn-an/nutrition/prenatal/fol-qa-qr-eng.php

$\underline{\text { Suggested Guidance to Increase Dietary Sources of Folate: Males and Females. }}$

As recommended by Health Canada:

Refer to Canada's Food Guide (http://www.hc-sc.gc.ca/fn-an/food-guide-aliment/index-eng.php). It describes a healthy eating pattern that is rich in dietary folate. Following Canada's Food Guide will also help your patient meet their needs for other nutrients and can help them achieve overall health.

Promote use of tools such My Food Guide Servings Tracker (http:/www.hc-sc.gc.ca/fn-an/food-guidealiment/track-suivi/index-eng.php). This can help your patient keep track of the amount and type of food they eat each day and compare their intake to Canada's Food Guide.

Encourage your patient to include grain products fortified with folic acid each day, such as enriched bread or enriched pasta. They can make informed choices, by looking for the term 'folic acid' in the ingredient list.

Encourage your patient to have legumes, such as beans or lentils, often and eat at least one dark green vegetable, such as peas or romaine lettuce, each day.

If you have any questions, please do not hesitate to contact me at any time.

Sincerely,

Deborah L. O'Connor PhD RD, Principal Investigator 


\section{Appendix H: Generation of the conversion equation step-by-step}

Abbreviations:

SK The Hospital for Sick Children (Sick Kids microassay)

HC Health Canada (CHMS Immulite 2000 immunoassay)

\section{Sick Kids (SK) vs. Health Canada (HC) equation:}

1. Descriptive analysis of raw data

a. Examined correlation SK (microassay) x HC (immunoassay)- noted it is low ( $\mathrm{r}=0.60)$

i. Deming regression more appropriate than ordinary least-squares. Deming regression offers an alternative to ordinary least-squares regression for estimating the linear relationship between two sets of measurements. Unlike ordinary leastsquares regression, Deming regression assumes both methods are subject to random measurement errors, but it still assumes constant measurements errors. If it is more appropriate to assume proportional measurements errors than constant measurements errors, weighted Deming regression should be used.

\begin{tabular}{r|rr}
$\mathrm{n}$ & 152 & \\
r statistic & 0.60 & \\
$95 \% \mathrm{Cl}$ & 0.48 to $0.69 \quad$ (normal approximation) \\
& & \\
t statistic & 9.12 & \\
$\mathrm{DF}$ & 150 & \\
2-tailed p & $<0.0001 \quad$ (t approximation)
\end{tabular}




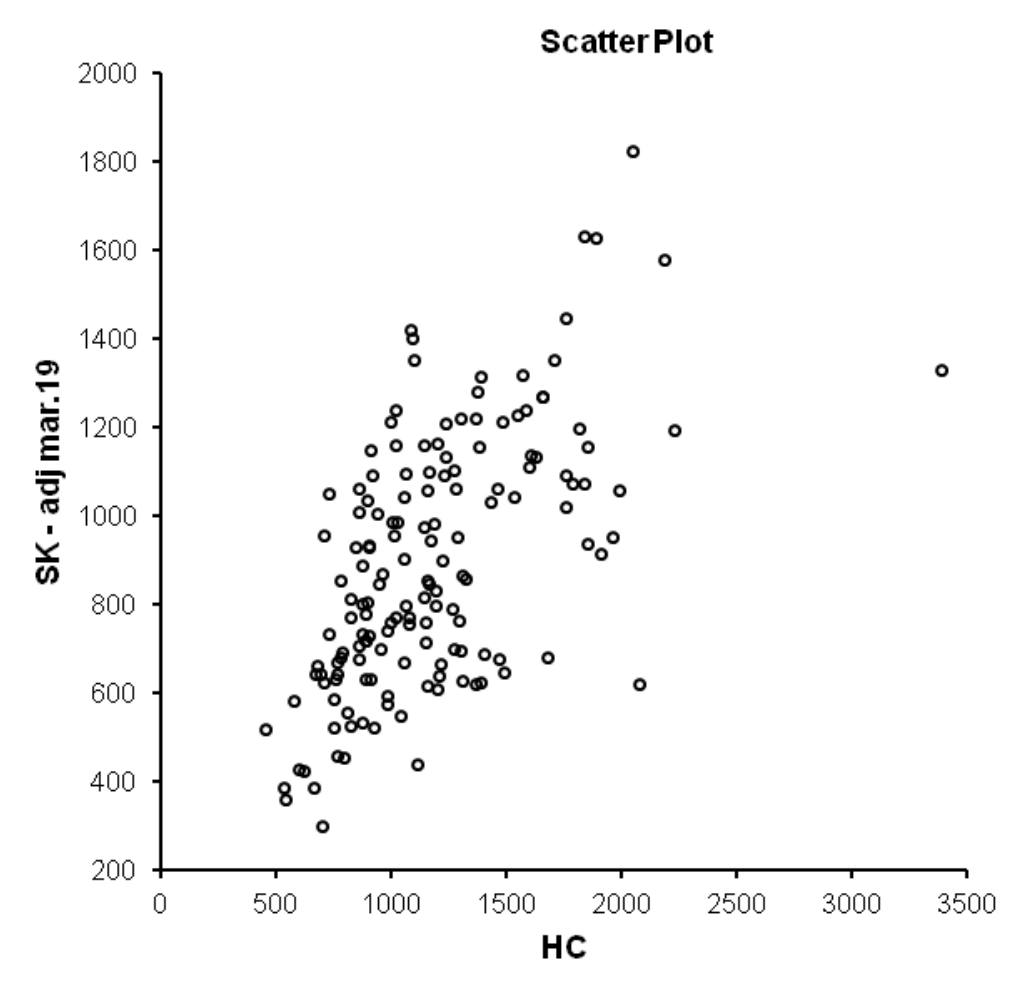

Figure 1: Scatterplot of correlation between SK (microassay) and HC (Immulite 2000 immunoassay)

b. Examined residuals - no need to normalize using log transformation as jackknife method is used to estimate standard errors of the slope in Deming regression (does not need to be Gaussian, can be non-parametric) ${ }^{1}$

2. Identified outliers:

i. Looked at multiple ways to remove outliers and the effect of this removal on the model -decided to use the difference between values and the overall mean of the assays ((1018-hc)-(1018-sk))

ii. Examined 2, 2.5 and 3 sd's from the mean of this difference

iii. 6 outliers were $>2$ sds and were removed (3.9\%): 46, 62, 131, 132, 143, 161

iv. $\mathrm{N}=146, \mathrm{r}=0.67$

3. Ran a Bland-Altman test to determine whether a weighted or unweighted model should be used. ${ }^{2}$ Bland-Altman uses a plot of the differences $\left(y_{i}-x_{i}\right)$ against the averages $\left(y_{i}+x_{i}\right) / 2$ (Figure 2). There seems to be a slight funnel effect, which suggests the variation of at least one of the techniques depends on the magnitude of the measurements (non-constant measurement errors). Decided to use weighted Deming. 


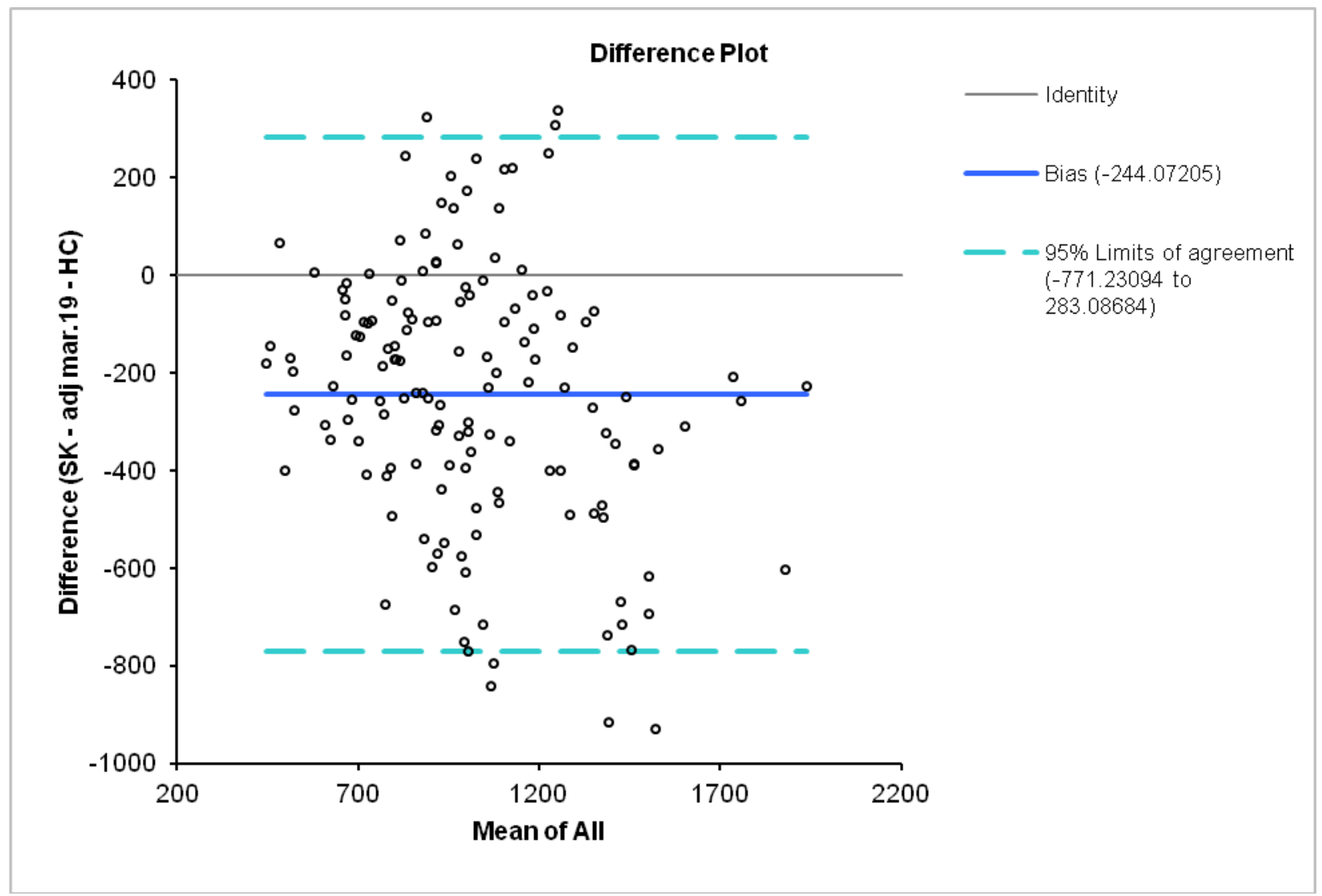

Figure 2: Bland-Altman Plot of difference HC (immunoassay) and SK (microassay) by averages.

4. Ran weighted Deming regression using Analyse-It software. ${ }^{3}$ This takes into account nonconstant measurement errors in both methods. Assumed the ratio between analytical SDs is constand and set the variance $(\lambda)$ to 1 . When replicate measurements are not available, a value must be assigned to $\lambda$. A common choice is to set $\lambda$ equal to one. " "... misspecification of variance may induce a considerable slope bias for the Deming method in electrolyte-like situations with a short range of data. Hypothesis-testing is also seriously affected. Thus, a correct specification of variance is important when applying the Deming method in situations with a limited range of values. With regard to the metabolite-like case, the bias problem is negligible; also with regard to the testing of hypotheses, the Deming procedure appears to be rather robust towards a misspecified error ratio in these examples."

a. Equation $Y=-22.95+0.81 x$

i. Mean of the absolute prediction error:

$$
1 / \mathrm{n} \sum_{\mathrm{t}=1}^{\mathrm{n}}(\mathrm{y}-\text { pred_y }) / \mathrm{y}=1 / 146 * 32.97=0.223
$$


$\mathrm{n} \mid 146 \quad$ (cases excluded: 4 due to missing values)

Range | $\quad 450.192$ to 2182.716

\begin{tabular}{r|r|r|r|r} 
& & & Repeatability & \multicolumn{2}{|c}{$\begin{array}{l}\text { Iterative } \\
\text { CV }\end{array}$} \\
\hline SK - adj mar.19 & Replicates & Assigned CV & CV & - \\
\hline HC & 1 & $1.0 \%$ & - & -
\end{tabular}

$\begin{array}{lr}\text { Variance ratio | } & 1.00 \\ \text { Sy } \mid x \text { (vertical) | } & 0.234\end{array}$

\begin{tabular}{|c|c|c|c|c|}
\hline & Bias & $95 \% \mathrm{Cl}$ & SE & $p$ \\
\hline Constant & -22.95 & -155.68 to 109.78 & 67.152 & 0.7330 \\
\hline Proportional & 0.81 & 0.68 to 0.94 & 0.066 & 0.0041 \\
\hline & $\begin{array}{l}\text { onstant bias } \\
\text { oportional }\end{array}$ & $\begin{array}{l}\text { Constant bias } \neq 0 \text {. } \\
\mathrm{H}_{1} \text { : Proportional bias } \neq 1 \text {. }\end{array}$ & & \\
\hline
\end{tabular}




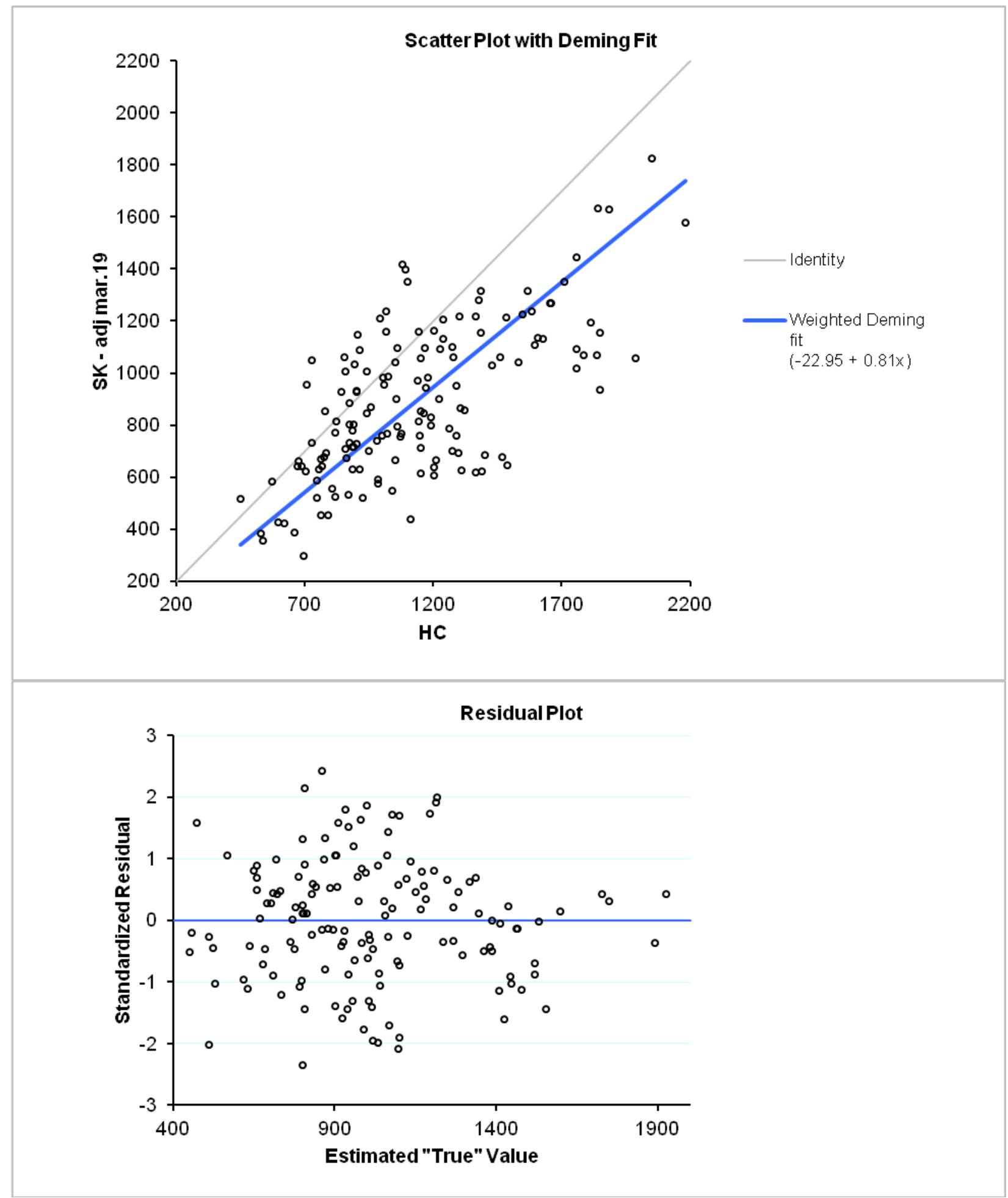

Figures 3 and 4: Deming regression plot for HC (immunoassay) vs. SK (microassay) and associated residual plot. 


\section{Validation of SK vs. HC equation}

1. Randomly split the sample into two groups (output not shown)

2. Generated the equation for group $1(\mathrm{~N}=73)$ using the method described above

a. Correlation $\mathrm{r}=0.64$

b. Bland-Altman shows funneling effect in difference plot, therefore, will use weighted Deming assuming variance $=1$.

c. $Y=-\mathbf{5 3}+\mathbf{0 . 8 4 x}$

d. MAPE for group $1=0.236$

3. Created an imputed value for group 2 using the equation generated for group 1

4. Examined the distribution between Y and Imputed_Y for group $2-r=0.69$

5. Mean of the absolute prediction error for group 2 is 0.229 , therefore, very similar to group 1 indicating good fit. 


\section{Examining effect of genotype:}

1. Ran 1-factor ANOVA for genotype for each method separately

a. Used 2 parameters $(\mathrm{C} / \mathrm{C}+\mathrm{C} / \mathrm{T}$ and $\mathrm{T} / \mathrm{T})$ and 3 parameters $(\mathrm{C} / \mathrm{C}, \mathrm{C} / \mathrm{T}, \mathrm{T} / \mathrm{T})$

b. FOUND no significant differences in RBC folate concentration by genotype for either method at 2 or 3 parameters (output below)

c. Ran with outliers out - FOUND no significant differences in RBC folate concentration by genotype for either method at 2 or 3 parameters (output not shown)

d. Microassay findings similar to Fazili et $\mathrm{l}^{5}$ whole blood folate concentrations crossover paper, need to do literature search re: genotype and immunoassay

\section{Frequencies}

$\begin{array}{rrrrr}\text { genotype_2 } & \text { Frequency } & \text { Percent } & \begin{array}{r}\text { Cumulative } \\ \text { Frequency }\end{array} & \begin{array}{r}\text { Cumulative } \\ \text { Percent }\end{array} \\ \mathbf{C} / \mathbf{C}+\mathbf{C} / \mathbf{T} & 135 & 88.82 & 135 & 88.82 \\ \text { T/T } & 17 & 11.18 & 152 & 100.00\end{array}$

\begin{tabular}{rrrrr|} 
genotype & Frequency & Percent & $\begin{array}{r}\text { Cumulative } \\
\text { Frequency }\end{array}$ & $\begin{array}{r}\text { Cumulative } \\
\text { Percent }\end{array}$ \\
C/C & 81 & 53.29 & 81 & 53.29 \\
$\mathbf{C} / \mathbf{T}$ & 54 & 35.53 & 135 & 88.82 \\
T/T & 17 & 11.18 & 152 & 100.00
\end{tabular}

ANOVA output

Dependent Variable: HC

$\begin{array}{|lrrrrr|}\text { Source } & \text { DF } & \text { Sum of Squares } & \text { Mean Square } & \text { F Value } & \text { Pr > F } \\ \text { Model } & 1 & 195939.18 & 195939.18 & 1.11 & 0.2941 \\ \text { Error } & 150 & 26515230.52 & 176768.20 & & \\ \text { Corrected Total } & 151 & 26711169.70 & & & \end{array}$

R-Square Coeff Var Root MSE HC Mean

$\begin{array}{llll}0.007335 & 35.77193 & 420.4381 & 1175.330\end{array}$

$\begin{array}{lrrrrrr}\text { Source } & \text { DF } & \text { Anova SS } & \text { Mean Square } & \text { F Value } & \text { Pr }>\text { F } \\ \text { genotype_2 } & 1 & 195939.1839 & 195939.1839 & 1.11 & 0.2941\end{array}$


Dependent Variable: SK

\begin{tabular}{|lrrrrr|} 
Source & DF & Sum of Squares & Mean Square & F Value & Pr > F \\
Model & 1 & 262074.37 & 262074.37 & 3.19 & 0.0759 \\
Error & 150 & 12307127.30 & 82047.52 & & \\
Corrected Total & 151 & 12569201.67 & & & \\
\hline
\end{tabular}

$$
\begin{array}{rrrr}
\text { R-Square } & \text { Coeff Var } & \text { Root MSE } & \text { SKadjMA Mean } \\
0.020851 & 32.14614 & 286.4394 & 891.0539
\end{array}
$$

\begin{tabular}{|lrrrrr|}
\hline Source & DF & Anova SS & Mean Square & F Value & Pr $>$ F \\
genotype_2 & 1 & 262074.3722 & 262074.3722 & 3.19 & 0.0759
\end{tabular}

Dependent Variable: HC

\begin{tabular}{|lrrrrr|} 
Source & DF & Sum of Squares & Mean Square & F Value & Pr > F \\
Model & 2 & 202473.63 & 101236.82 & 0.57 & 0.5673 \\
Error & 149 & 26508696.07 & 177910.71 & & \\
Corrected Total & 151 & 26711169.70 & & & \\
\hline
\end{tabular}

$$
\begin{array}{|rrrr|}
\hline \text { R-Square } & \text { Coeff Var } & \text { Root MSE } & \text { HC Mean } \\
0.007580 & 35.88735 & 421.7946 & 1175.330 \\
\hline
\end{array}
$$

\begin{tabular}{|lrrrrr}
\hline Source & DF & Anova SS & Mean Square & F Value & Pr > F \\
genotype & 2 & 202473.6304 & 101236.8152 & 0.57 & 0.5673
\end{tabular}


Dependent Variable: SK

\begin{tabular}{|lrrrrr|}
\hline Source & DF & Sum of Squares & Mean Square & F Value & Pr > F \\
Model & 2 & 306446.12 & 153223.06 & 1.86 & 0.1590 \\
Error & 149 & 12262755.55 & 82300.37 & & \\
Corrected Total & 151 & 12569201.67 & & & \\
\hline
\end{tabular}

R-Square Coeff Var Root MSE SKadjMA Mean

$\begin{array}{llll}0.024381 \quad 32.19563 \quad 286.8804 & 891.0539\end{array}$

\begin{tabular}{|lrrrrr} 
Source & DF & Anova SS & Mean Square & F Value & Pr $>$ F \\
genotype & 2 & 306446.1165 & 153223.0583 & 1.86 & 0.1590
\end{tabular}

REFERENCES:

1. Linnet, K. Evaluation of regression procedures for methods comparison studies. Clinical Chemistry. 1993;39(3):424-432.

2. Linnet, K. Estimation of the linear relationship between the measurements of two methods with proportional errors. Statistics in Medicine. 1990;9:1463-1473.

3. Analyse-it. Deming regression \& Weighted Deming regression. [Online] [Cited: July 12, 2012.] http://www.analyse-it.com/products/method evaluation/deming-regression.aspx.

4. Linnet, K. Performance of Deming regression analysis in case of misspecified analytical error ratio in method comparison studies. Clinical Chemistry.1998;44:1024-1031.

5. Fazili Z, Pfeiffer CM, Zhang M, Jain RB, Koontz D. Influence of 5,10methylenetetrahydrofolate reductase polymorphism on whole-blood folate concentrations measured by LC-MS/MS, microbiologic assay, and bio-rad radioassay. Clin Chem 2008 Jan;54(1):197-201. 